\title{
Welding Fume Exposure and Lung Cancer: Evidence of Lung Toxicity and Tumor Promotion from in vivo Studies in AJ Mice
}

\author{
Lauryn Falcone
}

Follow this and additional works at: https://researchrepository.wvu.edu/etd

\section{Recommended Citation}

Falcone, Lauryn, "Welding Fume Exposure and Lung Cancer: Evidence of Lung Toxicity and Tumor Promotion from in vivo Studies in AJ Mice" (2018). Graduate Theses, Dissertations, and Problem Reports. 5567.

https://researchrepository.wvu.edu/etd/5567

This Dissertation is protected by copyright and/or related rights. It has been brought to you by the The Research Repository @ WVU with permission from the rights-holder(s). You are free to use this Dissertation in any way that is permitted by the copyright and related rights legislation that applies to your use. For other uses you must obtain permission from the rights-holder(s) directly, unless additional rights are indicated by a Creative Commons license in the record and/ or on the work itself. This Dissertation has been accepted for inclusion in WVU Graduate Theses, Dissertations, and Problem Reports collection by an authorized administrator of The Research Repository @ WVU.

For more information, please contact researchrepository@mail.wvu.edu. 


\title{
Welding Fume Exposure and Lung Cancer: Evidence of Lung Toxicity and Tumor Promotion from in vivo Studies in A/J Mice
}

\author{
Lauryn Falcone
}

\author{
Dissertation submitted to the West Virginia University School of Medicine \\ in partial fulfillment of the requirements for the degree of \\ Doctor of Philosophy in Cellular and Integrative Physiology \\ David Siderovski, Ph.D., Chair \\ Patti Erdely, Ph.D. \\ Salik Hussain, Ph.D. \\ Stanley Hileman, Ph.D. \\ Kristin Cummings, M.D. \\ Timothy Nurkiewicz, Ph.D. \\ Chengfeng Yang, Ph.D.
}

Department of Physiology and Pharmacology

\author{
Morgantown, WV 2018
}

Keywords: welding fumes, lung cancer, A/J mice

Copyright Lauryn Falcone 2018 


\section{ABSTRACT \\ Welding Fume Exposure and Lung Cancer: Evidence of lung toxicity and tumor promotion from in vivo studies in $\mathrm{A} / \mathrm{J}$ mice}

\section{Lauryn Falcone}

Welding fumes were recently reclassified as carcinogenic to humans (Group 1) by the International Agency for Research on Cancer (IARC) based on sufficient epidemiological evidence and limited evidence in animals. It is estimated that 11 million workers worldwide weld full-time, and an additional 110 million have had some type of welding-related exposure. Welding exposures are complex because of the diversity of welding modalities used in the workplace; these modalities include exposures to non-carcinogenic and/or carcinogenic metal containing fumes.

The objective of this dissertation was to determine which welding fumes and their component metals are the most toxic and have the greatest tumorigenic potential. Male A/J mice received intraperitoneal injections of corn oil or the initiator 3-methylcholanthrene (MCA;10 $\mu \mathrm{g} / \mathrm{g}$ ) and one week later were exposed by whole body inhalation to air or gas metal arc-stainless steel (GMA-SS), GMA-mild steel (MS), or Copper-Nickel welding aerosols for 4 hours/day x 4 days/week x 8-9 weeks at a target concentration of $40 \mathrm{mg} / \mathrm{m}^{3}$. Lung nodules were enumerated at 30 weeks post-initiation. GMA-SS and GMA-MS fumes significantly promoted lung tumor multiplicity in A/J mice initiated with MCA $(16.11 \pm 1.18 ; 21.86 \pm 1.50$, respectively) compared to MCA/air-exposed mice $(7.93 \pm 0.82 ; 8.34 \pm 0.59$, respectively). $\mathrm{Cu}$-Ni welding aerosols significantly decreased lung tumor multiplicity compared to MCA/air controls $(7.11 \pm 0.93$ tumors vs. $15.57 \pm 0.75$ tumors, respectively). A separate group of mice also received intraperitoneal injections of MCA or corn oil and beginning one week later were exposed to $\mathrm{NiO}$, $\mathrm{Fe}_{2} \mathrm{O}_{3}, \mathrm{Cr}_{2} \mathrm{O}_{3}+\mathrm{CaCrO}_{4}$ or sham once per week for 5 weeks via oropharyngeal aspiration. 
Component $\mathrm{Fe}_{2} \mathrm{O}_{3}$ was the only metal to promote lung tumors in $\mathrm{A} / \mathrm{J}$ mice. To study lung pneumotoxicity of the welding fumes and their component metals, mice were given a single bolus low or high dose of $\mathrm{NiO}, \mathrm{Fe}_{2} \mathrm{O}_{3}, \mathrm{Cr}_{2} \mathrm{O}_{3}+\mathrm{CaCrO}_{4}$, total GMAW-SS fume or sham at sacrificed at 1 day, 7 days, 28 days, and 84 days post-exposure. An additional group of mice were exposed to GMAW-MS via inhalation for 4 hours/day for 10 days at a target concentration of $40 \mathrm{mg} / \mathrm{m}^{3}$ and sacrificed at the same time points. Bronchoalveolar lavage fluid was collected and analyzed for markers of inflammation and cytotoxicity. GMA-SS fume was more pneumotoxic than the individual components. Component $\mathrm{Fe}_{2} \mathrm{O}_{3}$ was the most toxic of the metal oxides. Inhalation of GMAW-MS did not induce inflammation or cytotoxicity in A/J mice. In conclusion, these studies demonstrates that inhalation of GMA-SS and GMA-MS welding fume as well as $\mathrm{Fe}_{2} \mathrm{O}_{3}$ promote lung tumor formation in vivo and provides support for the epidemiology that shows welders, using mild and/or stainless steel, are at an increased risk for lung cancer. It is unclear why $\mathrm{Cu}-\mathrm{Ni}$ welding aerosols decreased tumor size and number. However, the findings in this dissertation provide a framework for future epidemiological, in vivo, and in vitro studies of welding fumes to further understand the association between lung cancer and welding. A better understanding of which welding fumes and metal oxides are most toxic or tumorigenic could lead to more appropriate worksite regulations and even the development of safer welding consumables which lack the more dangerous components. 


\section{Acknowledgements}

A tremendous number of people helped me to have a successful graduate school experience, and it would be difficult to mention all of them here. However, I would like to thank some of the most influential people.

To begin, I would like to thank my mentor, Dr. Patti Erdely. Patti paved the way for me to immediately hit the ground running from day 1 in her lab. Throughout my graduate school training, she offered invaluable mentorship guidance that lead me to complete great science, present at numerous conferences, win research awards, and most important grow as a student, a writer, and a researcher. I appreciated that she was always looking out for my best interest and highly concerned with helping to advance my career. Rebecca Salmen also deserves recognition; we spent many hours in lab together, and I always appreciated her guidance, support, and encouragement. She was my go-to person for anything NIOSH-related, from learning how to mail a package to finding someone's office in the building. I would also like to thank all of my committee members, especially Dr. Siderovski and Dr. Brock. Dr. Siderovski has been someone I have worked with closely the past few years as he led the $\mathrm{MD} / \mathrm{PhD}$ scholars program, and I always felt like he was highly supportive of my goals and ambitions. No matter what I wanted to do, he was always optimistic and willing to stand behind any endeavors I chose to pursue. I have a significant amount of gratitude towards Dr. Brock; he has been an undeniable pillar in building my success these past three years. I especially appreciated how supportive he was of my career goals, even when they were outside the scope of my $\mathrm{PhD}$ focus. Of anyone I met during my $\mathrm{PhD}$ training, I felt like he was most supportive of the training of an MD/PhD student. He was instrumental in getting me back into the clinic during my $\mathrm{PhD}$ years by creating a clinical immersion program that let me get elective credit to rotate in my desired field, dermatology. In 
particular, he went through great lengths to help me schedule an early away rotation through this clinical immersion program in dermatology at Children's National Medical Center, an experience I regard as one of the highlights of my career thus far.

I would also like to thank my parents, Frank and Lisa, my sisters, Morgan, Kelsey, and Justine, and my grandparents, Anna, Frank, Thom, and Marlene. My family has been supportive of my career aspirations for a very long time, and I could not be where I am today without their encouragement and assistance. Lastly, I would like to thank my running and triathlon training partners in the surrounding area who helped me to have a thriving life outside of science and medicine during graduate school. 
Table of Contents

List of Symbols, Abbreviations, and Nomenclature......................................................................... viii

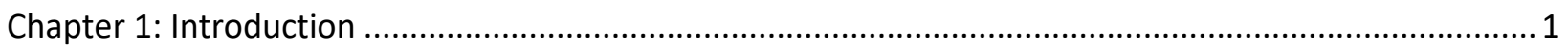

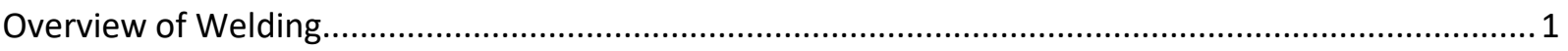

Types of Welding Processes and Welding Fumes ........................................................................... 3

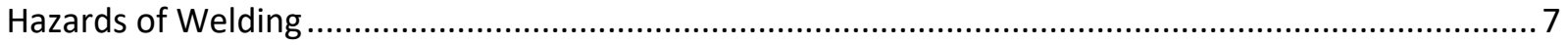

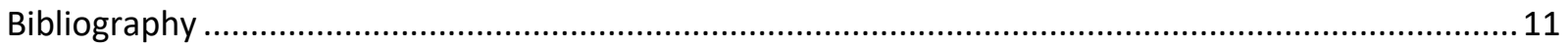

Chapter 2: Lung Cancer and Welding: A Review..............................................................................

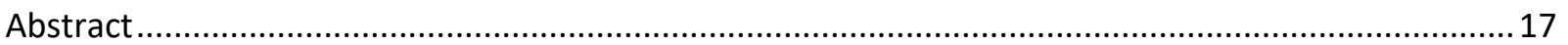

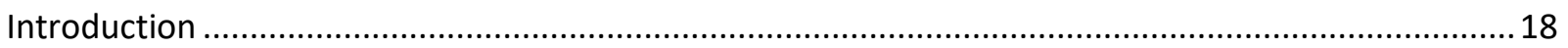

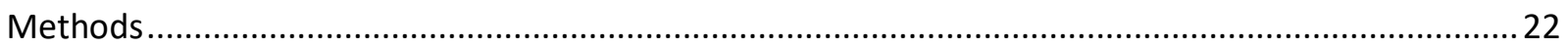

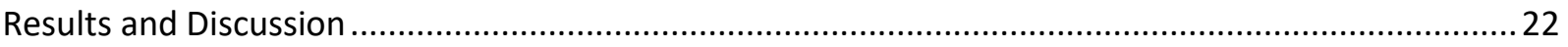

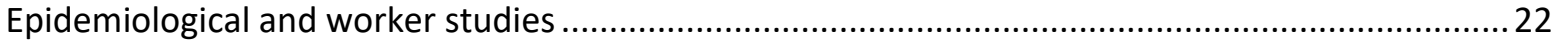

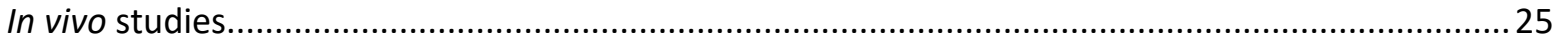

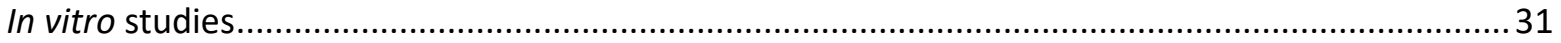

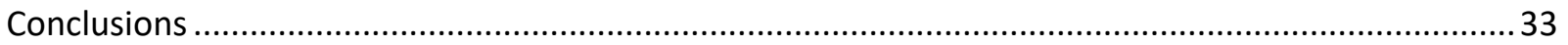

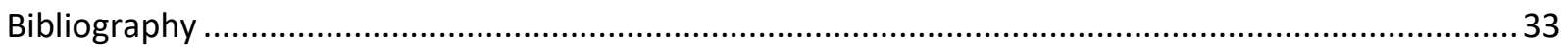

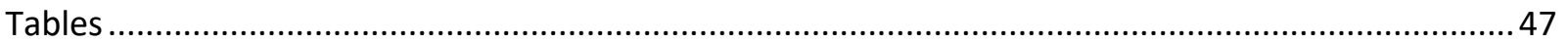

Chapter 3: Gas Metal Arc - Stainless Steel Welding Fume Promotes Lung Tumorigenesis in A/J Mice .... 49

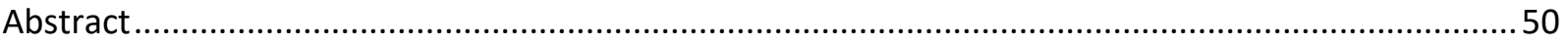

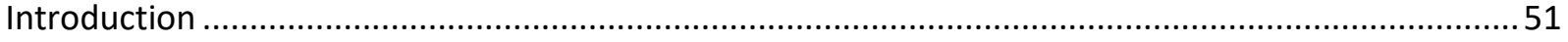

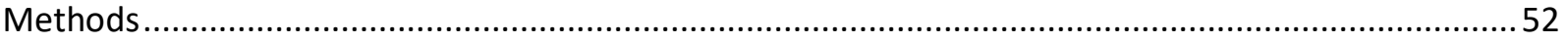

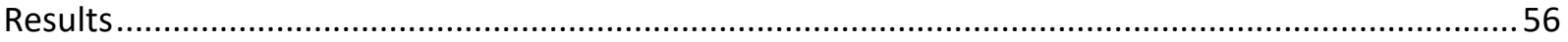

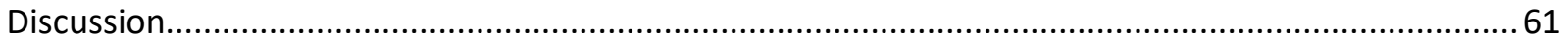

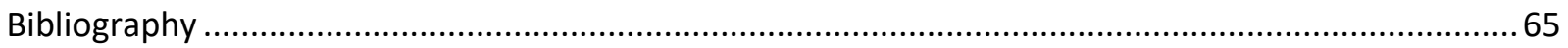

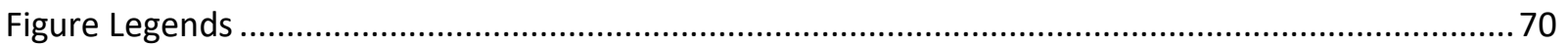

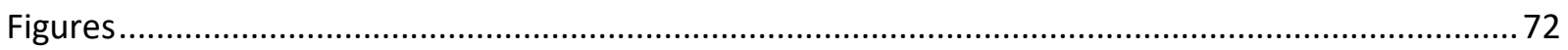

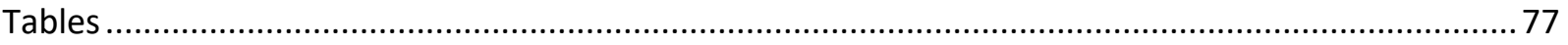

Chapter 4: Inhalation of Iron-Abundant Gas Metal Arc - Mild Steel Welding Fume Promotes Lung Tumors

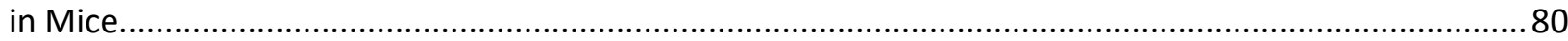

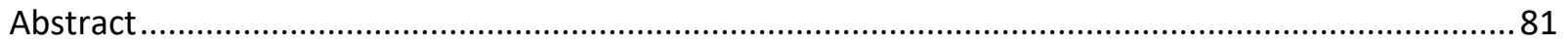

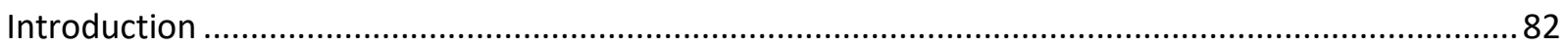




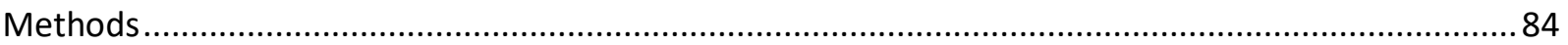

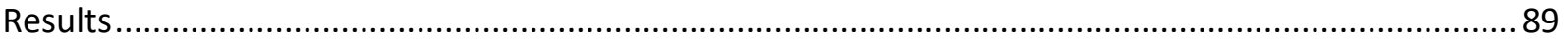

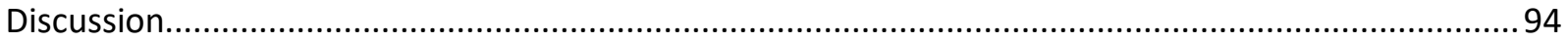

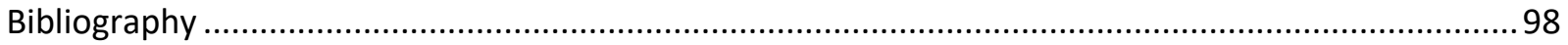

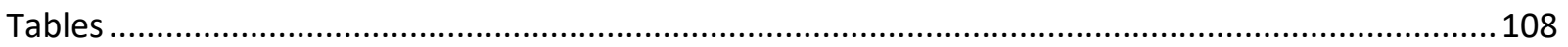

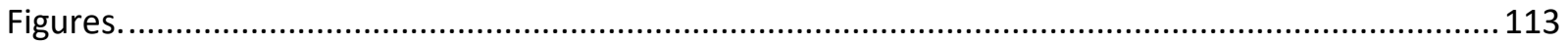

Chapter 5: Pulmonary Toxicity and Lung Tumorigenic Potential of Metal Oxides in Gas Metal ArcStainless Steel Welding Fume: Iron Oxide as a Lung Tumor Promoter ................................................118

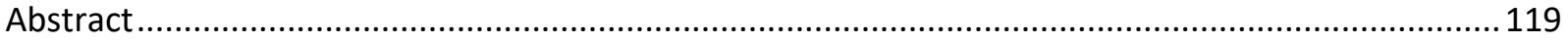

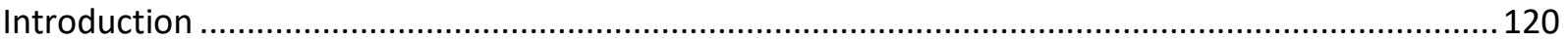

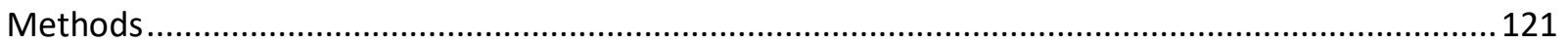

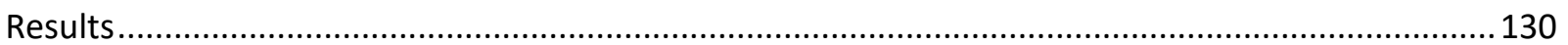

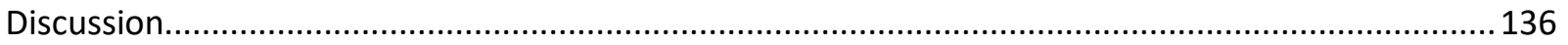

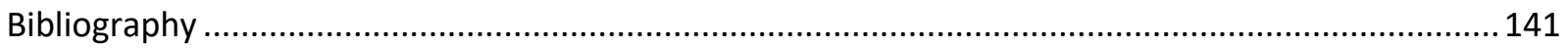

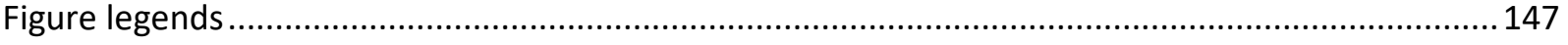

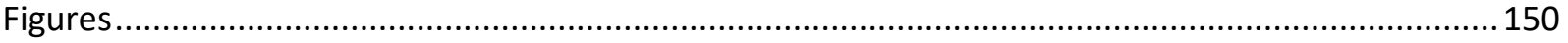

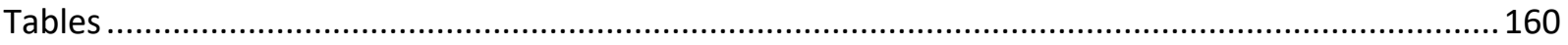

Chapter 6: Lack of Lung Tumor Promotion after Inhalation of a Copper- Nickel Welding Fume in A/J Mice

Abstract




\section{List of Symbols, Abbreviations, and Nomenclature}

$\mathrm{CO}-$ Corn oil

$\mathrm{Cr}-$ Chromium

$\mathrm{Cr}^{6+}-$ Hexavalent chromium

$\mathrm{Cu}$-Copper

$\mathrm{Fe}-$ Iron

FCAW - flux-cored arc welding

GMAW-SS - Gas metal arc welding - stainless steel

GMAW-MS - Gas metal arc welding - mild steel

GTAW - gas tungsten arc welding

MCA - 3-methylcholanthrene

MMA - Manual metal arc welding

Mn - Manganese

$\mathrm{Ni}$ - Nickel

PAW - Plasma arc welding

SAW - submerged arc welding

SMAW - Shielded manual metal arc welding 


\section{Chapter 1: Introduction}

\section{Overview of Welding}

For centuries, the ability to join metal parts has been a crux of our society. Prior to the late 1800 s, the only method to metallurgically connect metals was a laborious process known as forge welding, in which metals were heated and repeatedly pounded until a bond was formed [1]. It is unknown exactly when forge welding began. However, it is believed that the shaping of metals which formed the foundations for welding started in ancient tribes many centuries ago. There is also some evidence that ancient Egyptians used a type of welding similar to gas welding today by which they used a blowpipe and flames to melt the surface of metals [2]. By the late 1800 s, increased electrical power allowed more methods of welding to emerge, including arc welding, resistance welding, and oxyacetylene welding [1-3]. It is believed that an Englishman named Widdle was the first person to intentionally weld two metals, fusing two small pieces of iron in 1865 and receiving the first patent for a welding process[1].

By the early 1900s, arc welding, the most popular and commercially useful method of welding, had made its way to the United States [1]. Four manufacturers of arc welding equipment were established by 1917, including Lincoln Electric Company, which is still the largest supplier of welding equipment today. The popularity of welding continued to grow over time, but the first major demands on the industry came during World War I, with a sudden need for fleets of ships, aircraft and war supplies. Welding allowed for faster production of these transportation devices compared to earlier methods. After the war, welding was still not used extensively, but with the approach of World War II, the need for welding picked up again and welding became increasingly important [1].

Today, our ability to fuse metals has led to the production of everything from ships, 
automobiles, and bridges to mp3 players, medical devices, and computers [1-3]. When it comes to fastening or connecting metals, many options are available including simple bolts and screws, adhesives such as tapes and glues, riveting, brazing, soldering, and welding. Each method has its advantages, with some techniques like bolts, screws, and adhesives requiring only basic skills but providing a less durable union [4]. Welding, brazing, and soldering are similar processes in that they are three stronger methods of joining metals and require more skill to be performed. Depending on the strength of the union desired and the types of metals being joined, one process may be preferred over another. Soldering and brazing are very similar processes except that brazing is performed at higher temperatures above $450^{\circ} \mathrm{C}$ while soldering occurs at lower temperatures below $450^{\circ} \mathrm{C}$ [4]. Unlike soldering and brazing, which only melt the filler metal, welding is a true fusion process as it involves melting of both the work pieces and filler material. Thus, welding has the advantage of being the strongest possible method of joining metals, making it a highly utilized process in the construction and manufacturing industries.

The American Welding Society was founded in 1919 with the mission of advancing the science, technology, and application of welding processes worldwide. It is estimated that there are more than 110 million workers across the world that receive some sort of welding exposure, whether they are full-time or part-time welders or employed in other industries such as construction, farming, pipefitting, ship making, or automobile services $[4,5]$. The welding industry is expected to grow 4\% from 2014 to 2024, especially as the workforce ages and infrastructure degrades and needs to be replaced and repaired [4, 6]. In 2010, the manufacturing industry employed $61 \%$ of all welders, followed by the construction industry (11\%), wholesale trade (5\%), and maintenance and repair (5\%) [4]. Welding is a popular career choice as the skills 
of a welder are versatile and transferable; a welder who gets laid off in the manufacturing industry, for example, may easily find work building pipelines in the oil and gas industry [6].

Nearly 80 types of different welding processes exist but all welding processes are similar in that they generally require high heat and a filler material which is usually a stick or wire [3, 4]. The vast majority of metals are fused by an electric arc welding process. It is believed that the electric arc was discovered by Sir Humphrey Davy in 1801 when experimenting with electricity[1]. Davy discovered that this arc could be maintained and created with a high voltage electric circuit and noticed that it gave off significant amounts of light and heat. In arc welding, high temperatures of $5,000^{\circ} \mathrm{C}$ or more melt the joint between two metal work pieces as well as a filler material placed between them [4]. This extremely high heat capable of melting metals is produced by the electric arc which is established between the work pieces and a consumable wire electrode. As temperatures cool, the bond solidifies, firmly fusing the work pieces together. The bond created by welding is unique in that it is a mixture of the metal work pieces and the electrode filler material, making the bond extremely strong as it retains the strength of both initial metal parts $[1,4]$. This bond is unique to welding, as brazing, soldering, and adhesives are considered non-fusion methods of joining metals since the bond is not a mixture of both work pieces and filler material [4].

\section{Types of Welding Processes and Welding Fumes}

Welding processes are largely classified as either arc or non-arc welding, with arc welding being considerably more popular. Specific types of arc welding include shielded metal arc welding (SMAW), gas metal arc welding (GMAW), Flux-cored arc welding (FACW), gas tungsten arc welding (GTAW), submerged arc welding (SAW), and plasma arc welding (PAW) [7]. With arc welding, some type of shielding of the weld is needed, because the metals at high temperatures will chemically react with nitrogen and oxygen in the air, creating oxide and 
nitrides which would weaken the strength and toughness of the weld [1]. Shielding may be provided by a gas, vapor, or slag which serves to prevent contact of the molten weld puddle that is created with air. Non-arc welding includes resistance welding, oxyfuel gas welding, solid state welding, and high energy density welding. Choice of which type of welding to use depends on a variety of factors including desired strength of the weld, cost, speed of welding, and position and thickness of the material [4].

SMAW is also known as stick welding or manual metal arc (MMA) welding. It the most commonly used arc welding process as it is the cheapest and simplest method of welding [4]. As the name suggests, in SMAW a welder manually guides an electrode along the metal to be welded after creating an arc between the electrode and the metal [3]. The electrode is coated with a material which decomposes under high heat and shields the weld puddle from reacting with the atmosphere. Unlike some other types of welding, no pressure is used in SMAW and the filler material is provided by the consumable wire electrode. GMAW, also known as metal inert gas (MIG) welding, is a method commonly used commercially as it can be automated and performed at higher speeds $[1,4]$. In GMAW, an electric arc is established between the work piece and a consumable wire electrode. Unlike SMAW, the electrode in GMAW is bare rather than coated, so the weld is instead protected by an external gas source such as argon, helium, or carbon dioxide. A disadvantage of GMAW is that it produces a significant amount of welding fume, primarily from the consumable wire electrode [4]. FCAW is similar to GMAW in that an arc is again established between the work piece and a consumable electrode and in both processes a significant amount of fume is produced. However, in FCAW, shielding is primarily provided by a flux within the electrode as well as a central core which may contain scavengers, slag, deoxidizers or other shielding agents, rather than a coating on the electrode or solely an external 
gas $[1,4]$. Sometimes, additional shielding will also be provided by an external gas. In GTAW, an arc is still established between the work piece and electrode, but the electrode is nonconsumable tungsten and serves only to maintain the arc rather than shield the welding process. Shielding instead is provided by external gases. Pressure is sometimes used. Unlike GMAW and SMAW, very little welding fume is generated during GTAW. SAW is similar to GMAW in that an electric arc is established between the work piece and a bare electrode. It is the ideal welding process for fusing thick plates as it provides a high metal deposition rate and is among the fastest welding process [1]. Unlike other welding processes, the electric arc is not visible and shielding is provided by a granular flux which covers the work piece. This results in a much more contained welding process, without the production of sparks, radiation, and fume which is generated in other welding processes. The filler material is provided primarily by the bare electrode and pressure is not used. Lastly, PAW is most similar to GTAW in which an arc is established between the work piece and a non-consumable electrode. While the arc supplies heat, unlike with other welding processes, the arc is not diffused but rather forced through a small hole, constricting the arc $[1,4]$.

Despite the overwhelming popularity of arc welding, other types of non-arc welding are sometimes employed, such as resistance welding, oxyfuel gas welding, solid state welding, and high energy density welding[1,4]. Resistance welding refers to processes such as spot welding, induction welding, and flash welding in which the weld is created by heat provided from resistance to the flow of an electric current as well as pressure. Resistance spot welding is sometimes utilized in the production of automobiles or aircraft as it can be performed repetitively at high speeds to product a joint similar to a rivet although significantly stronger. In oxyfuel gas welding, a nozzle directs gas at the work piece surface and a combustion process between air, 
gas, and oxygen joins the metals. This type of welding generates some fume but not as much as some of the arc welding processes as it is performed at lower temperatures. However, oxyfuel gas welding is infrequently used in the industry as it produces a lower quality weld compared to arc welding. Solid state welding includes friction welding, diffusion welding, hot and cold pressure welding, ultrasonic welding, and explosive welding. It is unique in that no melting occurs and metals are instead joined by pressure and occasionally heat. However, solid state welding is very expensive and therefore not utilized for large production jobs. Lastly, high energy density welding includes processes like electron beam welding and laser beam welding. In these types of welding, lasers or a stream of electrons create high temperatures which allows melting and vaporization to fuse work pieces. However, like solid state welding, high energy density welding is very expensive and not widely used commercially [1, 4].

Welding fumes are created as a byproduct of many of the welding processes, particularly arc welding [4]. The welding fume composition varies depending on the specific type of welding process. However, it is typically composed of a mixture of vaporized metal oxides from the electrode and/or flux material which are small enough in size to be respired and reach the alveoli of the lungs [4]. Gases produced during welding can vary depending on the type of welding process and other conditions. Ozone can be formed during welding by reaction of atmospheric oxygen and UV radiation from the welding arc [4]. While the rate at which ozone can form varies greatly with the materials being welded, the shielding gas used, the welding process being performed and properties of the welding arc, ozone is generally unstable in the atmosphere [8]. The metal oxides of the fume also increase the rate of degradation of ozone. Thus, while ozone is well known to be a respiratory irritant, production during welding is typically negligible. CO can also sometimes be formed during the welding process by reduction 
of $\mathrm{CO}_{2}$ at high temperatures or from decomposition of compounds coating the electrode [4]. $\mathrm{CO}$ is a colorless, odorless gas which can be deadly if inhaled. NO is also sometimes formed during welding when high temperatures oxidize atmospheric nitrogen. NO is irritating to eyes, lungs, and mucous membranes $[4,9]$.

\section{Hazards of Welding}

Welders are exposed to a number of health and safety hazards owing to dangerous work environments and exposures from the welding process [6]. Welders may work indoors or outdoors, in confined or wide open spaces that may be well or poorly ventilated, and can sometimes be exposed to inclement weather. When welding in confined spaces lacking proper ventilation, welding fumes can rapidly accumulate, pushing out breathable air and causing suffocation of the welder [1]. When working outdoors, welders may work on scaffolds or platforms high above the ground. Some jobs involve heavy lifting and frequent bending and stooping down in uncomfortable, awkward positions $[3,6]$. In addition to a dangerous work environment, welders work with extremely hot materials and strong light $[1,6]$. Electrical shock and even potential explosions if combustible gases are mishandled or if welding sparks hit flammable materials are possible dangers of welding $[1,3]$. Work areas should be kept very clean as even dust particles have been known to become volatile in the heat of the arc, quickly oxidize, and cause a flash fire or explosion[1]. Because of these hazards, welders have higher rates of injury and illness than the national average for workers [6]. Injuries and illness can be minimized by following safety protocols and with the use of personal protective equipment such as gloves, googles, ear plugs, masks, and heat resistance clothing [1, 6].

Welders are also exposed to a number of hazards from heat, noise, or radiation [4]. Additionally, both respiratory and non-respiratory health effects have been reported in welders, 
including dermal toxicities, neurological changes, cardiovascular damage, and reproductive impairments.

Notably, the UV radiation from the welding arc can result in erythema of unprotected areas of welders' skin, most commonly in the head and neck regions [4]. Many welders suffer burns. The severity of the UV radiation exposure depends on a number of factors including distance from the source, susceptibility of the host, use of protective clothing, exposure time, and wavelength [8]. Some reports have suggested that welders have increased incidences of nonmelanoma skin cancers including basal cell carcinomas and actinic keratosis, a potential precursor to squamous cell carcinomas [4, 10-14].

Neurological effects from welding exposures largely stem from the presence of manganese in welding fumes [4, 15]. Manganese is a known neurotoxin and is present in many types of welding fumes. Most reported instances of neurological toxicities in workers occurred when welding fumes were abnormally high or when welding in confined, poorly ventilated or unmaintained workplaces $[4,16,17]$. Situations such as these can lead to manganese overexposure which may cause a Parkinson disease-like syndrome. It is believed that some inhaled welding fumes can deposit in the airways of the head and neck where they may reach the brain through areas such as the olfactory neurons in the nose [18]. Manganese then accumulates in the basal ganglia, an area of the brain that aids in movement control, and can cause irreversible brain damage. As the disease progresses, patients suffer from manganism which presents similarly to Parkinson's disease with tremor, gait abnormalities, muscle weakness or rigidity, and slow movements $[19,20]$. While the mechanism of this manganese toxicity is not entirely know, Criswell et al. demonstrated that the caudate regions of the brain in Mn-exposed welders took up significantly less fluorinated L-DOPA compared to controls, suggesting 
dysfunction of pre-synaptic dopaminergic neurons [21]. Chronic exposure to high levels of manganese has also shown to inhibit motor function and affect thalamic GABA levels in welders [22]. It is currently not clear if exposure to chronic, low levels of manganese may result in similar adverse neurological effects long term [15].

Because airborne pollution, a metal-rich particulate matter, is known to cause adverse cardiovascular effects in high risk populations such as the very young or old or those with underlying cardiac conditions, it has been suggested that welding fumes may have similar adverse effects [23]. However, because workers are typically healthier than the general population, they are unlikely to be members of a high risk, susceptible group, making risks of adverse cardiovascular events potentially less likely [4]. Nevertheless, some animal and epidemiological studies do suggest welding fumes may negatively impact the cardiovascular system. Li et al. found that welders had a moderate, but significant, increase in blood pressure compared to controls [24]. While no changes were noted in endothelial cells or other markers, the increase in blood pressure does suggest welding fume exposure has an effect on the cardiovascular system. Zheng et al. observed no differences in blood pressure or heart rate in rats after exposure to GMA-MS or MMA-hard surfacing welding fumes yet did note these fumes decreased left ventricular end diastolic pressure [25]. Erdely et al. noted that mice exposed to stainless steel welding fume developed increased atherosclerotic lesions [26]. Studies have also shown that exposure to stainless steel welding fumes may reduce contraction of cardiomyocytes isolated from rats [27]. It is possible that some of the adverse cardiovascular effects of welding fumes may be due to hypomethylation of coagulation factor II receptor-like 3 gene (F2RL3), a known marker for cardiovascular morbidity and mortality [28]. However, more studies are 
needed to investigate the association between welding fume exposure and adverse cardiovascular events to confirm a potential mechanistic link.

Concerns have also been raised about the potential for welding fumes to impair the reproductive system. In particular, some studies have shown that semen quality and quantity are decreased in welders [29]. Metals have also been shown to accumulate in the reproductive organs of rats and lead to changes in testosterone levels [30]. One epidemiological study observed an association between paternal exposure to low dose welding fumes and UV radiation and the development of spina bifida in offspring [31]. There is some evidence that maternal exposure to welding fumes may hinder fetus growth and that paternal exposure to welding fumes may increase the risk of premature delivery [32]. In general, however, very few studies have fully evaluated the risk to the fetus after maternal or paternal exposure to welding fumes. Further research is needed to more clearly investigate the potential effects of welding fume exposure on pregnancy and fetal outcomes.

Despite potential dermal, neural, or reproductive toxicities of welding fume exposure, most adverse health issues are pulmonary in nature [4]. In fact, most welders report experiencing respiratory problems due to welding at some point in their lifetime. These may include metal fume fever, bronchitis, siderosis, pulmonary fibrosis, asthma, and infection. However, perhaps the most severe adverse effect from welding fume exposure is the potential development of lung cancer. Numerous epidemiological studies have indicated that welders are at an increased risk of lung cancer $[4,5]$. Because of substantial epidemiological evidence and some evidence in animal studies, welding fumes were classified as a Group 1 carcinogen by the International Agency for Research on Cancer in 2017 [5].The following dissertation begins with a comprehensive literature review on welding fume exposure and the development of lung cancer 
followed by in vivo studies our laboratory has performed investigating GMAW-SS, GMAW-MS, and $\mathrm{Cu}-\mathrm{Ni}$ fumes.

Bibliography

1. The Procedure Handbook of Arc Welding. 14 edn. The James F. Lincoln Arc Welding Foundation; 2000.

2. Ferguson: Careers in Focus Technicians. New York: Infobase Publishing; 2010.

3. Ferguson: Careers in Focus Construction. New York: Ferguson; 2010.

4. Antonini JM: Health Effects Associated with Welding. 2014:49-70.

5. Guha N, Loomis D, Guyton KZ, Grosse Y, El Ghissassi F, Bouvard V, Benbrahim-Tallaa L, Vilahur N, Muller K, Straif K: Carcinogenicity of welding, molybdenum trioxide, and indium tin oxide. Lancet Oncol 2017, 18:581-582.

6. Welders, cutters, solderers, and brazers

7. Antonini JM: Health effects of welding. Crit Rev Toxicol 2003, 33:61-103.

8. Vilaume JE WK, Liss-Suter D, Hsiao S.: Effects of Welding on Health. Miami, FL: American Welding Society; 1979.

9. Payen DM: Inhaled nitric oxide and acute lung injury. Clin Chest Med 2000, 21:519529 , ix.

10. Heltoft KN, Slagor RM, Agner T, Bonde JP: Metal arc welding and the risk of skin cancer. Int Arch Occup Environ Health 2017, 90:873-881.

11. Zamanian Z, Mortazavi SM, Asmand E, Nikeghbal K: Assessment of Health Consequences of Steel Industry Welders' Occupational Exposure to Ultraviolet Radiation. Int J Prev Med 2015, 6:123. 
12. Wolfe CM, Green WH, Cognetta AB, Jr., Hatfield HK: Multiple squamous cell carcinomas and eruptive keratoacanthomas in an arc welder. Dermatol Surg 2013, 39:328-330.

13. Dixon A: Arc welding and the risk of cancer. Aust Fam Physician 2007, 36:255-256.

14. Currie CL, Monk BE: Welding and non-melanoma skin cancer. Clin Exp Dermatol 2000, 25:28-29.

15. Antonini JM, Santamaria AB, Jenkins NT, Albini E, Lucchini R: Fate of manganese associated with the inhalation of welding fumes: potential neurological effects. Neurotoxicology 2006, 27:304-310.

16. Confined Spaces. In Safety and Health Fact Sheets. Miami, Fl: American Welding Society; 1998

17. Ventilation Guide for Weld Fume. Miami, FL: American Welding Society; 2001.

18. McClellan RO: Particle Interactions with the Respiratory Tract. In Particle-Lung Interactions. Edited by Lenfant C. New York: Marcel Dekker, Inc.; 2000: 3-56

19. Wennberg A, Iregren A, Struwe G, Cizinsky G, Hagman M, Johansson L: Manganese exposure in steel smelters a health hazard to the nervous system. Scand $J$ Work Environ Health 1991, 17:255-262.

20. Mergler D, Baldwin M: Early manifestations of manganese neurotoxicity in humans: an update. Environ Res 1997, 73:92-100.

21. Criswell SR, Nielsen SS, Warden M, Perlmutter JS, Moerlein SM, Flores HP, Huang J, Sheppard L, Seixas N, Checkoway H, Racette BA: [18F]FDOPA positron emission tomography in manganese-exposed workers. Neurotoxicology 2017. 
22. Ma RE, Ward EJ, Yeh CL, Snyder S, Long Z, Gokalp Yavuz F, Zauber SE, Dydak U: Thalamic GABA levels and occupational manganese neurotoxicity: Association with exposure levels and brain MRI. Neurotoxicology 2017.

23. Brook RD, Rajagopalan S, Pope CA, 3rd, Brook JR, Bhatnagar A, Diez-Roux AV, Holguin F, Hong Y, Luepker RV, Mittleman MA, et al: Particulate matter air pollution and cardiovascular disease: An update to the scientific statement from the American Heart Association. Circulation 2010, 121:2331-2378.

24. Li H, Hedmer M, Karedal M, Bjork J, Stockfelt L, Tinnerberg H, Albin M, Broberg K: A Cross-Sectional Study of the Cardiovascular Effects of Welding Fumes. PLoS One 2015, 10:e0131648.

25. Zheng W, Antonini JM, Lin YC, Roberts JR, Kashon ML, Castranova V, Kan H: Cardiovascular effects in rats after intratracheal instillation of metal welding particles. Inhal Toxicol 2015, 27:45-53.

26. Erdely A, Hulderman T, Salmen-Muniz R, Liston A, Zeidler-Erdely PC, Chen BT, Stone S, Frazer DG, Antonini JM, Simeonova PP: Inhalation exposure of gas-metal arc stainless steel welding fume increased atherosclerotic lesions in apolipoprotein $\mathbf{E}$ knockout mice. Toxicol Lett 2011, 204:12-16.

27. Popstojanov R, Antonini JM, Salmen R, Ye M, Zheng W, Castranova V, Fekedulegn DB, Kan H: Alterations in cardiomyocyte function after pulmonary treatment with stainless steel welding fume in rats. J Toxicol Environ Health A 2014, 77:705-715.

28. Hossain MB, Li H, Hedmer M, Tinnerberg H, Albin M, Broberg K: Exposure to welding fumes is associated with hypomethylation of the F2RL3 gene: a cardiovascular disease marker. Occup Environ Med 2015, 72:845-851. 
29. Bonde JP: Semen quality and sex hormones among mild steel and stainless steel welders: a cross sectional study. Br J Ind Med 1990, 47:508-514.

30. Krajnak K, Sriram K, Johnson C, Roberts JR, Mercer R, Miller GR, Wirth O, Antonini JM: Effects of pulmonary exposure to chemically-distinct welding fumes on neuroendocrine markers of toxicity. J Toxicol Environ Health A 2017, 80:301-314.

31. Blatter BM, Hermens R, Bakker M, Roeleveld N, Verbeek AL, Zielhuis GA: Paternal occupational exposure around conception and spina bifida in offspring. Am J Ind Med 1997, 32:283-291.

32. Quansah R, Jaakkola JJ: Paternal and maternal exposure to welding fumes and metal dusts or fumes and adverse pregnancy outcomes. Int Arch Occup Environ Health 2009, 82:529-537. 


\section{Chapter 2: Lung Cancer and Welding: A Review}

LM Falcone $^{1,2}$, JM Antonini ${ }^{2}$, PC Zeidler-Erdely ${ }^{1,2}$

${ }^{1}$ West Virginia University, School of Medicine, Morgantown, WV; ${ }^{2}$ Health Effects Laboratory

Division, National Institute for Occupational Safety and Health, Morgantown, WV 


\begin{abstract}
Nearly 11 million people hold the job title of welder, and more than 110 million people around the world have some sort of welding-related exposure. While welding is a crucial industrial process, the hazardous fumes created during welding are known to cause acute and chronic health effects when inhaled. In 2017, the International Agency for Research on Cancer (IARC) classified welding fumes as Group 1 (carcinogenic to humans). This classification was based on sufficient epidemiological evidence and limited evidence in animals. This review summarizes the current literature surrounding epidemiological, in vivo, and in vitro research on lung cancer in welders. Although the epidemiological evidence is at times contradictory, it generally points to an increased risk. Additional animal and in vitro studies are needed to further explore the association between welding and lung cancer and help to understand a potential mechanistic link.
\end{abstract}

Keywords: welding, lung cancer, A/J mice, gas metal arc, stainless steel, mild steel 


\section{Introduction}

Approximately 11 million welders perform 80 different types of welding processes around the world to produce everything from ships, automobiles, and bridges to $\mathrm{mp} 3$ players, medical devices, and computers [1-5]. The vast majority of metals are fused by an electric arc welding process. Specific types of arc welding include manual metal arc welding [MMA; also known as shielded manual metal arc welding (SMAW)], gas metal arc welding (GMAW), Fluxcored arc welding (FCAW), gas tungsten arc welding (GTAW), submerged arc welding (SAW), and plasma arc welding (PAW) [6]. In arc welding, high temperatures of $5,000^{\circ} \mathrm{C}$ or more melt the joint between two metal work pieces as well as a filler material placed between them [1]. This extremely high heat capable of melting metals is produced by the electric arc which is established between the work pieces and, in most instances, a consumable wire electrode. As temperatures cool, the bond solidifies, firmly fusing the work pieces together. The bond created by welding is unique in that it is a mixture of the metal work pieces and the electrode filler material, making the bond extremely strong as it retains the strength of both initial metal parts [1, 4]. Given the variety of welding processes used in the workplace, welders' exposure are diverse, rather than homogenous [7].

Welding fumes are created as a byproduct of many of the welding processes, particularly arc welding [1]. The concentration of the fume in the personal breathing space of the welder depends on the volume of the space the welder is in as well as how well the area is ventilated.[8] Welding fume is generated by a process called nucleation, whereby metal oxides are vaporized at high temperature and then condense to form particles [9]. Coagulation then occurs in which particles collide to form clumped aggregates. These aggregates are held together by electrostatic forces, magnetism, and/or van der Waals forces [9-11]. The size of the welding fume particles formed vary depending on the welding process but can range from less than $0.1 \mu \mathrm{m}$ to over 20 
$\mu \mathrm{m}$. However, the mass median aerodynamic diameter of most welding fumes has been measured to be in the range of 0.2 to $0.5 \mu \mathrm{m}$ [9-12]. The size of the fume particles is important as this affects where they will end up in the lung. Particles that are larger may not make it beyond the upper airways while the smallest particles of $\sim 0.1-0.3 \mu \mathrm{m}$ have the potential to reach the alveolar space of the lungs [13]. The mucocilliary escalator helps to quickly clear particles from the middle and upper airways, sweeping debris towards the mouth to be swallowed and removed from the body [14]. Some remaining particles may be carried by macrophages or neutrophils into the lymphatic system while other particles may be directly taken up by type I pneumocytes and enter the bloodstream. However, clearance is slower in the alveoli compared to the upper airways. Here, it is likely that particles are engulfed by macrophages where they may remain for some time. The half-life of welding fume particles in the lungs is estimated to be almost 2 years $[1,15]$.

The welding aerosol composition varies depending on the specific type of welding process. However, it is typically composed of a mixture of vaporized metal oxides from the electrode and/or flux material which are small enough in size to be respired and reach the alveoli of the lungs [1]. Surface coatings or paint on the base metal or electrode can also contribute to the aerosol. Due to the contribution by the flux, MMA fume is much more complex than GMAW fume $[9,11]$. The presence of alkali metals in the flux also make MMA fume highly soluble compared to GMAW fumes which are mostly insoluble [16]. Nevertheless, welding generates a complex fume composed of potentially hazardous metals as well as gases such as carbon monoxide $(\mathrm{CO})$, nitrogen oxide $(\mathrm{NO})$, and ozone $\left(\mathrm{O}_{3}\right)$ [1]. While the metal composition of the fume varies depending on the type of welding process, it may include iron, chromium, manganese, and nickel with typically lower amounts of zinc, aluminum, cadmium, or fluorides. 
Table 1 summarizes the major metal composition of SS and MS welding fumes. Iron is one of the major metals in many welding fumes, and reports indicate that $70 \mathrm{mg}$ of iron are deposited in full-time welders' lungs each year [17]. Workers typically clear this iron slowly, and it is known to persist in their lungs for many years, with some estimates indicating retired welders only clear 10 to $20 \%$ of their accumulated iron burden each year $[1,17]$. Interestingly, iron exposure may cause a benign lung condition known as siderosis [1]. Increased incidences of lung cancer have been observed in iron-exposed workers such as iron-ore mining and welding, but because these do not represent pure exposures to iron, iron is currently not classified as a carcinogen by IARC [18]. Chromium is found in stainless steel welding fumes in both $\mathrm{Cr}^{3+}$ and $\mathrm{Cr}^{6+}$ oxidation states [19]. $\mathrm{Cr}^{3+}$ cannot enter cells and is therefore considered less toxic. $\mathrm{Cr}^{6+}$ is highly toxic as it can enter cells and is classified as a carcinogen [20]. The permissible exposure limit (PEL) of chromium was lowered to $5 \mu \mathrm{m} / \mathrm{m}^{3}$ in 2006 due to its harmful effects [21]. Manganese is used in welding because it hardens and strengthens the weld while minimizing cracking and can become a component in the fume $[1,22]$. Manganese is not considered carcinogenic, but has been reported to cause neurotoxic effects in humans and animals [23-27]. Nickel (Ni) is a component of stainless steel welding fume and Ni alloys are becoming increasingly popular in welding as a potential alternative to welding with chromium-containing materials. However, Ni is also known to be toxic and is classified as a human carcinogen [20].

Because the respiratory hazards associated with welding are due to inhalation of the fume, ventilation and respiratory controls can help to minimize these adverse effects [1]. Ventilation options include both local exhaust ventilation and general ventilation [4]. Local exhaust ventilation removes the welding fume right at the source without disrupting the welding process. General ventilation systems include natural ventilation through windows, doors, and 
vents as well as mechanical ventilation. However, in some situations, achieving proper ventilation can be difficult or not possible, and no local exhaust ventilation will capture $100 \%$ of generated welding fume [28]. In some situations, welding is performed in confined spaces which amplifies the hazards as fumes can rapidly accumulate. These confined spaces can include storage tanks, holds of ships, furnaces and boilers, tunnels, ducts, sewers, silos, pipelines, and underground utility vaults [29]. Respirators can help protect workers when engineering controls fail, but some studies have shown that respirators are not completely effective in protecting welders from welding fumes [30]. Despite the use of engineering controls, cases of adverse respiratory effects among welders are still reported.

Metal fume fever is among the most common respiratory condition in welders, presenting with flu-like symptoms such as cough, dyspnea, and malaise [1, 6]. Typically symptoms of metal fume fever occur 2 days after exposure and resolve 24 to 48 hours later. Given the symptoms and this time frame, cases of metal fume fever may be underreported and underdiagnosed. While the mechanism of metal fume fever is not fully understood, it is believed that metals in the welding fume cause a hypersensitivity reaction when inhaled due to the release of cytokines [31]. Chronic bronchitis is also not uncommon among welders [32,33]. This disease presents with a chronic productive cough characterized by copious mucus production and dyspnea [34]. Confounders complicate studies of bronchitis in welders, most notably smoking which is a known cause of the disease $[1,35]$. However, some studies have shown increased incidence of chronic bronchitis in welders, even when controlling for smoking status [36]. Siderosis, iron oxide deposits in the lung, is a well-documented yet usually nonthreatening and asymptomatic finding in long-term welders $[1,37]$. In some instances siderosis has been known to progress to pulmonary fibrosis, a restrictive lung disease which impairs lung function $[38,39]$. In the absence of pulmonary 
fibrosis, however, chronic welding fume exposure does not seem to lead to long term changes in lung function [40]. Some reports have indicated that exposure to welding fumes may cause an occupational asthma which would present as an obstructive lung disease when symptomatic [1, 41, 42]. Epidemiological studies have indicated that welders are more susceptible to lung infections such as pneumonia and have higher rates of mortality due to these infections [43-46]. Some case reports suggest that welders may even be at greater risk of infection and disease from generally benign, harmless organisms [45, 47].

While a number of respiratory complications are possible from welding fume exposure, by far the most feared adverse effect is the potential development of lung cancer. Numerous epidemiological studies have indicated that welders are at an increased risk of lung cancer [1]. Because of substantial epidemiological evidence and some evidence in animal studies, welding fumes were classified as a Group 1 (carcinogenic to humans) by the International Agency for Research on Cancer in 2017 [3]. The following report is meant to be a critical evaluation of the literature surrounding lung cancer in welders.

\section{Methods}

A comprehensive literature search was conducted using the databases PubMed and GoogleScholar. To identify applicable literature the following keywords were used: lung cancer, welding, tumorigenesis, adenocarcinoma, gas metal arc, stainless steel, and mild steel. All relevant literature published in English in the last 50 years was considered for this review.

\section{Results and Discussion}

\section{Epidemiological and worker studies}

The American Welding Society became concerned about possible adverse health effects from welding in the 1970s and conducted an in-depth literature review of epidemiological, 
animal, and in vitro studies [48]. They determined that epidemiological studies at the time were inconclusive as they did not account for factors such as smoking, asbestos exposure, previous type of work, family history, or genetics and that the potential carcinogenicity of welding fumes was "highly controversial."

In the years to follow, many worker studies reported an increased risk of lung cancer in welders [49-69]. However, whether confounders such as smoking can account for this increased risk has been controversial. Smoking is a well-known risk factor for lung cancer, and some studies have indicated that welders and metal workers are more likely to be smokers than the general population $[70,71]$. Stern et al. analyzed 22 epidemiological studies in the literature up until the 1980s. They concluded that welders have an approximately $30 \%$ increased risk of lung cancer compared to non-welders and this risk persisted even when considering potential confounders such as tobacco use or asbestos exposure in shipyards. Many other studies agreed with the finding that welders are at an increased risk of lung cancer even when considering and controlling for smoking status [53, 55, 58, 70-72]. Kendzia et al. analyzed a large database containing occupation and smoking status[70]. They adjusted for smoking status, concluding that while smoking may explain about $20 \%$ of the increased lung cancer risk in welders, it cannot explain all of it. They also noted that lung cancer risk was greater in never or light smokers compared to heavy smokers, further suggesting a direct carcinogenic effect of welding fumes [70]. Vallieres et al. agreed with this finding, observing that there was an excess risk of lung cancer in welders among light but not heavy smokers [73]. However, the epidemiological studies concerning smoking, welding, and lung cancer are conflicting, with some studies claiming confounding from smoking accounts for most of the excess lung cancer risk and other studies do not control for or consider smoking status in their analysis [54, 58, 74-77]. The general 
consensus seems to be that while smoking may contribute to increased lung cancer risk in welders, it cannot account for all of it.

Asbestos exposure has also been suggested to contribute to the increased lung cancer risk in welders. Asbestos is known to cause lung cancer and mesothelioma and in some workplaces, such as shipyards, workers can be exposed to this material. While asbestos fibers are not stable at the high temperatures created by welding, welders could sometimes still be exposed to it when asbestos was used as a filler material or for insulation [70]. It has been reported that welders have an increased mesothelioma risk [78]. A number of studies have concluded that the excess lung cancer risk in welders cannot be attributed to asbestos, however [58, 70, 72]. Kendzia et al. 2013 concluded that the excess risk of lung cancer in welders cannot be sufficiently explained by exposure to asbestos. Mannetje et al. adjusted for asbestos exposure in welders and still found an excess lung cancer risk [79]. However, the epidemiological studies are controversial, with some studies concluding that asbestos does account for the higher frequency of lung cancer in welders $[54-56,75,76,80-82]$. While some of these reports indicate that asbestos may be a confounder in their study, not all of them adjusted for asbestos exposure. Like was found with smoking, while asbestos may account for some of the increased risk of lung cancer in welders, it likely cannot account for all of it.

It is also frequently debated whether SS fume, containing the known carcinogens Ni and $\mathrm{Cr}$, is largely responsible for the increased lung cancer risk in welders compared to MS fume which contains mostly Fe. Melkild et. al and Danielsen et al. found an increased risk of lung cancer with MS welding, but the presence of confounders which were not accounted for in these studies limits these findings $[54,76]$. Simonato et al. observed an increased risk of lung cancer among both SS and MS welders but concluded the risk was greater with SS welders [56]. Other 
studies found no increased risk of lung cancer among MS welders [83, 84]. In a study by Steenland et al., however, welders only had to have two years of exposure for inclusion in the study, which may not have been long enough to increase lung cancer risk [84]. Nevertheless, numerous studies did find a significantly increased risk of lung cancer in MS welders [58-62, 79, 85]. Hansen et al. actually found that there was a significant excess risk of lung cancer in MS only welders but a non-significant excess risk of lung cancer among SS only welders [60]. Siew et al. specifically observed an increased risk of lung cancer in workers exposed to both iron and welding fumes [85]. However, because metal workers often weld with multiple different processes throughout their lifetime, many welders have mixed fume exposures which can make investigating these associations difficult [69].

Worker studies from the last 50 years have been at times contradictory and controversial. While some studies show clear, increased risks of lung cancer among welders, others show increased risk only with certain types of welding fumes or find that confounders such as smoking and asbestos exposure obscure any potential relationship. The results from epidemiological and worker studies emphasize the need for controlled in vivo and in vitro studies of welding fume exposures.

\section{In vivo studies}

Despite substantial human studies concerning lung cancer and welding, in vivo studies are comparatively lacking. Those studies which have been published have focused primarily on MMA and GMAW studies using mouse or rats. Table 1 summarizes in vivo studies directly investigating a tumorigenic effect of welding fumes. Some of the earliest in vivo studies were published in the 1980s with little to no further investigations for nearly a decade.

Ruezel et al. 1985 studied the effects of exposure to MMA-SS and GMAW-SS fumes in male Syrian golden hamsters [86]. Hamsters were exposed to 0.5 or $2.0 \mathrm{mg}$ of GMAW-SS or 
MMA-SS fume via intratracheal instillation once per week for 50 weeks. However, due to the high morbidity and mortality in the $2.0 \mathrm{mg}$ MMA-SS group, dosing in this group was reduced to once every 4 weeks after week 26. Histopathological analysis showed just two malignant tumors in the lungs of MMA-SS-exposed hamsters and none in the GMAW-SS-exposed animals. The authors concluded that MMA-SS may induce malignant lung tumors.

Berg et al. 1987 investigated the carcinogenic property of MMA-SS by implanting pellets into the bronchi of 100 male and female Sprague-Dawley rats [87]. Pellets were prepared by rolling 5 x $10 \mathrm{~mm}$ rectangle sheets of fine stainless steel wire which were then dipped into cholesterol containing the welding fume or a control substance. An incision was made at the level of the clavicle between the cartilaginous rings of the trachea and the pellet was implanted into the left bronchus. Rats were euthanized by exsanguination 34 months post-implantation of the pellet and the pellet was removed. Serial sections were cut from the lung near where the pellet had been located. The pellet remained in position in the majority of rats and produced local fibrosis which was not different between control and MMA-SS exposed mice. At no point in the study did any rats show signs of respiratory disease. While many rats developed non-respiratory tumors such as mammary and skin tumors, few lung tumors were observed. A subpleural squamous cell carcinoma was observed in the right lung lobe of one rat exposed to the welding fume pellet, opposite the site of pellet implantation. The appearance was more similar to a peripheral metastasis to the lung rather than a primary lung tumor. The authors concluded that this Cr-containing welding fume did not increase the risk of lung cancer in Sprague Dawley rats.

As the epidemiological support for an association between welding and lung cancer continued to grow, further in vivo studies were performed. In the late 1990s, Antonini et al. began to investigate the pneumotoxic and inflammatory properties of different types of welding 
fumes in vivo. When the pneumotoxic properties of GMAW-SS and GMAW-MS were investigated via intratracheal instillation into male CD/VA rats, it was observed that GMAW-SS induced greater lung injury and inflammation than GMAW-MS fume [88]. In a subsequent study, MMA-SS was compared to GMA-MS after intratracheal instillilation into male CD/VAF rats and bronchoalveolar lavage was performed at 1, 14, and 35 days post-exposure. Both fumes caused lung damage at the earlier time point, but this lung damage had resolved by 14 days postinstillation in the GMAW-MS exposed rats. However, significant lung damage was still observed at 14 days post-instillation in the MMA-SS exposed rats which subsided at 35 days postexposure. MMA-SS also caused a significantly greater release of TNF- $\alpha$ and IL- $1 \beta$ in the lavage fluid [89]. Similarly, it was observed that GMA-SS, GMA-MS, and MMA-SS caused increased cytotoxicity in Sprague-Dawley rats after intratracheal instillation. However, MMA-SS treatment caused maximal cytotoxicity and greater cellularity of lavage compared to GMA-SS or GMAMS fumes [90].

Solano-Lopez et al. investigated inflammatory and hyperplastic changes in the lungs of A/J mice following MMA-SS exposure via oropharyngeal aspiration [91]. They performed bronchoalveolar lavage at 1 day, 1 week, and 16 weeks post-exposure to assess lung injury and inflammation and 1, 8, 16, 24, and 48 weeks post-exposure to analyze histopathology. Lung injury and inflammation was increased at 1 day and 1 week post-exposure to MMA-SS but resided by 16 weeks. Bronchiolar epithelial cellular atypia and alveolar bronchioloalveolar hyperplasia as well as a lymphogranulomatous response characterized by lymphocytes and epitheloid macrophages was observed 1 week post-exposure to MMA-SS. The normal architecture of the pulmonary tissue was effaced with accumulation of brown pigment presumed to be SMA-SS. By 8 weeks post-exposure, the pulmonary architecture was restored but the 
inflammation, bronchiolar cellular atypia, and proliferation persisted. These results emphasized the need for ongoing animal studies exploring the tumorigenic potential of welding fumes.

Some studies have investigated potential mechanisms of welding fume toxicity and tumorigenic potential. Shoeb et al. investigated epigenetic changes following GMAW-MS and MMA-SS fume exposure [92]. Male Sprague-Dawley rats were exposed by intratracheal instillation to GMAW-MS or MMA-SS and bronchoalveolar lavage (BAL) was performed at 4 hours, 14 hours, 1 day, 3 days, 10 days, and 30 days post-exposure. Peripheral blood mononuclear cells were isolated from whole blood and dihydroethidium fluorescence and 4hydroxylnoneal protein adduct formation were assessed. DNA alterations including methylation and telomere changes were also investigated. It was observed that MMA-SS induced a greater, more persistent inflammatory response compared to GMA-MS or control. Markers of oxidative stress were only increased in mononuclear cells from MMA-SS-exposed rats. No significant differences were seen in DNA methylation between control and GMA-MS or MMA-SS at any time points. However, MMA-SS significantly increased telomere length 1 day and 30 days postexposure compared to GMA-MS or control.

In 2006, Antonini et al. designed and constructed a robotic welding fume inhalation exposure system at the National Institute for Occupational Safety and Health which allowed for advancements in in vivo studies of welding fumes [10]. This robotic welder generates welding fumes behind closed glass doors and the fume is picked up by a flexible tube and carried to a separate room where animals can be exposed by whole-body inhalation exposure. In this exposure room, conditions such as temperature, humidity, and gas production can be closely monitored and controlled. The construction of this robotic welder allowed for future in vivo inhalation studies which would more closely mirror worker exposures. 
One of the earlier welding fume inhalation studies investigated the pneumotoxic and inflammatory properties of GMAW-SS fume in male Sprague-Dawley rats [93]. Rats were exposed to 15 or $40 \mathrm{mg} / \mathrm{m}^{3}$ of GMAW-SS x 3 hours/day for 1, 3, or 10 days. Parameters of lung injury and inflammation were assessed at 1, 4, 6, 11, 14, and 30 days post-exposure. At all of the earlier time points, parameters of lung injury were significantly elevated but neutrophils were not increased until 6 days post-exposure. It was concluded that short-term inhalation of GMAW-SS causes significant lung damage and delayed pulmonary inflammation, but chronic inhalation studies were needed to further investigate the effect of welding fumes.

In 2008, Zeidler-Erdely et al. exposed male A/J and C57BL/6J mice to GMA-MS, GMASS, and MMA-SS via oropharyngeal aspiration in four separate bolus doses [94]. BAL was performed at 2, 7, and 28 days post-exposure and gross lung tumor counts and histopathological analysis were assessed at 48 and 78 weeks post-exposure. Results showed that GMAW-SS caused an acutely greater and more prolonged inflammatory response in the lungs of A/J mice. GMAW-SS also persisted in the lungs the longest and caused a trend towards increased tumor incidence. In a similar study, male A/J and C57BL/6J mice were exposed to MMA-SS fume by oropharyngeal aspiration once per month for four months [94]. At 78 weeks post-exposure, gross tumor counts and histopathology were assessed. MMA-SS-exposed A/J mice had significantly increased average tumor numbers per lung compared to air control, but this was only an average of about 1 more tumor per lung than control. There was no difference in tumor numbers among C57BL/6J mice exposed to air or MMA-SS. The authors concluded that MMA-SS fume on its own does not produce a significant tumorigenic response in an animal model. This study was accompanied by a short-term inhalation study of GMAW-SS fume in A/J and C57BL/6J mice [95]. Mice were exposed to GMAW-SS at $40 \mathrm{mg} / \mathrm{m}^{3}$ for 3 hours/day for 6 and 10 days. 
Pneumotoxicity and inflammation was observed in BAL at 1, 4, 7, 10, 14, and 28 days post the 10 day exposure. Lung tumor counts and histopathology were analyzed in A/J mice at 78 weeks post the 6 and 10 day exposures. While GMAW-SS induced a significant inflammatory response that was not recovered by 28 days in both mouse strains, no significant lung tumor development occurred in $\mathrm{A} / \mathrm{J}$ mice.

Given these findings and the strong epidemiological support for lung cancer in welders, more chronic in vivo exposure studies were needed. The first such study was conducted in 2013 by Zeidler-Erdely et al. in which the authors employed a two-stage initiation-promotion model to study potential lung tumor production in A/J mice following GMAW-SS exposure [96]. An initiation-promotion model was investigated as a potential mechanism of welding fume lung tumorigenesis given that the former studies showed that welding fumes were not significantly initiating lung tumor formation, despite the strong epidemiologic evidence of lung cancer in welders. In this study, male A/J mice were treated with the chemical initiatior 3methylcholanthrene (MCA) or a corn oil vehicle control and one week later were exposed to low or high doses of GMAW-SS via oropharyngeal aspiration once per week for 5 weeks. After 30 weeks post-initiation, lung tumors were enumerated. It was observed that MCA initiation followed by GMAW-SS promotion significantly increased lung tumor number compared to MCA/air controls $(12.1 \pm 1.5$ tumors/mouse for low dose GMAW-SS and 14.0 \pm 1.8 tumors/mouse for high dose GMAW-SS vs. $4.77 \pm 0.7$ tumors/mouse in MCA/air). This study provided support for the theory that welding fumes can act as lung tumor promoters in vivo. This study was followed by a chronic in vivo inhalation study [97]. Male A/J mice received intraperitoneal injections of corn oil or MCA and beginning one week later were exposed to air or GMAW-SS fume at a concentration of $40 \mathrm{mg} / \mathrm{m}^{3}$ for 8 hours/day, 4 days/week, for 9 weeks. 
After 30 weeks post-initiation, average tumors per mouse lung and histopathology were analyzed. Mice initiated with MCA and then promoted with GMAW-SS had significantly greater average lung tumor numbers compared to MCA/air controls $(16.11 \pm 1.18$ vs. $7.93 \pm 0.82)$.

Taken together, the results of these studies provide strong support that welding fumes can act as lung tumor promoters in vivo.

\section{In vitro studies}

Numerous in vitro studies have been performed investigating the toxicity of the individual metals that can be found in welding fumes. However, in vitro studies investigating the potential toxic and tumorigenic properties of the welding fumes themselves are scarcer.

Hedenstedt et al. 1977 investigated the mutagenicity of MMA-SS, MMA-MS, GMAWMS, and GMAW-SS fumes in Escherichia coli [98]. They observed that MS fume did not cause mutagenicity while SS fume did cause a mutagenic effect, which they attributed to the $\mathrm{Cr}^{6+}$ in the SS. They also found that MMA was more mutagenic than GMAW. MMA is known to be more soluble than GMAW, and the authors concluded this solubility contributed to its mutagenicity. Maxild et al. agree with these results, demonstrating that SS and MMA where more mutagenic than MS and GMAW, respectively, using the Salmonella/microsome mutagenicity test [99]. In 1983, White et al. exposed bovine alveolar macrophages to MMA-SS and MS fumes in vitro for 17 to 20 hours [100]. The results indicated that both welding fumes were more cytotoxic than control, but SS had even greater cytotoxicity than MS. It was also observed that MS and SS fumes did not reduce alveolar macrophage number, suggesting they damage cell membranes without destroying the cells up to 20 hours. Additionally, MS fume had reduced toxicity when added with DPPC, the main component of surfactant, which may make it less cytotoxic in vivo. More than a decade later, Antonini et al. investigated the effect of MMA-SS on free radical production and DNA damage in vitro [101]. Electron spin resonance demonstrated that 
MMA-SS fume had the ability to produce reactive hydroxyl radical, likely as a result of reduction of $\mathrm{Cr}(\mathrm{VI})$ in the fume to $\mathrm{Cr}(\mathrm{V})$. Using a DNA strand break assay, they observed that MMA-SS fume caused a concentration-dependent increase in DNA damage. These responses may help to explain a potential carcinogenic process of welding fumes. A similar study by Leonard et al. investigated free radical and reactive oxygen species generation after exposing mouse peritoneal monocytes to GMA-SS and GMAW-MS fumes in vitro [102]. It was observed that the welding fumes generated free radicals from reactions with $\mathrm{H}_{2} \mathrm{O}_{2}$ and caused lipid peroxidation and DNA damage. While both MS and SS produced free radicals, GMAW-SS consistently generated more reactivity and free radicals. Similar to Antonini et al., this heightened toxicity was thought to be due to the presence of $\mathrm{Cr}$ and/or Ni in the SS but not MS fume. It was therefore hypothesized that perhaps a newer $\mathrm{Cu}$-Ni welding fume would be a safer alternative to GMAW-SS or MMA-SS which contain Cr. Badding et al. exposed RAW 264.7 mouse macrophages to welding fumes and observed that GMA-MS and GMA-SS had greater ROS production than the $\mathrm{Cu}-\mathrm{Ni}$ welding fume [103]. However, the $\mathrm{Cu}-\mathrm{Ni}$ welding fume proved to be more cytotoxic as it induced cell death and mitochondrial dysfunction at a lower dose and impaired macrophage ability to phagocytose bacteria. Similarly, Antonini et al. observed that the $\mathrm{Cu}-\mathrm{Ni}$ welding fume, unlike GMAW-MS and GMAW-SS, did not significantly increased free radical production in vitro yet did reduce lung macrophage viability even more than GMAW-MS or GMAW-SS.[104] This suggested the Cu-Ni fume may have a direct cytotoxic effect on the lung rather than cause toxicity by ROS production [104]. These findings support the notion that it is not just the presence of $\mathrm{Cr}$ in the fumes that may be dangerous to worker health. Nevertheless, future in vitro studies could help to better explore which welding fumes and their component metals are most toxic. 


\section{Conclusions}

Significant evidence that welding fumes are carcinogenic led to their re-classification as a group 1 carcinogen by IARC in 2017. While epidemiological and worker studies have shown mixed results, this points to the difficulties of epidemiological studies given the potential for confounders like smoking and asbestos, the possibility of mixed welding fume exposures, personal safety habits, genetics, and other risk factors. In vitro and in vivo studies have demonstrated that many types of welding fumes have toxic and tumorigenic potential. Most notably, studies have demonstrated that some welding fumes have the ability to promote lung tumorigenesis in vivo. Nevertheless, little is known concerning the mechanisms by which welding fumes act as lung carcinogens. Continued research is needed to better elucidate potential mechanisms as well as continue to clarify which welding fumes and their metal constituents are most hazardous to worker health.

\section{Bibliography}

1. Antonini JM: Health Effects Associated with Welding. 2014:49-70.

2. Ferguson: Careers in Focus Construction. New York: Ferguson; 2010.

3. Guha N, Loomis D, Guyton KZ, Grosse Y, El Ghissassi F, Bouvard V, Benbrahim-Tallaa L, Vilahur N, Muller K, Straif K: Carcinogenicity of welding, molybdenum trioxide, and indium tin oxide. Lancet Oncol 2017, 18:581-582.

4. The Procedure Handbook of Arc Welding. 14 edn. The James F. Lincoln Arc Welding Foundation; 2000.

5. Ferguson: Careers in Focus Technicians. New York: Infobase Publishing; 2010.

6. Antonini JM: Health effects of welding. Crit Rev Toxicol 2003, 33:61-103. 
7. Kalliomaki PL, Kalliomaki K, Korhonen O, Nordman H, Rahkonen E, Vaaranen V: Respiratory status of stainless steel and mild steel welders. Scand $J$ Work Environ Health 1982, 8 Suppl 1:117-121.

8. Beckett WS: Welding. In Occupational and Environmental Respiratory Disease. Edited by Harber, P., Schenker MB, Balmes JR. St. Louis, MO: Mosby-Year Book, Inc.; 1996: $704-717$

9. Zimmer AT: The influence of metallurgy on the formation of welding aerosols. $J$ Environ Monit 2002, 4:628-632.

10. Antonini JM, Afshari AA, Stone S, Chen B, Schwegler-Berry D, Fletcher WG, Goldsmith WT, Vandestouwe KH, McKinney W, Castranova V, Frazer DG: Design, construction, and characterization of a novel robotic welding fume generator and inhalation exposure system for laboratory animals. J Occup Environ Hyg 2006, 3:194-203; quiz D145.

11. Jenkins NT, Pierce WMG, Eagar T: Particle size distribution of gas metal and flux cored arc welding fumes. 2005.

12. Sowards J, Ramirez A, Dickinson DW, Lippold JC: Characterization of Welding Fume from SMAW Electrodes - Part II. 2010.

13. McClellan RO: Particle Interactions with the Respiratory Tract. In Particle-Lung Interactions. Edited by Lenfant C. New York: Marcel Dekker, Inc.; 2000: 3-56

14. Antonini JM, Santamaria AB, Jenkins NT, Albini E, Lucchini R: Fate of manganese associated with the inhalation of welding fumes: potential neurological effects. Neurotoxicology 2006, 27:304-310. 
15. G. O: Kinestics of Inhaled Ultrafine Particles in the Organism. In Effects of Air Contaminants on the Respiratory Tract - Interpretations from Molecules to Meta Analysis. Hannover, Germany; 2004: 53-68

16. Antonini JM, Lawryk NJ, Murthy GG, Brain JD: Effect of welding fume solubility on lung macrophage viability and function in vitro. J Toxicol Environ Health A 1999, 58:343-363.

17. Kalliomaki PL, Kalliomaki K, Rahkonen E, Aittoniemi K: Follow-up study on the lung retention of welding fumes among shipyard welders. Ann Occup Hyg 1983, 27:449452.

18. Wild P, Bourgkard E, Paris C: Lung cancer and exposure to metals: the epidemiological evidence. Methods Mol Biol 2009, 472:139-167.

19. Cohen MD, Kargacin B, Klein CB, Costa M: Mechanisms of chromium carcinogenicity and toxicity. Crit Rev Toxicol 1993, 23:255-281.

20. Chromium, nickel and welding. IARC Monogr Eval Carcinog Risks Hum 1990, 49:1648.

21. Occupational exposure to hexavalent chromium. Final rule. Fed Regist 2006, 71:10099-10385.

22. Harris MK, Ewing WM, Longo W, DePasquale C, Mount MD, Hatfield R, Stapleton R: Manganese exposures during shielded metal arc welding (SMAW) in an enclosed space. J Occup Environ Hyg 2005, 2:375-382.

23. Laohaudomchok W, Lin X, Herrick RF, Fang SC, Cavallari JM, Shrairman R, Landau A, Christiani DC, Weisskopf MG: Neuropsychological effects of low-level manganese exposure in welders. Neurotoxicology 2011, 32:171-179. 
24. Mergler D, Baldwin M: Early manifestations of manganese neurotoxicity in humans: an update. Environ Res 1997, 73:92-100.

25. Roels HA, Bowler RM, Kim Y, Claus Henn B, Mergler D, Hoet P, Gocheva VV, Bellinger DC, Wright RO, Harris MG, et al: Manganese exposure and cognitive deficits: a growing concern for manganese neurotoxicity. Neurotoxicology 2012, 33:872-880.

26. Shukakidze A, Lazriev I, Mitagvariya N: Behavioral impairments in acute and chronic manganese poisoning in white rats. Neurosci Behav Physiol 2003, 33:263-267.

27. Wennberg A, Iregren A, Struwe G, Cizinsky G, Hagman M, Johansson L: Manganese exposure in steel smelters a health hazard to the nervous system. Scand J Work Environ Health 1991, 17:255-262.

28. Ventilation Guide for Weld Fume. Miami, FL: American Welding Society; 2001.

29. Confined Spaces. In Safety and Health Fact Sheets. Miami, Fl: American Welding Society; 1998

30. Chen HL, Chung SH, Jhuo ML: Efficiency of different respiratory protective devices for removal of particulate and gaseous reactive oxygen species from welding fumes. Arch Environ Occup Health 2013, 68:101-106.

31. Blanc PD, Boushey HA, Wong H, Wintermeyer SF, Bernstein MS: Cytokines in metal fume fever. Am Rev Respir Dis 1993, 147:134-138.

32. Sferlazza SJ, Beckett WS: The respiratory health of welders. Am Rev Respir Dis 1991, 143:1134-1148.

33. Al-Otaibi ST: Respiratory health of a population of welders. J Family Community Med 2014, 21:162-165. 
34. Standards for the diagnosis and care of patients with chronic obstructive pulmonary disease. American Thoracic Society. Am J Respir Crit Care Med 1995, 152:S77-121.

35. Holm M, Kim JL, Lillienberg L, Storaas T, Jogi R, Svanes C, Schlunssen V, Forsberg B, Gislason T, Janson C, Toren K: Incidence and prevalence of chronic bronchitis: impact of smoking and welding. The RHINE study. Int J Tuberc Lung Dis 2012, 16:553-557.

36. Cotes JE, Feinmann EL, Male VJ, Rennie FS, Wickham CA: Respiratory symptoms and impairment in shipyard welders and caulker/burners. Br J Ind Med 1989, 46:292-301.

37. Flors L, Domingo ML, Leiva-Salinas C, Mazon M, Rosello-Sastre E, Vilar J: Uncommon occupational lung diseases: high-resolution CT findings. AJR Am J Roentgenol 2010, 194:W20-26.

38. Buerke U, Schneider J, Rosler J, Woitowitz HJ: Interstitial pulmonary fibrosis after severe exposure to welding fumes. Am J Ind Med 2002, 41:259-268.

39. McCormick LM, Goddard M, Mahadeva R: Pulmonary fibrosis secondary to siderosis causing symptomatic respiratory disease: a case report. J Med Case Rep 2008, 2:257.

40. Morgan WK: On welding, wheezing, and whimsy. Am Ind Hyg Assoc J 1989, 50:59-69.

41. Hannu T, Piipari R, Kasurinen H, Keskinen H, Tuppurainen M, Tuomi T: Occupational asthma due to manual metal-arc welding of special stainless steels. Eur Respir $J$ 2005, 26:736-739.

42. Lee HS, Chia SE, Yap JC, Wang YT, Lee CS: Occupational asthma due to spotwelding. Singapore Med J 1990, 31:506-508. 
43. Coggon D, Inskip H, Winter P, Pannett B: Lobar pneumonia: an occupational disease in welders. Lancet 1994, 344:41-43.

44. Beaumont JJ, Weiss NS: Mortality of welders, shipfitters, and other metal trades workers in boilermakers Local No. 104, AFL-CIO. Am J Epidemiol 1980, 112:775786.

45. Palmer KT, Poole J, Ayres JG, Mann J, Burge PS, Coggon D: Exposure to metal fume and infectious pneumonia. Am J Epidemiol 2003, 157:227-233.

46. Zeidler-Erdely PC, Erdely A, Antonini JM: Immunotoxicology of arc welding fume: worker and experimental animal studies. J Immunotoxicol 2012, 9:411-425.

47. Miller JM, Hair JG, Hebert M, Hebert L, Roberts FJ, Jr., Weyant RS: Fulminating bacteremia and pneumonia due to Bacillus cereus. J Clin Microbiol 1997, 35:504-507.

48. Vilaume JE WK, Liss-Suter D, Hsiao S.: Effects of Welding on Health. Miami, FL: American Welding Society; 1979.

49. Becker N, Claude J, Frentzel-Beyme R: Cancer risk of arc welders exposed to fumes containing chromium and nickel. Scand J Work Environ Health 1985, 11:75-82.

50. Lerchen ML, Wiggins CL, Samet JM: Lung cancer and occupation in New Mexico. $J$ Natl Cancer Inst 1987, 79:639-645.

51. Oleru G, Ademiluyi SA: Some acute and long-term effects of exposure in welding and thermal-cutting operations in Nigeria. Int Arch Occup Environ Health 1987, 59:605612.

52. Sjogren B, Gustavsson A, Hedstrom L: Mortality in two cohorts of welders exposed to high- and low-levels of hexavalent chromium. Scand J Work Environ Health 1987, 13:247-251. 
53. Ronco G, Ciccone G, Mirabelli D, Troia B, Vineis P: Occupation and lung cancer in two industrialized areas of northern Italy. Int J Cancer 1988, 41:354-358.

54. Melkild A, Langard S, Andersen A, Tonnessen JN: Incidence of cancer among welders and other workers in a Norwegian shipyard. Scand J Work Environ Health 1989, 15:387-394.

55. Becker N, Chang-Claude J, Frentzel-Beyme R: Risk of cancer for arc welders in the Federal Republic of Germany: results of a second follow up (1983-8). Br J Ind Med 1991, 48:675-683.

56. Simonato L, Fletcher AC, Andersen A, Anderson K, Becker N, Chang-Claude J, Ferro G, Gerin M, Gray CN, Hansen KS, et al.: A historical prospective study of European stainless steel, mild steel, and shipyard welders. Br J Ind Med 1991, 48:145-154.

57. Keller JE, Howe HL: Cancer in Illinois construction workers: a study. Am J Ind Med 1993, 24:223-230.

58. Moulin JJ, Wild P, Haguenoer JM, Faucon D, De Gaudemaris R, Mur JM, Mereau M, Gary Y, Toamain JP, Birembaut Y, et al.: A mortality study among mild steel and stainless steel welders. Br J Ind Med 1993, 50:234-243.

59. Moulin JJ: Assessment of risk of lung cancer among mild steel and stainless steel welders. Occup Environ Med 1995, 52:284-285.

60. Hansen KS, Lauritsen JM, Skytthe A: Cancer incidence among mild steel and stainless steel welders and other metal workers. Am J Ind Med 1996, 30:373-382.

61. Lauritsen JM, Hansen KS: Lung cancer mortality in stainless steel and mild steel welders: a nested case-referent study. Am J Ind Med 1996, 30:383-391. 
62. Steenland K: Ten-year update on mortality among mild-steel welders. Scand J Work Environ Health 2002, 28:163-167.

63. Richiardi L, Boffetta P, Simonato L, Forastiere F, Zambon P, Fortes C, Gaborieau V, Merletti F: Occupational Risk Factors for Lung Cancer in Men and Women: A Population-Based Case-Control Study in Italy. Cancer Causes \& Control 2004, 15:285-294.

64. Ambroise D, Wild P, Moulin JJ: Update of a meta-analysis on lung cancer and welding. Scand J Work Environ Health 2006, 32:22-31.

65. Paris C, Clement-Duchene C, Vignaud JM, Gislard A, Stoufflet A, Bertrand O, Thiberville L, Grosdidier G, Martinet Y, Benichou J, Hainaut P: Relationships between lung adenocarcinoma and gender, age, smoking and occupational risk factors: A case-case study. Lung Cancer 2010, 68:146-153.

66. Guida F, Papadopoulos A, Menvielle G, Matrat M, Fevotte J, Cenee S, Cyr D, Schmaus A, Carton M, Paget-Bailly S, et al: Risk of lung cancer and occupational history: results of a French population-based case-control study, the ICARE study. J Occup Environ Med 2011, 53:1068-1077.

67. Tse LA, Yu IT, Qiu H, Au JS, Wang XR: Occupational risks and lung cancer burden for Chinese men: a population-based case-referent study. Cancer Causes Control 2012, 23:121-131.

68. Barkhordari A, Zare Sakhvidi MJ, Zare Sakhvidi F, Halvani G, Firoozichahak A, Shirali G: Cancer Risk Assessment in Welder's Under Different Exposure Scenarios. Iran J Public Health 2014, 43:666-673. 
69. Matrat M, Guida F, Mattei F, Cenee S, Cyr D, Fevotte J, Sanchez M, Menvielle G, Radoi L, Schmaus A, et al: Welding, a risk factor of lung cancer: the ICARE study. Occup Environ Med 2016, 73:254-261.

70. Kendzia B, Behrens T, Jockel KH, Siemiatycki J, Kromhout H, Vermeulen R, Peters S, Van Gelder R, Olsson A, Bruske I, et al: Welding and lung cancer in a pooled analysis of case-control studies. Am J Epidemiol 2013, 178:1513-1525.

71. Wong JYY, Bassig BA, Seow WJ, Hu W, Ji BT, Blair A, Silverman DT, Lan Q: Lung cancer risk in welders and foundry workers with a history of heavy smoking in the USA: The National Lung Screening Trial. Occup Environ Med 2017, 74:440-448.

72. Sjogren B, Hansen KS, Kjuus H, Persson PG: Exposure to stainless steel welding fumes and lung cancer: a meta-analysis. Occup Environ Med 1994, 51:335-336.

73. Vallieres E, Pintos J, Lavoue J, Parent ME, Rachet B, Siemiatycki J: Exposure to welding fumes increases lung cancer risk among light smokers but not among heavy smokers: evidence from two case-control studies in Montreal. Cancer Med 2012, 1:47-58.

74. Polednak AP: Mortality among welders, including a group exposed to nickel oxides. Arch Environ Health 1981, 36:235-242.

75. Hull CJ, Doyle E, Peters JM, Garabrant DH, Bernstein L, Preston-Martin S: Casecontrol study of lung cancer in Los Angeles county welders. Am J Ind Med 1989, 16:103-112.

76. Danielsen TE, Langard S, Andersen A, Knudsen O: Incidence of cancer among welders of mild steel and other shipyard workers. Br J Ind Med 1993, 50:1097-1103. 
77. Danielsen TE, Lang rd S, Andersen A: Incidence of lung cancer among shipyard welders investigated for siderosis. Int J Occup Environ Health 1998, 4:85-88.

78. Rolland P, Gramond C, Lacourt A, Astoul P, Chamming's S, Ducamp S, Frenay C, Galateau-Salle F, Ilg AG, Imbernon E, et al: Occupations and industries in France at high risk for pleural mesothelioma: A population-based case-control study (19982002). Am J Ind Med 2010, 53:1207-1219.

79. t Mannetje A, Brennan P, Zaridze D, Szeszenia-Dabrowska N, Rudnai P, Lissowska J, Fabianova E, Cassidy A, Mates D, Bencko V, et al: Welding and lung cancer in Central and Eastern Europe and the United Kingdom. Am J Epidemiol 2012, 175:706-714.

80. Jockel KH, Ahrens W, Bolm-Audorff U: Lung cancer risk and welding--preliminary results from an ongoing case-control study. Am J Ind Med 1994, 25:805-812.

81. Becker N: Cancer mortality among arc welders exposed to fumes containing chromium and nickel. Results of a third follow-up: 1989-1995. J Occup Environ Med 1999, 41:294-303.

82. Danielsen TE, Langard S, Andersen A: Incidence of cancer among welders and other shipyard workers with information on previous work history. J Occup Environ Med 2000, 42:101-109.

83. Tola S, Kalliomaki PL, Pukkala E, Asp S, Korkala ML: Incidence of cancer among welders, platers, machinists, and pipe fitters in shipyards and machine shops. $B r J$ Ind Med 1988, 45:209-218.

84. Steenland K, Beaumont J, Elliot L: Lung cancer in mild steel welders. Am J Epidemiol 1991, 133:220-229. 
85. Siew SS, Kauppinen T, Kyyronen P, Heikkila P, Pukkala E: Exposure to iron and welding fumes and the risk of lung cancer. Scand J Work Environ Health 2008, 34:444-450.

86. Reuzel PGJ BR, DeRaat WK, Lohman PHM. : Carcinogenicity and in vitro genotoxicity of the particulate fraction of two stainless steel welding fumes. In Proceedings of the International Conference on Health Hazards and Biological Effects of Welding Fumes and Gases. Edited by Stern RM BA, Fletcher AC, Jarvisalo J. New York: Excerpta Medica; 1985: 329-332

87. Berg NO, Berlin M, Bohgard M, Rudell B, Schutz A, Warvinge K: Bronchocarcinogenic properties of welding and thermal spraying fumes containing chromium in the rat. Am J Ind Med 1987, 11:39-54.

88. Antonini JM, Krishna Murthy GG, Rogers RA, Albert R, Ulrich GD, Brain JD: Pneumotoxicity and pulmonary clearance of different welding fumes after intratracheal instillation in the rat. Toxicol Appl Pharmacol 1996, 140:188-199.

89. Antonini JM, Krishna Murthy GG, Brain JD: Responses to welding fumes: lung injury, inflammation, and the release of tumor necrosis factor-alpha and interleukin-1 beta. Exp Lung Res 1997, 23:205-227.

90. Taylor MD, Roberts JR, Leonard SS, Shi X, Antonini JM: Effects of welding fumes of differing composition and solubility on free radical production and acute lung injury and inflammation in rats. Toxicol Sci 2003, 75:181-191.

91. Solano-Lopez C, Zeidler-Erdely PC, Hubbs AF, Reynolds SH, Roberts JR, Taylor MD, Young SH, Castranova V, Antonini JM: Welding fume exposure and associated 
inflammatory and hyperplastic changes in the lungs of tumor susceptible a/j mice. Toxicol Pathol 2006, 34:364-372.

92. Shoeb M, Kodali VK, Farris BY, Bishop LM, Meighan TG, Salmen R, Eye T, Friend S, Schwegler-Berry D, Roberts JR, et al: Oxidative stress, DNA methylation, and telomere length changes in peripheral blood mononuclear cells after pulmonary exposure to metal-rich welding nanoparticles. NanoImpact 2017, 5:61-69.

93. Antonini JM, Stone S, Roberts JR, Chen B, Schwegler-Berry D, Afshari AA, Frazer DG: Effect of short-term stainless steel welding fume inhalation exposure on lung inflammation, injury, and defense responses in rats. Toxicol Appl Pharmacol 2007, 223:234-245.

94. Zeidler-Erdely PC, Battelli LA, Salmen-Muniz R, Li Z, Erdely A, Kashon ML, Simeonova PP, Antonini JM: Lung tumor production and tissue metal distribution after exposure to manual metal ARC-stainless steel welding fume in $\mathrm{A} / \mathrm{J}$ and C57BL/6J mice. J Toxicol Environ Health A 2011, 74:728-736.

95. Zeidler-Erdely PC, Battelli LA, Stone S, Chen BT, Frazer DG, Young SH, Erdely A, Kashon ML, Andrews R, Antonini JM: Short-term inhalation of stainless steel welding fume causes sustained lung toxicity but no tumorigenesis in lung tumor susceptible A/J mice. Inhal Toxicol 2011, 23:112-120.

96. Zeidler-Erdely PC, Meighan TG, Erdely A, Battelli LA, Kashon ML, Keane M, Antonini JM: Lung tumor promotion by chromium-containing welding particulate matter in a mouse model. Part Fibre Toxicol 2013, 10:45.

97. Falcone LM, Erdely A, Meighan TG, Battelli LA, Salmen R, McKinney W, Stone S, Cumpston A, Cumpston J, Andrews RN, et al: Inhalation of gas metal arc-stainless 
steel welding fume promotes lung tumorigenesis in A/J mice. Arch Toxicol 2017, 91:2953-2962.

98. Hedenstedt A, Jenssen D, Lidestein BM, Ramel C, Rannug U, Stern RM: Mutagenicity of fume particles from stainless steel welding. Scand J Work Environ Health 1977, 3:203-211.

99. Maxild J, Andersen M, Kiel P: Mutagenicity of fume particles from metal arc welding on stainless steel in the Salmonella/microsome test. Mutat Res 1978, 56:235-243.

100. White LR, Marthinsen AB, Jakobsen K, Eik-Nes KB: Response of bovine alveolar macrophages in vitro to welding fume particles. Environ Health Perspect 1983, 51:211-215.

101. Antonini JM, Leonard SS, Roberts JR, Solano-Lopez C, Young SH, Shi X, Taylor MD: Effect of stainless steel manual metal arc welding fume on free radical production, DNA damage, and apoptosis induction. Mol Cell Biochem 2005, 279:17-23.

102. Leonard SS, Chen BT, Stone SG, Schwegler-Berry D, Kenyon AJ, Frazer D, Antonini JM: Comparison of stainless and mild steel welding fumes in generation of reactive oxygen species. Part Fibre Toxicol 2010, 7:32.

103. Badding MA, Fix NR, Antonini JM, Leonard SS: A comparison of cytotoxicity and oxidative stress from welding fumes generated with a new nickel-, copper-based consumable versus mild and stainless steel-based welding in RAW 264.7 mouse macrophages. PLoS One 2014, 9:e101310.

104. Antonini JM, Badding MA, Meighan TG, Keane M, Leonard SS, Roberts JR: Evaluation of the Pulmonary Toxicity of a Fume Generated from a Nickel-, Copper-Based 
Electrode to be Used as a Substitute in Stainless Steel Welding. Environ Health Insights 2014, 8:11-20. 
Tables

\begin{tabular}{|ccc|}
\hline Welding Fume Sample & Metal (weight \%) & Soluble/Insoluble Ratio \\
\hline \multirow{2}{*}{ GMA-MS } & $\mathrm{Fe}(85 \%)$ & 0.020 \\
& $\mathrm{Mn}(14 \%)$ & \\
\hline & $\mathrm{Fe}(57 \%)$ & 0.006 \\
GMA-SS & $\mathrm{Mn}(13.8 \%)$ & \\
& $\mathrm{Cr}(20.2 \%)$ & \\
& $\mathrm{Ni}(8.8 \%)$ & \\
& $\mathrm{Cu}(0.2 \%)$ & \\
\hline
\end{tabular}

Table 1. Metal composition of SS and MS welding fumes based on metal analysis previously presented in Antonini et al. 2006. 
Welding Fume

Exposure Route

Animal Model

Carcinogenic

Effect

Yes

Ruezel et al. 1985

Intratracheal

Syrian golden

hamster

instillation

MMA-SS

Intrabronchial pellet

implanation

Sprague-Dawley rat

No

Berg et al. 1987

Oropharyngeal

Aspiration

A/J mouse

C57BL/6J mouse

Intratracheal

instillation

Oropharyngeal

Aspiration

Oropharyngeal

Aspiration

GMAW-SS

Inhalation

Inhalation

Inhalation
$\mathrm{A} / \mathrm{J}$ mouse

C57BL/6J mouse

$\mathrm{A} / \mathrm{J}$ mouse

C57BL/6J mouse

A/J mouse

$\mathrm{A} / \mathrm{J}$ mouse

A/J mouse
Yes

No

No

Ruezel et al. 1985

No

Zeidler-Erdely et al. 2008

No

Yes

Zeidler-Erdely et al. 2011

No

Zeidler-Erdely et al. 2011

No

Yes

Zeidler-Erdely et al. 2013

Falcone et al. 2017

Table 2. Published in vivo studies investigating carcinogenic effects of welding fumes.

MMA-SS: Manual manual arc welding - stainless steel

GMAW - SS: Gas metal arc welding - stainless steel 


\section{Chapter 3: Gas Metal Arc - Stainless Steel Welding Fume Promotes Lung Tumorigenesis in A/J Mice}

Lauryn M Falcone ${ }^{1,2}$, Aaron Erdely ${ }^{2}$, Terence G Meighan ${ }^{2}$, Lori A Battelli ${ }^{2}$, Rebecca Salmen ${ }^{2}$, Walter McKinney ${ }^{2}$, Samuel Stone ${ }^{2}$, Amy Cumpston ${ }^{2}$, Jared Cumpston ${ }^{2}$, Ronnee N Andrews ${ }^{3}$, Michael Kashon ${ }^{2}$, James M Antonini², Patti C Zeidler-Erdely ${ }^{2}$

${ }^{1}$ West Virginia University, School of Medicine, Morgantown, WV; ${ }^{2}$ Health Effects Laboratory Division, National Institute for Occupational Safety and Health, Morgantown, WV; ${ }^{3}$ Division of Applied Research and Technology, National Institute for Occupational Safety and Health, Cincinnati, $\mathrm{OH}$

Originally published in: Falcone LM, Erdely A, Meighan TG, et al. Inhalation of gas metal arc stainless steel welding fume promotes lung tumorigenesis in A/J mice. Archives of Toxicology. 2017;91(8):2953-2962. 


\begin{abstract}
Epidemiologic studies suggest an increased risk of lung cancer with exposure to welding fumes, but controlled animal studies are needed to support this association. Oropharyngeal aspiration of collected "aged" gas metal arc-stainless steel (GMA-SS) welding fume has been shown by our laboratory to promote lung tumor formation in vivo using a two-stage initiation-promotion model. Our objective in this study was to determine if inhalation of freshly generated GMA-SS welding fume also acts as a lung tumor promoter in lung tumor susceptible mice. Male A/J mice received intraperitoneal (IP) injections of corn oil or the chemical initiator 3-methylcholanthrene (MCA;10 $\mu \mathrm{g} / \mathrm{g}$ ) and one week later were exposed by whole body inhalation to air or GMA-SS welding aerosols for $4 \mathrm{~h} / \mathrm{d} \times 4 \mathrm{~d} / \mathrm{w} \times 9 \mathrm{w}$ at a target concentration of $40 \mathrm{mg} / \mathrm{m}^{3}$. Lung nodules were enumerated at 30 weeks post-initiation. GMA-SS fume significantly promoted lung tumor multiplicity in A/J mice initiated with MCA (16.11 \pm 1.18$)$ compared to MCA/air-exposed mice $(7.93 \pm 0.82)$. Histopathological analysis found that the increased number of lung nodules in the MCA/GMA-SS group were hyperplasias and adenomas, which was consistent with developing lung tumorigenesis. Metal deposition analysis in the lung revealed a lower deposited dose, approximately 5 fold compared to our previous aspiration study, still elicited a significant lung tumorigenic response. In conclusion, this study demonstrates that inhaling GMA-SS welding fume promotes lung tumorigenesis in vivo which is consistent with the epidemiologic studies that show welders may be at an increased risk for lung cancer.
\end{abstract}




\section{Introduction}

Welding, a process of joining metals, is a common industrial practice worldwide. It is estimated that there are nearly 400,000 full-time welding occupations in the United States alone as of 2014 [1]. Gas metal arc (GMA) welding is a type of electric arc welding where an electric arc is established between the work piece and a consumable wire electrode. High temperatures create a molten pool into which the electrode is continuously fed and the metals fuse together as they cool. This process utilizes an inert shielding gas to protect the weld from oxidative weakening and vaporizes metals, forming metal oxides which react with air to form welding fumes. The welding fumes are a complex mixture of gases and metal oxides that are derived primarily from the electrode. However, the shielding gas, electrode coating, base metal, and paint or other surface coatings may also contribute to the welding fume composition [2].

GMA-stainless steel (SS) welding fumes contain a metal-rich particulate matter that contains carcinogenic (hexavalent chromium [Cr VI] and nickel [Ni]) and non-carcinogenic (manganese $[\mathrm{Mn}]$ and iron $[\mathrm{Fe}]$ ) metals. A number of well-documented, harmful effects have been associated with welding fume exposure. The most common acute health effect of welding fume inhalation is metal fume fever, characterized by flu-like symptoms, cough, and dyspnea, while the most common chronic health effect is bronchitis [2]. Along with complications such as infection or neurological effects, lung cancer from exposure to welding fumes is an area of concern, yet few controlled animal studies have investigated this association. Several epidemiological studies support the hypothesis that exposure to welding fume increases lung cancer risk [3-6]. The need for animal studies is critical, as worker exposure is not always welldocumented. In addition, workers may be exposed to additional occupational agents or confounders (e.g. smoking) that complicate epidemiological studies [7]. The International Agency for Research on Cancer (IARC) advisory group on the Monograph priorities for 2008 
listed welding fume as a high priority agent for further evaluation of lung cancer risk in humans. Welding fume is classified as a group 2B carcinogen (possibly carcinogenic to humans) and will be re-evaluated by an IARC working group in 2017 [8].

Previous research in our laboratory has shown that GMA-SS welding fume persists in the lung for 1.5 years and triggers mild, chronic inflammation, but does not initiate tumor formation in lung tumor-susceptible A/J mice [9]. In a two-stage initiation-promotion model of lung tumorigenesis, GMA-SS welding fume significantly increased lung tumor incidence and multiplicity at 30 weeks post-oropharyngeal aspiration [10]. This finding suggests stainless steel welding fume may act as a lung tumor promoter. Given these results, we aimed to determine if inhalation of GMA-SS welding fume also promotes lung tumor formation in $\mathrm{A} / \mathrm{J}$ mice. Inhalation is the preferred route for welding fume-related toxicity studies in animals because it closely simulates the occupational exposure with respect to both particle size and surface properties of the fume and lung particle deposition. Furthermore, "fresh" GMA-SS welding fume as delivered via inhalation is more reactive than "aged" welding fume which is used for oropharyngeal aspiration studies [11].

\section{Methods}

\section{Animals}

Male A/J mice, 4 to 5 weeks of age, were purchased from Jackson Laboratories (Bar Harbor, ME) and housed in an Association for Assessment and Accreditation of Laboratory Animal Care-Accredited, specific pathogen-free, environmentally-controlled facility. All mice were free of endogenous viral pathogens, parasites, mycoplasmas, Helicobacter, and CAR bacillus. Mice were housed in groups of five in ventilated cages and provided high-efficiency particulate filtered air under a controlled light cycle (12 hour light/12 hour dark) at a standard 
temperature $\left(22-24^{\circ} \mathrm{C}\right)$ and $30-70 \%$ relative humidity. Animals were acclimated to the animal facility for one week and allowed access to a conventional diet (6\% irradiated NIH-31 Diet, Envigo RMS, Inc., Madison, WI) and tap water ad libitum. All procedures were performed using protocols approved by the National Institute for Occupational Safety and Health (NIOSH) Institutional Animal Care and Use Committee.

\section{Experimental protocols for animal exposure and welding fume generator}

$\mathrm{A} / \mathrm{J}$ mice, 120 in total, were organized into 4 groups using a block design for randomization (Figure 1). On day 1, mice aged 5 to 6 weeks were intraperitoneally (IP) injected with the chemical initiator, 3-methylcholanthrene (MCA) (Sigma, St. Louis, MO) dissolved in corn oil (CO) (Sigma, St. Louis, MO) at a dose of $10 \mu \mathrm{g} / \mathrm{g}$ of body weight or CO alone. MCA was chosen as the initiating agent based on the efficient response of the $\mathrm{A} / \mathrm{J}$ mouse to this carcinogen in our oropharyngeal aspiration study [10]. One week post-initiation, mice were exposed in whole body inhalation chambers with individual steel mesh cages to aerosols generated during GMA-SS welding or air for $4 \mathrm{~h} / \mathrm{d}$ and $4 \mathrm{~d} / \mathrm{w}$ for 9 weeks at a target concentration of $40 \mathrm{mg} / \mathrm{m}^{3}$ (actual $32.3 \pm 2.8 \mathrm{mg} / \mathrm{m}^{3}$ ). The welding wire used was 0.045 inch diameter Lincoln Electric Blue Max MIG 308LSI and the welding parameters were set to 25 volts DC, 300 inch per minute wire feed, $30 \mathrm{~L} / \mathrm{min}$ of $95 \%$ Argon - 5\% $\mathrm{CO}_{2}$ shielding gas, and a typical welding current of 220 amps.

The design and construction of the welding fume aerosol generator were previously described [12]. This automated robotic welder continuously generated welding fumes by welding beads onto $1 / 4$ inch thick plates of mild steel. The resulting fume was carried into a whole body exposure chamber through a $3 / 4$ inch flexible tube by maintaining the chamber at a negative pressure (0.70 Inch $\left.\mathrm{H}_{2} \mathrm{O}\right)$. Particle concentrations within the exposure chamber were 
continuously monitored with a Data RAM (DR-40000 Thermo Electron Co, Franklin, MA), and gravimetric determinations ( $37 \mathrm{~mm}$ cassettes with $0.45 \mu \mathrm{m}$ pore-size Teflon filters) were used to calibrate and verify the Data RAM readings each day. Gas generation, including carbon monoxide $(\mathrm{CO})$, carbon dioxide $\left(\mathrm{CO}_{2}\right)$, oxygen $\left(\mathrm{O}_{2}\right)$, and ozone $\left(\mathrm{O}_{3}\right)$, was continuously monitored. During the welding exposure, $\mathrm{O}_{2}$ levels were maintained above the OSHA minimal acceptable level. $\mathrm{O}_{3}, \mathrm{CO}, \mathrm{CO}_{2}$ were below OSHA permissible exposure limits and NIOSH recommended exposure limits (REL) during the entire exposure duration. In the exposure chamber, $\mathrm{CO}$ and $\mathrm{O}_{3}$ levels were not significantly higher than background. The exposure system setup was slightly modified from that described previously [12] to reduce the travel time of the particulate fume from the welding torch to the exposure chamber. This was done to ensure delivery of fresher fumes to more closely mimic a worker's inhalation exposure.

\section{Body weight determination}

All mice were weight-matched prior to the inhalation exposure. Mice were weighed weekly throughout the experimental time course and at the 30 -week sacrifice.

\section{Whole lung metal analysis}

Male A/J mice were exposed by inhalation to GMA-SS welding aerosols $\left(40 \mathrm{mg} / \mathrm{m}^{3}\right)(\mathrm{n}=$ 25) or filtered air $(\mathrm{n}=10)$ for $4 \mathrm{~h}$. Immediately following exposure, whole lungs were excised, trimmed, and lyophilized. The freeze-dried tissue was weighed then acid digested. Inductively coupled argon plasma, atomic emission spectroscopy at NIOSH-Division of Applied Research and Technology (Cincinnati, $\mathrm{OH}$ ) was used to determine the amount of $\mathrm{Cr}, \mathrm{Ni}, \mathrm{Cu}, \mathrm{Fe}$, and $\mathrm{Mn}$ present in the lung according to the draft NIOSH method 8200 modified to accommodate the sample matrix (NIOSH 2003).

\section{Gross lung tumor counts and histopathology}


At 30 weeks post-exposure, A/J mice were euthanized with Fatal Plus [100-300 mg/kg IP; 390 mg/ml pentobarbital sodium] (Vortech Pharmaceuticals, Dearborn, MI), weighed, and then the vena cava was cut to exsanguinate the animal. All internal organs were examined for the presence of tumors. The whole lung was then excised. All tumors were clearly defined with no apparent merged tumors. The lungs were inflated and fixed with $10 \%$ neutral buffered formalin for $24 \mathrm{~h}$. Tumors were counted and measured $24 \mathrm{~h}$ after fixation. Lungs were embedded in paraffin, then a $5 \mu \mathrm{m}$ standardized section was cut. Slides were stained with hematoxylin and eosin and interpreted by two separate, contracted, board certified veterinary pathologists in a blinded fashion for evidence of hyperplasia and neoplasia, inflammation, lymphoid tissue response, and foreign materials by light microscopy. Diagnostic criteria for hyperplastic and neoplastic findings were according to goRENI (http://www.goreni.org/), the standard reference for nomenclature and diagnostic criteria in toxicologic pathology and at the same time the Internet discussion platform for the global initiative "INHAND" - the International Harmonization of Nomenclature and Diagnostic criteria [13, 14]. If abnormal changes were found, severity was scored using the following scale: 1=minimal, $2=$ mild, $3=$ moderate, 4=marked. The final severity score reflects the average of the right and left lung lobe scores and are presented as means \pm standard error. Because bronchiolo-alveolar hyperplasia (BAH) and bronchiolo-alveolar adenomas (BAA) represent a continuum of the proliferative process and there is possible overlap between these diagnoses, the numbers of lesions were combined to compare the oncogenic potential of each treatment [14]. However, the gross tumor count at necropsy is more representative of the response because examination of a single histological section per lung underestimates the total number of lesions per lung [15].

\section{Statistical comparisons and analysis}


Statistical analyses were performed using JMP version 12. Factorial analysis of variance (ANOVA) was utilized on continuous variables to make comparisons between the treatment groups. For some variables a log transformation was performed on the data to reduce heterogeneous variance and meet the assumptions of an ANOVA. Gross tumor counts and histopathology counts from sections were analyzed similarly. Tumor incidence (presence or absence of tumors) was analyzed using a chi-square test in SAS 'Proc Freq', while tumor multiplicity (number of tumors per lung) was analyzed using Poisson regression in SAS 'Proc Genmod'. In cases where overdispersion existed, a negative binomial regression was performed. Analyses were performed independently on CO and MCA treated animals, and only utilized data from those animals surviving to the 30 week time point. For all analyses, a $p$-value of $<0.05$ was set as the criteria for significance

\section{Results}

\section{Welding fume characteristics}

A summary of the characteristics of GMA-SS welding fume and images of the fume are presented in Figure 2. Particle mass size distribution was measured for this newer configuration using a Micro-Orifice Uniform Deposit Impactor (MOUDI, model 110; MSP corp., Shoreview, Minn.) with additional Nano-MOUDI stages (MSP model 115). The mass median aerodynamic diameter (MMAD) was $350 \mathrm{~nm}$. The count-based particle size distributions of the particles were measured using a Scanning Mobility Particle Sizer (SMPS model 3936, TSI Inc, Shoreview, MN). The SMPS estimated the count median aerodynamic diameter to be $230 \mathrm{~nm}$. Particle imaging was achieved with a scanning electron microscope (SEM; JEOL 6400, JEOL Inc). Inspection of physical characteristics of the particles showed many small nano-spheres (10 to 50 nm) linked together into long chain like structures often with several branches. Elemental 
analysis of the welding particles were previously measured [10]. The overall particulate fume was composed of $57 \% \mathrm{Fe}, 20.2 \% \mathrm{Cr}, 13.8 \% \mathrm{Mn}, 8.8 \% \mathrm{Ni}, 0.2 \%$ copper $(\mathrm{Cu})$ and trace amounts of silicon (Si), aluminum (Al), and vanadium (V). Hexavalent chromium (Cr (VI)) levels were also measured and determined to be $2929 \mathrm{ppm}$. GMA-SS welding fume is largely water insoluble with a soluble: insoluble ratio of 0.006 [16].

\section{Lung metal deposition after GMA-SS welding fume inhalation}

Shown in Table 1 is the lung metal deposition in $\mathrm{A} / \mathrm{J}$ mice after $4 \mathrm{~h}$ of inhalation of GMA-SS welding fume. The most abundant metal measured in the lung was $\mathrm{Fe}$ followed by $\mathrm{Cr}$, $\mathrm{Mn}, \mathrm{Ni}$, and $\mathrm{Cu}$, as predicted from the previous characterization of this fume [12]. The metal analysis by weight $\%$ of the whole lungs $(60 \% \mathrm{Fe}, 17 \% \mathrm{Cr}, 14 \% \mathrm{Mn}, 8 \% \mathrm{Ni}$, and $0.8 \% \mathrm{Cu})$ agrees with the weight $\%$ of collected fume.

The analysis of the metals shows a cumulative increase of $\sim 10.1 \mu \mathrm{g}$ of total GMA-SS fume deposited in the lung from a single $4 \mathrm{~h}$ exposure. The alveolar deposition in the mice was equated to the human by the equations below using the previous threshold limit value-time weighted average (TLV-TWA) of $5 \mathrm{mg} / \mathrm{m}^{3}$ for total welding fume and the PEL of $5 \mu \mathrm{g} / \mathrm{m}^{3}$ for $\mathrm{Cr}(\mathrm{VI})$. Previously, we estimated that $70 \%$ of the total dose reached the alveolar space $(10.1 \mu \mathrm{g} / \mathrm{d}$ x $0.70=7.07 \mu \mathrm{g} / \mathrm{d})[17,18]$. The mice were exposed for 36 days $(9 \mathrm{w}$ at $4 \mathrm{~d} / \mathrm{w})$ for an approximate total alveolar deposition of $254.5 \mu \mathrm{g}$.

\section{Factored for human dose using previous welding fume TLV of $5 \mathrm{mg} / \mathrm{m}^{3}$ :}

Fume concentration $\mathrm{x}$ min volume $\mathrm{x}$ exposure duration $\mathrm{x}$ deposition efficiency $=$ deposited human dose

$5 \mathrm{mg} / \mathrm{m}^{3} \times(20 \mathrm{~L} / \mathrm{min})\left(10^{-3} \mathrm{~m}^{3} / \mathrm{L}\right) \times(8 \mathrm{~h} /$ day $)(60 \mathrm{~min} / \mathrm{h}) \times 0.16=7.7 \mathrm{mg}$ deposited per $8 \mathrm{~h}$ day

\section{in humans}


Human equivalent dose to mouse by alveolar surface area (SA) [19]

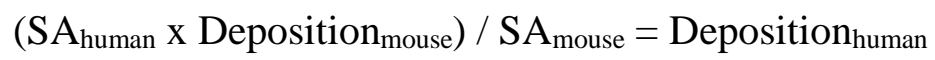

$\left(102 \mathrm{~m}^{2} \times 0.00707 \mathrm{mg}\right) / 0.05 \mathrm{~m}^{2}=\mathbf{1 4 . 4} \mathbf{~ m g}(\sim 2$ fold greater: $14.4 / 7.7)$

Factored for human dose using $\operatorname{Cr}(\mathrm{VI})$ PEL of $5 \mu \mathrm{g} / \mathrm{m}^{3}$ :

$\mathrm{Cr}(\mathrm{VI})$ concentration $\mathrm{x}$ min volume $\mathrm{x}$ exposure duration $\mathrm{x}$ deposition efficiency $)=$ deposited human dose

$5 \mu \mathrm{g} / \mathrm{m}^{3} \times(20 \mathrm{~L} / \mathrm{min})\left(10^{-3} \mathrm{~m}^{3} / \mathrm{L}\right) \times(8 \mathrm{~h} / \mathrm{day})(60 \mathrm{~min} / \mathrm{h}) \times 0.16=7.7 \mu \mathrm{g}$ deposited per $8 \mathrm{~h}$ day in humans

In the GMA-SS fume, $\mathrm{Cr}(\mathrm{VI})$ was $0.29 \%$ of the total welding fume $[10,20]$. Using our alveolar deposition dose of $7.07 \mu \mathrm{g}$ roughly $0.0205 \mu \mathrm{g}(7.07$ x 0.0029$)$ would be $\mathrm{Cr}(\mathrm{VI})$.

Human equivalent dose to mouse by SA:

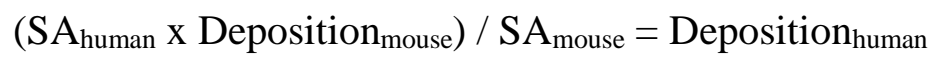

$\left(102 \mathrm{~m}^{2} \times 0.0205 \mu \mathrm{g}\right) / 0.05 \mathrm{~m}^{2}=\mathbf{4 1 . 8} \boldsymbol{\mu g}(\sim 5$ fold greater: $41.8 / 7.7)$

\section{Morbidity and mortality}

A timeline of the experimental protocol for the two-stage (initiation-promotion) carcinogenesis model is shown in Figure 1. Initial body weights at week 0 (means \pm standard error [SE]) were $18.56 \pm 0.35,19.1 \pm 0.39,18.25 \pm 0.31$, and $19.05 \pm 0.36$ for the CO/air, CO/GMA-SS, MCA/air, and MCA/GMA-SS groups, respectively. Body weights increased steadily and were not changed due to exposure from week 0 to 30 with $10.26 \pm 0.58,9.46 \pm 0.56$, $11.38 \pm 0.65,9.78 \pm 0.61$ for the CO/air, CO/GMA-SS, MCA/air, and MCA/GMA-SS groups, respectively. Morbidity and mortality throughout the study was low ( 5\%) and no 
abnormalities, such as other tumor types besides lung, were found at the terminal sacrifice at 30 weeks. In total, 6 mice died during the course of the study and were not included in the final analysis of the data. Necropsy determined that all 6 mice died from typical morbidities that included enlarged heart or otherwise undetermined.

\section{Gross tumor multiplicity and incidence}

GMA-SS welding fume significantly promoted lung tumors in the A/J mouse 30 weeks after initiation with MCA. The grossly observed tumor multiplicity (average tumor number/mouse lung $\pm \mathrm{SE}$ ) for all groups is shown in Figure 3. There was no effect of welding fume alone on tumor multiplicity (CO/air, $0.32 \pm 0.10$; CO/GMA-SS, $0.45 \pm 0.13 ; p=0.44)$. In animals initiated with MCA, tumor multiplicity was $7.93 \pm 0.82$ and $16.11 \pm 1.18$ for air and GMA-SS, respectively $(p<0.0001)$. Average tumor incidence $(\%$ of tumor-bearing mice) was $29 \%$ in CO/air and 38\% in CO/GMA-SS-exposed animals. Reports in the literature indicate the background tumor frequency in A/J mice between 43 and 53 weeks to be $31-40 \%$ [21, 22]. The mice in this study were 35 or 36 weeks old upon sacrifice, indicating the observed tumor incidence is consistent with the literature. As expected, tumor incidence was $>96 \%$ in all MCAinitiated groups ( $\mathrm{n}=29$ for MCA/air and $n=28$ for MCA/GMA-SS groups) which confirmed successful experimental administration as well as its carcinogenic effectiveness in A/J mice. Total and average tumor number per treatment group across each of the individual lung regions is described in Table 2. MCA/GMA-SS-exposed mice had significantly greater lung tumor multiplicity in every lung region compared to MCA/air $(p<0.009)$. There was no difference between CO/air and CO/GMA-SS groups $(p=0.44)$.

Gross lung morphology from a GMA-SS-exposed mouse initiated with MCA is shown in Figure 4. Welding fume deposition was visible in exposed mouse lungs and appeared black- 
brown in color. Tumors appeared white in color and opaque on initial gross exam and became more well-defined after fixation which aided enumeration. At 30 weeks, tumors were between $\sim 0.5 \mathrm{~mm}$ and $\sim 3 \mathrm{~mm}$, with most tumors $\sim 1 \mathrm{~mm}$.

\section{Histopathological evaluation of lung lesions, inflammation, and welding fume presence}

$\mathrm{CO} / a i r$ animals had no lymphoid infiltrate or foreign material (brown-black pigment, i.e., welding fume) and hyperplasia was unremarkable $(0.09 \pm 0.05)$. There were 5 total lesions reported in the CO/air group. The CO/GMA-SS-exposed group had minimal, but significant, lymphoid infiltrates $(0.22 \pm 0.063 ; p<0.03)$ and foreign material $(1.86 \pm 0.07 ; p<0.03)$ compared to $\mathrm{CO} /$ air. There were 2 total hyperplastic lesions reported in this group. Welding fume, indicated by blackbrown foreign material presence in the lungs, was found in both GMA-SS-exposed groups (CO and MCA) in every lung section. Significant hyperplasia $(1.20 \pm 0.11 ; p<0.03)$ and increased total preneoplastic/neoplastic lesions (BAH and BAA) were reported in the MCA/GMA-SS animals compared to MCA/air animals (114 versus 70; $p<0.03$ ). Histopathological assessment of the lungs from a separate, second board certified veterinary pathologist confirmed these findings (Table 3). The total number of proliferative lesions for MCA/GMA-SS-exposed mice was 153 compared to 90 for MCA/air. Increased perivascular mononuclear infiltrate in the MCA/GMA-SS group consisting of small aggregates or cuffs of lymphocytes, sometimes mixed with a few plasma cells, adjacent to or around multiple scattered vessels was also reported. This infiltrate was not observed in any of the MCA/air lungs. Because there were no significant findings in the $\mathrm{CO}$ groups besides evidence of welding fume and minimal lymphoid infiltrates in GMA-SS-exposed mice, a second evaluation was not deemed necessary. Figure 5a demonstrates a BAA and two areas of BAH. Figure $5 \mathrm{~b}$ shows the adenoma in panel a at 20x magnification adjacent to areas of welding fume deposition. Panels $\mathrm{c}$ and demonstrate a BAA at 40x and BAH at 20x, respectively. The 
BAA were more compact nodules composed of enlarged Type II cells that obscured the normal tissue morphology. These benign neoplasms had a smooth margin that frequently caused compression of surrounding tissue. The cells sometimes had prominent nucleoli and frequently formed radiating proliferations around blood vessels. BAH were round to irregular in shape with increased numbers of Type II cells lining alveolar septae. The cells were of normal size and normal tissue architecture was retained. The margins of these lesions were irregular and did not cause compression of surrounding tissues. Because $\mathrm{BAH}$ and BAA represent a continuum of the proliferative process and there is possible overlap between these diagnoses, the number of lesions were combined to compare the tumorigenic potential of each treatment [14]. In addition, the number of adenomas in the MCA/GMA-SS group was significantly greater than in the MCA/air group (p<0.05; Table 3) [23].

\section{Discussion}

This study was the first to find that inhalation of GMA-SS welding fume can promote lung tumorigenesis in vivo. Tumor multiplicity increased two-fold after initiation with the chemical initiator MCA. Histopathology analysis confirmed the gross findings and showed a significant increase in lung adenomas and combined adenomas and hyperplastic lesions in welding fume-exposed animals. In addition, welding fume exposure increased inflammatory infiltrates. Interestingly, the tumorigenic potential of the inhaled welding fume was achieved at a significantly lower total-deposited dose compared to our previous oropharyngeal aspiration exposure in mice [10]. The results of this study further support the epidemiological findings of an association between lung cancer and welding.

The measured lung deposition following welding fume exposure in this study after a single $(4 \mathrm{~h})$ exposure was $10.1 \mu \mathrm{g}$, or a cumulative dose of $254.5 \mu \mathrm{g}$ in the lung alveolar region (see calculation in results). This dose represents approximately two times the former TLV-TWA 
of $5 \mathrm{mg} / \mathrm{m}^{3}$ for $8 \mathrm{~h} / \mathrm{d}$, a level commonly exceeded in the workplace [3]. This exposure in terms of the TLV is equivalent to 14 weeks ( 36 days of exposure $\mathrm{x} 2=72$ days) of constant exposure to GMA-SS fume for $8 \mathrm{~h} / \mathrm{d}$. If a welder was exposed to GMA-SS fume for $5 \%(1 / 20)$ of their working time at the maximum concentration, then the exposure would be 280 weeks (14 weeks $x$ 20 ), or 5.6 years. Therefore, the deposited dose in our study is occupationally relevant because epidemiologic research has demonstrated a 70\% increase in the risk of lung cancer among workers who welded for at least 5\% or more of their working time [5].

Our lab previously demonstrated that at 78 weeks post-oropharyngeal aspiration, lung tumor incidence in $\mathrm{A} / \mathrm{J}$ mice approached significance $(\mathrm{p}=0.057 ; \mathrm{n}=16)$ and a trend for increased tumor multiplicity was found after exposure to GMA-SS welding PM alone [24]. In a follow up study, GMA-SS welding fume delivered via oropharyngeal aspiration significantly increased tumor multiplicity at 30 weeks post-initiation using a two-stage (initiation-promotion) model with the chemical initiator MCA [10]. These preliminary studies suggest that GMA-SS fume may be a weak carcinogen in $\mathrm{A} / \mathrm{J}$ mice; however, oropharyngeal aspiration is considered to be less relevant to a real-world exposure because it delivers a bolus exposure to the lung, potentially overestimating the hazard. Inhalation studies are an important next step as they closely resemble the occupational route of exposure in welders and avoid this potential bolus effect. Inflammation is well-known to be a hallmark of cancer, and epidemiologic studies have indicated nearly a quarter of human cancers are associated with inflammation [25, 26]. Our lab demonstrated that inhalation and oropharyngeal aspiration induce different inflammatory responses in $\mathrm{A} / \mathrm{J}$ mice, suggesting these exposure methods may also differ in their ability to promote lung tumor formation [9, 24]. Inhalation of GMA-SS welding fume causes a delayed rise in PMN compared to aspiration and also induces a more complex cytokine profile. A potential explanation for the 
differing inflammatory responses between oropharyngeal and inhalation exposure is the dose rate at which fume is deposited [27, 28]. Former studies have indicated that the dose rate is an important determinant of the acute inflammatory response in the respiratory tract. Baisch et al. demonstrated a higher inflammatory response in F-344 rats following intratracheal instillation of $\mathrm{TiO}_{2}$ compared with an equivalent dose delivered via inhalation. Our former aspiration protocol delivered five bolus doses of $340 \mu \mathrm{g}$ or $680 \mu \mathrm{g}$ ( $1.7 \mathrm{or} 3.4 \mathrm{mg}$ cumulative) of GMA-SS welding PM once a week for 5 weeks [10]. In this study, inhalation exposure deposited $\sim 10 \mu \mathrm{g}$ per day (or $360 \mu$ g estimated total) over 36 days. Despite this much lower calculated total lung burden and dose rate, we found a significant lung tumor promotion for inhalation of welding fume as was also observed with high dose rate delivery oropharyngeal aspiration in our previous study. The objective of the present study was to identify if GMA-SS fume at a reasonable exposure level is a tumor promoter. Limitations must be noted when comparing lung tumor multiplicity rates from this and our previous study published in 2013. Indeed, the present study reports results for only a single total inhaled dose, limiting its usefulness in determining thresholds and doseresponse effects. Also, the particle deposition patterns may differ (e.g. upper airways) between the inhalation and oropharyngeal aspiration exposure routes.

Interestingly, "fresh" GMA-SS welding fume as delivered via inhalation is more reactive than "aged" welding fume which is used for oropharyngeal aspiration studies [11]. Aged fume has shown to be less inflammatory because it generates significantly less reactive oxygen species than freshly generated welding fume that is used for inhalation studies or generated in the workplace. As such, welding fume is 6 to 9 times more potent when delivered by inhalation rather than oropharyngeal aspiration $[9,24,29]$. Although the metals are deposited in a lower amount with inhalation, their increased potency may make them more available for DNA 
damaging effects. Genomic mutations and instability are known enablers of carcinogenesis [30]. Cancer cells often increase their rates of mutation in order to acquire the hallmarks of inducing angiogenesis, resisting cell death, sustaining proliferative signaling, enabling replicative immortality, evading growth suppressors, and activating invasion and metastasis. The heightened free radicals and oxidative stress that occurs with welding fume inhalation exposure independent of dosing rate may also potentially contribute to tumorigenicity [31]. Therefore, it is likely that the amount of carcinogenic metals in the welding fume may not be the only factor contributing to the formation of lung cancer.

At 30 weeks post-initiation, adenomas and proliferative bronchiolo-alveolar epithelial lesions were the most commonly observed microscopic lung pathologies. This finding is consistent with the literature and our previous observations in A/J mice of this age [24, 32]. In humans, lung cancers are more diverse than in mice and adenocarcinoma is the most common diagnosis. The adenomas in $\mathrm{A} / \mathrm{J}$ mice are relevant to the production of adenocarcinomas in humans as these lung adenomas are often the direct precursor to lung adenocarcinomas. Likewise, human and $\mathrm{A} / \mathrm{J}$ mouse tumors both often arise in the context of atypical hyperplasia in the periphery of the lung [33-36]. Thus, the A/J mouse is a very useful and relevant model to study welding fume toxicity and lung tumorigenesis.

In conclusion, the current research suggests that SS welding fume may serve as a promoter of chemically-initiated lung tumors in the A/J mouse model. Future studies will be directed at investigating additional types of welding fumes. Nearly $90 \%$ of welding processes use mild steel (MS) while 10\% or less use SS [1]. However, SS welding is still widely utilized as it offers increased protection from corrosion and rusting to which other metals are susceptible [20]. Unlike SS electrodes, MS electrodes are comprised mainly of the non-carcinogenic metals Fe 
and various concentrations of Mn. Interestingly, both MS and SS fumes have been linked epidemiologically to lung cancer in welders. Future studies will focus on MS inhalation using a two stage initiation-promotion model in $\mathrm{A} / \mathrm{J}$ mice as reported here.

\section{Bibliography}

1. Welders, Cutters, Solderers, and Brazers [http://www.bls.gov/ooh/production/welderscutters-solderers-and-brazers.htm ]

2. Antonini JM: Health effects of welding. Crit Rev Toxicol 2003, 33:61-103.

3. Korczynski RE: Occupational health concerns in the welding industry. Appl Occup Environ Hyg 2000, 15:936-945.

4. Lauritsen JM, Hansen KS: Lung cancer mortality in stainless steel and mild steel welders: a nested case-referent study. Am J Ind Med 1996, 30:383-391.

5. Matrat M, Guida F, Mattei F, Cenee S, Cyr D, Fevotte J, Sanchez M, Menvielle G, Radoi L, Schmaus A, et al: Welding, a risk factor of lung cancer: the ICARE study. Occup Environ Med 2016, 73:254-261.

6. Steenland K: Ten-year update on mortality among mild-steel welders. Scand J Work Environ Health 2002, 28:163-167.

7. Antonini JM: Health Effects Associated with Welding. 2014:49-70.

8. IARC: Report of the advisory group to recommend priorities for IARC Monographs during 2010-2014. 08/001 edition; 2008.

9. Zeidler-Erdely PC, Battelli LA, Stone S, Chen BT, Frazer DG, Young SH, Erdely A, Kashon ML, Andrews R, Antonini JM: Short-term inhalation of stainless steel welding fume causes sustained lung toxicity but no tumorigenesis in lung tumor susceptible A/J mice. Inhal Toxicol 2011, 23:112-120. 
10. Zeidler-Erdely PC, Meighan TG, Erdely A, Battelli LA, Kashon ML, Keane M, Antonini JM: Lung tumor promotion by chromium-containing welding particulate matter in a mouse model. Part Fibre Toxicol 2013, 10:45.

11. Antonini JM, Clarke RW, Krishna Murthy GG, Sreekanthan P, Jenkins N, Eagar TW, Brain JD: Freshly generated stainless steel welding fume induces greater lung inflammation in rats as compared to aged fume. Toxicol Lett 1998, 98:77-86.

12. Antonini JM, Afshari AA, Stone S, Chen B, Schwegler-Berry D, Fletcher WG, Goldsmith WT, Vandestouwe KH, McKinney W, Castranova V, Frazer DG: Design, construction, and characterization of a novel robotic welding fume generator and inhalation exposure system for laboratory animals. J Occup Environ Hyg 2006, 3:194-203; quiz D145.

13. Keenan CM, Baker J, Bradley A, Goodman DG, Harada T, Herbert R, Kaufmann W, Kellner R, Mahler B, Meseck E, et al: International Harmonization of Nomenclature and Diagnostic Criteria (INHAND): Progress to Date and Future Plans. Toxicol Pathol 2015, 43:730-732.

14. Renne R, Brix A, Harkema J, Herbert R, Kittel B, Lewis D, March T, Nagano K, Pino M, Rittinghausen S, et al: Proliferative and nonproliferative lesions of the rat and mouse respiratory tract. Toxicol Pathol 2009, 37:5s-73s.

15. Rehm S, Ward JM: Quantitative analysis of alveolar type II cell tumors in mice by whole lung serial and step sections. Toxicol Pathol 1989, 17:737-742.

16. Antonini JM, Lawryk NJ, Murthy GG, Brain JD: Effect of welding fume solubility on lung macrophage viability and function in vitro. J Toxicol Environ Health A 1999 , 58:343-363. 
17. Erdely A, Hulderman T, Salmen-Muniz R, Liston A, Zeidler-Erdely PC, Chen BT, Stone S, Frazer DG, Antonini JM, Simeonova PP: Inhalation exposure of gas-metal arc stainless steel welding fume increased atherosclerotic lesions in apolipoprotein $\mathbf{E}$ knockout mice. Toxicol Lett 2011, 204:12-16.

18. Raabe OG, Al-Bayati, M.A., Teague, S.V., Rasolt, A., : Regional deposition of inhaled monodisperse coarse and fine aerosol particles in small laboratory animals. Ann Occup Hyg 1988, 32:53-63.

19. Stone KC, Mercer RR, Gehr P, Stockstill B, Crapo JD: Allometric relationships of cell numbers and size in the mammalian lung. Am J Respir Cell Mol Biol 1992, 6:235-243.

20. Keane M, Stone S, Chen B, Slaven J, Schwegler-Berry D, Antonini J: Hexavalent chromium content in stainless steel welding fumes is dependent on the welding process and shield gas type. J Environ Monit 2009, 11:418-424.

21. Groch KM, Khan MA, Brooks AL, Saffer JD: Lung cancer response following inhaled radon in the A/J and C57BL/6J mouse. Int J Radiat Biol 1997, 71:301-308.

22. Curtin GM, Higuchi MA, Ayres PH, Swauger JE, Mosberg AT: Lung tumorigenicity in $\mathrm{A} / \mathrm{J}$ and rasH2 transgenic mice following mainstream tobacco smoke inhalation. Toxicol Sci 2004, 81:26-34.

23. McConnell EE, Solleveld HA, Swenberg JA, Boorman GA: Guidelines for combining neoplasms for evaluation of rodent carcinogenesis studies. J Natl Cancer Inst 1986, 76:283-289.

24. Zeidler-Erdely PC, Kashon ML, Battelli LA, Young SH, Erdely A, Roberts JR, Reynolds SH, Antonini JM: Pulmonary inflammation and tumor induction in lung tumor 
susceptible $\mathbf{A} / \mathbf{J}$ and resistant $\mathbf{C 5 7 B L} / 6 \mathrm{~J}$ mice exposed to welding fume. Part Fibre Toxicol 2008, 5:12.

25. Colotta F, Allavena P, Sica A, Garlanda C, Mantovani A: Cancer-related inflammation, the seventh hallmark of cancer: links to genetic instability. Carcinogenesis 2009, 30:1073-1081.

26. Punturieri A, Szabo E, Croxton TL, Shapiro SD, Dubinett SM: Lung cancer and chronic obstructive pulmonary disease: needs and opportunities for integrated research. J Natl Cancer Inst 2009, 101:554-559.

27. Baisch BL, Corson NM, Wade-Mercer P, Gelein R, Kennell AJ, Oberdorster G, Elder A: Equivalent titanium dioxide nanoparticle deposition by intratracheal instillation and whole body inhalation: the effect of dose rate on acute respiratory tract inflammation. Part Fibre Toxicol 2014, 11:5.

28. Bonner JC, Silva RM, Taylor AJ, Brown JM, Hilderbrand SC, Castranova V, Porter D, Elder A, Oberdorster G, Harkema JR, et al: Interlaboratory evaluation of rodent pulmonary responses to engineered nanomaterials: the NIEHS Nano GO Consortium. Environ Health Perspect 2013, 121:676-682.

29. Erdely A, Salmen-Muniz R, Liston A, Hulderman T, Zeidler-Erdely PC, Antonini JM, Simeonova PP: Relationship between pulmonary and systemic markers of exposure to multiple types of welding particulate matter. Toxicology 2011, 287:153-159.

30. Hanahan D, Weinberg RA: Hallmarks of cancer: the next generation. Cell 2011, 144:646-674.

31. Valavanidis A, Vlachogianni T, Fiotakis K, Loridas S: Pulmonary oxidative stress, inflammation and cancer: respirable particulate matter, fibrous dusts and ozone as 
major causes of lung carcinogenesis through reactive oxygen species mechanisms. Int J Environ Res Public Health 2013, 10:3886-3907.

32. Gunning WT, Castonguay A, Goldblatt PJ, Stoner GD: Strain A/J mouse lung adenoma growth patterns vary when induced by different carcinogens. Toxicol Pathol 1991, 19:168-175.

33. Belinsky SA, Devereux TR, Foley JF, Maronpot RR, Anderson MW: Role of the alveolar type II cell in the development and progression of pulmonary tumors induced by 4-(methylnitrosamino)-1-(3-pyridyl)-1-butanone in the A/J mouse. Cancer Res 1992, 52:3164-3173.

34. Foley JF, Anderson MW, Stoner GD, Gaul BW, Hardisty JF, Maronpot RR:

Proliferative lesions of the mouse lung: progression studies in strain A mice. Exp Lung Res 1991, 17:157-168.

35. Westra WH: Early glandular neoplasia of the lung. Respir Res 2000, 1:163-169.

36. Westra WH, Baas IO, Hruban RH, Askin FB, Wilson K, Offerhaus GJ, Slebos RJ: K-ras oncogene activation in atypical alveolar hyperplasias of the human lung. Cancer Res 1996, 56:2224-2228. 


\section{Figure Legends}

Figure. 1 Experimental protocol and block design for two-stage initiation-promotion lung tumorigenesis model in $\mathbf{A} / \mathbf{J}$ mice. A/J mice, 120 in total, were randomized and separated into four blocks of $n=7$ or 8 per exposure group. Mice received intraperitoneal (IP) injections of either MCA or corn oil and one week later were exposed to GMA-SS welding fume $\left(40 \mathrm{mg} / \mathrm{m}^{3}\right)$ or air for $4 \mathrm{~h} / \mathrm{d}, 4 \mathrm{~d} / \mathrm{w}$, for $9 \mathrm{w}$. Animal weights were recorded weekly. At 30 weeks, mice were sacrificed for tumor multiplicity and incidence and histopathological studies

Figure 2 GMA-SS welding fume characteristics. Panels a and $b$ are SEM images depicting small nano-spheres (10 to $50 \mathrm{~nm}$ ) linked together in long chain-like structures often with several branches. The bottom panels show the particle size distribution of the generated welding fume in terms of the mass median aerodynamic diameter (MMAD) (c) and estimated count median aerodynamic diameter $(\mathrm{d})$

Figure 3 Lung tumor multiplicity upon gross examination in A/J mice promoted with air or GMA-SS welding fume. At 30 weeks, MCA initiation followed by GMA-SS welding fume exposure increased lung tumor multiplicity (average tumor number/mouse lung) significantly above MCA/air exposed animals $\left(7.93 \pm 0.82\right.$ and $16.11 \pm 1.18$, respectively). ${ }^{*} p<0.0001-$ compared to CO/air, ** $p<0.0001$ - compared to MCA/air

Figure 4 Gross images of lung tumors promoted by GMA-SS welding fume 30 weeks after initiation with MCA. Panel a shows lung tumor morphology before fixation and panel b represents tumors $24 \mathrm{~h}$ post-fixation. Asterisks $(*)$ indicate areas of welding fume deposition and arrows indicate lung tumors. Most tumors were $\sim 1 \mathrm{~mm}$ in diameter 
Figure 5 Photomicrographs of lung tissue from MCA/GMA-SS exposed mice. Panel a shows a bronchiolo-alveolar adenoma and two areas of bronchiolo-alveolar hyperplasia in the lung at $2 \mathrm{x}$ magnification. Panel $\mathrm{b}$ demonstrates the adenoma in panel a at 20x magnification. Panel c shows a bronchiolo-alveolar adenoma at 40x magnification. Cells are enlarged and forming a compact mass that obscures normal architecture and causes compression of adjacent tissue. Panel d shows a bronchiolo-alveolar hyperplasia in the lung at 20x magnification. Arrows depict brown pigment (welding fume particles) within alveolar macrophages. H\&E stain 


\section{Figures}

Figure 1.

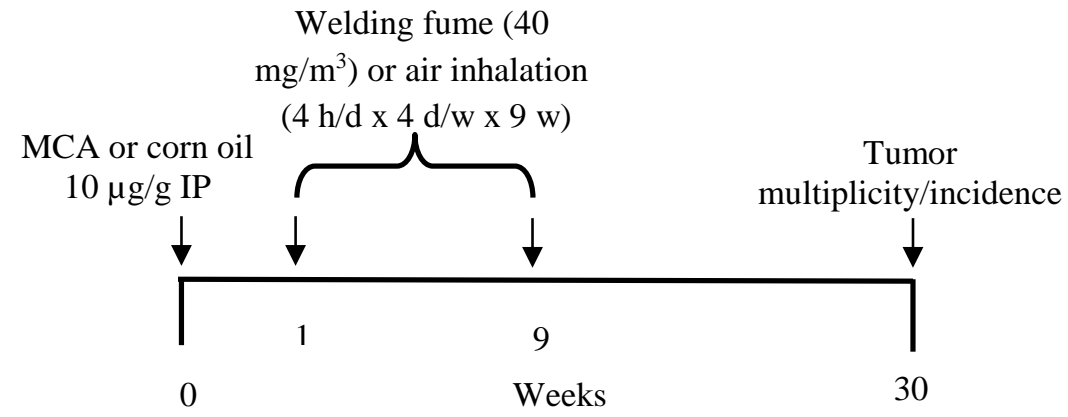

\begin{tabular}{|c|c|c|c|c|}
\hline & \multicolumn{2}{|c|}{ Air } & \multicolumn{2}{c|}{ GMA-SS } \\
\hline Block & $\begin{array}{c}\text { Corn } \\
\text { oil (n= } \\
)\end{array}$ & $\begin{array}{c}\text { MCA } \\
(\mathrm{n}=)\end{array}$ & $\begin{array}{c}\text { Corn } \\
\text { oil }(\mathrm{n}= \\
)\end{array}$ & $\begin{array}{c}\text { MCA } \\
(\mathrm{n}=)\end{array}$ \\
\hline 1 & 7 & 7 & 7 & 7 \\
\hline 2 & 7 & 7 & 7 & 7 \\
\hline 3 & 8 & 8 & 8 & 8 \\
\hline 4 & 8 & 8 & 8 & 8 \\
\hline $\begin{array}{c}\mathrm{n} \\
\text { group }\end{array}$ & 30 & 30 & 30 & 30 \\
\hline
\end{tabular}


Figure 2.

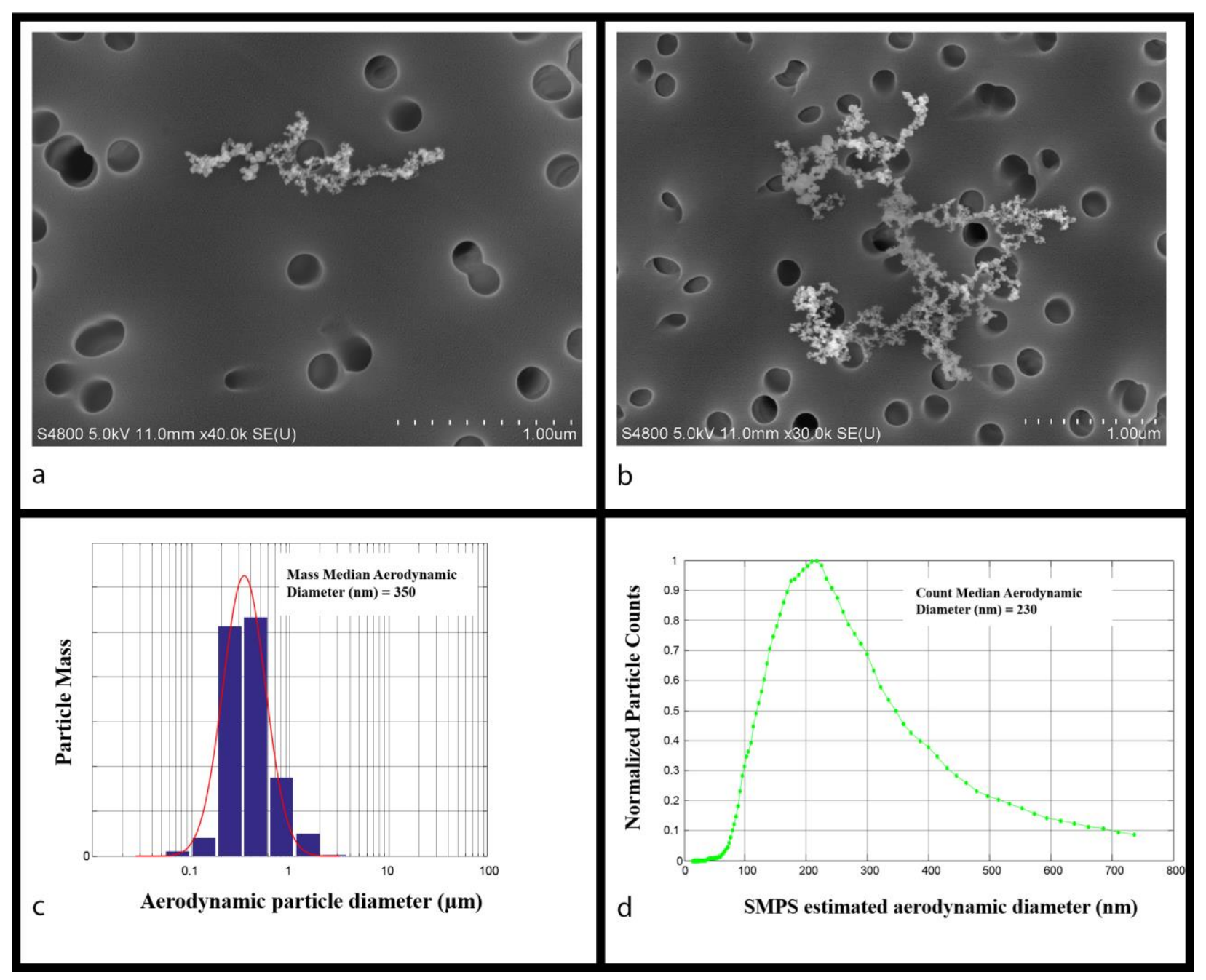


Figure 3.

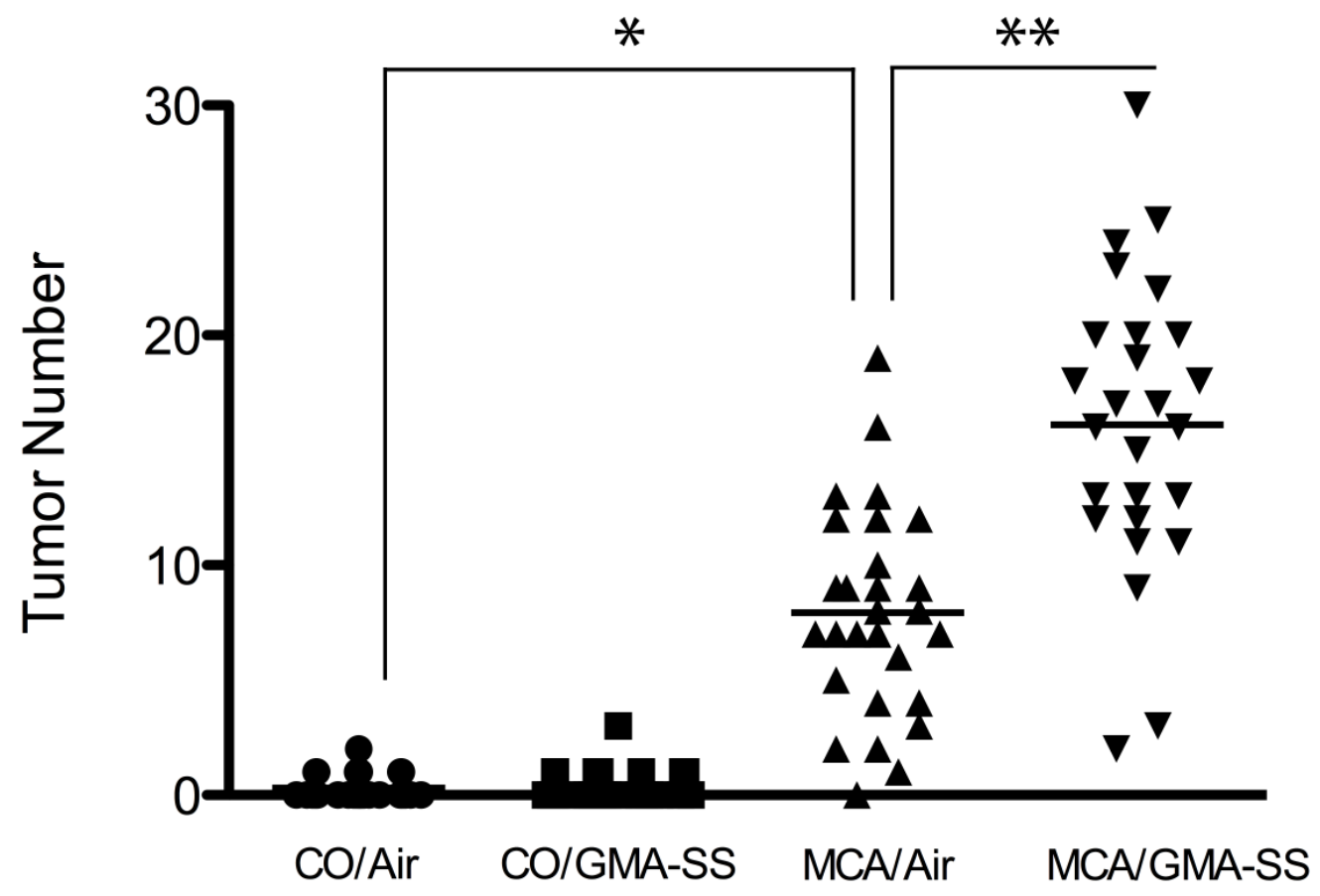


Figure 4.

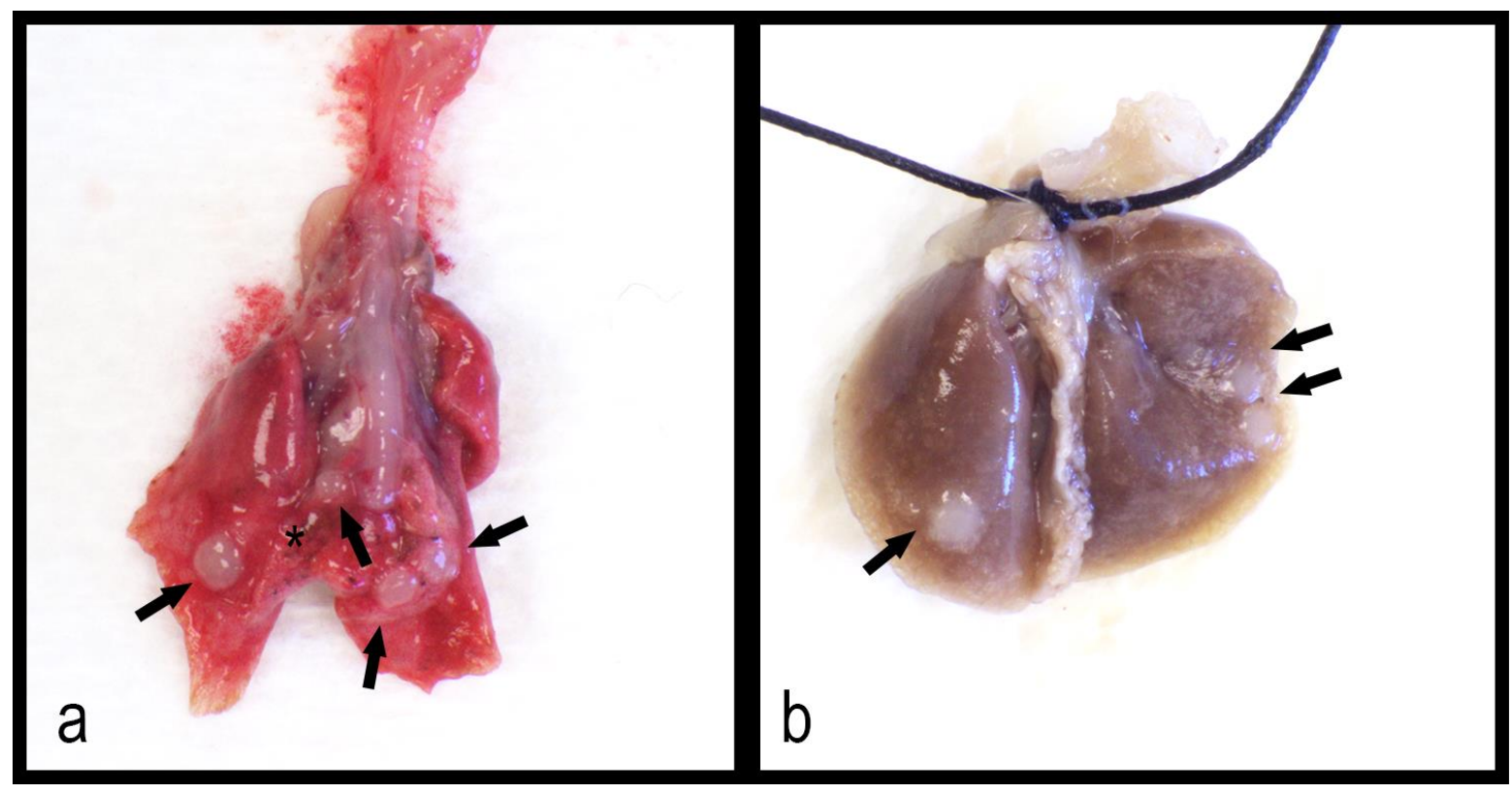


Figure 5.

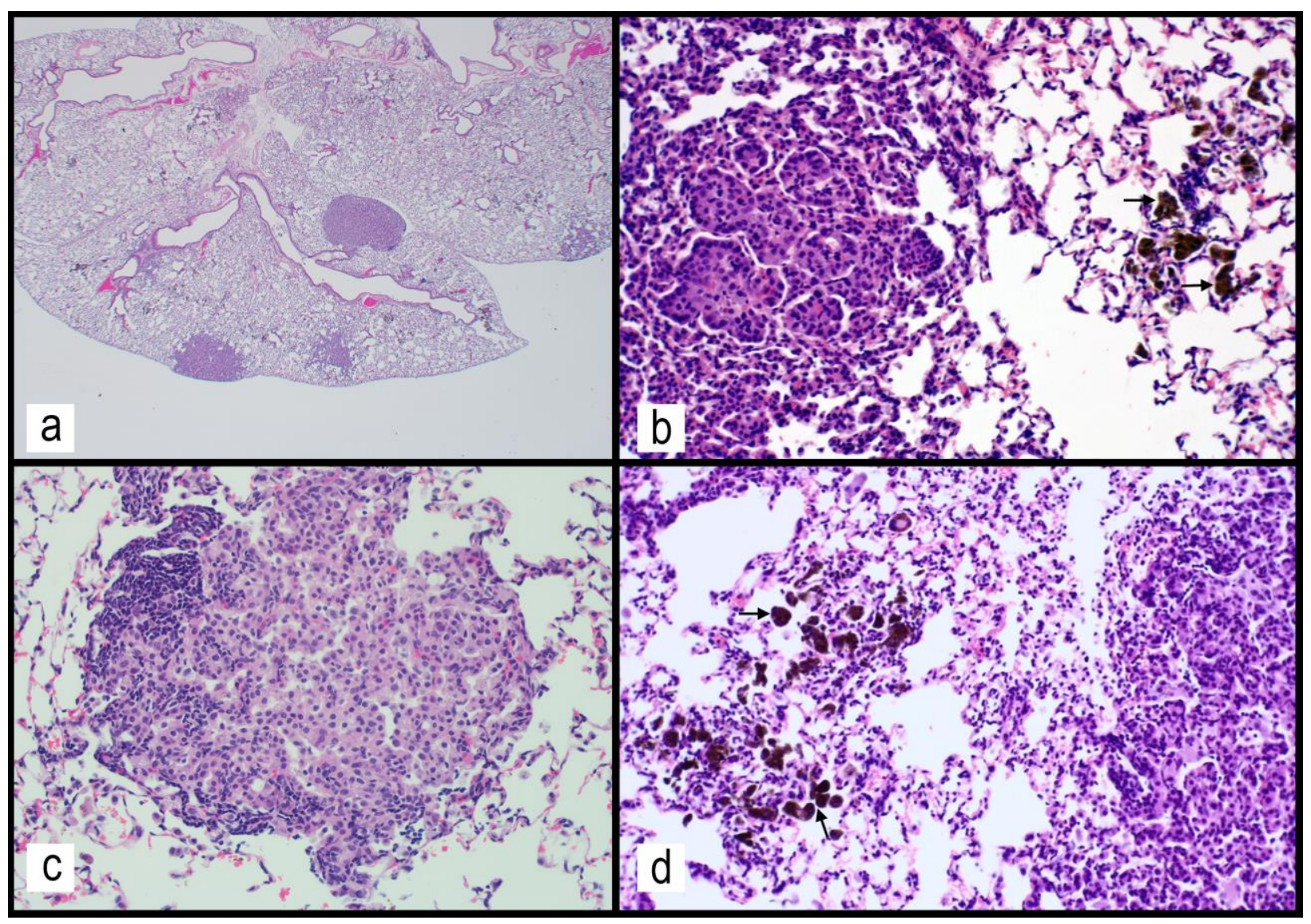


Tables

Table 1. Lung metal deposition in A/J mice after stainless steel welding fume inhalation for $4 \mathrm{~h}$ at a target concentration of $40 \mathrm{mg} / \mathrm{m}^{3}$

\begin{tabular}{c|ccccc}
\hline Exposure & $\mathrm{Cr}(\mu \mathrm{g} / \mathrm{lung})$ & $\mathrm{Cu}(\mu \mathrm{g} / \mathrm{lung})$ & $\mathrm{Fe}(\mu \mathrm{g} / \mathrm{lung})$ & $\mathrm{Mn}(\mu \mathrm{g} / \mathrm{lung})$ & $\mathrm{Ni}(\mu \mathrm{g} / \mathrm{lung})$ \\
\hline Air & $0.02 \pm 0.01$ & $0.22 \pm 0.03$ & $8.97 \pm 0.36$ & $0.02 \pm 0.00$ & $0.01 \pm 0.00$ \\
\hline GMA-SS & $1.65 \pm 0.05$ & $0.32 \pm 0.01$ & $15.12 \pm 0.39$ & $1.48 \pm 0.04$ & $0.82 \pm 0.02$ \\
\hline
\end{tabular}

Freeze-dried whole lung tissue was analyzed for aluminum $(\mathrm{Al})$, chromium $(\mathrm{Cr})$, copper $(\mathrm{Cu})$, iron $(\mathrm{Fe})$, manganese $(\mathrm{Mn})$, nickel $(\mathrm{Ni})$, titanium $(\mathrm{Ti})$, and zinc $(\mathrm{Zn})$ by Inductively Coupled Plasma-Atomic Emission Spectroscopy. Samples were prepared according to draft NIOSH Analytical Method 8200 for bulk tissue samples. Trace amounts of Al, Ti, and Zn were found. In cases in which no result was measured, the limit of quantification (LOQ) was used in calculating the average deposition. Note: Values are mean \pm standard error of the mean $(n=10$ air; n=25 GMA-SS); GMA-SS - gas metal arc-stainless steel welding fume. 
Table 2. Total and average (in parenthesis) tumor number across individual lung lobes following GMA-SS welding fume inhalation exposure 30 weeks post-initiation with MCA or corn oil

\begin{tabular}{ccccccc}
\hline & $\mathrm{n}$ & Left & Apical & Cardiac & Diaphragmatic & Azygos \\
\hline Corn oil/air & 28 & $3(0.11 \pm 0.06)$ & $3(0.11 \pm 0.06)$ & 0 & $3(0.11 \pm 0.06)$ & 0 \\
\hline Corn oil/GMA-SS & 29 & $5(0.17 \pm 0.07)$ & $1(0.03 \pm 0.03)$ & 0 & $5(0.17 \pm 0.09)$ & $2(0.07 \pm 0.05)$ \\
\hline MCA/air & 29 & $78(2.69 \pm 0.39)^{*}$ & $30(1.03 \pm 0.20)^{*}$ & $25(0.86 \pm 0.15)^{*}$ & $67(2.31 \pm 0.36)^{*}$ & $30(1.03 \pm 0.25)^{*}$ \\
\hline MCA/GMA-SS & 28 & $150(5.35 \pm 0.54)^{* *}$ & $68(2.43 \pm 0.42)^{* *}$ & $63(2.25 \pm 0.35)^{* *}$ & $110(3.93 \pm 0.37)^{* *}$ & $60(2.14 \pm 0.32)^{* *}$ \\
\hline
\end{tabular}

GMA-SS: gas metal arc- stainless steel, MCA: 3-methylcholanthrene

${ }^{*} p<0.0001$ - compared to Corn oil/air

$* * p<0.009$-compared to MCA/air 
Table 3. Severity scores for abnormal morphological findings and numbers of adenomas and hyperplastic lesions observed in lung sections of A/J mice exposed to GMA-SS welding fume by inhalation at 30 weeks post-initiation with MCA

\begin{tabular}{ccccccc}
\hline & $\begin{array}{c}\text { Lymphoid } \\
\text { Infiltrates* }\end{array}$ & $\begin{array}{c}\text { Foreign } \\
\text { material* }^{*}\end{array}$ & $\begin{array}{c}\text { Hyperplasia } \\
\text { Severity* }\end{array}$ & Hyperplasia & Adenoma & Total lesions \\
\hline MCA/air & -- & $0.03 \pm 0.03$ & $1.41 \pm 0.19$ & 70 & 20 & 90 \\
\hline MCA/GMA-SS & $0.34 \pm 0.07^{* *}$ & $1.5 \pm 0.08^{* *}$ & $1.86 \pm 0.19$ & $119^{\ddagger}$ & $34^{\wedge}$ & $153^{\ddagger}$
\end{tabular}

GMA-SS: gas metal arc-stainless steel, MCA: 3-methylcholanthrene.

* Severity scores are the averages of the left and right lung lobes and are presented as mean \pm standard error. Lymphoid infiltrates represents perivascular and peribronchiolar mononuclear cells. Foreign material refers to the presence of brown pigment in the lungs. Severity was scored as $1=$ minimal, $2=$ mild, $3=$ moderate, $4=$ marked.

-- indicates no findings

${ }^{* *} p<0.0002$ - compared to MCA/air

${ }^{\ddagger} p<0.004-$ compared to MCA/air

${ }^{\wedge} p<0.05$ - compared to MCA/air 


\section{Chapter 4: Inhalation of Iron-Abundant Gas Metal Arc - Mild Steel Welding Fume Promotes Lung Tumors in Mice}

LM Falcone ${ }^{1,2}$, A Erdely $^{1,2}$, V. Kodali ${ }^{1}$, R Salmen $^{1}$, LA Battelli ${ }^{1}$, T Dodd ${ }^{1}$, W McKinney ${ }^{1}, \mathrm{~S}$

Stone $^{1}$, M Donlin ${ }^{1}$, HD Leonard ${ }^{1}$, JL Cumpston ${ }^{1}$, JB Cumpston ${ }^{1}$, RN Andrews ${ }^{3}$, M Kashon ${ }^{1}$, JM Antonini ${ }^{1}$, PC Zeidler-Erdely ${ }^{1,2}$

'Health Effects Laboratory Division, National Institute for Occupational Safety and Health, Morgantown, WV; ${ }^{2}$ West Virginia University, School of Medicine, Morgantown, WV; ${ }^{3}$ Division of Applied Research and Technology, National Institute for Occupational Safety and Health, Cincinnati, $\mathrm{OH}$ 


\section{Abstract}

Welding fumes were reclassified as a Group 1 carcinogen by the International Agency for Research on Cancer (IARC) in 2017. Gas metal arc welding (GMAW) is a process widely used in industry. Fume generated from GMAW-mild steel (MS) is abundant in iron with some manganese, while GMAW-stainless steel (SS) fume also contains significant amounts of chromium and nickel, known carcinogenic metals. It has been shown that exposure to GMAWSS fume in A/J mice promotes lung tumors. The objective was to determine if GMAW-MS fume, which lacks known carcinogenic metals, also promotes lung tumors in mice. Male A/J mice received a single intraperitoneal injection of corn oil or the initiator 3-methylcholanthrene (MCA; $10 \mu \mathrm{g} / \mathrm{g}$ ) and, one week later, were exposed by whole-body inhalation to GMAW-MS aerosols for 4 hours/day x 4 days/week x 8 weeks at a mean concentration of $34.5 \mathrm{mg} / \mathrm{m}^{3}$. Lung nodules were enumerated by gross examination at 30 weeks post-initiation. GMAW-MS fumes significantly promoted lung tumor multiplicity in mice initiated with MCA $(21.86 \pm 1.50)$ compared to MCA/air-exposed mice $(8.34 \pm 0.59)$. Histopathological analysis confirmed these findings and revealed absence of inflammation. Bronchoalveolar lavage analysis also indicated a lack of lung inflammation and toxicity after short-term inhalation exposure to GMAW-MS fume. In conclusion, this study demonstrates that inhalation of GMAW-MS fume promotes lung tumors in vivo and aligns with epidemiologic evidence that shows MS welders, despite less exposure to carcinogenic metals, are at an increased risk for lung cancer.

Keywords: mild steel, welding, inhalation, iron, A/J mice 


\section{Introduction}

Welding fumes were recently reclassified as carcinogenic to humans (Group 1) by the International Agency for Research on Cancer (IARC) based on strong epidemiological evidence and limited evidence in animals [1]. It is estimated that 11 million workers worldwide weld fulltime and an additional 110 million have had some type of welding-related exposure [1]. Arc welding, including one type known as gas metal arc welding (GMAW), is the most common industrial welding process. In GMAW, an electric arc is established between a work piece and a consumable wire electrode $[2,3]$. High temperatures create a molten pool into which the electrode is continuously fed and the work pieces are fused together as temperatures cool. While this process is the strongest method of joining metals, it creates a significant amount of welding fume. The composition of the fume largely depends on whether a stainless steel (SS) or mild steel (MS) electrode is used. GMAW-SS fume contains largely iron (Fe), chromium $(\mathrm{Cr})$, nickel (Ni), copper $(\mathrm{Cu})$, and manganese $(\mathrm{Mn})$, whereas GMAW-MS contains primarily Fe and $\mathrm{Mn}$. Most experimental studies have focused on the presumably more toxic $\mathrm{Cr}$ and $\mathrm{Ni}$ and largely overlooked Fe when examining pulmonary toxicity and/or carcinogenicity of welding fume. Importantly, many epidemiological studies suggest that both GMAW-SS and GMAW-MS are associated with increased risk of lung cancer, even though GMAW-MS exposure is predominantly limited to $\mathrm{Fe}$ and $\mathrm{Mn}[4,5]$. Some studies are conflicting, however [6]. Welding exposures are complex because of the diversity of welding modalities used in the workplace and the potential for confounders or additional occupational exposures [2, 7]. Welders often perform multiple types of welding processes throughout their working lifetime, further complicating epidemiological studies. Therefore, controlled animal studies are crucial to better understand which welding fumes and their component metals are the most toxic and have the greatest tumorigenic potential. 
It was previously shown that GMAW-SS fume persists in the lung for 1.5 years and triggers mild, chronic inflammation in lung tumor-susceptible $\mathrm{A} / \mathrm{J}$ mice compared to other welding fumes [8]. In a two-stage initiation-promotion model of lung tumorigenesis, GMAW-SS fume significantly increased lung tumor multiplicity after both an oropharyngeal aspiration and inhalation exposure in $\mathrm{A} / \mathrm{J}$ mice $[9,10]$. It was also demonstrated that GMAW-MS increased lung toxicity as measured by elevated lactate dehydrogenase (LDH) levels in mice 2 and 7 days after an oropharyngeal aspiration exposure [11]. However, GMAW-SS had a greater cytotoxic effect than GMAW-MS. Similarly, studies in rats have indicated that GMAW-MS seems to be less toxic than GMAW-SS [12-14]. Antonini et al. found that GMAW-MS caused no lung inflammation or lung injury in Sprague-Dawley rats 1, 4, or 11 days post-inhalation compared to GMAW-SS, which caused significant lung damage $[12,13]$.

It is well known that certain conditions associated with iron-overloaded states lead to an increased risk of cancer. While iron plays a vital role in redox reactions and as a cofactor for enzymatic reactions in the body, too much iron can increase cancer risk via the production of reactive oxygen species $[15,16]$. Asbestosis, hemochromatosis, myelodysplastic syndromes, and endometriosis are all diseases in which there is iron excess and increased risk of cancer [17, 18]. Epidemiologic studies concerning iron oxide exposures and lung cancer are conflicting. An early study of iron ore miners found that these workers had a $70 \%$ greater mortality of lung cancer than the general population [19]. Yet, other reports suggest that iron oxide is not a human carcinogen [20, 21]. An early in vivo study by Campbell 1940 found an increase in lung carcinomas in mice exposed to iron oxide [22]. Regardless, in vivo studies investigating occupational exposures to iron oxides, as occurs with mild steel welding, are lacking. In this 
study, we aimed to characterize the lung toxicity of GMAW-MS, which contains primarily Fe, and determine if it could promote lung tumors in mice following inhalation exposure.

Methods

\section{Animals}

Male A/J mice (age 4-5 week) were purchased from Jackson Laboratories (Bar Harbor, $\mathrm{ME}$ ) and housed in an AAALAC International - specific pathogen-free, environmentallycontrolled facility. All mice were free of endogenous pathogens including viruses, bacteria, mycoplasmas, and parasites. Mice were housed in groups of two in ventilated cages and provided high-efficiency particulate filtered air under a controlled light cycle (12 h light/12 h dark) at a standard temperature $\left(22-24^{\circ} \mathrm{C}\right)$ and $30-70 \%$ relative humidity. Animals were acclimated to the animal facility for one week before beginning the experimental protocols and allowed access to a conventional diet (6\% irradiated NIH-31 Diet, Envigo RMS, Inc.; Madison, WI) and tap water ad libitum. All procedures were performed using protocols approved by the National Institute for Occupational Safety and Health (NIOSH) Institutional Animal Care and Use Committee.

\section{Welding fume inhalation exposure system}

The design and construction of the welding fume aerosol generator were previously described [23]. This automated robotic welder continuously generated welding fumes by welding beads onto $1 / 4$ inch thick plates of mild steel. The welding wire used was 0.045 inch diameter Lincoln Electric Super Arc MIG L56 and the welding parameters were set to 25 volts DC, 300 inch per minute wire feed, $30 \mathrm{~L} / \mathrm{min}$ of $95 \%$ argon $-5 \% \mathrm{CO}_{2}$ shielding gas, and a typical welding current of 220 amps. The resulting fume was carried into a whole body exposure chamber through a $3 / 4$ inch flexible tube by maintaining the chamber at a negative pressure $(0.70$ inch $\mathrm{H}_{2} \mathrm{O}$ ). Particle concentrations within the exposure chamber were continuously monitored 
with a Data RAM (DR-40000 Thermo Electron Co; Franklin, MA), and gravimetric determinations ( $37 \mathrm{~mm}$ cassettes with $0.45 \mu \mathrm{m}$ pore-size Teflon filters) were used to calibrate and verify the Data RAM readings each day. Gas generation, including carbon monoxide $(\mathrm{CO})$, carbon dioxide $\left(\mathrm{CO}_{2}\right)$, oxygen $\left(\mathrm{O}_{2}\right)$, and ozone $\left(\mathrm{O}_{3}\right)$, was continuously monitored. During the welding exposure, $\mathrm{O}_{2}$ levels were maintained above the OSHA minimal acceptable level. $\mathrm{O}_{3}, \mathrm{CO}$, $\mathrm{CO}_{2}$ were below OSHA permissible exposure limits and NIOSH recommended exposure limits (REL) during the entire exposure duration. In the exposure chamber, $\mathrm{CO}$ and $\mathrm{O}_{3}$ levels were not significantly higher than background. The exposure system was modified slightly from that described previously to reduce the travel time of the particulate fume from the welding torch to the exposure chamber [23].

\section{Welding fume metal analysis}

A small amount of welding fume was collected gravimetrically onto 47-mm Nucleopore polycarbonate filters (Whatman; Clinton, PA) for field emission scanning electron microscopy (FESEM) to assess particle size and morphology. The particles were imaged using a Hitachi S4800 Field Emission Scanning Electron Microscope (Hitachi; Tokyo, Japan). For elemental analysis of GMAW-MS fume, generated particles were collected inside the exposure chamber onto $5.0 \mu \mathrm{m}$ polyvinyl chloride membrane filters in $37-\mathrm{mm}$ cassettes during three 30 minute collections. The particle samples were digested and the metals were analyzed by inductively coupled plasma atomic emission spectroscopy according to the NIOSH method 7303 for hot block/HCL/HNO 3 digestion (NIOSH, 1994) as previously described [23]. Metal content of blank filters also were analyzed for control purposes.

\section{Experimental protocol for whole lung metal analysis}


Weight-matched A/J mice were exposed by whole-body inhalation in individual steel mesh cages to GMAW-MS welding aerosols (mean concentration $36.4 \mathrm{mg} / \mathrm{m}^{3}$ over 4 hours) $(\mathrm{n}=$ 10) or filtered air $(\mathrm{n}=10)$ (Figure 1A). Immediately following exposure (time zero), whole lungs were excised, trimmed, and lyophilized. The freeze-dried tissue was weighed then acid digested. Inductively coupled argon plasma atomic emission spectroscopy at NIOSH-Division of Applied Research and Technology (Cincinnati, $\mathrm{OH}$ ) was used to determine the amount of $\mathrm{Al}, \mathrm{Cr}, \mathrm{Cu}, \mathrm{Fe}$, $\mathrm{Mn}, \mathrm{Ni}, \mathrm{Zn}$ present in the lung according to the NIOSH method 7300 modified to accommodate the sample matrix (NIOSH 2003).

\section{Experimental protocol for two-stage lung carcinogenesis assay in $\mathbf{A} / \mathbf{J}$ mice}

For the two-stage initiation-promotion protocol, 120 mice were weight-matched and randomized into four exposure groups ( $n=30$ /group). On day 1 , mice were intraperitoneally (IP) injected with the chemical initiator, 3-methylcholanthrene (MCA) (Sigma-Aldrich; St. Louis, MO) dissolved in corn oil (CO) (Sigma-Aldrich; St. Louis, MO) at a dose of $10 \mu \mathrm{g} / \mathrm{g}$ of body weight or $\mathrm{CO}$ alone (Figure 1B). MCA was chosen as the initiating agent based on the efficient response of the $\mathrm{A} / \mathrm{J}$ mouse to this carcinogen in our previous oropharyngeal aspiration and inhalation studies $[10,24]$. Beginning 1 week post-initiation, mice were exposed by whole-body inhalation to GMAW-MS aerosols or filtered air for 4 hours/day, 4 days/week, for 8 weeks at a target concentration of $40 \mathrm{mg} / \mathrm{m}^{3}$ (actual mean concentration $34.5 \mathrm{mg} / \mathrm{m}^{3}$ over 8 weeks). Throughout the study, mice were weighed biweekly including at the terminal sacrifice at 30weeks post-initiation. Mice were euthanized with sodium pentobarbital [100-300 mg/kg IP] (Vortech Pharmaceuticals; Dearborn, MI), weighed, and exsanguinated via the vena cava. All internal organs were examined for the presence of tumors. Then, the whole lung was excised and inflated with $10 \%$ neutral buffered formalin. Twenty-four hours post-fixation, lung tumors were 
counted. Lung tumor incidence was recorded as the percent of tumor-bearing mice out of the total. Lung tumor multiplicity was determined as the average tumor number per mouse lung including mice with no tumors. Any apparent merged tumors were counted as one tumor. Lungs were embedded in paraffin before a $5 \mu \mathrm{m}$ standardized section was cut and slides were made.

Slides were stained with hematoxylin and eosin, and a contracted, board-certified veterinary pathologist observed the slides in a blinded fashion for evidence of hyperplasia or neoplasia, inflammation, lymphoid tissue response, and foreign materials by light microscopy. The diagnosis of alveolar hyperplasia, adenoma, and adenocarcinoma was based upon wellestablished criteria [25]. If abnormal changes were found, severity was scored as: $1=$ minimal, 2 = mild, $3=$ moderate, 4 = marked. Severity of hyperplasia was graded based upon the overall size of the lesion, and ranged from small foci, which were graded as minimal, to large foci, which were graded as marked. The severity of the hyperplasia was recorded as the severity of the most severe lesion seen in each lung. The final severity score reflects the average of the right and left lung lobe scores and is presented as means \pm standard error. Because bronchioloalveolar hyperplasia (BAH), bronchioloalveolar adenomas (BAA), and bronchioloalveolar adenocarcinomas (BAC) represent a continuum of the proliferative process, and there is possible overlap between these diagnoses, the numbers of lesions were combined to compare the tumorigenic potential of each treatment [25]. However, examination of a single histological section per lung underestimates the total number of lesions per lung, making the gross tumor count at time of sacrifice more indicative of the actual response [26].

\section{Experimental protocol for bronchoalveolar lavage (BAL) and biochemical measurements}

\section{of lung toxicity}


For the BAL and lung toxicity protocol, 64 male A/J mice were exposed to filtered air or GMAW-MS fume at a target concentration of $40 \mathrm{mg} / \mathrm{m}^{3}$ (actual mean concentration 36.28 $\mathrm{mg} / \mathrm{m}^{3}$ ) for 4 hours/day for 10 days (Figure 1C). Whole-lung BAL was used to assess lung injury and inflammation at $1,7,28$, and 84 days post-exposure $(n=8$ per treatment group per time point). Mice were anesthetized with sodium pentobarbital (100-300 mg/kg IP; Vortech Pharmaceuticals) then weighed. Once unresponsive, blood was drawn from the vena cava and serum was frozen at $-80{ }^{\circ} \mathrm{C}$. The mouse was then exsanguinated. For BAL, the trachea was cannulated with a blunted 22 gauge needle, and the thorax was massaged as $0.6 \mathrm{ml}$ of cold calcium and magnesium-free phosphate buffered saline (PBS) was instilled into the lungs. The thorax was massaged for 10 seconds before the fluid was withdrawn and placed in a $15 \mathrm{ml}$ conical tube. This consisted of the first lavage fraction. BAL was repeated 3 times using $1 \mathrm{ml}$ of PBS per instillate and this second fraction was collected in a separate $15 \mathrm{ml}$ conical tube. The BAL fluid was preserved on ice then centrifuged at $500 \mathrm{x} \mathrm{g}, 10 \mathrm{~min}$, and $4^{\circ} \mathrm{C}$. The acellular supernatant of the first lavage fraction was used to measure lactate dehydrogenase (LDH) activity, indicative of lung cytotoxicity. LDH activity was analyzed using a COBAS MIRA Plus auto-analyzer (Roche Diagnostic Systems; Montclair, NJ) which measured the oxidation of lactate to pyruvate coupled with the formation of $\mathrm{NADH}$ at $340 \mathrm{~nm}$. The supernatant from the second lavage fraction was discarded. The cell pellets of both fractions were combined and resuspended in $800 \mu 1$ of PBS. This final cell pellet was used for cell enumeration and differentials. For cell enumeration, cells were gently vortexed then combined in a 1:2 dilution with trypan blue (Sigma-Aldrich). The suspension was slowly mixed with a pipette and $10 \mu 1$ was loaded onto the hemocytometer. The number of live cells in the four outer squares were recorded and cell concentration was calculated as: total cell count in 4 squares $\mathrm{x} 2500 \times 2$ 
(dilution factor). For cell differentials, cells were plated onto glass slides using a Cytospin 3 centrifuge (Shandon Life Sciences International; Cheshire, England) set at $800 \mathrm{rpm}$ for 5 minutes. Slides were stained with Hema 3 Fixative and Solutions (Fisher Scientific; Pittsburgh, PA) then cover slipped. A minimum of 300 cells/slide were identified using light microscopy. Statistical comparisons and analysis

Statistical analyses were performed using either JMP version 13, or SAS version 9.4 for Windows. Continuous variables were analyzed using treatment by day factorial analyses of variance (ANOVA), followed by Fishers LSD for pairwise comparisons. For some variables, a natural $\log$ transformation was performed on the data to reduce heterogeneous variance and meet the assumptions of an ANOVA. Score variables such as hyperplasia severity were analyzed using nonparametric Kruskal-Wallis tests and followed by pair-wise comparisons using the Wilcoxon Rank Sums test. Gross tumor counts and histopathology count data from sections were analyzed similarly. Tumor incidence was analyzed using a Chi-square test in SAS 'Proc Freq,' while tumor multiplicity was analyzed using Poisson regression in SAS 'Proc Genmod.' In cases where over dispersion existed, a negative binomial regression was performed. Analyses were performed independently on $\mathrm{CO}$ and MCA-treated animals, and only utilized data from those animals surviving to the 30 -week time point. For all analyses, a p value of $<0.05$ was set as the criteria for significance.

\section{Results}

\section{Welding fume characteristics}

Scanning electron microscope (SEM) images of GMAW-MS fume are presented in Figure 2 and show the particles forming chain-like aggregates. GMAW-MS fume ranged in size from nanoparticles to larger, coarse particles with most particles between 0.1 to $1 \mu \mathrm{m}$ in size. 
The mass median aerodynamic diameter $(\mathrm{MMAD})$ was $0.31 \mu \mathrm{m}$. Elemental analysis indicated that GMAW-MS was primarily Fe and Mn (Table 1). Fe content by weight percent averaged $83.67 \%$ and $\mathrm{Mn}$ was $14.33 \%$. Approximately $2 \%$ of fume consisted of other trace metals.

\section{Whole lung metal deposition after GMAW-MS fume inhalation}

The lung metal deposition in A/J mice measured at time 0 after 4 hours of inhalation of GMAW-MS fume is shown in Table 2 and was calculated as done previously [24]. The most abundant metals measured were Fe $(5.17 \mu \mathrm{g}$ Fe/6.1 $\mu \mathrm{g}$ total metal deposition $=84.75 \%)$ and $\mathrm{Mn}$ $(0.87 \mu \mathrm{g} \mathrm{Mn} / 6.1 \mu \mathrm{g}$ total metal deposition $=14.26 \%)$, which equates to the elemental analysis of the GMAW-MS fume shown in Table 1. Human relevance deposition calculation:

The analysis of the metals showed a cumulative increase of $6.1 \mu \mathrm{g}$ of total GMAW-MS fume deposited in the lung from a single 4 hour exposure (Table 2). The alveolar deposition in the mice was equated to the human by the equations below using the previous threshold limit value-time weighted average (TLV-TWA) of $5 \mathrm{mg} / \mathrm{m}^{3}$ for total welding fume. Previously, we estimated that $70 \%$ of the total dose reached the alveolar space $(6.1 \mu \mathrm{g} / \mathrm{d} \times 0.70=4.27 \mu \mathrm{g} / \mathrm{d})[27$, 28]. The mice were exposed for 32 days ( 8 weeks at 4 days/week) for an approximate total alveolar deposition of $136.64 \mu \mathrm{g}$.

Estimated human daily deposition using previous welding fume TLV-TWA of $5 \mathrm{mg} / \mathrm{m}^{3}$ :

Fume concentration $\mathrm{x}$ min volume $\mathrm{x}$ exposure duration $\mathrm{x}$ deposition efficiency $=$ deposited human dose

$5 \mathrm{mg} / \mathrm{m}^{3} \times(20 \mathrm{l} / \mathrm{min})\left(10^{-3} \mathrm{~m}^{3} / \mathrm{l}\right) \times(8$ hours/day $)(60$ minutes/hour $) \times 0.16=7.7 \mathrm{mg}$ deposited per 8 hour day in humans 
Estimated human equivalent deposition from quantified deposition in mouse using alveolar surface area (SA)[29]

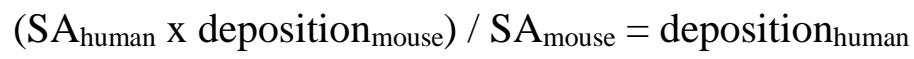

$\left(102 \mathrm{~m}^{2} \times 0.13664 \mathrm{mg}\right) / 0.05 \mathrm{~m}^{2}=278.75 \mathrm{mg}$

$278.75 \mathrm{mg} / 7.7 \mathrm{mg} /$ day = approximately 36 working days for a human working at $5 \mathrm{mg} / \mathrm{m}^{3}$ for 8 hours/day. While it is understood that welding is usually not done for 8 hours/day, and the exposure levels are likely not to consistently reach $5 \mathrm{mg} / \mathrm{m}^{3}$ as a TWA, the deposition in this study model was representative of cumulative exposure in a human.

\section{Morbidity and mortality}

Initial body weights at week 0 (means \pm standard error $[\mathrm{SE}])$ were $19.24 \pm 0.30,19.10 \pm$ $0.28,19.41 \pm 0.27$, and $19.18 \pm 0.28 \mathrm{~g}$ for the CO/air, CO/GMAW-MS, MCA/air, and MCA/GMAW-MS groups, respectively. Body weights were not significantly changed due to exposure and increased steadily from week 0 to 30 with average net weight gains of 10.82 , $10.28,10.25$, and $10.91 \mathrm{~g}$ for the CO/air, CO/GMAW-MS, MCA/air, and MCA/GMAW-MS groups, respectively. Morbidity and mortality throughout the study was low $(\sim 5 \%)$ and no abnormalities, such as other tumor types besides lung, were found at the terminal sacrifice at 30 weeks. In total, 6 mice died during the course of the study and were not included in the final analysis of the data. The deaths were distributed equally among treatment groups. Necropsy determined that all 6 mice died from morbidities that included groin-associated skin lesions or a cause of death otherwise undetermined but not associated with the experimental protocol.

\section{Gross tumor incidence and multiplicity}


The total tumor number per mouse lung for each exposure group (lines indicate average gross-observed tumor multiplicity) is shown in Figure 3. GMAW-MS fume significantly promoted lung tumors in mice at 30 weeks after initiation with MCA. Lung tumor multiplicity was $8.34 \pm 0.59$ and $21.86 \pm 1.50$ for MCA/air and MCA/GMAW-MS, respectively $(p<0.0001)$. There was no effect of welding fume alone on tumor multiplicity (CO/air, $0.28 \pm 0.11$; CO/GMAW-MS, $0.18 \pm 0.07 ; p=0.44)$. Average tumor incidence ( $\%$ of tumor-bearing mice) was $21 \%$ in $\mathrm{CO} /$ air and $17 \%$ in CO/GMAW-MS-exposed animals. Reports in the literature indicate the background tumor frequency in A/J mice between 43 and 53 weeks to be 31-40\% $[30,31]$. The mice in this study were 35 or 36 weeks old upon sacrifice, indicating the observed tumor incidence is consistent with reported findings. As expected, tumor incidence was $100 \%$ in all MCA-initiated groups ( $\mathrm{n}=29$ for MCA/air and $\mathrm{n}=28 \mathrm{MCA} / \mathrm{GMAW}-\mathrm{MS}$ groups), which confirmed the successful administration as well as its carcinogenic effectiveness in A/J mice. Total and average tumor number per treatment group across each of the individual lung lobes are reported in Table 3. MCA/GMAW-MS-exposed mice had significantly greater lung tumor multiplicity in every lung region compared to MCA/air $(p<0.05)$.

Gross lung morphology from a GMAW-MS-exposed mouse initiated with MCA is shown in Figure 4. Welding fume deposition was visible in all exposed mouse lungs and appeared reddish to black-brown in color. Tumors appeared white in color and opaque on initial gross exam and became more well-defined after fixation which aided enumeration. At 30 weeks, tumors were between $\sim 0.5 \mathrm{~mm}$ and $\sim 4 \mathrm{~mm}$ in diameter, with most tumors $\sim 1 \mathrm{~mm}$. Mean tumor sizes were $1.14 \pm 0.12,0.98 \pm 0.20,1.14 \pm 0.02$, and $1.19 \pm 0.02 \mathrm{~mm}$ for CO/air, CO/GMAWMS, MCA/air, and MCA/GMAW-MS, respectively.

\section{Histopathological evaluation of lung lesions, inflammation, and welding fume presence}


Severity scores for abnormal morphological findings and numbers of lung lesions observed in lung sections from A/J mice are shown in Table 4. Histopathology analysis confirmed the gross findings, with significantly greater lung tumor multiplicity in the MCA/GMAW-MS animals ( $9.86 \pm 0.88)$ compared to MCA/air (3.34 \pm 0.34$), \mathrm{CO} / \mathrm{GMAW}-\mathrm{MS}$ $(0.14 \pm 0.07)$, or $\mathrm{CO} /$ air animals $(0.27 \pm 0.12)$. In addition, two bronchioloalveolar adenocarcinomas were present in the MCA/GMAW-MS-exposed mice. None were observed in other treatment groups. Bronchiolo-alveolar adenomas and adenocarcinomas can arise from foci of alveolar hyperplasia [25]. Some of the adenomas in this study were solid discrete nodular masses, typical of adenoma, but the majority of the lesions diagnosed as adenomas arose within hyperplasias. Hyperplasias generally had irregular borders and consisted of alveoli lined by plump, round to ovoid to cuboidal epithelial cells that formed a single layer and, occasionally, small foci of hypercellularity, but still maintained the normal alveolar architecture (Figure 5A and 5B). Lesions were distinguished by focal nodular areas characterized by abnormal growth structure characteristic of adenoma, such as solid hypercellular areas and hypercellular papillary structures sometimes containing slightly atypical cells, that were clearly different from the adjacent areas of hyperplasia, resulting in disruption of the normal alveolar architecture (Figure 5C and 5D). This represented transition from hyperplasia to neoplasia and these lesions were diagnosed simply as bronchioloalveolar adenoma.

Foreign material, (i.e., GMAW-MS fume), was observed in the right and left lobes of nearly all MCA/GMAW-MS and CO/GMAW-MS-exposed lungs. The foreign material ranged in appearance from multiple, scattered small clusters of minute discrete focal aggregates of histiocytes to a few widely scattered individual histiocytes containing black intracytoplasmic granules. Foreign material was graded based upon the amount of accumulated material present 
and was considered minimal in all cases. Unremarkable inflammation was observed in any of the treatment groups. No significant monocytic or lymphoid infiltrate was observed in any mouse lungs, indicating a lack of inflammation from GMAW-MS inhalation exposure.

\section{BAL findings 1 day, 7 days, 28 days, and 84 days post-exposure to GMAW-MS fume}

At 1 day post-exposure, cytotoxicity as measured by LDH levels was not significantly increased in GMAW-MS-exposed compared to air-exposed mice $(111.10 \pm 7.08$ and $101.90 \pm$ 4.65 U/L, respectively). The same result was found at 7, 28, and 84 days post-exposure (Table 5). In both the GMAW-MS fume and air-exposed groups, cell populations were > 99\% AM. Similarly, slides from control animals typically contained $>99 \%$ AM. A significant increase in macrophage cell number was seen in GMAW-MS-exposed mice at 28 and 84 days post-exposure $(p<0.05)$. No significant neutrophils, eosinophils, or lymphocytes were observed at any time point post-exposure (data not shown).

\section{Discussion}

This study demonstrated that GMAW-MS fume is a lung tumor promoter in A/J mice, despite a lack of significant chronic lung inflammation or the presence of known carcinogenic metals in the fume. Gross and histopathological examination revealed significantly increased lung tumor multiplicity in MCA/GMAW-MS-exposed mice compared to MCA/air controls. This tumor promotion effect was achieved at a lower fume deposition than our previous GMAW-SS oropharyngeal aspiration or inhalation studies $[9,10]$. The results of this study support epidemiological findings that MS welders are still at increased risk of lung cancer despite absence of known carcinogens in the MS fume [4, 5].

Whole lung metal analysis revealed $6.1 \mu \mathrm{g}$ of GMAW-MS fume was deposited after a single 4 hour exposure, which equates to an approximate total deposition of $136.64 \mu \mathrm{g}$ in the alveolar region of the lung throughout the course of the exposure. In comparison, a previous 
GMAW-SS inhalation study by Falcone et al. found a lung metal deposition of $\sim 10.1 \mu \mathrm{g}$, or an approximate total deposition of $254.4 \mu \mathrm{g}$ in the alveolar region [24]. This GMAW-MS deposition is approximately $46 \%$ lower than the GMAW- SS study, yet the tumor multiplicity after exposure to GMAW-MS was similar (21.86 \pm 1.50 compared to $16.11 \pm 1.18$, respectively).

GMAW-SS has been shown to induce a mild, chronic inflammation in the lung [11]. Histopathological analysis of mouse lung sections after GMAW-SS fume exposure revealed significantly increased perivascular and peribronchiolar mononuclear cell infiltrates [11]. In contrast, no significant lung inflammation or cytotoxicity was found in this study after a shortterm GMAW-MS fume exposure. Histopathological analysis of lung sections showed no evidence of chronic inflammation. These findings agree with earlier occupational and rat MS welding fume studies $[12,32]$. Despite the lack of overt inflammation following this exposure, substantial evidence indicates that tumor promotion and inflammation are often connected, and inflammation is considered an enabling hallmark of carginogenesis [33-35]. Many carcinogens are now thought to cause both genetic and/or epigenetic changes that may lead to cancer. It is possible there may be an epigenetic effect occurring with welding fume exposures [36]. A number of metals such as nickel, cadmium, and arsenic, as well as exposure to substances like alcohol and cigarette smoke, are known to cause epigenetic changes such as DNA methylation and histone modification which can lead to the development of cancer [36, 37]. Totsuka et al. observed DNA damage and increased formation of DNA adducts in mice after exposure to iron oxide [38]. Epigenetic changes are now considered an important contributor to carcinogenesis and this may be an important area to investigate with welding fumes in the future. Indeed, stainless steel welding fume exposure has been shown to cause epigenetic changes (e.g., increased telomere length) in circulating peripheral blood monocytes of rats [39]. Similar studies 
that examine these epigenetic effects in lung epithelial cells isolated from A/J mice after inhalation exposure to GMAW-MS fume are needed.

Although there was a lack of overt inflammation following in vivo exposure to GMAWMS fume in this study, worker studies have indicated that welders are at increased risk of lobar pneumonia from Streptococcus pneumoniae infection as well as other lung infections [40-43]. A cross-sectional study of shipyard workers in the Middle East found that those exposed to welding fumes had a higher prevalence of respiratory symptoms and were more likely to report to healthcare professionals concerning respiratory infections [44]. Epidemiological studies have found that welders are at increased risk of developing and dying from pneumococcal and lobar pneumonia, suggesting a need for pneumococcal vaccination among welders [45]. According to prevailing hypotheses, the reasons for increased risk of infection in welders include the ability of Fe to act as a micronutrient for bacteria, inhibition of the immune system, and enhanced binding of Streptococcus pneumoniae to lung epithelial cells [41]. Recent research most strongly supports enhanced bacterial binding to lung epithelial cells as the primary mechanism for the increased Streptococcal infection risk [40, 42, 46]. Research concerning inhibition of the immune system is less consistent. A study investigating inflammatory markers in welders saw no inflammatory response nor a change in inflammatory markers that would be expected with an inhibited immune response [47]. Antonini et al. 2014 observed that pre-treatment of RAW 264.7 macrophages with GMA-MS had no effect on phagocytic function at 3 and 6 hours [48]. However, a later study by Antonini et al. found that inhalation of GMAW-MS fume suppressed lung defense responses following bacterial challenge in rats [12]. If GMAW-MS suppressed mouse lung defenses in this study, it is possible this represents a potential mechanism by which tumor promotion is occurring. 
Even though GMAW-MS fume is composed of both Mn and Fe, the majority of studies in the literature suggest Mn as having primarily neurotoxic effects. These can potentially include Manganism and a Parkinson disease-like disorder in welders [2, 49, 50]. Studies have also indicated impairment in learning and memory in rats exposed to Mn [51, 52]. In contrast, it is widely accepted that Fe overload increases cancer risk, with evidence from Fe over-load diseases like hemochromatosis, mylodysplastic syndromes, and endometriosis in which Fe excess can contribute to the development of cancer $[15,18,53,54]$. Fe overload has also been shown to be a contributory cause of pathogenesis in asbestos-induced mesothelioma [54]. Although Fe is a crucial micronutrient for the body, too much Fe can increase cancer risk via the production of reactive oxygen species. The Fe in welding fume is present as various forms of iron oxides, including $\mathrm{Fe}_{2} \mathrm{O}_{3}$. Once inhaled, this $\mathrm{Fe}^{3+}$ could be reduced and then oxidized by the Fenton reaction to create hydroxyl radical. This radical can damage lipids and DNA leading to mutations that can cause cancer. Hydroxyl radical has also been shown to accelerate migratory and invasive capabilities of lung cancer cells and modulate signals that regulate cell transformation, increase apoptosis, and alter gene expression, although it is unclear if this is occurring in this study given the lack of overt inflammation $[18,55]$. Fe homeostasis has also been shown to be associated with airway obstruction, with elevated serum ferritin corresponding to lower $\mathrm{FEV}_{1} / \mathrm{FVC}$ ratios [56]. As Fe accumulates, it may progressively damage the airway and lungs, leading to obstructive disease as well as lead to accompanying diseases such as cancer and infections. In this study, we observed increased macrophages in the GMAW-MS-exposed mice at 28 and 84 days post-exposure which likely infiltrated into the lungs to clear the welding fume particles. Epidemiological evidence from numerous worker studies involving industrial exposures to iron oxides, such as iron ore mining, iron and steel founding, and welding, reveal increased cancer 
risks in these populations $[19,57]$. However, the results are conflicting, with some reports suggesting no increased cancer risk [21]. Iron oxide exposures are difficult to study in isolation, however, as many of these occupations also involve exposures to other cancer-causing materials such as radon, cigarette smoke, or known carcinogenic metals. Furthermore, in vivo inhalation studies of iron oxide exposures are scarce [58]. Because of limited evidence from "pure" human iron oxide exposures, iron oxide is currently not classified as carcinogenic to humans according to the IARC [57].

In conclusion, this study is the first to demonstrate that GMAW-MS fume, despite containing no metals currently classified as carcinogens, promotes lung tumors in A/J mice. Future studies in our laboratory will investigate the toxicity and tumorigenic potential of the individual metal components of GMAW-SS and GMAW-MS fumes. Results of these studies may help to identify the metal components that are most toxic and tumorigenic. Ultimately, a more complete understanding of the toxicity and tumorigenic potential of the welding fume components can lead to a safer work environment for welders.

\section{Bibliography}

1. Guha N, Loomis D, Guyton KZ, Grosse Y, El Ghissassi F, Bouvard V, Benbrahim-Tallaa L, Vilahur N, Muller K, Straif K: Carcinogenicity of welding, molybdenum trioxide, and indium tin oxide. Lancet Oncol 2017, 18:581-582.

2. Antonini JM: Health Effects Associated with Welding. 2014:49-70.

3. The Procedure Handbook of Arc Welding. 14 edn. The James F. Lincoln Arc Welding Foundation; 2000.

4. Hansen KS, Lauritsen JM, Skytthe A: Cancer incidence among mild steel and stainless steel welders and other metal workers. Am J Ind Med 1996, 30:373-382. 
5. Lauritsen JM, Hansen KS: Lung cancer mortality in stainless steel and mild steel welders: a nested case-referent study. Am J Ind Med 1996, 30:383-391.

6. Sorensen AR, Thulstrup AM, Hansen J, Ramlau-Hansen CH, Meersohn A, Skytthe A, Bonde JP: Risk of lung cancer according to mild steel and stainless steel welding. Scand J Work Environ Health 2007, 33:379-386.

7. Matrat M, Guida F, Mattei F, Cenee S, Cyr D, Fevotte J, Sanchez M, Menvielle G, Radoi L, Schmaus A, et al: Welding, a risk factor of lung cancer: the ICARE study. Occup Environ Med 2016, 73:254-261.

8. Zeidler-Erdely PC, Battelli LA, Stone S, Chen BT, Frazer DG, Young SH, Erdely A, Kashon ML, Andrews R, Antonini JM: Short-term inhalation of stainless steel welding fume causes sustained lung toxicity but no tumorigenesis in lung tumor susceptible A/J mice. Inhal Toxicol 2011, 23:112-120.

9. Falcone LM, Erdely A, Meighan TG, Battelli LA, Salmen R, McKinney W, Stone S, Cumpston A, Cumpston J, Andrews RN, et al: Inhalation of gas metal arc-stainless steel welding fume promotes lung tumorigenesis in A/J mice. Arch Toxicol 2017, 91:2953-2962.

10. Zeidler-Erdely PC, Meighan TG, Erdely A, Battelli LA, Kashon ML, Keane M, Antonini JM: Lung tumor promotion by chromium-containing welding particulate matter in a mouse model. Part Fibre Toxicol 2013, 10:45.

11. Zeidler-Erdely PC, Kashon ML, Battelli LA, Young SH, Erdely A, Roberts JR, Reynolds SH, Antonini JM: Pulmonary inflammation and tumor induction in lung tumor susceptible $\mathrm{A} / \mathrm{J}$ and resistant $\mathbf{C 5 7 B L / 6 J}$ mice exposed to welding fume. Part Fibre Toxicol 2008, 5:12. 
12. Antonini JM, Roberts JR, Stone S, Chen BT, Schwegler-Berry D, Frazer DG: Shortterm inhalation exposure to mild steel welding fume had no effect on lung inflammation and injury but did alter defense responses to bacteria in rats. Inhal Toxicol 2009, 21:182-192.

13. Antonini JM, Stone S, Roberts JR, Chen B, Schwegler-Berry D, Afshari AA, Frazer DG: Effect of short-term stainless steel welding fume inhalation exposure on lung inflammation, injury, and defense responses in rats. Toxicol Appl Pharmacol 2007, 223:234-245.

14. Taylor MD, Roberts JR, Leonard SS, Shi X, Antonini JM: Effects of welding fumes of differing composition and solubility on free radical production and acute lung injury and inflammation in rats. Toxicol Sci 2003, 75:181-191.

15. Manz DH, Blanchette NL, Paul BT, Torti FM, Torti SV: Iron and cancer: recent insights. Ann N Y Acad Sci 2016, 1368:149-161.

16. Andrews NC: Iron homeostasis: insights from genetics and animal models. Nat Rev Genet 2000, 1:208-217.

17. Akatsuka S, Toyokuni S: [Iron function and carcinogenesis]. Nihon Rinsho 2016, 74:1168-1175.

18. Steegmann-Olmedillas JL: The role of iron in tumour cell proliferation. Clin Transl Oncol 2011, 13:71-76.

19. Boyd JT, Doll R, Faulds JS, Leiper J: Cancer of the lung in iron ore (haematite) miners. Br J Ind Med 1970, 27:97-105. 
20. Pease C, Rucker T, Birk T: Review of the Evidence from Epidemiology, Toxicology, and Lung Bioavailability on the Carcinogenicity of Inhaled Iron Oxide Particulates. Chem Res Toxicol 2016, 29:237-254.

21. Bourgkard E, Wild P, Courcot B, Diss M, Ettlinger J, Goutet P, Hemon D, Marquis N, Mur JM, Rigal C, et al: Lung cancer mortality and iron oxide exposure in a French steel-producing factory. Occup Environ Med 2009, 66:175-181.

22. Campbell JA: Effects of Precipitated Silica and of Iron Oxide on the Incidence of Primary Lung Tumours in Mice. Br Med J 1940, 2:275-280.

23. Antonini JM, Afshari AA, Stone S, Chen B, Schwegler-Berry D, Fletcher WG, Goldsmith WT, Vandestouwe KH, McKinney W, Castranova V, Frazer DG: Design, construction, and characterization of a novel robotic welding fume generator and inhalation exposure system for laboratory animals. J Occup Environ Hyg 2006, 3:194-203; quiz D145.

24. Falcone LM, Erdely A, Meighan TG, Battelli LA, Salmen R, McKinney W, Stone S, Cumpston A, Cumpston J, Andrews RN, et al: Inhalation of gas metal arc-stainless steel welding fume promotes lung tumorigenesis in A/J mice. Arch Toxicol 2017.

25. Renne R, Brix A, Harkema J, Herbert R, Kittel B, Lewis D, March T, Nagano K, Pino M, Rittinghausen S, et al: Proliferative and nonproliferative lesions of the rat and mouse respiratory tract. Toxicol Pathol 2009, 37:5s-73s.

26. Rehm S, Ward JM: Quantitative analysis of alveolar type II cell tumors in mice by whole lung serial and step sections. Toxicol Pathol 1989, 17:737-742.

27. Erdely A, Hulderman T, Salmen-Muniz R, Liston A, Zeidler-Erdely PC, Chen BT, Stone S, Frazer DG, Antonini JM, Simeonova PP: Inhalation exposure of gas-metal arc 
stainless steel welding fume increased atherosclerotic lesions in apolipoprotein $\mathrm{E}$ knockout mice. Toxicol Lett 2011, 204:12-16.

28. Raabe OG, Al-Bayati, M.A., Teague, S.V., Rasolt, A., : Regional deposition of inhaled monodisperse coarse and fine aerosol particles in small laboratory animals. Ann Occup Hyg 1988, 32:53-63.

29. Stone KC, Mercer RR, Gehr P, Stockstill B, Crapo JD: Allometric relationships of cell numbers and size in the mammalian lung. Am J Respir Cell Mol Biol 1992, 6:235-243.

30. Groch KM, Khan MA, Brooks AL, Saffer JD: Lung cancer response following inhaled radon in the A/J and C57BL/6J mouse. Int J Radiat Biol 1997, 71:301-308.

31. Curtin GM, Higuchi MA, Ayres PH, Swauger JE, Mosberg AT: Lung tumorigenicity in $\mathrm{A} / \mathrm{J}$ and rasH2 transgenic mice following mainstream tobacco smoke inhalation. Toxicol Sci 2004, 81:26-34.

32. Antonini JM: Health effects of welding. Crit Rev Toxicol 2003, 33:61-103.

33. Hanahan D, Weinberg RA: Hallmarks of cancer: the next generation. Cell 2011, 144:646-674.

34. Fujiki H, Sueoka E, Suganuma M: Tumor promoters: from chemicals to inflammatory proteins. J Cancer Res Clin Oncol 2013, 139:1603-1614.

35. Fujiki H, Suganuma M, Okabe S, Sueoka E, Suga K, Imai K, Nakachi K: A new concept of tumor promotion by tumor necrosis factor-alpha, and cancer preventive agents ()-epigallocatechin gallate and green tea--a review. Cancer Detect Prev 2000, 24:9199. 
36. Herceg Z, Lambert MP, van Veldhoven K, Demetriou C, Vineis P, Smith MT, Straif K, Wild CP: Towards incorporating epigenetic mechanisms into carcinogen identification and evaluation. Carcinogenesis 2013, 34:1955-1967.

37. Chappell G, Pogribny IP, Guyton KZ, Rusyn I: Epigenetic alterations induced by genotoxic occupational and environmental human chemical carcinogens: A systematic literature review. Mutat Res Rev Mutat Res 2016, 768:27-45.

38. Totsuka Y, Ishino K, Kato T, Goto S, Tada Y, Nakae D, Watanabe M, Wakabayashi K: Magnetite Nanoparticles Induce Genotoxicity in the Lungs of Mice via Inflammatory Response. Nanomaterials (Basel) 2014, 4:175-188.

39. Shoeb M, Kodali VK, Farris BY, Bishop LM, Meighan TG, Salmen R, Eye T, Friend S, Schwegler-Berry D, Roberts JR, et al: Oxidative stress, DNA methylation, and telomere length changes in peripheral blood mononuclear cells after pulmonary exposure to metal-rich welding nanoparticles. NanoImpact 2017, 5:61-69.

40. Coggon D, Inskip H, Winter P, Pannett B: Lobar pneumonia: an occupational disease in welders. Lancet 1994, 344:41-43.

41. Coggon D, Palmer KT: Are welders more at risk of respiratory infections? Thorax 2016, 71:581-582.

42. Suri R, Periselneris J, Lanone S, Zeidler-Erdely PC, Melton G, Palmer KT, Andujar P, Antonini JM, Cohignac V, Erdely A, et al: Exposure to welding fumes and lower airway infection with Streptococcus pneumoniae. J Allergy Clin Immunol 2016, 137:527-534.e527.

43. Zeidler-Erdely PC, Erdely A, Antonini JM: Immunotoxicology of arc welding fume: worker and experimental animal studies. J Immunotoxicol 2012, 9:411-425. 
44. Marongiu A, Hasan O, Ali A, Bakhsh S, George B, Irfan N, Minelli C, Canova C, Schofield S, De Matteis S, Cullinan P: Are welders more at risk of respiratory infections? Findings from a cross-sectional survey and analysis of medical records in shipyard workers: the WELSHIP project. Thorax 2016, 71:601-606.

45. Coggon D, Harris EC, Cox V, Palmer KT: Pneumococcal vaccination for welders. Thorax 2015, 70:198-199.

46. Wong A, Marrie TJ, Garg S, Kellner JD, Tyrrell GJ: Welders are at increased risk for invasive pneumococcal disease. Int J Infect Dis 2010, 14:e796-799.

47. Palmer KT, McNeill Love RM, Poole JR, Coggon D, Frew AJ, Linaker CH, Shute JK: Inflammatory responses to the occupational inhalation of metal fume. Eur Respir J 2006, 27:366-373.

48. Antonini JM, Badding MA, Meighan TG, Keane M, Leonard SS, Roberts JR: Evaluation of the Pulmonary Toxicity of a Fume Generated from a Nickel-, Copper-Based Electrode to be Used as a Substitute in Stainless Steel Welding. Environ Health Insights 2014, 8:11-20.

49. Laohaudomchok W, Lin X, Herrick RF, Fang SC, Cavallari JM, Shrairman R, Landau A, Christiani DC, Weisskopf MG: Neuropsychological effects of low-level manganese exposure in welders. Neurotoxicology 2011, 32:171-179.

50. Roels HA, Bowler RM, Kim Y, Claus Henn B, Mergler D, Hoet P, Gocheva VV, Bellinger DC, Wright RO, Harris MG, et al: Manganese exposure and cognitive deficits: a growing concern for manganese neurotoxicity. Neurotoxicology 2012, 33:872-880. 
51. Liang G, Qin H, Zhang L, Ma S, Huang X, Lv Y, Qing L, Li Q, Xiong Y, Huang Y, et al: Effects of chronic manganese exposure on the learning and memory of rats by observing the changes in the hippocampal cAMP signaling pathway. Food Chem Toxicol 2015, 83:261-267.

52. Shukakidze A, Lazriev I, Mitagvariya N: Behavioral impairments in acute and chronic manganese poisoning in white rats. Neurosci Behav Physiol 2003, 33:263-267.

53. Zhang C, Zhang F: Iron homeostasis and tumorigenesis: molecular mechanisms and therapeutic opportunities. Protein Cell 2015, 6:88-100.

54. Jiang L, Chew SH, Nakamura K, Ohara Y, Akatsuka S, Toyokuni S: Dual preventive benefits of iron elimination by desferal in asbestos-induced mesothelial carcinogenesis. Cancer Sci 2016, 107:908-915.

55. Luanpitpong S, Talbott SJ, Rojanasakul Y, Nimmannit U, Pongrakhananon V, Wang L, Chanvorachote P: Regulation of lung cancer cell migration and invasion by reactive oxygen species and caveolin-1. J Biol Chem 2010, 285:38832-38840.

56. Ghio AJ, Hilborn ED: Indices of iron homeostasis correlate with airway obstruction in an NHANES III cohort. Int J Chron Obstruct Pulmon Dis 2017, 12:2075-2084.

57. Wild P, Bourgkard E, Paris C: Lung cancer and exposure to metals: the epidemiological evidence. Methods Mol Biol 2009, 472:139-167.

58. Kornberg TG, Stueckle TA, Antonini JA, Rojanasakul Y, Castranova V, Yang Y, Wang L: Potential Toxicity and Underlying Mechanisms Associated with Pulmonary Exposure to Iron Oxide Nanoparticles: Conflicting Literature and Unclear Risk. Nanomaterials (Basel) 2017, 7. 
Figure 1. Timelines of experimental protocols. Panel A - Experimental protocol for whole lung metal analysis. Mice were exposed by whole-body inhalation to filtered air $(\mathrm{n}=10)$ or GMAW-MS fume $(\mathrm{n}=10)$ for 4 hours/day for 10 days. Inductively coupled argon plasma, atomic emission spectroscopy was used to analyze metal content of lungs. Panel B Experimental protocol for two-stage (initiation-promotion) bioassay. Mice received MCA ( $\mathrm{n}=$ $60)$ or corn oil $(n=60)$ injections and beginning 1 week later were exposed to GMAW-MS or air inhalation 4 hours/day x 4 day/week x 8 weeks before terminal sacrifice at 30 weeks. Panel C Experimental protocol for whole lung bronchoalveolar lavage (BAL). Sixty-four mice were exposed to GMAW-MS or air for 4 hours/day for 10 days. Whole lung BAL was used to assess lung injury and inflammation at 1 day, 7 days, 28 days, and 84 days post-exposure $(n=8$ per treatment group per time point).

Figure 2. SEM images of GMAW-MS fume. Particles form small clustered aggregates ranging in size from less than $0.01 \mu \mathrm{m}$ to over $1 \mu \mathrm{m}$, with a mass median aerodynamic diameter of 0.31 $\mu \mathrm{m} .[12]$ Primary particles were mainly in the nanometer size range and primarily composed of iron $(83.67 \%)$ and manganese $(14.33 \%)$.

Figure 3. Average tumor number per mouse lung (tumor multiplicity) upon gross examination in A/J mice following initiation-promotion study at 30 week sacrifice. MCA/GMAW-MS significantly increased lung tumor number compared to air controls (21.86 \pm 1.50 vs $8.34 \pm 0.59$, respectively). As expected, mice not initiated with MCA had low tumor number. Horizontal bars represent mean tumor numbers per group. Circles $=\mathrm{CO} /$ Air, squares $=$ MCA/air, upward triangles = MCA/air, downward triangles $=$ MCA/GMAW-MS. ${ }^{*} p<0.0001-$ compared to $\mathrm{CO} /$ air; $* * p<0.0001$ - compared to MCA/air 
Figure 4. Gross images of A/J mouse lung promoted by GMAW-MS 30 weeks postinitiation with MCA. Panel A - Lung tumor morphology before fixation. Panel B - Lung tumors 24 hours after fixation. Fixation allows for more accurate enumeration of tumors. Tumors (arrows) were on average $\sim 1 \mathrm{~mm}$ in diameter and opaque in color.

Figure 5. Photomicrographs of lung tissue from MCA/GMAW-MS exposed mice. Panel Amoderate bronchioloalveolar hyperplasia, 4x magnification. Panel B - moderate bronchioloalveolar hyperplasia,10x magnification. Panel $\mathrm{C}$ - bronchioloalveolar adenoma as a solid discrete mass, 10x magnification. Panel D - bronchioloalveolar adenoma, 20x magnification. 


\section{Tables}

Table 1. Metal composition of GMAW-MS fume

\begin{tabular}{cc}
\hline Metals Analyzed & Weight \% of Metals \\
$\mathrm{Fe}$ & $83.67 \pm 0.47$ \\
$\mathrm{Mn}$ & $14.33 \pm 0.37$ \\
$\mathrm{Cu}$ & $0.13 \pm 0.03$ \\
\hline
\end{tabular}

GMAW-MS fume was analyzed for aluminum (Al), chromium $(\mathrm{Cr})$, copper $(\mathrm{Cu})$, iron $(\mathrm{Fe})$, manganese (Mn), nickel (Ni), silicon ( $\mathrm{Si})$, titanium (Ti), vanadium (V), and zinc (Zn) by Inductively Coupled Plasma-Atomic Emission Spectroscopy. Samples were prepared according to the NIOSH method 7303 modified for microwave digestion. Trace amounts of $\mathrm{Al}, \mathrm{Cr}, \mathrm{Ni}, \mathrm{Si}$, $\mathrm{Ti}$, and V were found. Note: Values are mean \pm standard error of the mean $(\mathrm{n}=3$ welding fume collection periods of 30 minutes). Weight $\%$ is relative to all metals analyzed. GMAW-MS - gas metal arc welding-mild steel. 
Table 2. Lung metal deposition in A/J mice after air or GMAW-MS fume inhalation for 4 hours at a concentration of $36.4 \mathrm{mg} / \mathrm{m}^{3}$

\begin{tabular}{c|ccc}
\hline Exposure & Fe $(\boldsymbol{\mu g} / \mathbf{l u n g})$ & Mn $(\boldsymbol{\mu g} / \mathbf{l u n g})$ & $\mathbf{C u}(\boldsymbol{\mu g} / \mathbf{l u n g})$ \\
\hline Air & $9.45 \pm 0.29$ & $0.01 \pm 0.00$ & $0.23 \pm 0.01$ \\
\hline GMAW-MS & $14.62 \pm 0.45$ & $0.88 \pm 0.05$ & $0.29 \pm 0.01$ \\
\hline
\end{tabular}

Freeze-dried whole lung tissue was analyzed for aluminum $(\mathrm{Al})$, chromium $(\mathrm{Cr})$, copper $(\mathrm{Cu})$, iron $(\mathrm{Fe})$, manganese $(\mathrm{Mn})$, nickel $(\mathrm{Ni})$, titanium $(\mathrm{Ti})$, and zinc ( $\mathrm{Zn})$ by Inductively Coupled Plasma-Atomic Emission Spectroscopy. Samples were prepared according to the NIOSH method 7300 for bulk tissue samples. Levels of $\mathrm{Al}, \mathrm{Cr}, \mathrm{Ni}, \mathrm{Ti}$, and $\mathrm{Zn}$ were not significantly increased in exposed animals or not detected. Note: Values are mean \pm standard error of the mean $(\mathrm{n}=10$ air; n=10 GMAW-MS); GMAW-MS - gas metal arc welding-mild steel. 
Table 3. Total and average (in parenthesis) tumor number in $\mathrm{A} / \mathrm{J}$ mice across each of the individual lung lobes following GMAW-MS or air exposure 30 weeks post-initiation with MCA or corn oil.

\begin{tabular}{ccccccc}
\hline & $\mathbf{n}$ & Left & Apical & Cardiac & Diaphragmatic & Azygos \\
CO/air & 29 & $4(0.14 \pm 0.07)$ & $2(0.07 \pm 0.05)$ & 0 & $1(0.03 \pm 0.03)$ & $1(0.03 \pm 0.03)$ \\
CO/GMA-MS & 28 & $3(0.12 \pm 0.06)$ & 0 & 0 & $1(0.04 \pm 0.04)$ & $1(0.04 \pm 0.04)$ \\
MCA/air & 29 & $81(2.79 \pm 0.32)^{* *}$ & $28(0.97 \pm 0.16)^{* *}$ & $37(1.28 \pm 0.24)^{* *}$ & $67(2.31 \pm 0.29)^{* *}$ & $29(1.00 \pm 0.16)^{* *}$ \\
$\begin{array}{c}\text { MCA/GMA- } \\
\text { MS }\end{array}$ & 28 & $226(8.07 \pm 0.74)^{*}$ & $77(2.75 \pm 0.31)^{*}$ & $77(2.75 \pm 0.36)^{*}$ & $187(6.68 \pm 0.48)^{*}$ & $45(1.61 \pm 0.28)^{\wedge}$ \\
\hline
\end{tabular}

CO - corn oil, GMAW-MS - gas metal arc welding - mild steel, MCA - 3-methylchloanthrene ${ }^{*} \mathrm{p}<0.0001$ - compared to MCA/air, ** $\mathrm{p}<0.0001$ - compared to CO/air, ${ }^{\wedge} \mathrm{p}<0.05$ - compared to MCA/air 
Table 4. Lung histopathological findings including number of microscopically observed lung lesions at 30 weeks post-initiation with MCA or CO in A/J mice exposed to GMAW-MS fume or filtered air by inhalation

\begin{tabular}{|c|c|c|c|c|c|c|c|}
\hline & $\bar{n}$ & $\begin{array}{c}\text { Foreign } \\
\text { Material }^{\wedge}\end{array}$ & $\begin{array}{c}\text { Hyperplasia } \\
\text { Severity }^{\wedge}\end{array}$ & Hyperplasia" $^{\#}$ & Adenoma $^{\#}$ & Adenocarcinoma $^{\#}$ & Total Lesions ${ }^{\#}$ \\
\hline $\mathrm{CO} /$ air & 15 & -- & $0.1 \pm 0.05$ & $0.2 \pm 0.11$ & $0.07 \pm 0.07$ & -- & $0.27 \pm 0.12$ \\
\hline CO/GMAW-MS & 28 & $0.91 \pm 0.05^{* *}$ & $0.02 \pm 0.02$ & $0.07 \pm 0.05$ & $0.07 \pm 0.05$ & -- & $0.14 \pm 0.07$ \\
\hline MCA/air & 29 & $0.02 \pm 0.02$ & $1.79 \pm 0.18^{* *}$ & $2.93 \pm 0.34(85)^{* *}$ & $0.41 \pm 0.13(12)^{\ddagger}$ & -- & $3.34 \pm 0.34(97)^{* *}$ \\
\hline MCA/GMAW-MS & 28 & $0.96 \pm 0.02 *$ & $2.55 \pm 0.16^{*}$ & $7.11 \pm 0.64(199)^{*}$ & $2.67 \pm 0.36(75)^{*}$ & $0.07 \pm 0.05$ & $9.86 \pm 0.86(276) *$ \\
\hline
\end{tabular}

GMAW-MS - gas metal arc welding - mild steel, MCA - 3 - methylcholanthrene, CO - corn oil ${ }^{\wedge}$ Severity scores are the averages of the left and right lung lobes and are presented as mean \pm standard error. Foreign material refers to presence of presumptive GMAW-MS fume (brownblack pigment) in the lungs. Severity was scored as $1=$ minimal, $2=$ mild, $3=$ moderate, $4=$ marked.

${ }^{\#}$ Hyperplasias, adenomas, and adenocarcinomas are presented as mean \pm standard error with total lesion number in parenthesis.

-- indicates no findings

$* \mathrm{p}<0.0001$ compared to MCA/air, ** $\mathrm{p}<0.0001$ compared to $\mathrm{CO} /$ air, $\neq \mathrm{p}<0.02$ compared to $\mathrm{CO} / \mathrm{air}$ 
Table 5. Bronchoalveolar lavage parameters after exposure to air or GMAW-MS fume at a concentration $36.28 \mathrm{mg} / \mathrm{m}^{3}$ for 4 hours/day for 10 days

\begin{tabular}{ccccc}
\hline Exposure & $\begin{array}{c}\text { Time Point } \\
\text { (days) }\end{array}$ & $\mathbf{n}$ & LDH (U/L) & $\begin{array}{c}\text { Macrophages } \\
\text { (BAL cell \#/ml) }\end{array}$ \\
Air & 1 & 8 & $101.90 \pm 4.65$ & $414286 \pm 23234$ \\
GMAW-MS & & 8 & $111.10 \pm 7.08$ & $442500 \pm 40820$ \\
Air & 7 & 8 & $91.80 \pm 4.06$ & $452500 \pm 28800$ \\
GMAW-MS & & 8 & $100.50 \pm 2.86$ & $411021 \pm 33726$ \\
Air & 28 & 8 & $84.30 \pm 4.42$ & $282500 \pm 54052$ \\
GMAW-MS & & 8 & $85.10 \pm 6.00$ & $491250 \pm 67445^{*}$ \\
Air & 84 & 8 & $103.70 \pm 6.57$ & $327143 \pm 47193$ \\
GMAW-MS & & 8 & $84.50 \pm 2.41$ & $520000 \pm 56901^{*}$ \\
\hline
\end{tabular}

Total bronchoalveolar (BAL) lavage differential based on cell count of $>300$ cells.

Lymphocytes, neutrophils, and eosinophils were absent from BAL and excluded from the table.

Data are means \pm SE. - indicates no findings. Abbreviations: GMAW-SS - gas metal arc welding - mild steel. LDH - lactate dehydrogenase. ${ }^{*} p<0.05$. 


\section{Figures.}

Figure 1.
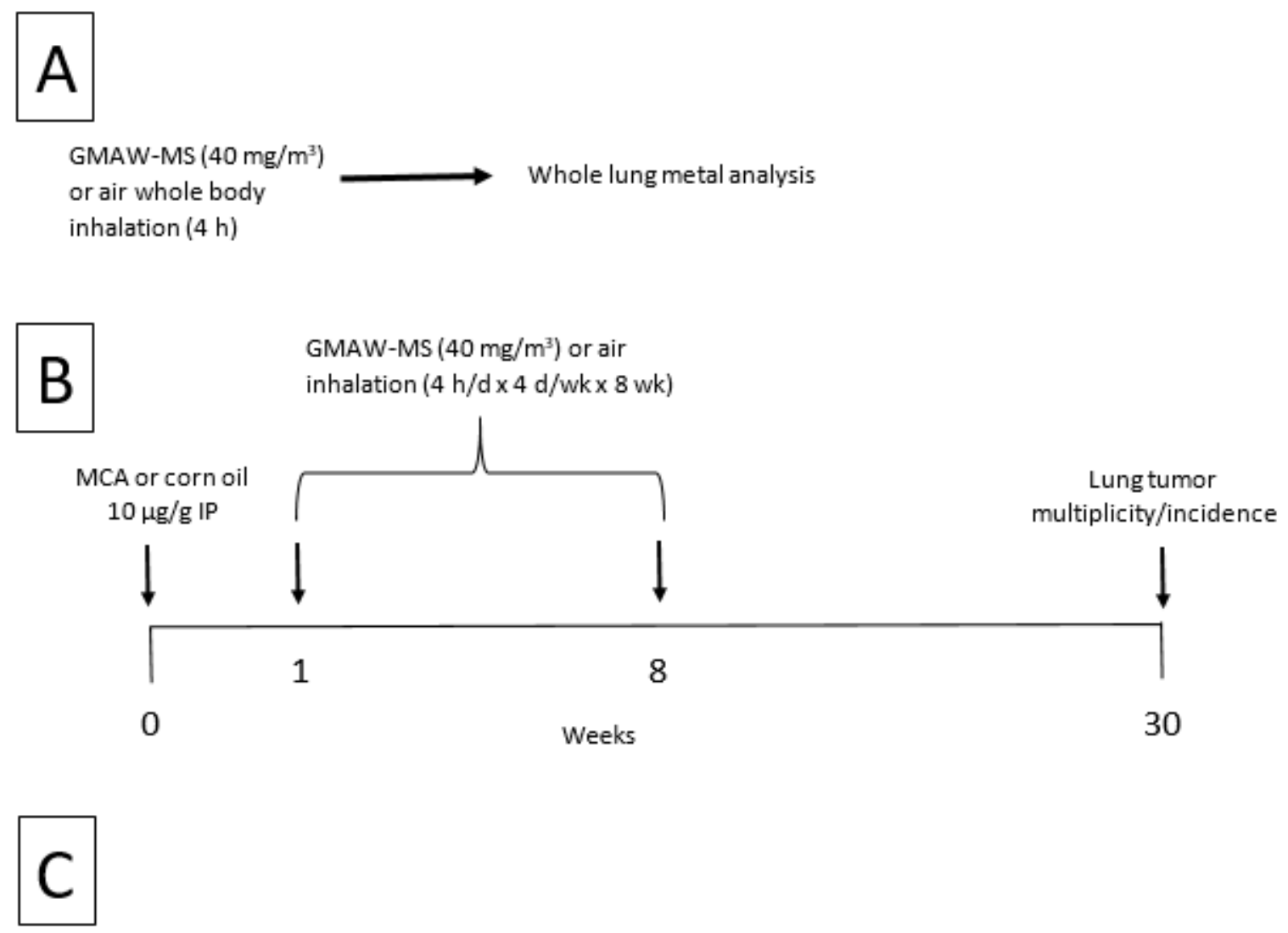

GMAW-MS $\left(40 \mathrm{mg} / \mathrm{m}^{3}\right)$ or air inhalation $(4 \mathrm{~h} / \mathrm{d} \times 10 \mathrm{~d})$

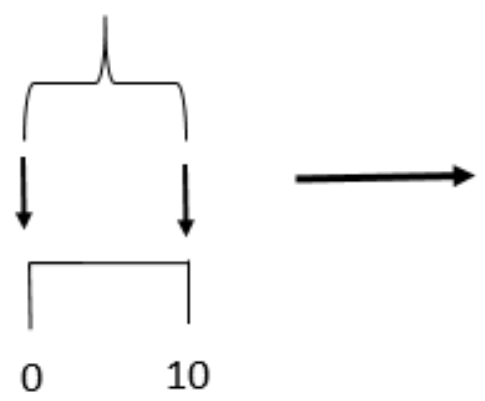

Days of exposure
Whole lung bronchoalveolar lavage

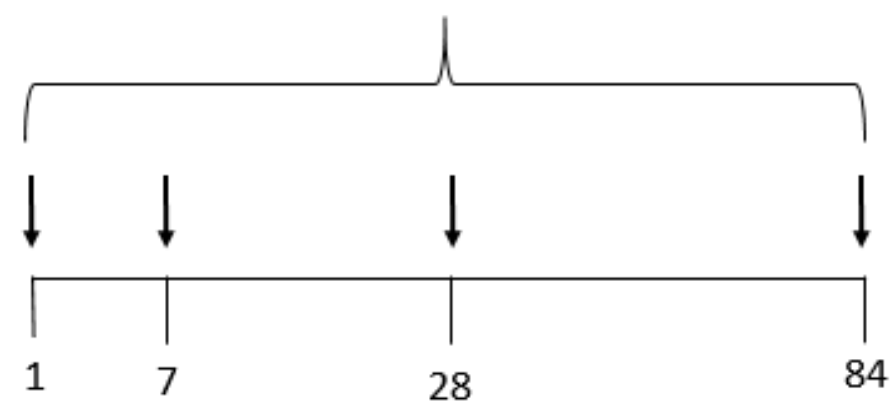

Days post-exposure 
Figure 2.
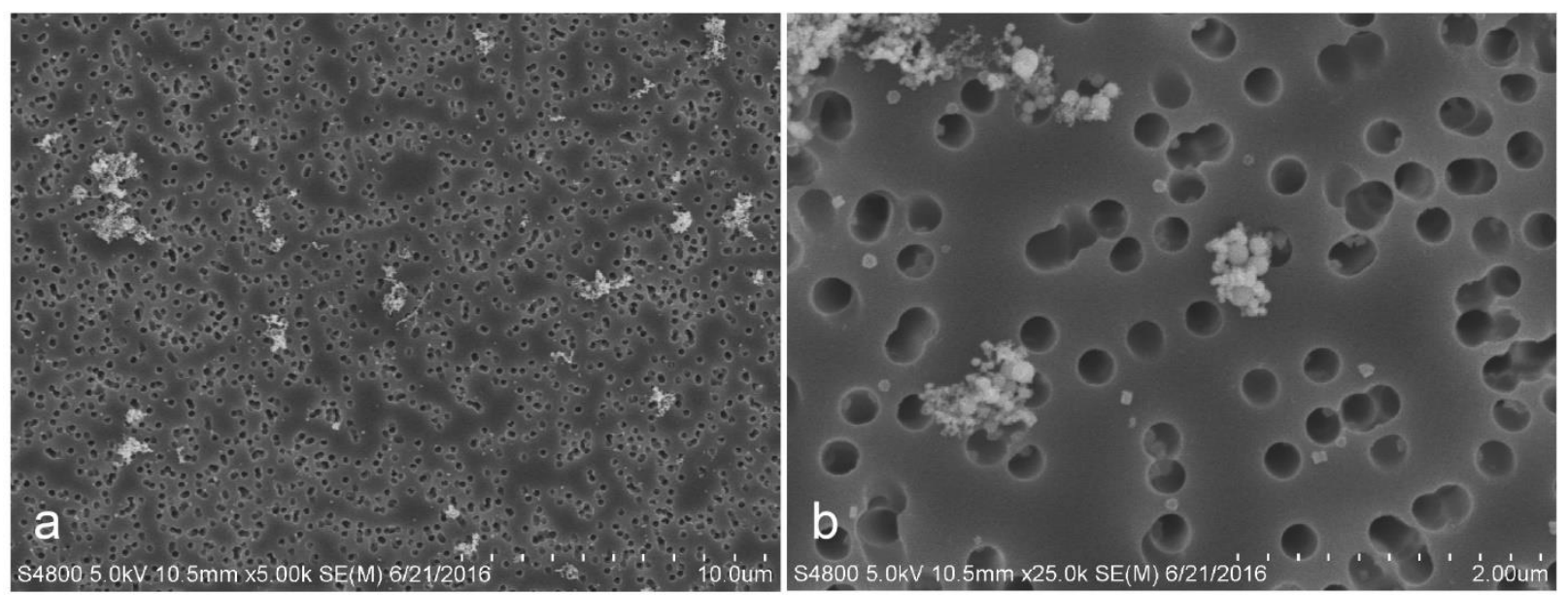
Figure 3.

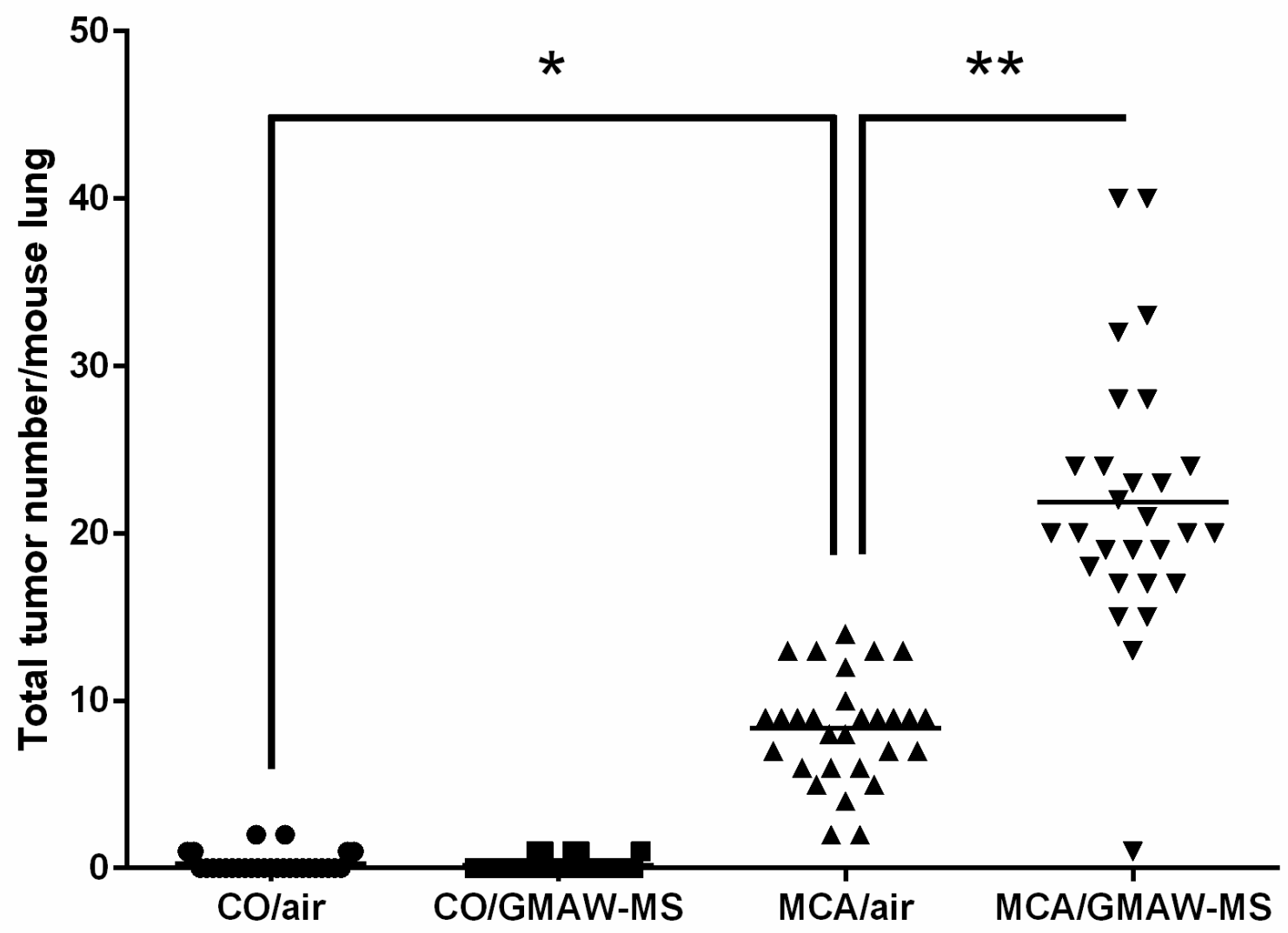


Figure 4.

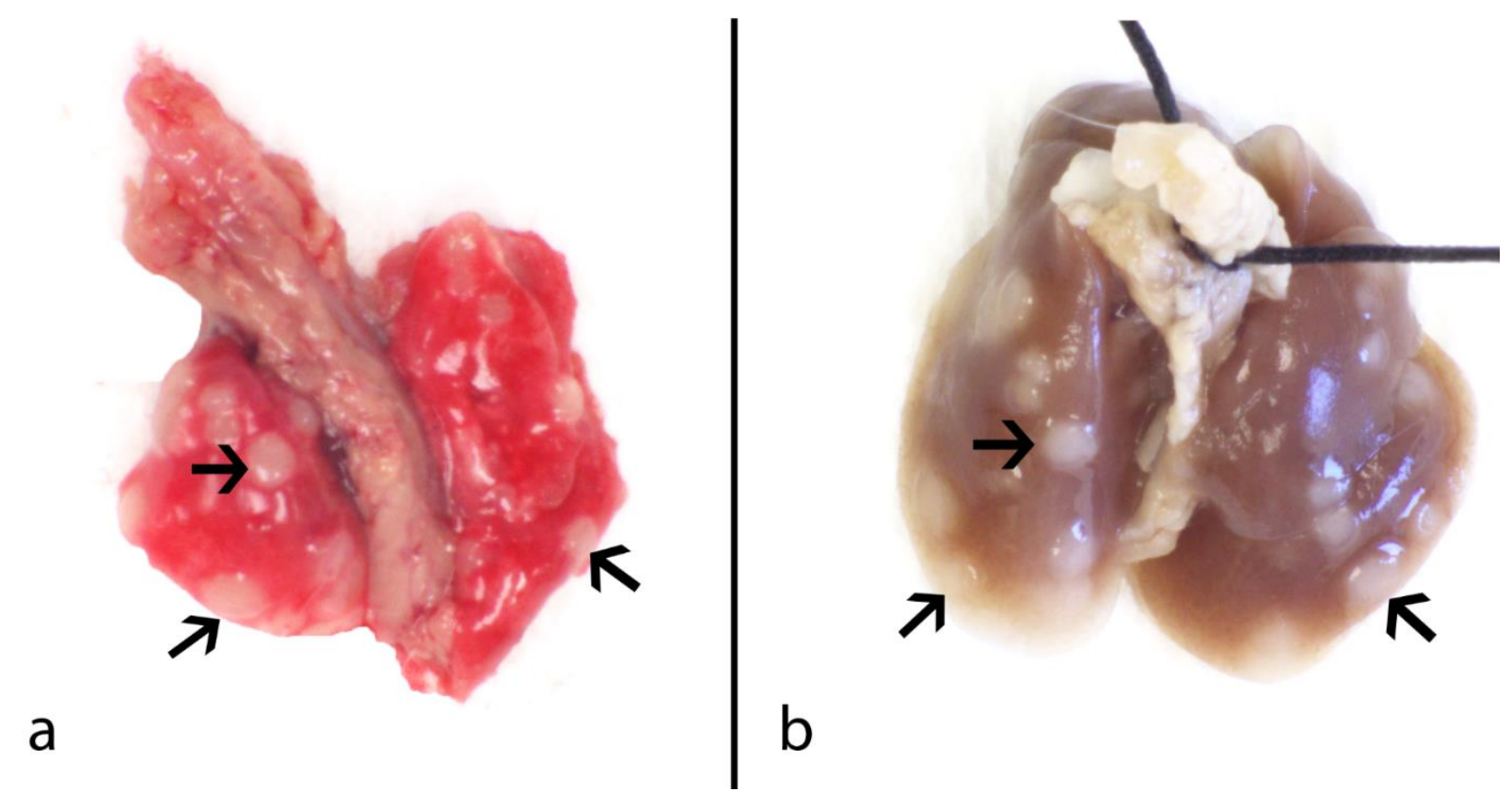


Figure 5.

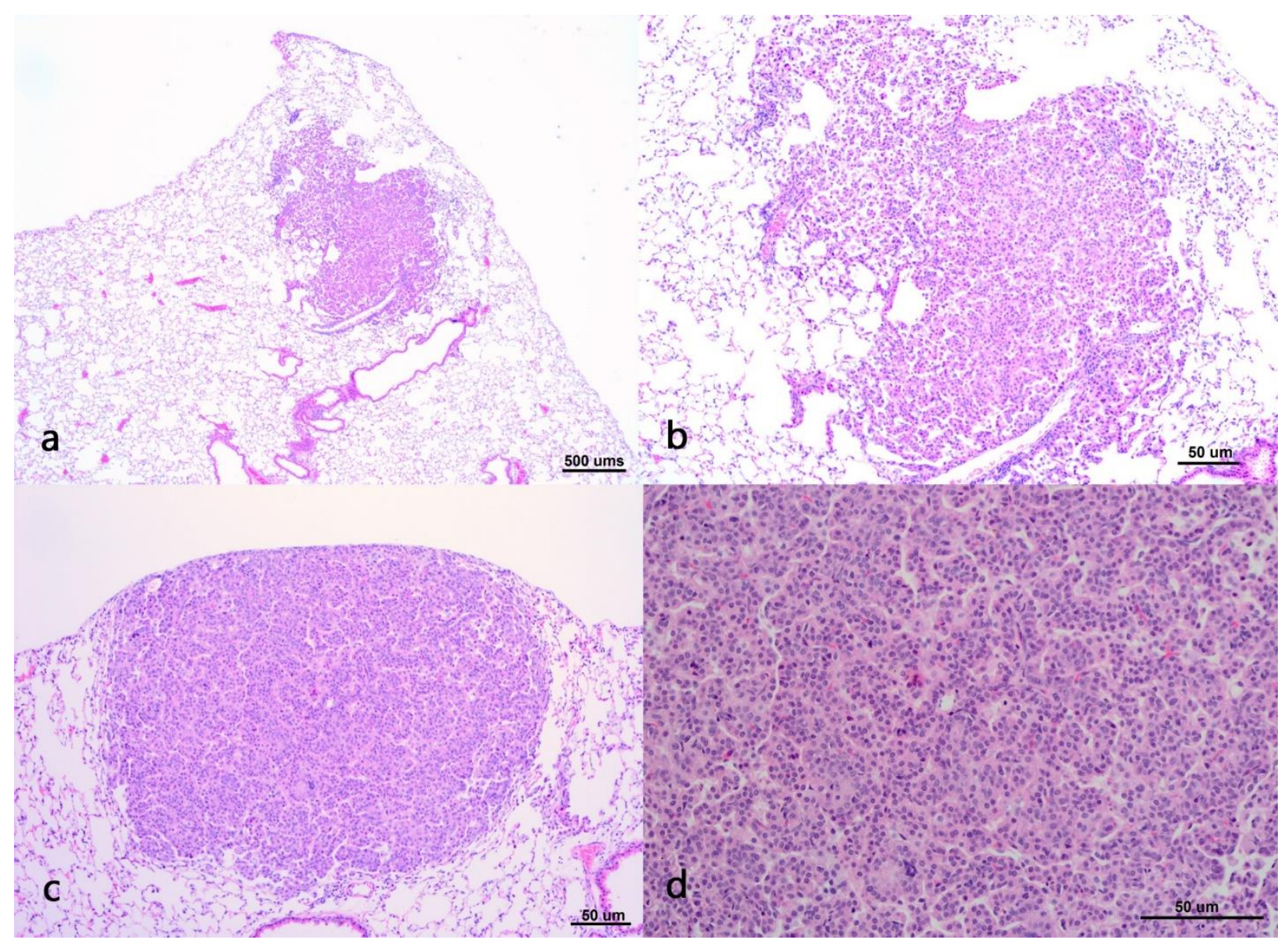




\section{Chapter 5: Pulmonary Toxicity and Lung Tumorigenic Potential of Metal Oxides in Gas Metal Arc - Stainless Steel Welding Fume: Iron Oxide as a Lung Tumor Promoter}

Lauryn M Falcone ${ }^{1,2}$, Aaron Erdely ${ }^{1,2}$, Rebecca Salmen ${ }^{1}$, Lori Battelli ${ }^{1}$, Michael Keane ${ }^{1}$, Vamsi

Kodali $^{1}$, Lauren Bowers ${ }^{3}$, Aleksandr B Stefaniak ${ }^{3}$, Michael L Kashon ${ }^{1}$, James M Antonini ${ }^{1}$, Patti C Zeidler-Erdely ${ }^{1,2}$

${ }^{1}$ Health Effects Laboratory Division, National Institute for Occupational Safety and Health, Morgantown, WV; ${ }^{2}$ West Virginia University, School of Medicine, Morgantown, WV;

${ }^{3}$ Respiratory Health Division, National Institute for Occupational Safety and Health, Morgantown, WV 


\begin{abstract}
In 2017, the International Agency for Research on Cancer classified welding fumes as "carcinogenic to humans" (Group 1). Only some of the metals found in welding fume are considered pneumotoxic or carcinogenic, however. The objectives of this study were (1) to compare the pulmonary toxicity of chromium (as chromium [III] oxide or $\mathrm{Cr}_{2} \mathrm{O}_{3}$ and calcium chromate $[\mathrm{Cr} \mathrm{VI}]$ as $\left.\mathrm{CaCrO}_{4}\right)$, nickel [II] oxide $(\mathrm{NiO})$, iron [III] oxide $\left(\mathrm{Fe}_{2} \mathrm{O}_{3}\right)$, and gas metal arc welding-stainless steel (GMAW-SS) fume; and (2) determine if these metal oxides can promote lung tumors in A/J mice, a lung tumor susceptible strain. Male A/J mice (4-5 weeks) were exposed by oropharyngeal aspiration to a suspension of GMAW-SS fume at a cumulative dose $(1.7 \mathrm{mg})$ that was previously found to promote lung tumors or a low or high dose of metal oxides based on the respective weight percent of each metal in the fume: $\mathrm{Cr}_{2} \mathrm{O}_{3} / \mathrm{CaCrO}_{4}(366 / 5 \mu \mathrm{g}$ and 731/11 $\mu \mathrm{g})$, $\mathrm{NiO}(141$ and $281 \mu \mathrm{g})$, or $\mathrm{Fe}_{2} \mathrm{O}_{3}$ (1 and $2 \mathrm{mg}$ ). Shams were exposed to $50 \mu \mathrm{PBS}$ (vehicle). Bronchoalveolar lavage, histopathology, and lung/liver qPCR were done at 1, 7, 28, and 84 days post-aspiration. In a separate study of two-stage lung carcinogenesis, mice received corn oil or 3-methylcholanthrene $(10 \mu \mathrm{g} / \mathrm{g}$; IP) and then were exposed by oropharyngeal aspiration to metal oxides or PBS (1 x/week for 5 weeks; cumulative dose for each metal equaled high dose from toxicity study). Lung tumor incidence and multiplicity were evaluated at 30 weeks post-initiation. GMAW-SS-induced lung cytotoxicity and inflammatory cell influx was significantly greater than any individual metals through 84 days post-exposure. The metals, therefore, may have a synergistic effect on lung toxicity and inflammation. Among the metal oxides, $\mathrm{Fe}_{2} \mathrm{O}_{3}$ was the most pneumotoxic and the only metal that significantly promoted lung tumors in mice.
\end{abstract}




\section{Introduction}

Nearly half of all U.S. products require welding for their production and there are millions of welders worldwide[1]. Welding, the strongest method of joining metals, is therefore a common industrial practice, with gas metal arc welding (GMAW) being among the most popular modalities. In GMAW, an electric arc is established between the work piece and a consumable electrode, often mild or stainless steel (MS or SS). High temperatures create a molten pool into which the electrode is fed and the work pieces fuse as the weld cools. Arc welding processes can generate a significant amount of welding fume- vaporized metals that react with air to form metal oxides particles that are respirable. The fume may contain particles from the base metal, wire/electrode, and coatings on the base metal or electrode.

Welding fumes have known adverse human health effects [2-4]. In 2017, the International Agency for Research on Cancer (IARC) classified welding fumes as a Group 1 (carcinogenic to humans) [1]. This classification was based on sufficient epidemiological evidence for an increased risk of lung cancer in welders even after adjustment for smoking and/or asbestos that potentially confound these studies. Positive associations were found for welding on SS which generate fumes that contains carcinogenic metals [i.e., chromium $(\mathrm{Cr})$, nickel $(\mathrm{Ni})$ ] and MS welding where the fume is primarily oxides of iron $(\mathrm{Fe})$ and manganese (Mn) [5-8]. Animal evidence for the carcinogenicity of welding fumes is limited, however. In a two-stage (initiation-promotion) model of lung carcinogenesis, inhalation and oropharyngeal aspiration of GMAW-SS fume promoted lung tumors in mice. Previous experimental evidence in mice showed that GMAW-SS persists in the lungs and causes a chronic, mild inflammatory response compared to GMAW-MS or manual metal arc (MMA)-SS fumes [9]. It is unknown which metal components of the fume are responsible for its toxic and tumorigenic effects. 
Welding fume currently has no occupational exposure limit as the former Threshold Limit Value ${ }^{\circledR}$ of $5 \mathrm{mg} / \mathrm{m}^{3}$ as an 8-hour time-weighted average was retracted [10]. In the workplace, more emphasis is placed on regulating the exposure to the most toxic metals contained in the fume (i.e., $\mathrm{Cr}$ or Ni). The first aim of this study was to compare the pulmonary toxicity of metal oxides found in GMAW-SS fume. The second aim was to investigate the potential of those metals to promote lung tumors in $\mathrm{A} / \mathrm{J}$ mice to gain an understanding of the metals that drive the carcinogenicity of SS fume. Minimizing the hazardous components of the welding fume could offer a better approach for maintaining welder health and safety as sustained inflammation and oxidative stress along with persistence of toxic components are likely key to lung tumorigenesis.

\section{Methods}

\section{Animals}

Male A/J mice, 4 to 5 weeks of age, were housed in an AAALAC International, specific pathogen-free, environmentally-controlled facility in groups of 2 as previously described [11]. All procedures were performed using protocols approved by the National Institute for Occupational Safety and Health (NIOSH) Institutional Animal Care and Use Committee.

\section{GMAW-SS fume generation and metal oxide characterization}

The welding fume used in this study was generated by the NIOSH robotic welder [12]. The individual metal oxides utilized were $\mathrm{Cr}_{2} \mathrm{O}_{3}$ (product number 393703; $151.99 \mathrm{~g} / \mathrm{mol}$ ), $\mathrm{CaCrO}_{4}$ (product number CDS001277; $156.07 \mathrm{~g} / \mathrm{mol}$ ), NiO (product number 203882; 74.69 $\mathrm{g} / \mathrm{mol}$ ), and $\mathrm{Fe}_{2} \mathrm{O}_{3}$ (product number 310050; $159.69 \mathrm{~g} / \mathrm{mol}$ ) and were purchased from SigmaAldrich (St. Louis, MO). Specific surface area $\left(\mathrm{m}^{2} / \mathrm{g}\right)$ of the powders was determined using nitrogen gas adsorption (ASAP 2020, Micromeritics Instrument Corporation, Norcross, GA). 
$\mathrm{Cr}_{2} \mathrm{O}_{3}$, NiO, GMAW-SS, or $\mathrm{Fe}_{2} \mathrm{O}_{3}$ powder was added to separate sample tubes and degassed under light vacuum at $300{ }^{\circ} \mathrm{C}$ for 2 hours then allowed to cool. $\mathrm{CaCrO}_{4}$ was degassed using the same procedure, but was held at $80{ }^{\circ} \mathrm{C}$ for $6 \mathrm{hrs}$. A value of $1.62 \times 10^{-19} \mathrm{~m}^{2}$ was used for the molecular cross-sectional area of $\mathrm{N}_{2}$ at $77 \mathrm{~K}$ and surface area was calculated from at least five adsorption points in the range $\mathrm{p} / \mathrm{p}^{0}=0.01$ to 0.3 . Measurements were repeated 4 times for each sample except GMAW-SS, which was repeated twice. Hydrodynamic diameter and zeta potential of each study material were determined using dynamic light scattering (DLS) and laser Doppler electrophoresis, respectively (Zetasizer ZS90, Malvern Instruments, Worcestershire, UK) following dispersion in the PBS dosing medium. The $\mathrm{pH}$ of each sample was measured before each run using a SevenMulti calibrated electrode (Mettler-Toledo, LLC, Columbus, OH). All measurements were made at $25^{\circ} \mathrm{C}$. Parameters of the dispersant were as follows: refractive index $=1.334$, viscosity $=0.9110 \mathrm{cP}$, dielectric constant $=80.2$, and Henry function approximation of 1.5. Material-specific refractive index and absorbance values were used for each metal oxide. Certain metal oxides were too polydisperse for size measurement via DLS and were instead analyzed using nanoparticle tracking analysis (NTA) (NanoSight NS300, Malvern Instruments, Worcestershire, UK) to characterize mean hydrodynamic particle size (nm). For NTA analysis, the samples were injected through a Low Volume Flow Cell (LVFC) and measured at room temperature. Camera levels in the NTA instrument varied with each sample to insure accurate particle characterization. Each sample was captured 5 times for 60 seconds.

\section{GMAW-SS fume and metal oxide preparation}

Previous metal analyses of GMAW-SS have shown that the metal content of the fume is $57 \% \mathrm{Fe}, 20.2 \% \mathrm{Cr}, 13.8 \% \mathrm{Mn}, 8.8 \% \mathrm{Ni}$, and $0.2 \% \mathrm{Cu}[12,13]$. These metals are present in the fume as metal oxides which were volatilized from the electrode/rod during welding and then 
reacted with air to form particles. However, the $\mathrm{Cr}$ component of the fume consists of both $\mathrm{Cr}^{3+}$ and $\mathrm{Cr}^{6+}$, with approximately $0.29 \%$ as $\mathrm{Cr}^{6+}[13]$. Therefore, for this study, mice were exposed to a low or high dose of $\mathrm{Ni}$ as $\mathrm{NiO}, \mathrm{Fe}$ as $\mathrm{Fe}_{2} \mathrm{O}_{3}$, and $\mathrm{Cr}$ as a mixture of $\mathrm{Cr}_{2} \mathrm{O}_{3} / \mathrm{CaCrO}_{4}$. Mn and $\mathrm{Cu}$ were not investigated as they are not known to be carcinogenic to humans or cause lung disease. To calculate the doses in this study, the following formula was used:

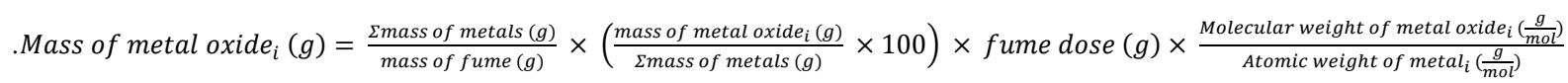

The first value in this equation represents that the metal content is $74 \%$ of the fume mass, with the remaining fume mass contributed by gases including $\mathrm{O}_{2}$. The second value in the equation represents the percentage of each metal (listed above) that contributed to that $74 \%$ of the fume mass. The third value in the equation uses the cumulative low dose $(1.7 \mathrm{mg})$ or high dose (3.4 mg) of GMAW-SS which resulted in lung tumorigenesis in our previous study [13]. Lastly, the fourth value in the equation represents the atomic weight ratio of the metal oxide to metal. For example, mass $(\mathrm{g})$ of $\mathrm{NiO}($ low dose $)=0.74 * 0.088 * 1.7 *(74.7 / 58.7)=141 \mu \mathrm{g}$.

The respective low and high doses of each metal oxide are shown in Figure 1A and scanning electron microscopy images are presented in Figure 1B, C, and D. The fume and each component metal were suspended in USP-grade calcium and magnesium-free phosphate buffered saline (PBS; vehicle) in a sterile conical tube. $\mathrm{Fe}_{2} \mathrm{O}_{3}$ was vortexed then sonicated at 40 amps for 15 seconds using a GE 130PB ultrasonic processor (Cole Parmer). GMAW-SS and NiO were vortexed then sonicated twice at 40 amps for 15 seconds with a 1 minute rest period in between. $\mathrm{Cr}_{2} \mathrm{O}_{3} / \mathrm{CaCrO}_{4}$ was not sonicated.

\section{Mouse oropharyngeal aspiration exposure}

A/J mice were exposed to the metal oxides or the GMAW-SS fume by oropharyngeal aspiration as previously described $[9,14]$. In brief, each mouse was placed in a glass jar with 
gauze containing a histology cassette moistened with isoflurane (Abbott Laboratories, North Chicago, IL). Once slow breathing was observed, the mouse was suspended by its front incisors on a slanted board in a supine position. Forceps were used to extend the tongue and $50 \mu 1$ of metal oxide suspension was placed by pipette at the back of the throat. Shams received an equal volume of vehicle (PBS). The suspension was aspirated into the lungs by normal breathing and the tongue was released after three deep breaths were observed. All solutions were thoroughly vortexed immediately prior to dosing. This technique loses little solution to the gastrointestinal tract when performed properly. The mouse returned to normal activity in its cage within 10 to 20 seconds.

\section{Experimental Protocol 1: biochemical measurements of lung toxicity, histopathology, and gene expression}

In two parallel studies, 256 male A/J mice were organized into 4 blocks of 64 mice and then separated into 8 treatment groups within each block $(n=8 /$ group) consisting of a single low or high bolus dose of $\mathrm{Cr}_{2} \mathrm{O}_{3}+\mathrm{CaCrO}_{4}$ mixture, $\mathrm{NiO}, \mathrm{Fe}_{2} \mathrm{O}_{3}$, GMAW-SS fume (low dose only) or PBS (sham control). Doses are shown in Figure 1A and a timeline of the exposure and the block design are shown in Figure 2. Animals were euthanized at 1, 7, 28, and 84 days postoropharyngeal aspiration exposure. Mice were weighed after an acclimation period, throughout the dosing, and at the 1, 7, 28, and 84 days sacrifices. Mice were anesthetized with Fatal Plus ([100-300 mg/kg IP; $390 \mathrm{mg} / \mathrm{ml}$ pentobarbital sodium] (Henry Schein, Dublin, Ohio) then weighed. Once unresponsive to a toe pinch, the abdomen was the mouse was exsanguinated.

Whole lung bronchoalveolar lavage (BAL) toxicity profile

A blunted cannula was placed in the trachea through a small incision and the thorax was massaged as $0.6 \mathrm{~mL}$ of cold PBS was instilled into the lungs. After 10 seconds, the BAL fluid 
was withdrawn and placed in a $15 \mathrm{~mL}$ conical tube. This consisted of the first lavage fraction.

This process was then repeated 3 times using $1 \mathrm{~mL}$ of PBS per instillate and this second fraction was collected in a separate $15 \mathrm{~mL}$ conical tube. The BAL fluid was kept on ice until all the mice were sacrificed and then the samples were centrifuged $\left(500 \mathrm{x} \mathrm{g}, 10\right.$ minutes, $\left.4^{\circ} \mathrm{C}\right)$.

Bronchoalveolar lavage fluid cytokine analysis

Cytokine concentrations from the first fraction of BAL supernatant at 1 day and 28 days post-exposure were quantified simultaneously by using a Discovery Assay® called the Mouse Cytokine Array / Chemokine Array 32-Plex (Eve Technologies Corp, Calgary, AB, Canada). The multiplex assay was performed at Eve Technologies by using the Bio-Plex ${ }^{\mathrm{TM}} 200$ system (Bio-Rad Laboratories, Inc., Hercules, CA, USA), and a Milliplex Mouse Cytokine / Chemokine kit (Millipore, St. Charles, MO, USA) according to their protocol. The 32-plex consisted of Eotaxin, granulocyte-colony stimulating factor (G-CSF), granulocyte monocyte- colony stimulating factor (GM-CSF), interferon gamma (IFN $\gamma$ ), interleukin-1 $\alpha$ (IL-1 $\alpha)$, IL-1 $\beta$, IL-2, IL3, IL-4, IL-5, IL-6, IL-7, IL-9, IL-10, IL-12 (p40), IL-12 (p70), IL-13, IL-15, IL-17, interferongamma-inducible protein 10 (IP-10), keratinocyte chemoattractant (KC), leukemia inhibitory factor (LIF), C-X-C motif chemokine 5 (CXCL5), monocyte chemotactic protein 1 (MCP-10), macrophage- colony stimulating factor (M-CSF), monokine induced by gamma interferon (MIG), marcrophage inflammatory protein $1 \alpha$ (MIP-1 $\alpha)$, MIP-1 $\beta$, MIP-2, regulated on activation, normal T-cell expressed and secreted (RANTES), tumor necrosis factor $\alpha$ (TNF $\alpha$, and vascular endothelial growth factor (VEGF). Standard curves with a range of 0 to $>25,000$ $\mathrm{pg} / \mathrm{mL}$ were determined for each cytokine. The lowest concentration in the group was used for any value that was out of range. The assay sensitivities of these markers range from $0.1-33.3$ 
$\mathrm{pg} / \mathrm{mL}$. Individual analyte values and other assay details are available on Eve Technologies' website or in the Milliplex protocol.

Lactate dehydrogenase (LDH) activity and BAL cell profile.

The acellular supernatant of the first lavage fraction was used to measure LDH activity, indicative of lung cytotoxicity. LDH activity was analyzed using a COBAS MIRA Plus autoanalyzer (Roche Diagnostic Systems, Montclair, NJ) which measured the oxidation of lactate to pyruvate coupled with the formation of NADH at $340 \mathrm{~nm}$.

For analysis of the BAL cells, the supernatant from the second lavage fraction was discarded and the cell pellets of both fractions were combined. The final cell pellet suspended in $800 \mu \mathrm{L}$ of PBS was used for cell counts and differential staining. Total cell numbers were determined using a hemocytometer. For cell differentials, cells were plated onto glass slides using a Cytospin 3 centrifuge (Shandon Life Sciences International, Cheshire, England) set at 800 rpm for 5 minutes. Slides were stained with Hema 3 Fixative and Solutions (Fisher Scientific, Pittsburgh, Pa) then coverslipped. A minimum of 300 cells/slide consisting of alveolar macrophages, lymphocytes, neutrophils, or eosinophils were identified using light microscopy. Slides from shams typically contained $>99 \%$ alveolar macrophages.

\section{Alveolar macrophage functional assay}

To study the impact of the metal oxides on innate immune function, alveolar macrophages from the suspended cell pellet at 1,7 , and 28 days post-exposure to sham, SS, or the metal oxides were challenged with Escherichia coli (E.coli) GFP for 2 hours at 1:25 MOI (multiplicity of infection). The E.coli uptake by alveolar macrophages was quantified by flow cytometry.

Quantitative real-time polymerase chain reaction (qPCR) and lung histopathology. 
The left lung lobe was ligated and flash frozen and then stored at $-80 \mathrm{C}$ for RNA isolation while the right lung lobes were fixed in $10 \%$ neutral buffered formalin for histopathology. Liver was cut ( $30 \mathrm{mg}$ piece) and flash frozen before storage. RNA was isolated from the lung and liver tissue using RNeasy Mini Kits (Qiagen, Hilden, Germany) and $1 \mu \mathrm{g}$ was reverse transcribed using random hexamers, dNTP mix and SuperScript ${ }^{\mathrm{TM}}$ III Reverse Transcriptase (Invitrogen, ThermoFisher Scientific, Waltham, MA). Diluted cDNA (1:10) was combined with Taqman® Gene Expression Mastermix (ThermoFisher Scientific, Waltham, Ma) and one of the following genes of interest for the lung: nuclear receptor subfamily 1 , group D, member 1 ( $N r l d l$; Mm00520708_m1), nuclear receptor subfamily 1, group D, member 2 (Nrld2; Mm01310356_g1), heme oxygenase 1 (Hmox1; Mm00516005_m1), transferrin receptor(Tfcr; Mm00441941_m1), solute carrier family 40 (iron-regulated transporter), member 1 (Slc40al; Mm01254822_m1), cyclin dependent kinase 4 (CDK4; Hs00364847_m1), cyclin-dependent kinase inhibitor 1A (p21; Mm04205640_g1), and SRY (sex determining region Y)-box 9 (Sox9; Mm00448840_m1). For the liver, the following genes of interest were analyzed: metallothionein 1 (Mt1; Mm00496660_g1), metallothionein 2 (Mt2; Mm00809556_s1), haptoglobin (Hp; Mm00516884_m1), and serum amyloid A1 (Saa1; Mm00656927_g1). Hypoxanthine phosphoribosyltransferase (HPRT) was used as the reference gene (Mm03024075_m1, ThermoFisher Scientific, Waltham, MA). Amplification parameters included 10 minutes at $95^{\circ} \mathrm{C}, 1$ second at $95^{\circ} \mathrm{C}$ and 20 seconds at $60^{\circ} \mathrm{C}$. Relative mRNA levels were calculated using the comparative threshold method (2- $\Delta \Delta \mathrm{Ct})$.

For histopathology studies, the right lung (consisting of apical, cardiac, azygos, and diaphragmatic lobes) was embedded in paraffin then a $5 \mu \mathrm{m}$ standardized section was cut. Slides were stained with hematoxylin and eosin and interpreted by a contracted board certified 
veterinary pathologist in a blinded fashion. Any type or degree of lung injury and inflammation in the airways and alveolar region and evidence of changes in lung structure related to allergy including thickening around airways (epithelium and/or smooth muscle), eosinophil and lymphocyte influx, and development of bronchus-associated lymphoid tissue was evaluated. If abnormal changes were found, severity was scored as follows: $1=$ minimal, $2=$ mild, $3=$ moderate, $4=$ marked .

\section{Experimental Protocol 2: Two-stage (initiation-promotion) lung tumor bioassay}

Male A/J mice (200) were organized into 5 groups ( $n=40$ per group) for a two stage initiation-promotion study. Mice were initiated with 3-methylcholanthrene (MCA) or corn oil (vehicle control) by intraperitoneal (IP) injection. Beginning one week later, mice were exposed once per week to a mixture of $\mathrm{Cr}_{2} \mathrm{O}_{3}+\mathrm{CaCrO}_{4}(146.2 \mu \mathrm{g} / 2.2 \mu \mathrm{g}), \mathrm{NiO}(56.2 \mu \mathrm{g}), \mathrm{Fe}_{2} \mathrm{O}_{3}(400$ $\mu \mathrm{g}$ ), or PBS (sham control) for 5 weeks via oropharyngeal aspiration (Figure 3A). The cumulative dose $\mathrm{Cr}_{2} \mathrm{O}_{3}+\mathrm{CaCrO}_{4}(731 \mu \mathrm{g} / 11 \mu \mathrm{g}), \mathrm{NiO}(281 \mu \mathrm{g}), \mathrm{Fe}_{2} \mathrm{O}_{3}(2 \mathrm{mg})$ was equivalent to the bolus high dose for each metal oxide as described in experimental protocol 1 (Figure 3B). Mice were weighed after a short acclimation period, throughout the dosing, and at sacrifice.

At 30 weeks post-initiation, A/J mice were euthanized as described above. All internal organs were examined for the presence of tumors. The whole lung was then excised. The lungs were inflated and fixed with $10 \%$ neutral buffered formalin for 24 hours. Tumors were counted and measured 24 hours after fixation. Any apparent merged tumors were counted as one. Lungs were embedded in paraffin, and then a 5- $\mu \mathrm{m}$ standardized section was cut. Slides were stained with hematoxylin and eosin and interpreted by a contracted, board-certified veterinary pathologist in a blinded fashion for evidence of hyperplasia and neoplasia, inflammation, lymphoid tissue response, and foreign materials by light microscopy. Diagnostic criteria for 
hyperplastic and neoplastic findings were according to goRENI (http://www.goreni.org/), the standard reference for nomenclature and diagnostic criteria in toxicologic pathology and "INHAND" - the International Harmonization of Nomenclature and Diagnostic criteria [15, 16]. If abnormal changes were found, severity was scored using the following scale: $1=$ minimal, $2=$ mild, $3=$ moderate, $4=$ marked. The final severity score reflects the average of the right and left lung lobe scores and are presented as means \pm standard error. Because bronchiolo-alveolar hyperplasia (BAH) and bronchiolo-alveolar adenomas (BAA) represent a continuum of the proliferative process, and there is possible overlap between these diagnoses, the numbers of lesions were combined to compare the tumorigenic potential of each treatment [16]. However, the gross tumor count at necropsy is more representative of the response because examination of a single histological section per lung underestimates the total number of lesions per lung [17].

\section{Statistical comparisons and analysis}

Statistical analyses were done using JMP version 12 and SAS version 9.4 for Windows (SAS Institute, Cary NC, USA). Factorial analysis of variance (ANOVA) was performed on continuous variables from the BAL fluid and the log fold changes from the PCR analytes to make comparisons between the treatment groups. For some variables, data were log transformed to reduce heterogeneous variance and meet the assumptions of an ANOVA. Histopatholgoical findings using the graded scale were analyzed using nonparametric Kruskal Wallis tests followed by Wilcoxon Rank Sum tests for pairwise comparisons. Gross tumor counts and histopathology counts from sections were analyzed similarly. Tumor incidence (presence or absence of tumors) was analyzed using a Chi-square test in SAS 'Proc Freq,' while tumor multiplicity (number of tumors per lung) was analyzed using Poisson regression in SAS 'Proc Genmod'. In cases where overdispersion existed, a negative binomial regression was performed using data from those 
animals surviving to the 30 -week time point. For all analyses, a $\mathrm{p}$ value of $<0.05$ was set as the criteria for significance.

Results

\section{Metal oxide characterization}

Table 1 summarizes results of the material characterization. Specific surface area (SSA) of the study materials ranged from about 1 to $6 \mathrm{~m}^{2} / \mathrm{g}$, consistent with their smooth micronscale compact particle morphology (Figure 1), whereas the welding fume had SSA that was at least a factor of eight higher. The higher SSA of the welding fume is consistent with its nanoscale cluster particle agglomerates [18]. Among study materials, hydrodynamic diameter ranged from about $150 \mathrm{~nm}$ (chromium-containing particles) to $1000 \mathrm{~nm}$ (GMAW-SS). For a given study material, values of hydrodynamic diameter were similar for both the high and low dose concentration suspensions, indicating that particles did not agglomerate at the higher concentration. Values of zeta potential, which is a measure of colloidal stability, were similar among materials and for a given material did not differ between dosing concentrations.

\section{Lung Cytotoxicity after exposure to GMAW-SS fume or metal oxides}

At 1 day post-exposure, $\mathrm{LDH}$ activity in the BAL was significantly increased in all exposed groups compared to sham except for the low and high dose $\mathrm{NiO}$ groups (Figure 4). At 7 days, lung cytotoxicity remained significantly increased in the GMAW-SS fume ( $\sim 5$ fold $)$, Fe${ }_{2} \mathrm{O}_{3}$ low and high (>2 and 3 fold, respectively), and the $\mathrm{Cr}_{2} \mathrm{O}_{3} / \mathrm{CaCrO}_{4}$ high dose groups. $\mathrm{Cr}_{2} \mathrm{O}_{3} / \mathrm{CaCrO}_{4}$ low and $\mathrm{NiO}$ groups were not significantly different from sham. At 28 days postexposure, only GMAW-SS fume- and $\mathrm{Fe}_{2} \mathrm{O}_{3}$ high-exposed groups had significant lung cytotoxicity. Cytotoxicity had decreased by 84 days, but remained significantly increased in the $\mathrm{Fe}_{2} \mathrm{O}_{3}$ high and GMAW-SS exposed groups. 


\section{BAL cell profile after exposure to GMAW-SS or metal oxides}

Total BAL cells were significantly increased compared to sham in all groups except for low and high dose $\mathrm{NiO}$ at 1 day post-exposure (Figure 5A). The greatest increase in total BAL cells at 1 day, 7 days, and 28 days post exposure was observed in GMAW-SS fume-exposed mice. The $\mathrm{Fe}_{2} \mathrm{O}_{3}$ high group also had significantly increased BAL cells at every time point. The BAL cell increases at 1 day post-exposure were mostly due to neutrophil influx, as few changes in macrophages were observed at this time point (Figure 5B and 5C). However, significant neutrophil and macrophage influx was observed in GMAW-SS-exposed mice at 7 and 28 days post-exposure, but the macrophage influx was greater. Some eosinophil influx was observed in GMAW-SS, Cr low and high dose, and $\mathrm{Fe}_{2} \mathrm{O}_{3}$ high dose exposed mice 1 day post-exposure but this was minor compared to neutrophil and macrophage changes (data not shown). By 28 days post-exposure, no eosinophils were present. At 84 days post-exposure, only GMAW-SS and Fe${ }_{2} \mathrm{O}_{3}$ high groups had slightly increased total BAL cells compared to control mice which were largely due to increased macrophages. Neutrophils were not significantly increased in any treatment group at 84 days post-exposure. No lymphocytes were observed in the BAL fluid in any treatment group at any time point. Macrophages had a decreased ability to phagocytose $E$.

Coli 1 day and 7 days post-exposure to all component metals but returned to control levels by 28 days post-exposure (Figure 6).

\section{BAL cytokine analysis at 1 and 28 days post-exposure}

At 1 day post-exposure increases in G-CSF, GM-CSF, IL-5, IL-6, IP-10, KC, LIF, MIG, MIP-1 $\alpha$, MIP-1 $\beta$, MIP-2, TNF $\alpha$, and VEGF were noted in the exposed groups compared to sham (Table 2A). Most cytokine protein levels were highest in GMAW-SS-exposed groups and closest to sham in the NiO-exposed groups. GM-CSF levels were increased two to three-fold in only 
GMAW-SS and $\mathrm{Fe}_{2} \mathrm{O}_{3}$ exposed animals at 1 day post-exposure but were increased almost sixfold in GMAW-SS at 28 days post-exposure (Table 2B). Most other cytokines were not significantly increased above sham levels at 28 days post-exposure.

\section{Lung and liver gene expression analysis}

Relative lung and liver mRNA levels are shown for selected genes at 1 day post-exposure to GMAW-SS fume, $\mathrm{Fe}_{2} \mathrm{O}_{3}$ low, and $\mathrm{Fe}_{2} \mathrm{O}_{3}$ high in Table 3 and Figure 7 . By 7 days postexposure, most liver and lung genes had returned to control levels in these treatment groups. However, metallothionein $1(M t 1)$ was still increased $\sim 3$ to 4 fold in all three groups, and serum amyloid A1 (SAA-1) was increased $\sim 3$ fold and $\sim 2$ fold in GMAW-SS and $\mathrm{Fe}_{2} \mathrm{O}_{3}$ low dose groups, respectively, at 7 days post-exposure (data not shown).

Fewer changes in lung and liver relative mRNA levels were observed in $\mathrm{NiO}$ or $\mathrm{Cr}_{2} \mathrm{O}_{3} / \mathrm{CaCrO}_{4}$ groups compared to the GMAW-SS and $\mathrm{Fe}_{2} \mathrm{O}_{3}$ exposed groups (data not shown). No changes in relative mRNA levels were seen in $\mathrm{NiO}$ low or high exposed groups in any genes at any time points. At 1 day post-exposure to $\mathrm{Cr}_{2} \mathrm{O}_{3} / \mathrm{CaCrO}_{4}$ low and high dose, levels of liver $M t 1$ and $S A A-1$ were significantly increased above sham $(\sim 5$ and $\sim 12$ fold for low dose and $\sim 8$ and $\sim 17$ fold for high dose $M t 1$ and $S A A-1$ levels, respectively; $p<0.05)$. At 7 days postexposure, MtI and $S A A-1$ levels were still significantly elevated $\sim 2$ and $\sim 3$ fold in the $\mathrm{Cr}_{2} \mathrm{O}_{3} / \mathrm{CaCrO}_{4}$ high dose exposed group, respectively $(p<0.05)$. Among relative lung mRNA levels, only heme oxygenase 1 (HMOXI) levels were significantly elevated in $\mathrm{Cr}_{2} \mathrm{O}_{3} / \mathrm{CaCrO}_{4}$ high dose animals compared to sham $(\sim 2$ fold; $\mathrm{p}<0.05)$.

\section{Effects on body weight and survival post-welding fume or component metal exposure}

Mice for experimental protocol 1 weighed on average $18.33 \pm 0.13 \mathrm{~g}$ at the start of dosing. Mice for experimental protocol 2 weighed on average $18.94 \pm 0.13 \mathrm{~g}$ at the start of 
dosing. All groups gained weight throughout the study and there were no significant differences found among the exposure groups versus sham for either protocol.

\section{Histopathological evaluation of lung toxicity in $\mathbf{A} / \mathbf{J}$ mice}

Abnormal morphological findings and inflammation are presented in Table 1 with images in Figure 8. The response to $\mathrm{NiO}$ exposure was characterized by the presence of black foreign bodies and pigmented macrophages in terminal bronchioles and adjacent alveoli. At 1 and 7 days post-exposure, there was minimal to mild infiltration of neutrophils around terminal bronchioles and/or vessels in some instances. The response to the high dose was not notably different from the low dose, with the exception that black pigment and pigmented macrophages were more often detected 84 days post-exposure.

The response to $\mathrm{Cr}_{2} \mathrm{O}_{3} / \mathrm{CaCrO}_{4}$ exposure was characterized by the presence of black foreign bodies and pigmented macrophages in terminal bronchioles and adjacent alveoli. At 1 and 7 days post-exposure, there was minimal infiltration of neutrophils around terminal bronchioles and/or vessels and neutrophil exudate in bronchiolar and alveolar lumens in many animals, especially in the high dose exposure animals.

Exposure to $\mathrm{Fe}_{2} \mathrm{O}_{3}$ was characterized by the presence of black foreign bodies and pigmented macrophages in terminal bronchioles and adjacent alveoli. At 1 and 7 days, there was minimal or mild infiltration of neutrophils around terminal bronchioles and/or vessels and neutrophil/macrophage exudate in alveolar lumens in many animals, especially in the high dose group. Hyperplasia of bronchiolar epithelium was rarely present. At 84 days, black foreign bodies and pigmented macrophages were consistently present in terminal bronchioles and adjacent alveolar lumens. Also, at 84 days the incidence and severity of lymphoid nodules was slightly increased. 
The response to GMAW-SS fume was greater than any of the metal oxides alone and characterized by the presence of brown foreign bodies and pigmented macrophages in terminal bronchioles and adjacent alveoli. At 1 and 7 days post-exposure there was a prominent neutrophil response often filling both terminal bronchioles and adjacent alveoli. Also, the alveolar walls are often thickened due to mononuclear cell infiltration and hyperplasia of bronchial epithelium was also sometimes present at 1 and 7 days. Amorphic brown foreign bodies were occasionally present in bronchial lumens, particularly at 1 and 7 days post-exposure. At 28 and 84 days post-exposure, the response tended to transition from neutrophilic to mononuclear cell (macrophage and lymphocyte), including formation of lymphocytic nodules around vessels in affected regions. Notable lesions were still present on day 84, including pigment in terminal bronchioles that is surrounded by spindle shaped mononuclear cell that appeared to be walling off a focal accumulation of brown pigment.

\section{Gross tumor multiplicity and incidence}

Among the component metals, only $\mathrm{Fe}_{2} \mathrm{O}_{3}$ significantly promoted lung tumors in the $\mathrm{A} / \mathrm{J}$ mouse after initiation with MCA compared to MCA/sham (15.18 \pm 0.83 and $9.78 \pm 0.80$, respectively; $p$ <.0001). The grossly observed lung tumor multiplicity (average tumor number/mouse lung \pm SE including mice with no tumors) after exposure to MCA or a metal oxide is shown in Figure 9. There was no effect of the other metal oxides or sham on lung tumor multiplicity $\left(\mathrm{MCA} / \mathrm{NiO}, 8.62 \pm 0.69 ; \mathrm{MCA} / \mathrm{Cr}_{2} \mathrm{O}_{3} / \mathrm{CaCrO}_{4}, 10.57 \pm 0.72 ; \mathrm{MCA} / \mathrm{sham}, 9.78 \pm\right.$ 0.80; CO/sham, $0.14 \pm 0.07$ ). As expected, average tumor incidence ( $\%$ of tumor-bearing mice out of the total) was low in animals initiated with $\mathrm{CO}(\mathrm{CO} / \mathrm{sham}, 13.79 \%)$ and at or near $100 \%$ in animals initiated with MCA (MCA/sham, 100\%; $\mathrm{MCA} / \mathrm{Cr}_{2} \mathrm{O}_{3} / \mathrm{CaCrO}_{4}, 97.22 \%$; $\mathrm{MCA} / \mathrm{NiO}$, $100 \% ; \mathrm{MCA} / \mathrm{Fe}_{2} \mathrm{O}_{3}, 100 \%$ ). Gross lung morphology 1 day post-fixation in sham, $\mathrm{Cr}_{2} \mathrm{O}_{3} / \mathrm{CaCrO}_{4}$, 
$\mathrm{NiO}$, and $\mathrm{Fe}_{2} \mathrm{O}_{3}$ exposed mice is presented in Figure 10. $\mathrm{Fe}_{2} \mathrm{O}_{3}$ and $\mathrm{Cr}_{2} \mathrm{O}_{3} / \mathrm{CaCrO}_{4}$ deposition were visible in mouse lungs and appeared red and green in color, respectively. Tumors appeared white in color and opaque on initial gross exam and became well-defined after fixation which aided enumeration. At 30 weeks, tumors were between $\sim 0.5$ and $\sim 3 \mathrm{~mm}$. Average tumor size was $1.00 \mathrm{~mm}, 1.30 \mathrm{~mm}, 1.17 \mathrm{~mm}, 1.18 \mathrm{~mm}$, and $1.11 \mathrm{~mm}$ for CO/Sham, MCA/sham, MCA/NiO, $\mathrm{MCA} / \mathrm{Cr}_{2} \mathrm{O}_{3} / \mathrm{CaCrO}_{4}$, and $\mathrm{MCA} / \mathrm{Fe}_{2} \mathrm{O}_{3}$, respectively. No significant difference in sizes among groups was found.

\section{Histopathological evaluation of lung lesions, inflammation, and presence of metals}

Microscopic findings of the lungs of mice exposed to MCA and one of the metal oxides or sham are presented in Table 2. The most common findings were one or more bronchioloalveolar adenomas, and one or more foci of alveolar epithelial hyperplasia. Adenoma and hyperplasia were observed in the right and/or left lungs in all animals in all treatment groups. No carcinomas were observed. A few of the adenomas in this study were well demarcated and formed solid hypercellular masses and/or hypercellular papillary structures that had replaced the normal alveolar architecture. The adenomas were composed primarily of cells that appeared similar to those of hyperplasias, although some slightly enlarged, somewhat atypical appearing cells with enlarged nuclei were sometimes present. Mitotic figures were rare. Maintenance of the normal alveolar structure versus replacement by an abnormal growth pattern, is the single most important characteristic distinguishing hyperplasia from adenoma. Alveoli within larger hyperplasias generally were collapsed and appeared hypercellular, but close examination of the lesion demonstrated that the normal alveolar structure was still intact and that the lesion was a hyperplasia and not an adenoma. Alveolar epithelial hyperplasia was greatest and most severe in $\mathrm{MCA} / \mathrm{Fe}_{2} \mathrm{O}_{3}$ exposed mice. Foreign material, presumably the metal, was observed in MCA/NiO, 
$\mathrm{MCA} / \mathrm{Fe}_{2} \mathrm{O}_{3}$, and $\mathrm{MCA} / \mathrm{Cr}_{2} \mathrm{O}_{3} / \mathrm{CaCrO}_{4}$ treatment groups. The foreign material appeared as multiple, widely scattered individual or small clusters of minute discrete focal aggregates of black granules. In some cases the granules clearly were present within an alveolar histiocyte. In other cases the granules appeared to be within an alveolar histiocyte but the histiocyte was obscured by the granules. Occasionally, granules were scattered within an alveolus and not within a histiocyte. Mild lymphocytic infiltrate was observed in a few $\mathrm{MCA} / \mathrm{Fe}_{2} \mathrm{O}_{3}$ and $\mathrm{MCA} / \mathrm{Cr}_{2} \mathrm{O}_{3} / \mathrm{CaCrO}_{4}$ exposed animals but was not significantly different than control. Total lung lesions, recorded as the average of hyperplasias and adenomas per mouse lung, were significantly increased in $\mathrm{MCA} / \mathrm{Fe}_{2} \mathrm{O}_{3}$ exposed animals only compared to controls $(6.91 \pm 0.52$ versus $4.33 \pm 0.64$, respectively; $p<0.0001$ ).

\section{Discussion}

The results of this study show that the total GMAW-SS fume is more pneumotoxic than any of the individual component metal oxides. These findings are consistent with other studies which have shown that components of the fume are less toxic than the total fume $[9,19]$. Among the metals present in GMAW-SS fume, $\mathrm{Fe}_{2} \mathrm{O}_{3}$ was the most toxic and the only metal oxide to significantly promote lung tumors at a dose equivalent to the weight percentage found in the fume.

Numerous worker and animal studies have implicated chromium as contributing to lung cancer development, and $\mathrm{Cr}^{6+}$ is classified as carcinogenic to humans (Group 1) by the IARC [20-24]. While $\mathrm{Cr}^{6+}$ has been linked to cancer, research concerning $\mathrm{Cr}^{3+}$ is more conflicting and $\mathrm{Cr}^{3+}$ is not currently classified by the IARC [22]. It has been reported that $\mathrm{Cr}^{3+}$ cannot enter cells as readily as $\mathrm{Cr}^{6+}$ and is therefore less harmful $[3,21]$. However, $\mathrm{Cr}^{6+}$ is reduced to $\mathrm{Cr}^{3+}$ once inside cells and in the process can generate reactive oxygen species which damage DNA [21]. In 
the present study, $\mathrm{Cr}_{2} \mathrm{O}_{3} / \mathrm{CaCrO}_{4}$ exposure did not promote lung tumors in the two-stage mouse model but did cause mild cytotoxicity and inflammation at 1 day and 7 day post-exposure. However, Cr exposure resulted in smaller BAL cytokine, gene expression, and lung histopathology changes compared to Fe and GMAW-SS fume. The mild cytotoxicity and lack of tumorigenic effect may be due to the low doses used in this study. Nettesheim et al. 1971 performed one of the first in vivo $\mathrm{Cr}^{6+}$ exposure studies, exposing $\mathrm{C} 57 \mathrm{BL} / 6$ mice to calcium chromate via inhalation for 5 hours per day, 5 days per week for the lifetime of the animals [25]. They observed a fourfold increase in adenoma incidence in mice chronically exposed to calcium chromate [26]. Although the inhalation dose used in Nettesheim et al. was not reported, the authors performed a subsequent study in hamsters exposed intratracheally to 15 weekly calcium chromate injections of 0.5 or $0.1 \mathrm{mg}$ for a total dose of 7.5 and $1.5 \mathrm{mg}$, respectively, and they also observed increased lung lesions in these animals [26]. Steinhoff et al. performed intratracheal instillation of $\mathrm{Cr}^{6+}$ once per week for up to 30 months in rats and saw no lung tumor incidence at doses of 0.05 or $0.25 \mathrm{mg} / \mathrm{kg} \mathrm{Cr}^{6+}[27]$. Instead, they observed that $17.5 \%$ of rats that received a single $1.25 \mathrm{mg} / \mathrm{kg}$ dose developed tumors in the lung. This suggests that a single, higher dose is more tumorigenic than multiple smaller doses of $\mathrm{Cr}^{6+}$. Similarly, Glaser et al. exposed rats to $\mathrm{Cr}^{6+}$ via inhalation and found zero incidence of lung cancer (adenomas and adenocarcinomas) at 25 and $50 \mu \mathrm{m} / \mathrm{m}^{3}$ while at concentrations of $63 \mu \mathrm{m} / \mathrm{m}^{3}$ and $100 \mu \mathrm{m} / \mathrm{m}^{3}$, rats had $5 \%$ and $15 \%$ incidences of lung cancer, respectively [28]. Therefore, these studies suggest that higher doses of $\mathrm{Cr}^{6+}$ are needed to observe its carcinogenic effects in vivo [25]. In contrast, while the dose of $\mathrm{Cr}^{6+}$ utilized in this study (cumulative $11 \mu \mathrm{g}$ ) reflected the percentage found in the GMAW-SS fume, it may have been too small to cause a tumorigenic effect. Interestingly, 
both Steinhoff et al. and Glaser et al. also concluded that inflammation was essential for tumorigenesis, and in this study $\mathrm{Cr}$ caused only mild inflammation and cytotoxicity.

Like $\mathrm{Cr}^{6+}, \mathrm{Ni}$ is classified as carcinogenic to humans by the IARC, with support from many worker and animal studies [24, 29-32]. In particular, Ni (II) seems to be the most carcinogenic Ni species, damaging DNA directly as well as through reactive oxygen species production, epigenetic effects, and chromosomal aberrations [24, 30, 31, 33-39]. In 2012, the IARC concluded that high cytotoxic concentrations as well as the presence of inflammation may be needed to see some of these potentially carcinogenic effects [24, 34, 37, 40, 41]. In the present study, Ni was not cytotoxic or inflammatory, which may explain its lack of tumor promotion. Few in vivo studies have specifically investigated the tumorigenic potential of $\mathrm{NiO}$, which is the main form of Ni found in welding fumes [24]. Most notably, the National Toxicology Program performed studies which demonstrated that $\mathrm{NiO}$ caused inflammation and tumorigenesis in $\mathrm{F} 344$ rats and $\mathrm{B} 6 \mathrm{C} 3 \mathrm{~F} 1$ mice; however, these were all inhalation studies utilizing higher doses [42]. $\mathrm{NiO}$ concentrations of $1.25,2.5$, or $5 \mathrm{mg} / \mathrm{m}^{3}$ by inhalation for 6 hours/day, 5 day/week for 104 weeks in mice increased the incidence of alveolar and bronchiolar adenomas and/or carcinomas. Additionally, inhalation exposures may be more toxic than oropharyngeal aspiration exposures, as Antonini et al. demonstrated that welding fume, when freshly generated, caused more lung inflammation than aged fume dosed via intratracheal instillation due to higher production of free radicals [43]. Thus, the exposure route and low doses used in this study could partially explain the lack of lung tumor promotion by $\mathrm{NiO}$ that we observed. Nevertheless, the doses used in this study were calculated to represent the actual percentages of these metals in the GMAW-SS fume, and the objective of this study was not to evaluate if $\mathrm{NiO}$ could act as a lung tumor promoter. 
Rather, we sought to determine what metal oxides(s) may be responsible for the carcinogenic properties of SS fume. This study suggests it may not be just $\mathrm{Cr}$ or Ni.

An Interesting finding in this study was that among the metal oxides, $\mathrm{Fe}_{2} \mathrm{O}_{3}$ was the only metal to significantly promote lung tumors in vivo. While it is well known that iron overload can contribute to the development of a variety of cancers, Fe is currently not classified as to its carcinogenicity by the IARC $[44,45]$. This is largely due to the fact that most occupational exposures to $\mathrm{Fe}$ are mixed exposures to $\mathrm{Fe}$ as well as other metals or potential carcinogens, making epidemiologic studies of worker exposures difficult to associate a carcinogenic effect [22]. The results of this study support the epidemiology that mild steel welders, despite exposure to mainly $\mathrm{Mn}$ and $\mathrm{Fe}$, are at increased risk of lung cancer $[7,8,46]$. $\mathrm{Fe}_{2} \mathrm{O}_{3}$ was also the most pneumotoxic of the component metals, as the Fe high dose group still had significant lung cytotoxicity and macrophages at 28 days post-exposure. Similarly, among the component metals, Fe had the greatest effects on increased BAL cytokine levels, liver relative mRNA abundance, and histopathological lung findings.

Interestingly, GMAW-SS fume was more cytotoxic than any of the individual metals. While this study demonstrated that none of the metals besides Fe could individually promote lung tumors, previous studies in our lab have demonstrated that GMAW-SS fume promotes lung tumor in $\mathrm{A} / \mathrm{J}$ mice after both oropharyngeal aspiration and inhalation exposure $[11,13]$. Results from previous studies have also suggested that the total fume may be more cytotoxic than any of its individual components. Earlier studies in our laboratory have shown that SS fume is more pneumotoxic than $\mathrm{Cr}$ after four bolus doses in mice, causing a greater increase in LDH, lymphocyte and neutrophil levels [9]. Antonini et al. observed that the lung toxicity and inflammation of SS fume from manual metal arc welding was due to both the soluble and 
insoluble fraction of the fume, with neither fraction individually having as much toxicity as the total SS fume. They observed that the toxicity of the soluble and insoluble fractions were equal and added together to equal the toxicity of the total fume [19]. The results of these studies along with our findings suggest that the metal oxides may have a synergistic or additive effect when combined in the fume to create a greater toxicity than any individual component can have alone.

Abnormal morphological lung histopathological changes were also found in mice exposed to GMAW-SS fume, including both a mononuclear and neutrophilic infiltration that was not observed with the individual metals. Changes in BAL cytokine levels as well as liver mRNA abundance were also greatest in GMAW-SS fume-exposed groups. Most notably, GMAW-SS fume increased G-CSF and IP-10 protein levels, which promote neutrophil survival and function and act as a chemoattractant for macrophages, respectively. These cytokine changes mirror the neutrophil and macrophage influx that was observed in the BAL at the early time points. The greatest changes in gene expression were observed in liver of GMAW-SS WF exposed mice at 1 day post-exposure, with increased expression of Mt1, Mt2, and SAA-a in Fe and GMAW-SS exposed mice compared to controls, indicating a potential acute phase protein response.

There are a number of limitations to this study. First, the metal oxides which the mice were exposed to are pure oxides and not isolated directly from the fume. The metals in the freshly generated fume are likely more complex and may consist of different chemical compositions of these oxides; therefore, the oxides in the fume may also differ in morphology and reactivity compared to those used in this study. For this reason, we characterized the metal oxides used in this study and noted that each oxide had much smaller SSA and different hydrodynamic diameters than the GMAW-SS. A second limitation to this study was that the exposures were done by oropharyngeal aspiration. Although this is a well-established method, it 
is a bolus dose and less representative of actual worker inhalation exposures. A further limitation of this study is that we only dosed metals individually and did not combine different metals in doses which eliminated the ability to observe any specific potential additive or synergistic effects among two metal oxides.

In summary, the results of this study provide new insight into the toxicity and tumorigenic potential of the metal oxide components of welding fumes. In particular, it was shown that $\mathrm{Fe}_{2} \mathrm{O}_{3}$ is a lung tumor promoter in vivo and may be the main metal oxide responsible for the carcinogenic effect of SS fume. Additional studies can be focused on further investigating these metal components in vivo and in vitro and exploring potential mechanisms of tumorigenesis of welding fumes and their component metal oxides.

\section{Bibliography}

1. Guha N, Loomis D, Guyton KZ, Grosse Y, El Ghissassi F, Bouvard V, Benbrahim-Tallaa L, Vilahur N, Muller K, Straif K: Carcinogenicity of welding, molybdenum trioxide, and indium tin oxide. Lancet Oncol 2017, 18:581-582.

2. Antonini JM: Health effects of welding. Crit Rev Toxicol 2003, 33:61-103.

3. Antonini JM: Health Effects Associated with Welding. 2014:49-70.

4. Zeidler-Erdely PC, Erdely A, Antonini JM: Immunotoxicology of arc welding fume: worker and experimental animal studies. J Immunotoxicol 2012, 9:411-425.

5. Kendzia B, Behrens T, Jockel KH, Siemiatycki J, Kromhout H, Vermeulen R, Peters S, Van Gelder R, Olsson A, Bruske I, et al: Welding and lung cancer in a pooled analysis of case-control studies. Am J Epidemiol 2013, 178:1513-1525. 
6. Matrat M, Guida F, Mattei F, Cenee S, Cyr D, Fevotte J, Sanchez M, Menvielle G, Radoi L, Schmaus A, et al: Welding, a risk factor of lung cancer: the ICARE study. Occup Environ Med 2016, 73:254-261.

7. Hansen KS, Lauritsen JM, Skytthe A: Cancer incidence among mild steel and stainless steel welders and other metal workers. Am J Ind Med 1996, 30:373-382.

8. Lauritsen JM, Hansen KS: Lung cancer mortality in stainless steel and mild steel welders: a nested case-referent study. Am J Ind Med 1996, 30:383-391.

9. Zeidler-Erdely PC, Kashon ML, Battelli LA, Young SH, Erdely A, Roberts JR, Reynolds SH, Antonini JM: Pulmonary inflammation and tumor induction in lung tumor susceptible $\mathrm{A} / \mathrm{J}$ and resistant $\mathrm{C57BL} / 6 \mathrm{~J}$ mice exposed to welding fume. Part Fibre Toxicol 2008, 5:12.

10. 2004 TLVs and BEIs. Cincinnati, Ohio: American Conference of Governmental Industrial Hygienists; 2004.

11. Falcone LM, Erdely A, Meighan TG, Battelli LA, Salmen R, McKinney W, Stone S, Cumpston A, Cumpston J, Andrews RN, et al: Inhalation of gas metal arc-stainless steel welding fume promotes lung tumorigenesis in A/J mice. Arch Toxicol 2017.

12. Antonini JM, Afshari AA, Stone S, Chen B, Schwegler-Berry D, Fletcher WG, Goldsmith WT, Vandestouwe KH, McKinney W, Castranova V, Frazer DG: Design, construction, and characterization of a novel robotic welding fume generator and inhalation exposure system for laboratory animals. J Occup Environ Hyg 2006, 3:194-203; quiz D145. 
13. Zeidler-Erdely PC, Meighan TG, Erdely A, Battelli LA, Kashon ML, Keane M, Antonini JM: Lung tumor promotion by chromium-containing welding particulate matter in a mouse model. Part Fibre Toxicol 2013, 10:45.

14. Rao GV, Tinkle S, Weissman DN, Antonini JM, Kashon ML, Salmen R, Battelli LA, Willard PA, Hoover MD, Hubbs AF: Efficacy of a technique for exposing the mouse lung to particles aspirated from the pharynx. J Toxicol Environ Health A 2003, 66:1441-1452.

15. Keenan CM, Baker J, Bradley A, Goodman DG, Harada T, Herbert R, Kaufmann W, Kellner R, Mahler B, Meseck E, et al: International Harmonization of Nomenclature and Diagnostic Criteria (INHAND): Progress to Date and Future Plans. Toxicol Pathol 2015, 43:730-732.

16. Renne R, Brix A, Harkema J, Herbert R, Kittel B, Lewis D, March T, Nagano K, Pino M, Rittinghausen S, et al: Proliferative and nonproliferative lesions of the rat and mouse respiratory tract. Toxicol Pathol 2009, 37:5s-73s.

17. Rehm S, Ward JM: Quantitative analysis of alveolar type II cell tumors in mice by whole lung serial and step sections. Toxicol Pathol 1989, 17:737-742.

18. Falcone LM, Erdely A, Meighan TG, Battelli LA, Salmen R, McKinney W, Stone S, Cumpston A, Cumpston J, Andrews RN, et al: Inhalation of gas metal arc-stainless steel welding fume promotes lung tumorigenesis in A/J mice. Arch Toxicol 2017, 91:2953-2962.

19. Antonini JM, Taylor MD, Zimmer AT, Roberts JR: Pulmonary responses to welding fumes: role of metal constituents. J Toxicol Environ Health A 2004, 67:233-249. 
20. Barkhordari A, Zare Sakhvidi MJ, Zare Sakhvidi F, Halvani G, Firoozichahak A, Shirali G: Cancer Risk Assessment in Welder's Under Different Exposure Scenarios. Iran J Public Health 2014, 43:666-673.

21. Cohen MD, Kargacin B, Klein CB, Costa M: Mechanisms of chromium carcinogenicity and toxicity. Crit Rev Toxicol 1993, 23:255-281.

22. Wild P, Bourgkard E, Paris C: Lung cancer and exposure to metals: the epidemiological evidence. Methods Mol Biol 2009, 472:139-167.

23. Occupational exposure to hexavalent chromium. Final rule. Fed Regist 2006, 71:10099-10385.

24. Arsenic, metals, fibres, and dusts. IARC Monogr Eval Carcinog Risks Hum 2012, 100:11-465.

25. Proctor DM, Suh M, Campleman SL, Thompson CM: Assessment of the mode of action for hexavalent chromium-induced lung cancer following inhalation exposures. Toxicology 2014, 325:160-179.

26. Nettesheim P, Hanna MG, Jr., Doherty DG, Newell RF, Hellman A: Effect of calcium chromate dust, influenza virus, and $100 \mathrm{R}$ whole-body $\mathrm{x}$ radiation on lung tumor incidence in mice. $J$ Natl Cancer Inst 1971, 47:1129-1144.

27. Steinhoff D, Gad SC, Hatfield GK, Mohr U: Carcinogenicity study with sodium dichromate in rats. Exp Pathol 1986, 30:129-141.

28. Glaser U, Hochrainer D, Kloppel H, Oldiges H: Carcinogenicity of sodium dichromate and chromium (VI/III) oxide aerosols inhaled by male Wistar rats. Toxicology 1986, 42:219-232. 
29. Chromium, nickel and welding. IARC Monogr Eval Carcinog Risks Hum 1990, 49:1648.

30. Costa M: Molecular mechanisms of nickel carcinogenesis. Annu Rev Pharmacol Toxicol 1991, 31:321-337.

31. Kasprzak KS, Sunderman FW, Jr., Salnikow K: Nickel carcinogenesis. Mutat Res 2003, 533:67-97.

32. Shen HM, Zhang QF: Risk assessment of nickel carcinogenicity and occupational lung cancer. Environ Health Perspect 1994, 102 Suppl 1:275-282.

33. Nickel compounds and metallic nickel. Rep Carcinog 2011, 12:280-283.

34. Cai Y, Zhuang Z: [DNA damage in human peripheral blood lymphocyte caused by nickel and cadmium]. Zhonghua Yu Fang Yi Xue Za Zhi 1999, 33:75-77.

35. Chiou YH, Wong RH, Chao MR, Chen CY, Liou SH, Lee H: Nickel accumulation in lung tissues is associated with increased risk of p53 mutation in lung cancer patients. Environ Mol Mutagen 2014, 55:624-632.

36. Dumala N, Mangalampalli B, Chinde S, Kumari SI, Mahoob M, Rahman MF, Grover P: Genotoxicity study of nickel oxide nanoparticles in female Wistar rats after acute oral exposure. Mutagenesis 2017, 32:417-427.

37. M'Bemba-Meka P, Lemieux N, Chakrabarti SK: Nickel compound-induced DNA single-strand breaks in chromosomal and nuclear chromatin in human blood lymphocytes in vitro: role of oxidative stress and intracellular calcium. Mutat Res 2005, 586:124-137.

38. Tessier DM, Pascal LE: Activation of MAP kinases by hexavalent chromium, manganese and nickel in human lung epithelial cells. Toxicol Lett 2006, 167:114-121. 
39. Zhao J, Shi X, Castranova V, Ding M: Occupational toxicology of nickel and nickel compounds. J Environ Pathol Toxicol Oncol 2009, 28:177-208.

40. Pool-Zobel BL, Lotzmann N, Knoll M, Kuchenmeister F, Lambertz R, Leucht U, Schroder HG, Schmezer P: Detection of genotoxic effects in human gastric and nasal mucosa cells isolated from biopsy samples. Environ Mol Mutagen 1994, 24:23-45.

41. Dally $\mathrm{H}$, Hartwig A: Induction and repair inhibition of oxidative DNA damage by nickel(II) and cadmium(II) in mammalian cells. Carcinogenesis 1997, 18:1021-1026.

42. NTP Toxicology and Carcinogenesis Studies of Nickel Oxide (CAS No. 1313-99-1) in F344 Rats and B6C3F1 Mice (Inhalation Studies). Natl Toxicol Program Tech Rep Ser 1996, 451:1-381.

43. Antonini JM, Clarke RW, Krishna Murthy GG, Sreekanthan P, Jenkins N, Eagar TW, Brain JD: Freshly generated stainless steel welding fume induces greater lung inflammation in rats as compared to aged fume. Toxicol Lett 1998, 98:77-86.

44. Manz DH, Blanchette NL, Paul BT, Torti FM, Torti SV: Iron and cancer: recent insights. Ann N Y Acad Sci 2016, 1368:149-161.

45. Toyokuni S: Iron overload as a major targetable pathogenesis of asbestos-induced mesothelial carcinogenesis. Redox Rep 2014, 19:1-7.

46. Siew SS, Kauppinen T, Kyyronen P, Heikkila P, Pukkala E: Exposure to iron and welding fumes and the risk of lung cancer. Scand J Work Environ Health 2008, 34:444-450. 
Figure legends

Figure 1A, B, C, D. Panel A - Low and high doses of the metal oxides or GMAW-SS fume. Panel B- Scanning electron microscopy images of $\mathrm{NiO}$ (panel B), $\mathrm{Fe}_{2} \mathrm{O}_{3}$ (panel C), and $\mathrm{Cr}_{2} \mathrm{O}_{3}$ $/ \mathrm{CaCrO}_{4}$ (panel D).

Figure 2. Experimental timeline and block design for Experimental protocol 1: BAL and histopathology/gene expression studies. The experimental timeline shows 4 time points for sacrifice post-exposure. Two groups of 256 mice were used for parallel BAL and histopathology/gene expression studies. Each group of 256 mice was separated into 4 blocks with 8 treatment groups corresponding to the low or high doses of metal oxides, sham or GMAW-SS fume ( 8 groups $* 8$ mice/group $* 4$ blocks $=256$ mice $)$.

Figure 3. Experimental protocol 2: Two-stage initiation-promotion lung tumor bioassay. 200 male A/J mice were organized into 5 groups: $\mathrm{MCA} / \mathrm{NiO}, \mathrm{MCA} / \mathrm{Cr}_{2} \mathrm{O}_{3}+\mathrm{CaCrO}_{4}$, MCA/ $\mathrm{Fe}_{2} \mathrm{O}_{3}, \mathrm{MCA} /$ sham, or $\mathrm{CO} /$ sham. Beginning one week post-initiation with MCA or CO, mice were exposed to the metal oxide or sham by oropharyngeal aspiration once per week for 5 weeks (panel a). Doses of metal oxides were the cumulative high doses from experimental protocol 1 (panel b).

Figure 4. LDH activity after exposure to GMAW-SS fume or metal oxides. Data are presented as percent control compared to sham (dashed line). ${ }^{*} p<0.0001$ compared to control, ${ }^{* *} p<0.0001$ compared to control and all other low dose groups, $\# p<0.0001$ compared to low and high dose metals within a group. 
Figure 5. Total BAL cells (panel a), neutrophils (panel b), and macrophages (panel c) after exposure to GMAW-SS fume or metal oxides. ${ }^{*} p<0.0001$ compared to control, ${ }^{*} * p<0.0001$ compared to sham and all other low dose groups, $\# p<0.0001$ compared to low and high dose metals within a group.

Figure 6. Ability of macrophages to phagocytose $E$. Coli green fluorescent protein after exposure to metal oxides. E. Coli uptake by macrophages was quantified by flow cytometry. $*_{p}<0.05$ - compared to sham

Figure 7. Relative mRNA levels at 1 day post-exposure to GMAW-SS, $\mathrm{Fe}_{2} \mathrm{O}_{3}$ low, or $\mathrm{Fe}_{2} \mathrm{O}_{3}$ high in the lung (panel A) or liver (panel B). Data presented as fold change respective to relative sham $* * p<0.001$ compared to sham, ${ }^{*} p<0.05$ compared to sham.

Figure 8. Lung histopathological findings following exposure to GMAW-SS or metal oxides. Exudate and brown material (arrow) in the bronchial lumen of a mouse exposed to GMAW-SS fume and sacrificed 1 day post-exposure (panel A; 10x magnification). Mononuclear cell infiltrate of alveolar wall in a mouse exposed to GMAW-SS fume (panel B; 20x magnification) or low dose $\mathrm{Fe}_{2} \mathrm{O}_{3}$ (panel C; 40x magnification) and sacrificed 7 days postexposure. A bronchiolo-alveolar adenoma in an $\mathrm{Fe}_{2} \mathrm{O}_{3}$ - exposed mouse 30 weeks post-initiation with MCA at 10x magnification (panel D) and 20x magnification(panel E).

Figure 9. Total tumor number per mouse lung following exposure to $\mathrm{CO}$ or MCA and a metal oxide or sham. Bars represent lung tumor multiplicity (average tumor number per mouse lung) for each group. ${ }^{*} \mathrm{p}<0.0001$ compared to $\mathrm{CO} / \mathrm{Sham},{ }^{*} \mathrm{p}<0.0001$ compared to MCA/sham 
Figure 10. Grossly observed lung tumors pre-fixation (left) and $24 \mathrm{~h}$ post-fixation (right) following exposure to $\mathrm{Cr}_{2} \mathrm{O}_{3} / \mathrm{CaCrO}_{4}$ (panel $\mathrm{A}$ ), $\mathrm{Fe}_{2} \mathrm{O}_{3}$ (panel B), and $\mathrm{NiO}$ (panel $\mathrm{C}$ ). Tumors (arrows) were on average $\sim 1 \mathrm{~mm}$ and opaque in color. 
Figures

Figure 1.

\begin{tabular}{|c|c|c|}
\hline Axposure & Low Dose & High Dose \\
\hline $\mathrm{NiO}$ & $141 \mu \mathrm{g}$ & $281 \mu \mathrm{g}$ \\
\hline $\mathrm{Cr}_{2} \mathrm{O}_{3} / \mathrm{CaCrO}_{4}$ & $366 \mu \mathrm{g} / 5 \mu \mathrm{g}$ & $731 \mu \mathrm{g} / 11 \mu \mathrm{g}$ \\
\hline $\mathrm{Fe}_{2} \mathrm{O}_{3}$ & $1 \mathrm{mg}$ & $2 \mathrm{mg}$ \\
\hline GMAW-SS & $1.7 \mathrm{mg}$ & - \\
\hline
\end{tabular}
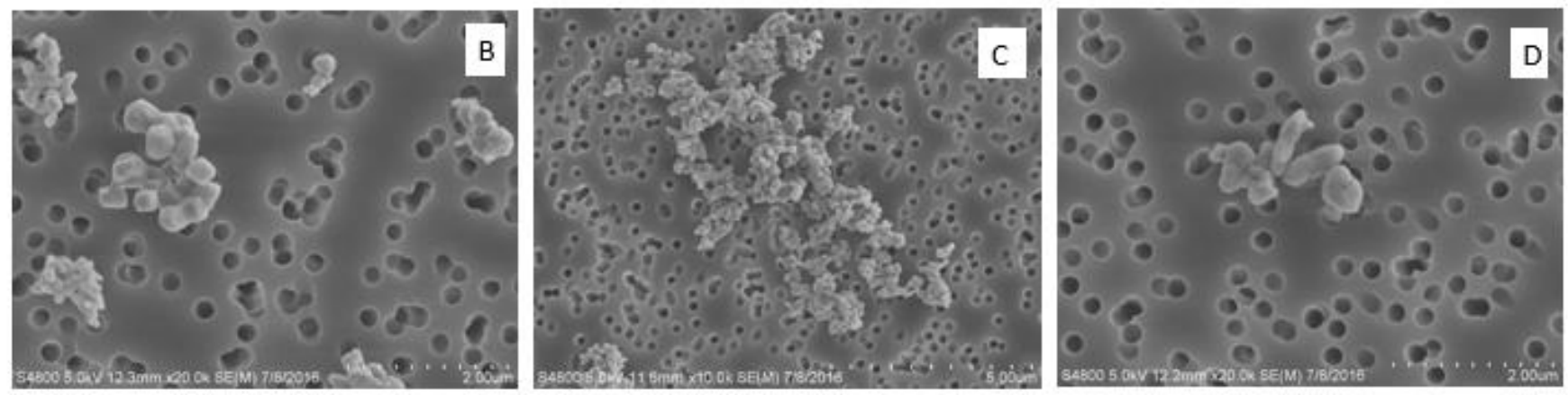
Figure 2.

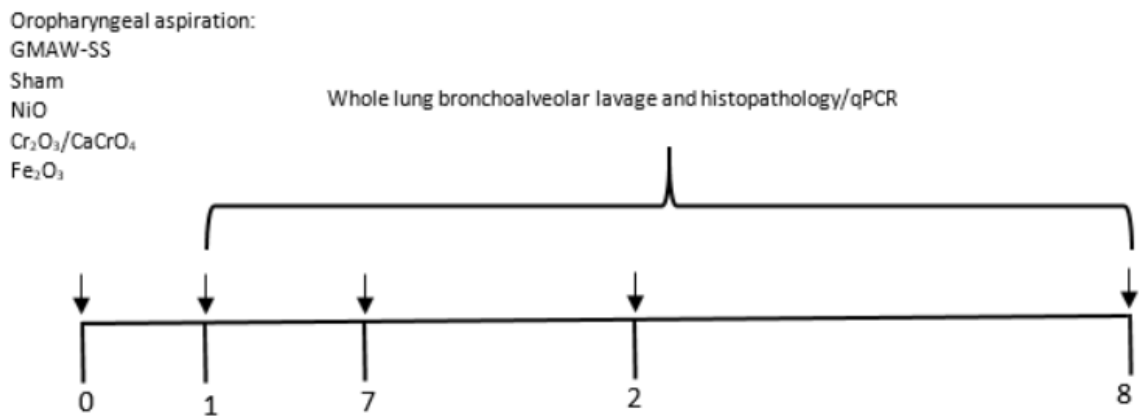

\begin{tabular}{|c|c|c|c|c|c|c|c|c|c|}
\hline Block & PBS & $\begin{array}{c}\mathrm{NiO} \\
\text { low dose }\end{array}$ & $\begin{array}{c}\mathrm{NiO} \\
\text { high dose }\end{array}$ & $\begin{array}{c}\mathrm{Cr}_{2} \mathrm{O}_{3} / \mathrm{CaCrO}_{4} \\
\text { Low dose }\end{array}$ & $\begin{array}{c}\mathrm{Cr}_{2} \mathrm{O}_{3} / \mathrm{CaCrO}_{4} \\
\text { High dose }\end{array}$ & $\begin{array}{c}\mathrm{Fe}_{2} \mathrm{O}_{3} \\
\text { Low dose }\end{array}$ & $\begin{array}{c}\mathrm{Fe}_{2} \mathrm{O}_{3} \\
\text { High dose }\end{array}$ & $\begin{array}{c}\text { GMAW-SS } \\
\text { Low dose }\end{array}$ & Total n \\
\hline $\mathbf{1}$ & 8 & 8 & 8 & 8 & 8 & 8 & 8 & 8 \\
\hline $\mathbf{2}$ & 8 & 8 & 8 & 8 & 8 & 8 & 8 & 8 & 64 \\
\hline $\mathbf{3}$ & 8 & 8 & 8 & 8 & 8 & 8 & 8 & 8 & 64 \\
\hline $\mathbf{4}$ & 8 & 8 & 8 & 8 & 8 & 8 & 8 & 8 & 64 \\
\hline Total n & 32 & 32 & 32 & 32 & 32 & 32 & 32 & 32 & 256 \\
\hline
\end{tabular}


Figure 3.

A.

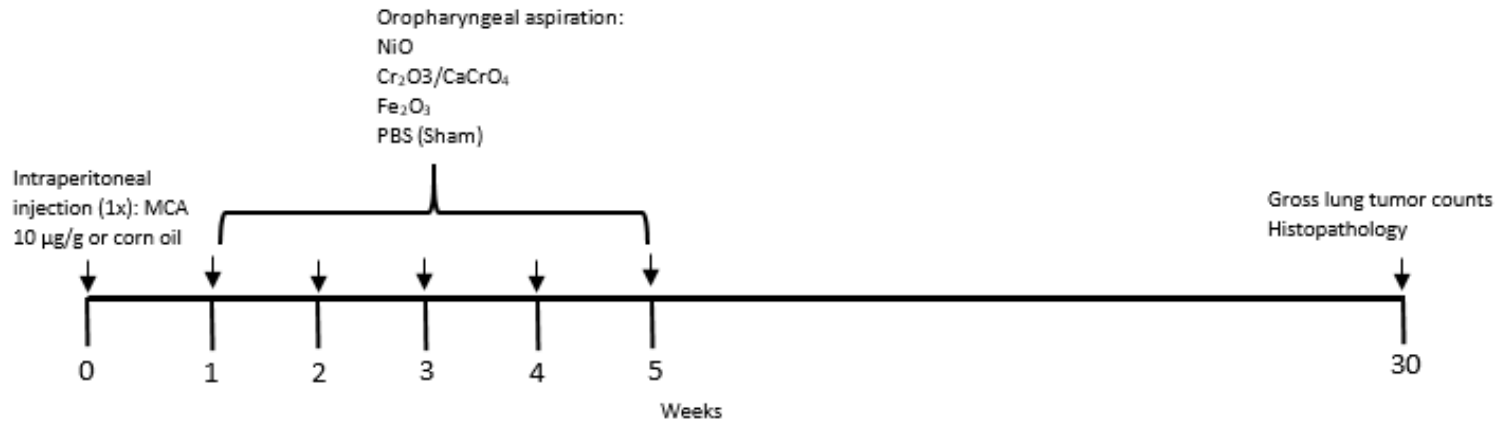

B.

\begin{tabular}{|c|c|c|}
\hline Exposure & Weekly Dose & Cumulative Dose \\
\hline NiO & $56.2 \mu \mathrm{g}$ & $281 \mu \mathrm{g}$ \\
\hline $\mathrm{Cr}_{2} \mathrm{O}_{3} / \mathrm{CaCrO}_{4}$ & $146.2 \mu \mathrm{g} / 2.2 \mu \mathrm{g}$ & $731 \mu \mathrm{g} / 11 \mu \mathrm{g}$ \\
\hline $\mathrm{Fe}_{2} \mathrm{O}_{3}$ & $400 \mu \mathrm{g}$ & $2 \mathrm{mg}$ \\
\hline
\end{tabular}


Figure 4.

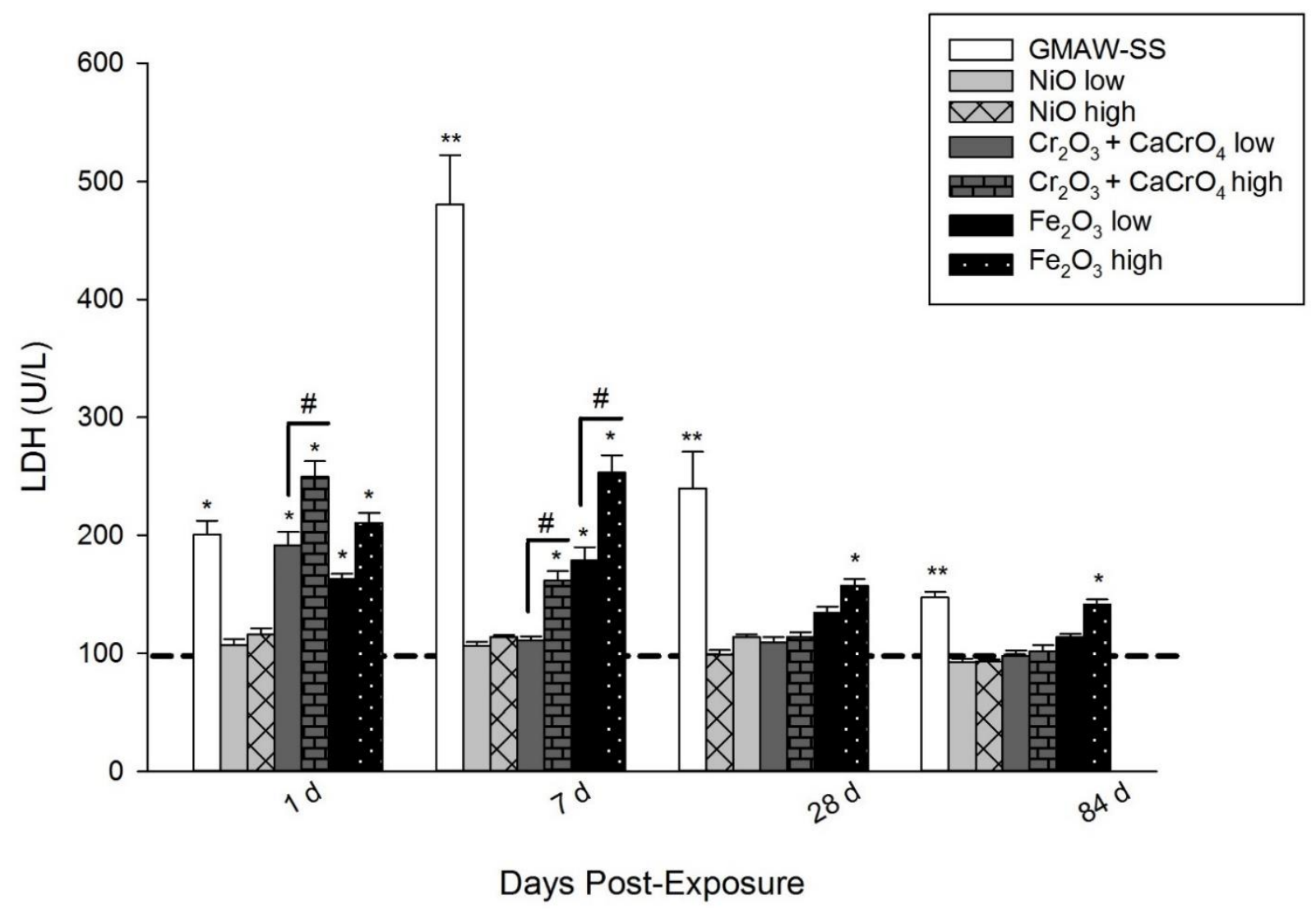


Figure 5.

A

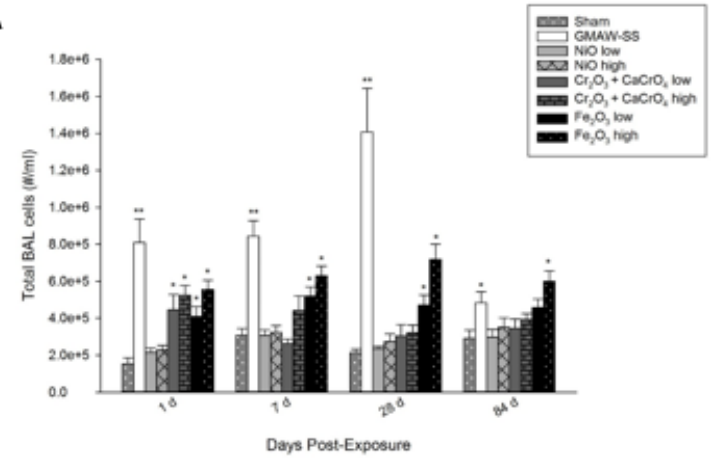

B

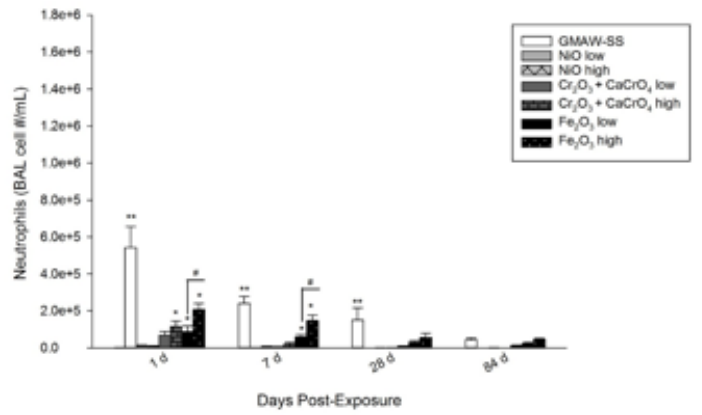

C

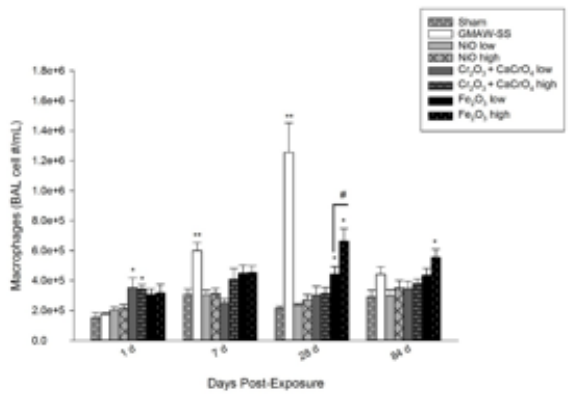


Figure 6.

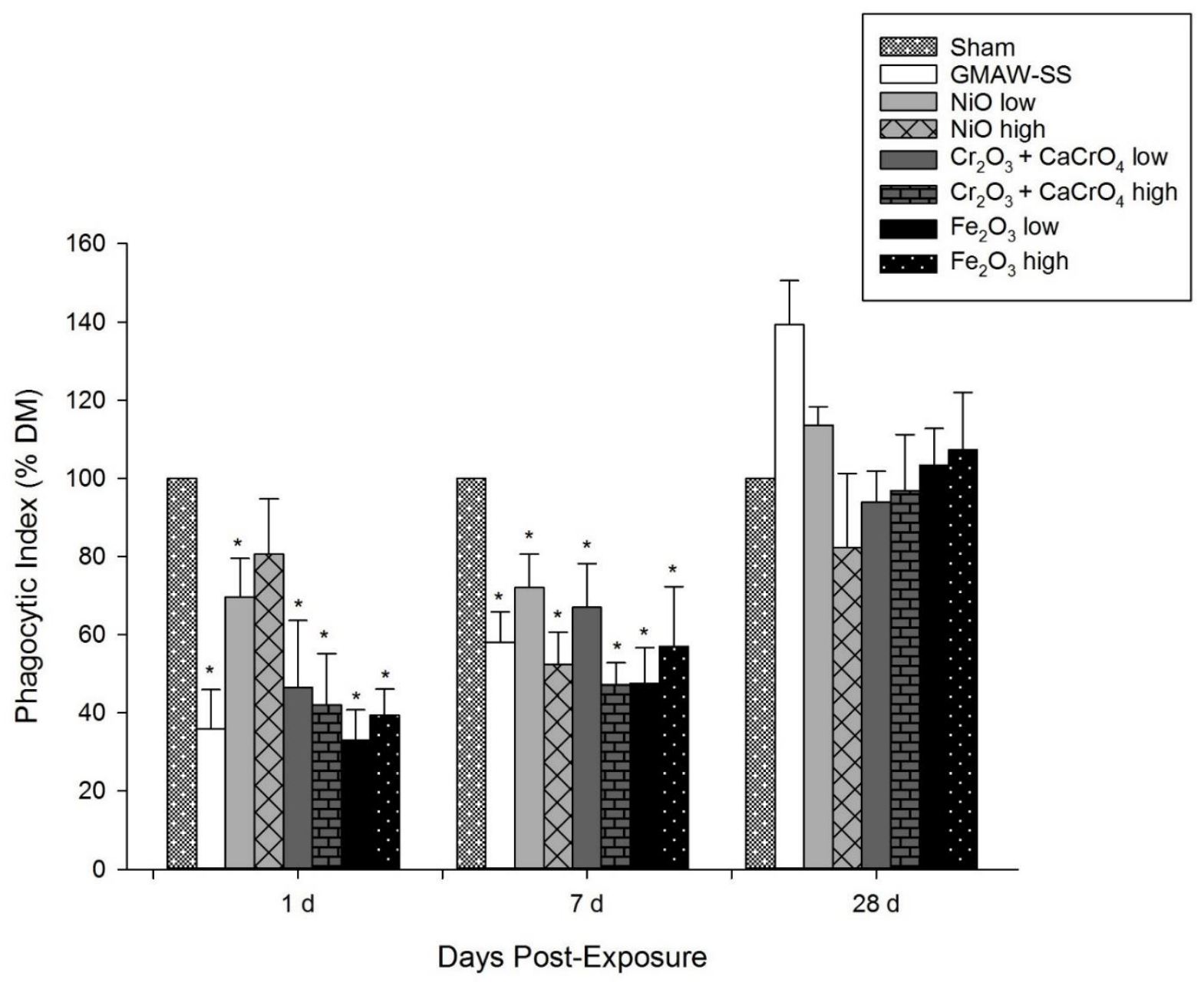


Figure 7.
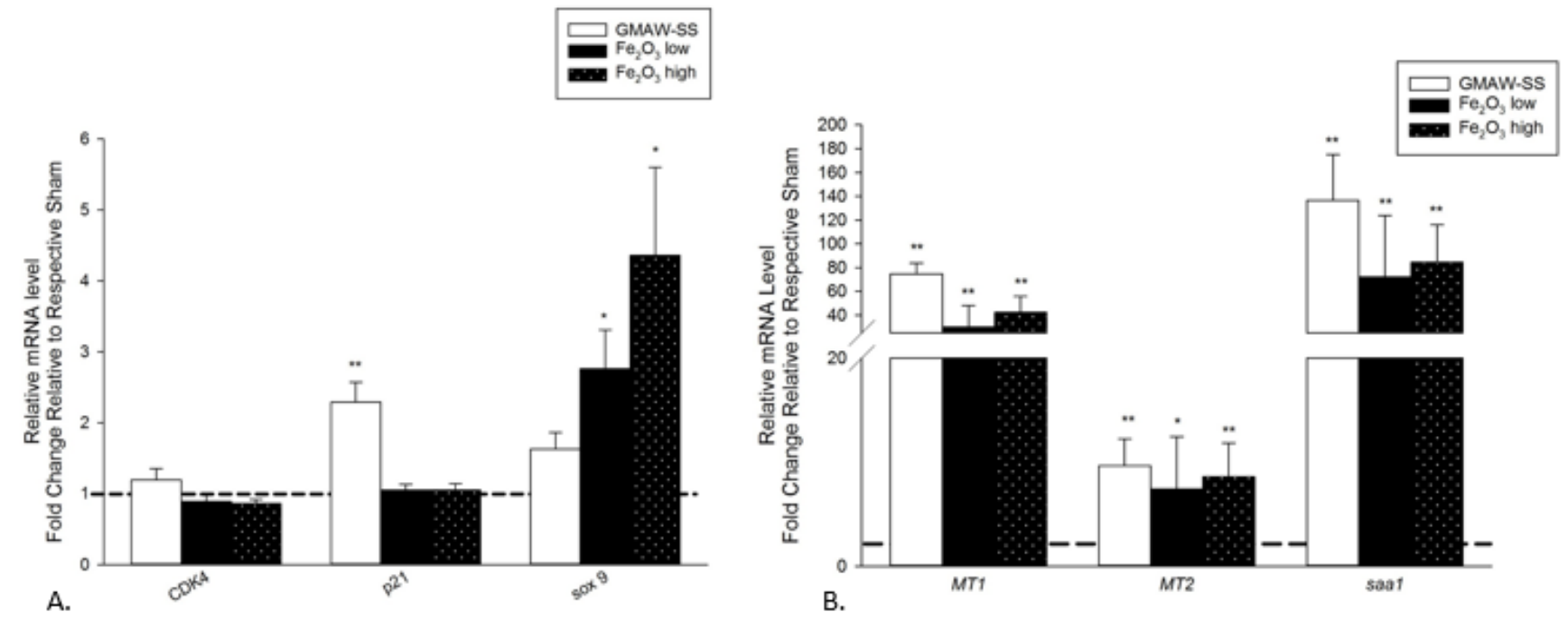
Figure 8.

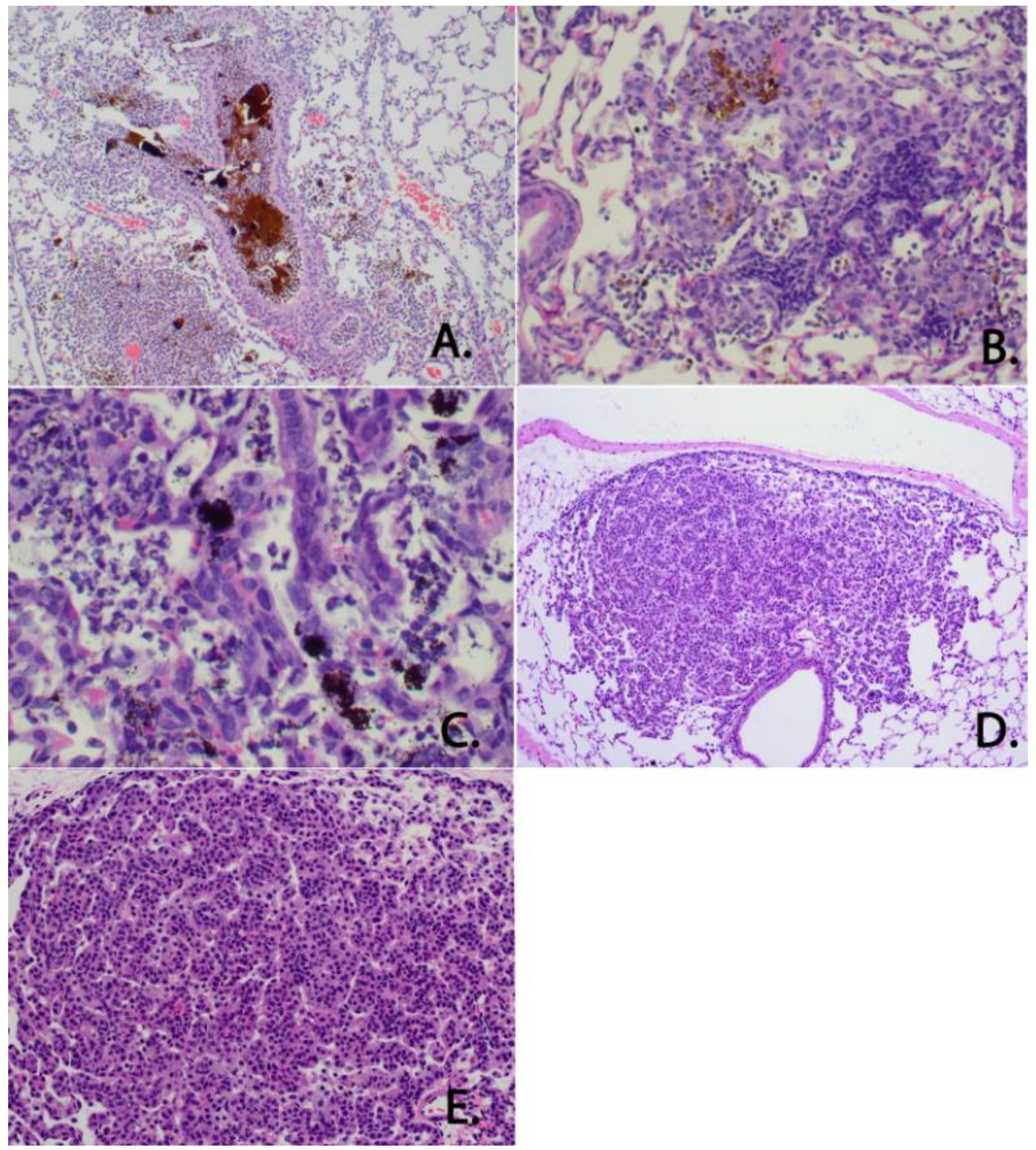


Figure 9.

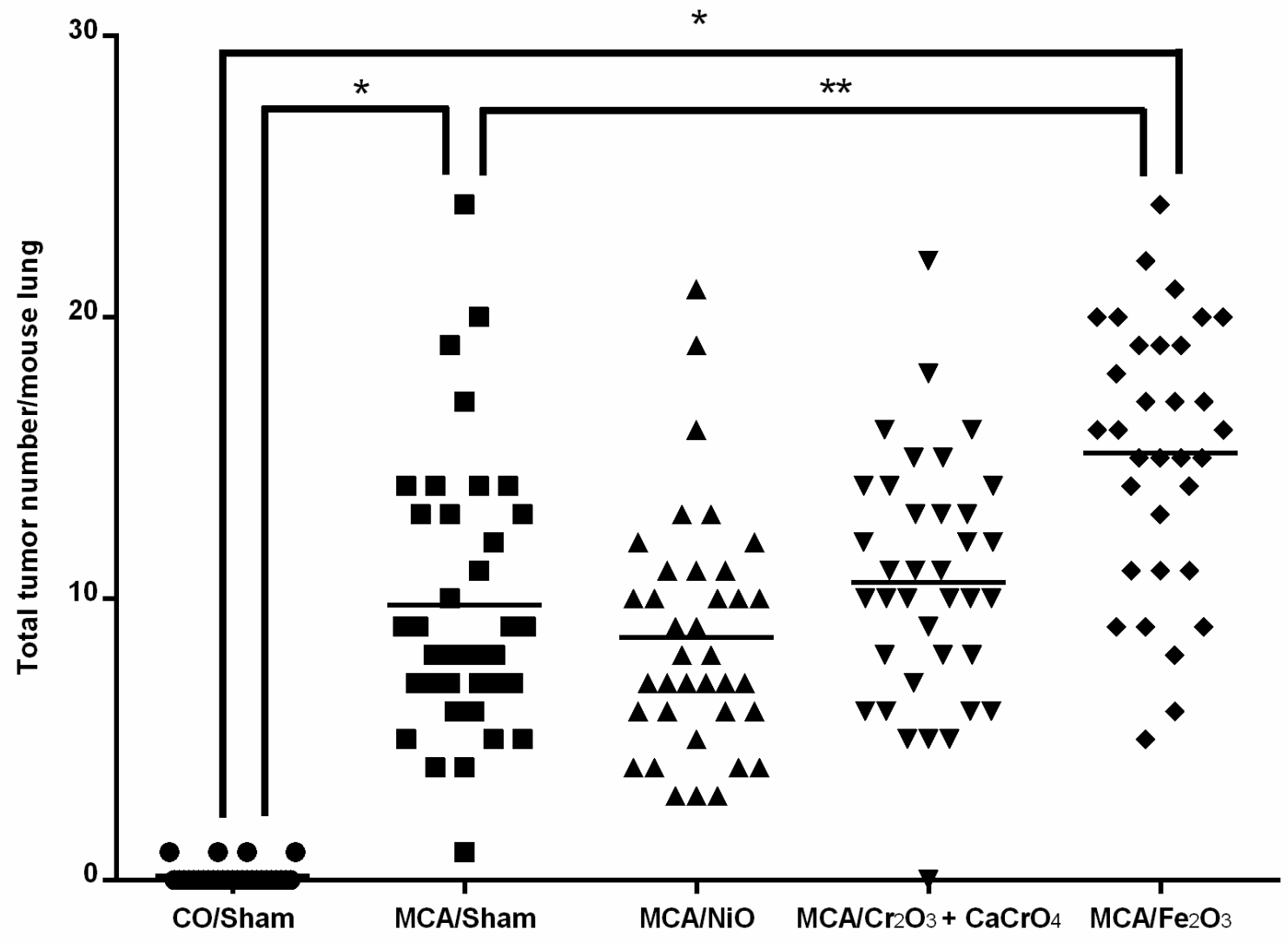


Figure 10.

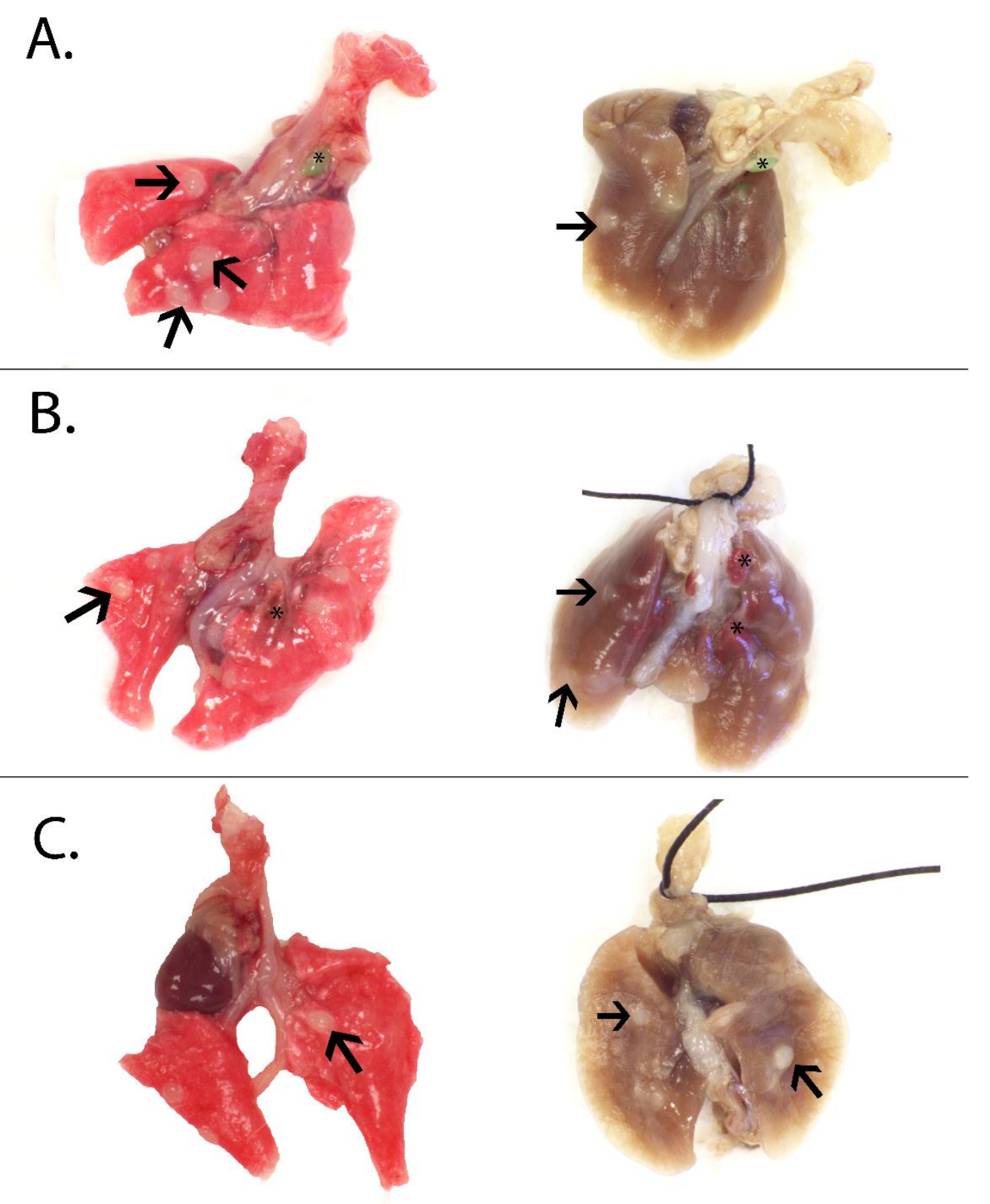


Tables

Table 1

\begin{tabular}{|c|c|c|c|c|}
\hline Sample & Dose & SSA $\left(\mathrm{m}^{2} / \mathrm{g}\right)$ & $\begin{array}{c}\text { Hydrodynamic } \\
\text { Diameter }(\mathrm{nm})\end{array}$ & $\begin{array}{c}\text { Zeta Potential } \\
(\mathrm{mV})^{* *}\end{array}$ \\
\hline \multirow{2}{*}{$\mathrm{Cr}_{2} \mathrm{O}_{3} / \mathrm{CaCrO}_{4}$} & High & \multirow{2}{*}{$2.7 \pm 0.01 / 0.78 \pm 0.01$} & $147 \pm 0.3^{*}$ & $-28.7 \pm 2.1$ \\
\cline { 2 - 4 } & Low & $142 \pm 2.0^{*}$ & $-28.4 \pm 2.3$ \\
\hline \multirow{2}{*}{$\mathrm{Fe}_{2} \mathrm{O}_{3}$} & High & \multirow{2}{*}{$6.0 \pm 0.01$} & $699 \pm 200$ & $-31.4 \pm 0.9$ \\
\cline { 4 - 5 } & Low & & $639 \pm 32$ & $-32.0 \pm 0.8$ \\
\hline \multirow{2}{*}{$\mathrm{NiO}$} & High & \multirow{2}{*}{$2.0 \pm 0.01$} & $124 \pm 0.6^{*}$ & $-25.8 \pm 2.0$ \\
\cline { 2 - 4 } & Low & & $126 \pm 1.1$ & $-28.1 \pm 1.7$ \\
\hline GMAW-SS & -- & $53.1 \pm 0.26$ & $1068 \pm 197$ & $-27.1 \pm 0.8$ \\
\hline
\end{tabular}

Table 1.

*Value determined using NTA, all other values determined using DLS

** pH of study materials: $\mathrm{Cr}_{2} \mathrm{O}_{3} / \mathrm{CaCrO}_{4}$ high (7.2), low (7.3); $\mathrm{Fe}_{2} \mathrm{O}$ high (7.4), low (7.4); $\mathrm{NiO}$ high (7.4), low (7.4); GMAW-SS (6.9) 
Table 2

A.

\begin{tabular}{|c|c|c|c|c|c|c|c|c|c|c|c|c|c|}
\hline & G-CSF & -CSF & IL-5 & IL-6 & IP-10 & $\mathrm{KC}$ & LIF & MIG & MIP-1a & MIP-1B & MIP-2 & TNFa & VEGF \\
\hline PBS & 1 & 1 & 1 & 1 & 1 & 1 & 1 & 1 & 1 & 1 & 1 & 1 & 1 \\
\hline NI low & 7.08 & 1.05 & 2.71 & 2.52 & 1.42 & 2.08 & 1.74 & 2.44 & 3.28 & 7.53 & 1.32 & 4.1 & 1.56 \\
\hline Ni high & 12.35 & 1.25 & 3.58 & 6.24 & 1.75 & 2.26 & 6.38 & 3.1 & 3.59 & 7.64 & 1.2 & 3.14 & 1.66 \\
\hline Cr low & 64.05 & 1.5 & 5.7 & 24.99 & 10.08 & 7.36 & 25.63 & 22.17 & 16.36 & 48.1 & 1.18 & 9.13 & 4.88 \\
\hline Cr high & 128.74 & 1.92 & 15.75 & 74.61 & 10.09 & 16.54 & 130.58 & 16.26 & 24.01 & 85.9 & 1.36 & 10.44 & 8.06 \\
\hline GMA-SS & 854.8 & 2.84 & 18.56 & 1152.63 & 93.39 & 35.28 & 903.43 & 25.72 & 10.3 & 67.77 & 5.51 & 70.11 & 21.06 \\
\hline Fe low & 303.29 & 2.22 & 12.1 & 261.51 & 85.35 & 13.51 & 345.98 & 63.91 & 19.39 & 221.71 & 5.73 & 132.77 & 9.76 \\
\hline Fe high & 507.46 & 3.45 & 23.32 & 253.73 & 11.58 & 8.64 & 1002.59 & 16.64 & 8.97 & 41.97 & 1.61 & 15.93 & 9.9 \\
\hline
\end{tabular}

B.

\begin{tabular}{c|rrr|r|r|r|r|r|r|r|r|} 
& G-CSF & GM-CSF & IL-6 & IP-10 & KC & MIP-1a & MIP-1B & MIP-2 & TNFa & VEGF \\
\hline PBS & 1 & 1 & 1 & 1 & 1 & 1 & 1 & 1 & 1 & 1 \\
\hline NI low & 1.2 & 6.9 & 0.98 & 1.16 & 0.99 & 1.23 & 1.03 & 0.93 & 0.92 & 0.97 \\
\hline Ni high & 0.89 & 1.13 & 1.9 & 4.67 & 1.98 & 3.43 & 1.4 & 0.78 & 0.68 & 0.82 \\
\hline Cr low & 1.09 & 6.27 & 0.66 & 0.82 & 0.96 & 3.4 & 1.23 & 0.96 & 0.97 & 1.01 \\
\hline Cr high & 1.14 & 3.58 & 0.95 & 1.18 & 1.46 & 6.44 & 2.91 & 0.73 & 0.9 & 1.03 \\
\hline GMA-SS & 8.58 & 5.68 & 11.13 & 48.44 & 11.68 & 15.38 & 7.27 & 2.42 & 2.94 & 1.84 \\
\hline Fe low & 1.15 & 0.81 & 0.84 & 5.62 & 2 & 4.75 & 2.3 & 0.77 & 0.61 & 1.12 \\
\hline Fe high & 1.12 & 2.06 & 3 & 9.03 & 3.57 & 6.99 & 4.04 & 1.27 & 1.18 & 1.61
\end{tabular}

Table 2. BAL cytokine analysis at $1 \mathrm{~d}$ (panel a) and $28 \mathrm{~d}$ (panel b) post-exposure to component metals or sham. 
Table 3

\begin{tabular}{|c|c|c|c|c|}
\hline & & GMAW-SS & $\mathrm{Fe}_{2} \mathrm{O}_{3}$ low & $\mathrm{Fe}_{2} \mathrm{O}_{3}$ high \\
\hline \multirow{5}{*}{ Liver genes } & $H A M P$ & $1.58 \pm 0.25$ & $1.3 \pm 0.30$ & $1.23 \pm 0.24$ \\
\hline & $M T 1$ & $74.64 \pm 9.02 *$ & $29.89 \pm 18.16^{*}$ & $42.26 \pm 13.46^{*}$ \\
\hline & $M T 2$ & $9.65 \pm 2.58^{*}$ & $7.41 \pm 5.03^{* *}$ & $8.59 \pm 3.23^{*}$ \\
\hline & $H P$ & $3.93 \pm 0.64 *$ & $3.24 \pm 1.48^{*}$ & $2.31 \pm 0.48^{*}$ \\
\hline & $S A A-1$ & $136.57 \pm 38.32 *$ & $72.02 \pm 51.83^{*}$ & $84.34 \pm 31.52 *$ \\
\hline \multirow{8}{*}{ Lung genes } & $p 21$ & $2.29 \pm 0.28 *$ & $1.05 \pm 0.08$ & $1.05 \pm 0.08$ \\
\hline & $C D K 4$ & $1.19 \pm 0.16$ & $0.89 \pm 0.09$ & $0.86 \pm 0.06$ \\
\hline & Nrldl & $1 \pm 0.17$ & $1.37 \pm 0.19$ & $1.07 \pm 0.28$ \\
\hline & $\operatorname{Nrld} 2$ & $1.34 \pm 0.21$ & $1.95 \pm 0.31^{* *}$ & $1.67 \pm 0.47$ \\
\hline & Hmox 1 & $2.69 \pm 0.23 *$ & $1.54 \pm 0.15^{* *}$ & $1.92 \pm 0.37^{* *}$ \\
\hline & Tfrc & $1.37 \pm 0.15$ & $1.13 \pm 0.10$ & $1.37 \pm 0.28$ \\
\hline & Slc40a1 & $1.32 \pm 0.12^{* *}$ & $1.05 \pm 0.06$ & $1.15 \pm 0.13$ \\
\hline & Sox 9 & $1.63 \pm 0.23$ & $2.76 \pm 0.55^{* *}$ & $4.36 \pm 1.24 * *$ \\
\hline
\end{tabular}

Table 3. Relative mRNA levels as mean fold change compared to sham (mean fold change of 1) in the lungs and liver at 1 day post-exposure to GMAW-SS or $\mathrm{Fe}_{2} \mathrm{O}_{3}$ low or high dose. No changes were seen for $\mathrm{NiO}$ treated animals for any gene at any time point. GMAW-SS - gas metal arc welding - stainless steel, HAMP - hepcidin , Mt1 - metallothionein 1, Mt2 metallothionein 2, HP - haptoglobin, SAA1 - serum amyloid A1, p21 - cyclin-dependent kinase inhibitor 1, CDK4 - cyclin-dependent kinase 4, NR1D1 - nuclear receptor subfamily 1 group D member 1, NR1D2 - nuclear receptor subfamily 1 group D member 2, HMOX1 - heme oxygenase 1 , TFRC - transferrin receptor, SLC40A1 - solute carrier family 40 member 1 , SOX 9 - SRY - box 9

$* p<0.0001, * * p<0.05$ 
Table 4

\begin{tabular}{|c|c|c|c|c|c|c|c|c|}
\hline & $\mathrm{n}$ & $\begin{array}{l}\text { Infiltration, } \\
\text { mononuclear }\end{array}$ & $\begin{array}{l}\text { Infiltration, } \\
\text { neutrophils }\end{array}$ & $\begin{array}{c}\text { Pigmented } \\
\text { macrophages }\end{array}$ & $\begin{array}{c}\text { Foreign } \\
\text { bodies, black }\end{array}$ & hyperplasia & $\begin{array}{c}\text { phagocytes } \\
\text { with cell } \\
\text { debris }\end{array}$ & $\begin{array}{c}\text { Neutrophilic } \\
\text { exudates }\end{array}$ \\
\hline Sham & 6 & -- & -- & -- & -- & -- & -- & -- \\
\hline $\mathrm{NiO}$ low & 6 & -- & $1.33 \pm 0.42$ & $1 \pm 0.26$ & $1 \pm 0.26$ & -- & -- & -- \\
\hline $\mathrm{NiO}$ high & 6 & -- & $1.67 \pm 0.21 *$ & $1.17 \pm 0.17$ & $1.17 \pm 0.17$ & $0.67 \pm 0.33$ & $0.33 \pm 0.33$ & -- \\
\hline $\mathrm{Cr}_{2} \mathrm{O}_{3} / \mathrm{CaCrO}_{4}$ low & 6 & $1 \pm 0.45$ & $1.67 \pm 0.21 *$ & 2 & 2 & $0.17 \pm 0.17$ & $1.33 \pm 0.42$ & -- \\
\hline $\mathrm{Cr}_{2} \mathrm{O}_{3} / \mathrm{CaCrO}_{4}$ high & 6 & $0.83 \pm 0.40$ & $1.33 \pm 0.33$ & $2.67 \pm 0.21 * *$ & $2.67 \pm 0.21 *$ & $0.17 \pm 0.17$ & $1.67 \pm 0.76$ & $1 \pm 0.52$ \\
\hline GMA-SS & 6 & $2.17 \pm 0.17 * *$ & $1.67 \pm 0.21 *$ & $2.83 \pm 0.17^{\wedge}$ & $3 * *$ & $0.67 \pm 0.42$ & $3.17 \pm 0.17 * *$ & $1.83 \pm 0.60$ \\
\hline $\mathrm{Fe}_{2} \mathrm{O}_{3}$ low & 6 & $1.17 \pm 0.17$ & 1 & $2.5 \pm 0.22 *$ & -- & -- & $1.67 \pm 0.42$ & -- \\
\hline $\mathrm{Fe}_{2} \mathrm{O}_{3}$ high & 6 & $1 \pm 0.37$ & $1.83 \pm 0.17 * *$ & $3^{\wedge}$ & $4 \pm 0.26^{\wedge}$ & $0.33 \pm 0.33$ & $1.5 \pm 0.5$ & $0.5 \pm 0.5$ \\
\hline
\end{tabular}

Table 4. Abnormal morphological findings in lungs of mice 1 day post-exposure to GMAW-SS

fume, low and high dose metal oxides, or sham. Severity scores are the averages of the right

lung lobes and presented as mean \pm standard error. Severity was scored as $1=\operatorname{minimal}, 2=$

mild, $3=$ moderate, 4 = marked. ${ }^{*} p<0.03,{ }^{*} p<0.003, \wedge p<0.0007$ - compared to sham.

GMAW-SS: gas metal arc welding - stainless steel; MCA: 3-methylcholanthrene. 
Table 5

\begin{tabular}{|c|c|c|c|c|c|c|c|}
\hline & $\mathrm{n}$ & $\begin{array}{c}\text { Lymphocytic } \\
\text { infiltrate* }\end{array}$ & $\begin{array}{c}\text { Foreign } \\
\text { material* }\end{array}$ & $\begin{array}{c}\text { Hyperplasia } \\
\text { severity* }\end{array}$ & $\begin{array}{c}\text { Alveolar epithelial } \\
\text { Hyperplasia** }\end{array}$ & $\begin{array}{c}\text { Bronchiolo- } \\
\text { alveolar } \\
\text { adenoma }\end{array}$ & Total lesions \\
\hline $\mathrm{MCA} / \mathrm{sham}$ & 24 & -- & -- & $1.69 \pm 0.30$ & $3.00 \pm 0.60(75)$ & $1.33 \pm 0.25(32)$ & $4.33 \pm 0.64(107)$ \\
\hline $\mathrm{MCA} / \mathrm{NiO}$ & 26 & -- & $0.77 \pm 0.17^{\wedge}$ & $1.77 \pm 0.42$ & $2.77 \pm 0.68(72)$ & $1.62 \pm 0.48(42)$ & $4.38 \pm 0.86(114)$ \\
\hline $\mathrm{MCA} / \mathrm{Fe}_{2} \mathrm{O}_{3}$ & 33 & $0.45 \pm 0.08$ & $1.83 \pm 0.05^{\wedge}$ & $2.33 \pm 0.16^{+}$ & $4.96 \pm 0.44(164)$ & $1.94 \pm 0.24(64)$ & $6.91 \pm 0.52(228)^{\wedge}$ \\
\hline $\mathrm{MCA} / \mathrm{Cr}_{2} \mathrm{O}_{3} / \mathrm{CaCrO}_{4}$ & 32 & $0.06 \pm 0.06$ & $0.97 \pm 0.05^{\wedge}$ & $2.19 \pm 0.38$ & $3.91 \pm 0.90(125)$ & $1.50 \pm 0.43(48)$ & $5.41 \pm 1.02(173)$ \\
\hline
\end{tabular}

Table 5. Two stage (initiation-promotion) lung cancer bioassay: Lung histopathology severity scores for abnormal morphological findings and number of lesions in $\mathrm{A} / \mathrm{J}$ mice at 30 weeks

*Severity scores are the averages of the left and right lung lobes and presented as mean \pm standard error. Severity was scored as $1=$ minimal, $2=$ mild, $3=$ moderate, $4=$ marked.

**hyperplasia and adenoma were the only two lung lesions present and represented as count data presented as average or total lesions (in parenthesis).

-- indicates no findings

$\hat{\mathrm{p}}<0.0001$ - compared to MCA/sham

${ }^{+} \mathrm{p}<0.003$ - compared to MCA/sham

GMAW-SS: gas metal arc welding - stainless steel

MCA: 3-methylcholanthrene 


\section{Chapter 6: Lack of Lung Tumor Promotion after Inhalation of a Copper- Nickel Welding Fume in A/J Mice}

LM Falcone ${ }^{1,2}$, A Erdely ${ }^{1,2}$, R Salmen ${ }^{1}$, LA Battelli ${ }^{1}$, T Dodd $^{1}$, M Keane ${ }^{1}$, W McKinney ${ }^{1}$, S Stone $^{1}$, M Donlin ${ }^{1}$, HD Leonard ${ }^{1}$, JL Cumpston ${ }^{1}$, JB Cumpston ${ }^{1}$, R Mercer ${ }^{1}$, TB Chen ${ }^{1}$, RN Andrews $^{3}$, M Kashon ${ }^{1}$, JM Antonini ${ }^{1}$, PC Zeidler-Erdely ${ }^{1,2}$

'Health Effects Laboratory Division, National Institute for Occupational Safety and Health, Morgantown, WV; ${ }^{2}$ West Virginia University, School of Medicine, Morgantown, WV; ${ }^{3}$ Division of Applied Research and Technology, National Institute for Occupational Safety and Health, Cincinnati, $\mathrm{OH}$ 


\begin{abstract}
The International Agency for Research on Cancer classified welding fumes as a Group 1 (carcinogenic to humans) in 2017. The process of stainless steel welding creates fumes rich in carcinogenic metals such as chromium (Cr). Our lab has previously demonstrated that stainless steel welding fumes promote lung tumors in tumor susceptible $\mathrm{A} / \mathrm{J}$ mice. Consumables devoid of $\mathrm{Cr}$ are being produced in an attempt to limit worker exposures to potentially carcinogenic metals. The aim of this study was to characterize a new copper-nickel $(\mathrm{Cu}-\mathrm{Ni})$ fume and then investigate if inhalation of this fume would promote lung tumors in mice using a two-stage (initiationpromotion) model. Male A/J mice (4 - 5 weeks) were initiated with 3-methylcholanthrene (10 $\mu \mathrm{g} / \mathrm{g}$ intraperitoneally) or corn oil and beginning 1 week later were exposed to air or $\mathrm{Cu}-\mathrm{Ni}$ welding fumes for 4 hours/day, 4 days/week, for 9 weeks. At 30 weeks, mice were sacrificed and lung tumor multiplicity and incidence were evaluated. $\mathrm{MCA} / \mathrm{Cu}-\mathrm{Ni}$ welding fume exposure significantly decreased tumor size and tumor number compared MCA/air controls $(15.57 \pm 0.75$ tumors vs. $7.11 \pm 0.93$ tumors and $1.15 \mathrm{~mm}$ in diameter vs. $0.57 \mathrm{~mm}$ in diameter, respectively). Characterization of the fume indicated that most of the particles were between 0.1 and $1 \mu \mathrm{m}$ in diameter, with a mass median aerodynamic diameter of $0.43 \mu \mathrm{m}$. Future studies are planned to investigate the pneumotoxicity of $\mathrm{Cu}-\mathrm{Ni}$ fume in $\mathrm{A} / \mathrm{J}$ mice.
\end{abstract}




\section{Introduction}

Welding, a method of joining metals, employs millions of workers around the world [1]. However, many types of welding produce significant amounts of fumes which are known to be hazardous to human health $[2,3]$. Acute and chronic conditions such as metal fume fever, bronchitis, and increased infection incidence have been reported in welders [3-7]. However, welding fumes also cause lung cancer. Welding fumes are classified as carcinogenic to humans (Group 1) by the International Agency for Research on Cancer (IARC) and can contain metals such as iron $(\mathrm{Fe})$, manganese $(\mathrm{Mn})$, chromium $(\mathrm{Cr})$, copper $(\mathrm{Cu})$, and nickel $(\mathrm{Ni}) .[1] \mathrm{Cr}$ and $\mathrm{Ni}$ are also classified as Group 1 carcinogens [8]. The carcinogenicity of welding fumes is sometimes favored to be due to $\mathrm{Cr}^{6+}$ which is present in the fume. In 2006, the Occupational Safety and Health Administration (OSHA) reduced the $\mathrm{Cr}^{6+}$ concentration in the workplace from 52 to $5 \mathrm{ug} / \mathrm{m}^{3}$. This reduction can be challenging to maintain with stainless steel welding. For this reason, newer welding consumables containing primarily $\mathrm{Cu}$ and $\mathrm{Ni}$ have been produced that may prove less hazardous to workers' health.

Epidemiological studies have investigated lung cancer after exposure to both mild steel (MS) and stainless steel (SS) welding fumes. The former fume is composed of entirely Fe and $\mathrm{Mn}$, while the latter contains $\mathrm{Fe}, \mathrm{Ni}, \mathrm{Cr}, \mathrm{Cu}$, and $\mathrm{Mn}$. Most notably, worker studies suggest that both MS and SS fume exposures increase lung cancer in welders, even though MS fume contains no known human carcinogens [9-12]. There are no epidemiological studies investigating worker exposure to fume from the newer $\mathrm{Cu}-\mathrm{Ni}$ welding consumables and only limited in vivo and in vitro studies on the pneumotoxicity of the fume are available. There are no in vivo studies on the tumorigenic potential of this fume.

Previous studies in our laboratory have employed a two-stage (initiation-promotion) model of lung tumorigenesis to study welding fume exposure. It was demonstrated using a two- 
stage initiation-promotion model that GMAW-SS fume promotes lung tumors in A/J mice [13, 14]. The aim of this study was to investigate if inhalation of a $\mathrm{Cu}-\mathrm{Ni}$ welding fume would also promote lung tumor formation in A/J mice. Results of this study could help to clarify whether or not newer $\mathrm{Cu}-\mathrm{Ni}$ welding consumables are safer alternatives to improve worker health.

\section{Methods}

\section{Animals}

Male A/J mice (age 4-5 week) were purchased from Jackson Laboratories (Bar Harbor, $\mathrm{ME}$ ) and housed in an AAALAC International - specific pathogen-free, environmentallycontrolled facility. All mice were free of endogenous pathogens including viruses, bacteria, mycoplasmas, and parasites. Mice were housed in groups of two in ventilated cages and provided high-efficiency particulate filtered air under a controlled light cycle (12 h light/12 h dark) at a standard temperature $\left(22-24^{\circ} \mathrm{C}\right)$ and $30-70 \%$ relative humidity. Animals were acclimated to the animal facility for one week before beginning the experimental protocols and allowed access to a conventional diet (6\% irradiated NIH-31 Diet, Envigo RMS, Inc.; Madison, WI) and tap water ad libitum. All procedures were performed using protocols approved by the National Institute for Occupational Safety and Health (NIOSH) Institutional Animal Care and Use Committee.

\section{Welding fume inhalation exposure system}

The design and construction of the welding fume aerosol generator were previously described [15]. This automated robotic welder continuously generated welding fumes by welding beads onto $1 / 4$ inch thick plates of mild steel. The welding wire used was 0.045 inch diameter Lincoln Electric Techalloy 413 MIG and the welding parameters were set to 25 volts DC, 300 inch per minute wire feed, $30 \mathrm{~L} / \mathrm{min}$ of $75 \%$ argon $-25 \%$ helium shielding gas, and a typical welding current of 200 amps. The resulting fume was carried into a whole body exposure chamber through a $3 / 4$ inch flexible tube by maintaining the chamber at a negative pressure $(0.70$ 
inch $\mathrm{H}_{2} \mathrm{O}$ ). Particle concentrations within the exposure chamber were continuously monitored with a Data RAM (DR-40000 Thermo Electron Co; Franklin, MA), and gravimetric determinations ( $37 \mathrm{~mm}$ cassettes with $0.45 \mu \mathrm{m}$ pore-size Teflon filters) were used to calibrate and verify the Data RAM readings each day. Gas generation, including carbon monoxide (CO), carbon dioxide $\left(\mathrm{CO}_{2}\right)$, oxygen $\left(\mathrm{O}_{2}\right)$, and ozone $\left(\mathrm{O}_{3}\right)$, was continuously monitored. During the welding exposure, $\mathrm{O}_{2}$ levels were maintained above the OSHA minimal acceptable level. $\mathrm{O}_{3}, \mathrm{CO}$, $\mathrm{CO}_{2}$ were below OSHA permissible exposure limits and NIOSH recommended exposure limits (REL) during the entire exposure duration. In the exposure chamber, $\mathrm{CO}$ and $\mathrm{O}_{3}$ levels were not significantly higher than background. The exposure system was modified slightly from that described previously to reduce the travel time of the particulate fume from the welding torch to the exposure chamber [15].

\section{Experimental protocol for welding fume metal analysis and characterization}

A small amount of welding fume was collected gravimetrically onto 47-mm Nucleopore polycarbonate filters (Whatman; Clinton, PA) for field emission scanning electron microscopy (FESEM) to assess particle size and morphology. The particles were imaged using a Hitachi S4800 Field Emission Scanning Electron Microscope (Hitachi; Tokyo, Japan). For elemental analysis of $\mathrm{Cu}-\mathrm{Ni}$ fume, generated particles were collected inside the exposure chamber onto 5.0 $\mu \mathrm{m}$ polyvinyl chloride membrane filters in $37-\mathrm{mm}$ cassettes during three 30 minute collections. The particle samples were digested and the metals were analyzed by inductively coupled plasma atomic emission spectroscopy according to the NIOSH method 7303 for hot block/HCL/HNO 3 digestion (NIOSH, 1994) as previously described [15]. Metal content of blank filters also were analyzed for control purposes. To determine particle mass size distribution, a Micro-Orifice Uniform Deposit Impactor (MOUDI, model 110; MSP corp., Shoreview, Minn.) with additional 
Nano-MOUDI stages (MSP model 115) was used. Lastly, welding fume samples were also analyzed using energy dispersive X-ray analysis (SEM-EDX; Princeton Gamma-Tech, Rocky Hill, N.J.) at $20 \mathrm{keV}$.

\section{Experimental protocol for whole lung metal analysis}

Weight-matched A/J mice were exposed by whole-body inhalation in individual steel mesh cages to $\mathrm{Cu}-\mathrm{Ni}$ welding aerosols (mean concentration $43 \mathrm{mg} / \mathrm{m}^{3}$ over 4 hours) $(\mathrm{n}=10)$ or filtered air $(\mathrm{n}=6)$. Immediately following exposure (time zero), whole lungs were excised, trimmed, and lyophilized. The freeze-dried tissue was weighed then acid digested. Inductively coupled argon plasma atomic emission spectroscopy at NIOSH-Division of Applied Research and Technology (Cincinnati, $\mathrm{OH}$ ) was used to determine the amount of $\mathrm{Al}, \mathrm{Ba}, \mathrm{Ca}, \mathrm{Co}, \mathrm{Cr}, \mathrm{Cu}$, Fe, K, Li, Mg, Mn, Ni, P, Pb, Sr, Ti, V, Zn and Zr present in the lung according to the draft NIOSH method 8200 used for bulk tissue samples (NIOSH 2003).

\section{Experimental protocol for two-stage lung carcinogenesis bioassay in A/J mice}

For the two-stage initiation-promotion protocol, 120 mice were weight-matched and randomized into four exposure groups ( $\mathrm{n}=30$ /group). On day 1 , mice were intraperitoneally (IP) injected with the chemical initiator, 3-methylcholanthrene (MCA) (Sigma-Aldrich; St. Louis, MO) dissolved in corn oil (CO) (Sigma-Aldrich; St. Louis, MO) at a dose of $10 \mu \mathrm{g} / \mathrm{g}$ of body weight or $\mathrm{CO}$ alone (Figure 1B). MCA was chosen as the initiating agent based on the efficient response of the $\mathrm{A} / \mathrm{J}$ mouse to this carcinogen in our previous oropharyngeal aspiration and inhalation studies $[14,16]$. Beginning 1 week post-initiation, mice were exposed by whole-body inhalation to $\mathrm{Cu}-\mathrm{Ni} \mathrm{WF}$ aerosols or filtered air for 4 hours/day, 4 days/week, for 9 weeks at a target concentration of $40 \mathrm{mg} / \mathrm{m}^{3}$ (actual mean concentration 32.6 over 9 weeks). Throughout the study, mice were weighed biweekly including at the terminal sacrifice at 30 -weeks post- 
initiation. Mice were euthanized with sodium pentobarbital [100-300 mg/kg IP] (Vortech Pharmaceuticals; Dearborn, MI), weighed, and exsanguinated via the vena cava. All internal organs were examined for the presence of tumors. Then, the whole lung was excised and inflated with $10 \%$ neutral buffered formalin. Twenty-four hours post-fixation, lung tumors were counted. Lung tumor incidence was recorded as the percent of tumor-bearing mice out of the total, and lung tumor multiplicity was determined as the average tumor number per mouse lung including mice with no tumors. Any apparent merged tumors were counted as one tumor. Lungs were embedded in paraffin before a $5 \mu \mathrm{m}$ standardized section was cut and slides were made.

Welding fume particles in sections from exposed lungs were assessed using an enhanced dark-field optical system. Welding fume particles scatter light significantly greater than the surrounding tissues due to a significant difference in refractive index, nanometer size and the crystalline structure of the particles. The enhanced dark-field optical system images light scattered in the section and, thus, particles in the section stand-out from the surrounding tissues with high contrast. As has been described previously, this method of imaging can be used to scan lung sections at relatively low magnification to identify particles that would not be detected by other means [17-20]. Typically, the image intensity of particles in tissue sections is approximately 20fold that of the embedded tissue [20]. Sections for dark-field examination were cut from paraffin blocks at 5 microns thickness and collected on ultrasonically cleaned, laser cut slides (Schott North America Inc, Elmsford, N.Y. 10523) to avoid contamination from the ground edges of traditional slides. After staining with Sirius Red-Hematoxylin, slides were dehydrated in xylene and coverslipped with Permount (Fisher Scientific Co., Pittsburgh, PA) containing 5\%, by volume xylene. Just before mounting, the xylene-Permount was centrifuged at $10,000 \mathrm{x} g$ for 10 minutes to remove contaminating particles in the Permount. The optical microscopes consist of a 
transmitted light microscope (Olympus B63 with motorized condenser, controller and reflected light system) and a CytoViva EDM (CytoViva, Auburn, AL 36830). The CytoViva EDM has a high signal-to-noise, dark-field illumination optical system adapted to an Olympus BX41 microscope which also includes a hyperspectral imaging camera with ENVI 4.8 analysis software and the CytoViva 3-D positioning and analysis software for serial section reconstruction. Both transmission light microscope and EDM were equipped with an Olympus DP73 digital camera with cellsens Dimension camera control and measurement software (Olympus America Inc., Center Valley, PA 18034). Images for both systems were taken at either high resolution 4800x3600 pixels or 2400x1800 pixels.

\section{Statistical comparisons and analysis}

Statistical analyses were performed using either JMP version 13, or SAS version 9.4 for Windows. Continuous variables were analyzed using treatment by day factorial analyses of variance (ANOVA), followed by Fishers LSD for pairwise comparisons. For some variables, a natural log transformation was performed on the data to reduce heterogeneous variance and meet the assumptions of an ANOVA. Gross tumor counts were analyzed using nonparametric Kruskal-Wallis tests and followed by pair-wise comparisons using the Wilcoxon Rank Sums test. Tumor incidence was analyzed using a Chi-square test in SAS 'Proc Freq,' while tumor multiplicity was analyzed using Poisson regression in SAS 'Proc Genmod.' In cases where over dispersion existed, a negative binomial regression was performed. Analyses were performed independently on CO and MCA-treated animals and only utilized data from those animals surviving to the 30-week time point. For tumor size comparisons between MCA-treated animals, a two-sided t test was performed only on data from animals with tumors. For all analyses, a $p<$ 0.05 was set as the criteria for significance. 


\section{Results}

\section{Characterization of Generated Welding Fume}

Elemental analysis indicated that GMAW-MS was primarily $\mathrm{Cu}$ and $\mathrm{Ni}$ (Table 1). $\mathrm{Cu}$ content by weight percent averaged $76.35 \%$ and $\mathrm{Ni}$ was $11.60 \%$. Approximately $5 \%$ of fume consisted of $\mathrm{Ti}$ and $\mathrm{Mn}$ and the remaining metal content of the fume was trace metals. Because welding is known to generate a significant number of nanosized particles, both MOUDI and Nano-MOUDI samplers were used to determine particle size distribution. Most of the particles were between 0.1 and $1 \mu \mathrm{m}$ in diameter, with a mass median aerodynamic diameter of $0.43 \mu \mathrm{m}$ (Figure 2).

\section{Enhanced Dark-field Light Microscopy Imaging of Welding Fumes}

Enhanced dark-field microscopy confirmed the deposition of $\mathrm{Cu}-\mathrm{Ni}$ welding fume particles in fume-exposed animals as the particles scattered light at a much greater intensity than the surrounding lung tissues (Figure 3). The lung tissue adjacent to the fume deposits was made visible only by the addition of transmitted light. Welding particle deposits appeared almost exclusively inside macrophages, indicating this fume is phagocytosed by alveolar macrophages. Microscopy images of air-exposed mice showed intact lung tissue and the presence of macrophages devoid of any particulate matter. No difference was seen in microscopy images of MCA or CO-exposed mice, indicating that the MCA or CO exposure did not affect lung burden of fume.

\section{Whole lung metal deposition after $\mathrm{Cu}-\mathrm{Ni}$ fume inhalation}

The lung metal deposition in A/J mice measured at time 0 after 4 hours of inhalation of $\mathrm{Cu}-\mathrm{Ni}$ fume is shown in Table 2 and was calculated as done previously [16]. The most abundant metals measured were $\mathrm{Cu}(5.11 \mu \mathrm{g} \mathrm{Cu} / 7.33 \mu \mathrm{g}$ total metal deposition $=69.7 \%)$ and $\mathrm{Ni}(1.18 \mu \mathrm{g}$ $\mathrm{Ni} / 7.33 \mu \mathrm{g}$ total metal deposition $=16.1 \%$ ), which equates to the elemental analysis of the GMAW-MS fume shown in Table 1. 
$\underline{\text { Human relevance deposition calculation: }}$

The analysis of the metals showed a cumulative increase of $7.33 \mu \mathrm{g}$ of total $\mathrm{Cu}-\mathrm{Ni}$ fume deposited in the lung from a single 4 hour exposure (Table 2). The alveolar deposition in the mice was equated to the human by the equations below using the previous threshold limit valuetime weighted average (TLV-TWA) of $5 \mathrm{mg} / \mathrm{m}^{3}$ for total welding fume. Previously, we estimated that $70 \%$ of the total dose reached the alveolar space $(7.33 \mu \mathrm{g} / \mathrm{d} \times 0.70=5.13 \mu \mathrm{g} / \mathrm{d})$ $[21,22]$. The mice were exposed for 36 days ( 9 weeks at 4 days/week) for an approximate total alveolar deposition of $184.68 \mu \mathrm{g}$.

Estimated human daily deposition using previous welding fume TLV-TWA of $5 \mathrm{mg} / \mathrm{m}^{3}$ : Fume concentration $\mathrm{x}$ min volume $\mathrm{x}$ exposure duration $\mathrm{x}$ deposition efficiency $=$ deposited human dose $5 \mathrm{mg} / \mathrm{m}^{3} \times(20 \mathrm{l} / \mathrm{min})\left(10^{-3} \mathrm{~m}^{3} / \mathrm{l}\right) \times(8$ hours/day $)(60$ minutes/hour $) \times 0.16=7.7 \mathrm{mg}$ deposited per 8 hour day in humans

Estimated human equivalent deposition from quantified deposition in mouse using alveolar surface area (SA)[23]

$\left(\mathrm{SA}_{\text {human }} \mathrm{X}\right.$ deposition mouse $) / \mathrm{SA}_{\text {mouse }}=$ deposition $_{\text {human }}$ $\left(102 \mathrm{~m}^{2} \times 0.18468 \mathrm{mg}\right) / 0.05 \mathrm{~m}^{2}=376.75 \mathrm{mg}$

$376.75 \mathrm{mg} / 7.7 \mathrm{mg} /$ day = approximately 49 working days for a human working at $5 \mathrm{mg} / \mathrm{m}^{3}$ for 8 hours/day. While it is understood that welding is usually not done for 8 hours/day, and the exposure levels are likely not to consistently reach $5 \mathrm{mg} / \mathrm{m}^{3}$ as a TWA, the deposition in this study model was representative of cumulative exposure in a human.

\section{Gross tumor multiplicity and incidence}


$\mathrm{Cu}-\mathrm{Ni}$ welding fume significantly decreased lung tumors in mice at 30 weeks after initiation with MCA (Figure 4). Lung tumor multiplicity was $15.57 \pm 0.75$ and $7.11 \pm 0.93$ for MCA/air and MCA/Cu-Ni fume, respectively $(p<0.0001)$. There was no effect of welding fume alone on tumor multiplicity (CO/air, $0.30 \pm 0.12$; CO/GMAW-MS, $0.07 \pm 0.05)$. The percentage of tumor-bearing mice out of the total (tumor incidence) was $22 \%$ in CO/air and $7 \%$ in CO/GMAW-MS-exposed animals. This low tumor incidence in 35 to 36 week old, CO-exposed mice is consistent with previous studies in our lab as well as other reports in the literature [13, $24,25]$. As expected, tumor incidence was high in all MCA-initiated groups (100\% for MCA/air and $93 \%$ for MCA/Cu-Ni fume groups), which confirmed the successful administration as well as its carcinogenic effectiveness in $\mathrm{A} / \mathrm{J}$ mice. The total and average tumor number per treatment group across each of the individual lung lobes is reported in Table 3. MCA/air-exposed mice had significantly greater lung tumor multiplicity in the left, apical, diaphragmatic, and azygos lung regions compared to $\mathrm{MCA} / \mathrm{Cu}-\mathrm{Ni}$ fume $(p<0.05)$.

Figure 5 shows the gross lung morphology of a MCA/air-exposed lung (panel A) and a MCA/Cu-Ni - exposed lung (panel B) 24 hours post-fixation with formalin. Welding fume deposition was not grossly visible in any exposed mouse lungs but was visible by enhanced darkfield microscopy (Figure 3). Tumors appeared white in color and opaque on initial gross exam and became more well-defined after fixation which aided enumeration. At 30 weeks, tumors were on average $1.15 \mathrm{~mm}$ in diameter in MCA/air-exposed mice and $0.57 \mathrm{~mm}$ in diameter in MCA/Cu-Ni fume-exposed mice $(p<0.0001)$.

\section{Morbidity and mortality}

Initial body weights at week 0 (means \pm standard error [SE]) were $15.64 \pm 0.48,15.79 \pm$ $0.31,15.76 \pm 0.39$, and $16.13 \pm 0.43 \mathrm{~g}$ for the $\mathrm{CO} / \mathrm{air}, \mathrm{CO} / \mathrm{Cu}-\mathrm{Ni} \mathrm{WF}, \mathrm{MCA} / \mathrm{air}$, and MCA/Cu-Ni 
WF groups, respectively. Body weights increased steadily from week 0 to 30 and did not differ among exposure groups. At terminal sacrifice, body weights were $28.46 \pm 0.43,27.77 \pm 0.50$, $28.29 \pm 0.52$, and $27.70 \pm 0.64 \mathrm{~g}$ for the $\mathrm{CO} /$ air, $\mathrm{CO} / \mathrm{Cu}-\mathrm{Ni} \mathrm{WF}, \mathrm{MCA} /$ air, and MCA/Cu-Ni WF groups, respectively. Morbidity and mortality throughout the study was low ( 7\%) and no abnormalities, such as other tumor types besides lung, were found at the terminal sacrifice at 30 weeks. In total, 9 mice died during the course of the study and were not included in the final analysis of the data. Deaths were distributed evenly across treatment groups. Necropsy determined that all 9 mice died from morbidities not associated with the experimental protocol.

\section{Discussion}

The novel findings in this study were that inhalation of a $\mathrm{Cu}-\mathrm{Ni}$ welding fume significantly decreased lung tumor size and tumor number in vivo in a two-stage model of lung tumorigenesis. While MCA/air-exposed mice averaged $15.57 \pm 0.75$ tumors per mouse lung, $\mathrm{MCA} / \mathrm{Cu}-\mathrm{Ni}$ fume averaged $7.11 \pm 0.93$ tumors per lung $(p<0.0001)$. Notably, tumors in MCA/air mice averaged over $1 \mathrm{~mm}$ in diameter, while tumors in $\mathrm{MCA} / \mathrm{Cu}-\mathrm{Ni}$ appeared much smaller on gross examination and averaged just $0.57 \mathrm{~mm}$ in diameter $(p<0.0001)$. To our knowledge, this is the first in vivo inhalation study investigating a $\mathrm{Cu}-\mathrm{Ni}$ welding fume.

The $\mathrm{Cu}-\mathrm{Ni}$ welding fume in this study contains $\sim 76 \% \mathrm{Cu}$ and $12 \% \mathrm{Ni}$ according to metal analysis. Comparatively less studies have investigated the $\mathrm{Cu}$ in welding fumes compared to other metals like $\mathrm{Cr}, \mathrm{Ni}$, and $\mathrm{Fe}$. While some reports have indicated that $\mathrm{Cu}$ in welding fumes is a respiratory irritant and contributes to metal fume fever, other literature suggests $\mathrm{Cu}$ is relatively benign in the lungs and does not cause this condition $[3,26]$. However, Markert et al. investigated the $\mathrm{Cu}$ in welding fumes and found that $\mathrm{Cu}$ alone was able to increase levels of $\mathrm{C}$ reactive protein (CRP) [27]. Increases in CRP are believed to represent an early stage of metal 
fume fever. Additionally, elevated levels of $\mathrm{Cu}$ have been found in lung, prostate, breast, and brain cancers, and $\mathrm{Cu}$ chelators can be useful as anti-cancer therapies [28]. Significantly more literature is available investigating $\mathrm{Ni}$ in welding fumes, and $\mathrm{Ni}$ is classified as carcinogenic to humans by the IARC, as supported by many worker and animal studies [3, 8, 29-33]. Many studies have shown that Ni can damage DNA directly as well as through reactive oxygen species production, epigenetic effects, and chromosomal aberrations [8, 30, 31, 34-40]. Inhalation studies in humans and animals have shown that $\mathrm{Ni}$ is a lung irritant and can cause inflammation as well as adversely affect the immune system [3,40]. Numerous worker and in vivo studies have shown that exposure to Ni-containing stainless-steel welding fumes increases lung cancer risk [3, $13,14,41]$. In vitro studies have also shown that the Ni in stainless steel welding fumes may be mutagenic [30, 42]. However, because welding fume exposures do not represent pure exposure to $\mathrm{Ni}$, this elevated risk cannot be definitely linked to $\mathrm{Ni}$ or any other single metal component of the fume [3, 31]. Moreover, in 2012, IARC concluded that high cytotoxic concentrations as well as the presence of inflammation may be needed to potentially see carcinogenic effects from $\mathrm{Ni}$ exposures $[8,35,38,43,44]$.

Only two published studies have investigated the pneumotoxicity of a $\mathrm{Cu}-\mathrm{Ni}$ welding fume. Antonini et al. 2014 investigated the pulmonary toxicity of a $\mathrm{Cu}-\mathrm{Ni}$ based fume generated by shielded metal arc welding (SMAW) using both in vitro and in vivo assays [45]. This fume only contained trace amounts of $\mathrm{Cr}$ and yet caused a persistent increase in lung injury and inflammation even greater than SS and MS fumes. Interestingly, the $\mathrm{Cu}-\mathrm{Ni}$ fume did not increase reactive oxygen species (ROS), so it was hypothesized that the toxicity was due to a direct cytotoxic effect. An in vitro study by Badding et al. found that the $\mathrm{Cu}-\mathrm{Ni}$ fume was more cytotoxic than SS or MS fume, causing cell death and mitochondrial dysfunction at lower doses 
than the other fumes [46]. The authors likewise noted that the fume did not cause ROS production but did impair ability of exposed macrophages to phagocytose bacteria. Hence, these studies suggest that $\mathrm{Cu}-\mathrm{Ni}$ fume from SMAW may still be toxic and inflammatory in the lungs. However, it is important to note that the metal composition of the welding fumes used in these studies was more complex than the $\mathrm{Cu}-\mathrm{Ni}$ fume in this study because it was produced by SMAW. The fume in the cited studies contained $\sim 30 \%$ potassium and $\sim 21 \%$ aluminum with only $13.4 \%$ and $6 \% \mathrm{Ni}$ and $\mathrm{Cu}$, respectively. Therefore, it is likely the pneumotoxicity of the $\mathrm{Cu}-\mathrm{Ni}$ used in this study would differ. Additionally, no studies have investigated pneumotoxicity in vivo following inhalation exposure to the $\mathrm{Cu}-\mathrm{Ni}$ fume produced by GMAW.

It is unclear why the $\mathrm{Cu}-\mathrm{Ni}$ welding fume decreased lung tumor size and was not a lung tumor promoter in this study. However, this study highlights the need for ongoing future research investigating $\mathrm{Cu}-\mathrm{Ni}$ welding fumes. Additional in vivo and in vitro studies can help determine the toxicity of this fume and in particular, clarify whether the $\mathrm{Cu}$ in welding fumes is beneficial, benign, or harmful to worker health. While the results of the present study suggest $\mathrm{Cu}-\mathrm{Ni}$ welding fume may pose a smaller health threat to welders, additional studies are needed to better clarify this risk.

\section{Bibliography}

1. Guha N, Loomis D, Guyton KZ, Grosse Y, El Ghissassi F, Bouvard V, Benbrahim-Tallaa L, Vilahur N, Muller K, Straif K: Carcinogenicity of welding, molybdenum trioxide, and indium tin oxide. Lancet Oncol 2017, 18:581-582.

2. Antonini JM: Health effects of welding. Crit Rev Toxicol 2003, 33:61-103.

3. Antonini JM: Health Effects Associated with Welding. 2014:49-70.

4. Coggon D, Inskip H, Winter P, Pannett B: Lobar pneumonia: an occupational disease in welders. Lancet 1994, 344:41-43. 
5. Holm M, Kim JL, Lillienberg L, Storaas T, Jogi R, Svanes C, Schlunssen V, Forsberg B, Gislason T, Janson C, Toren K: Incidence and prevalence of chronic bronchitis: impact of smoking and welding. The RHINE study. Int J Tuberc Lung Dis 2012, 16:553-557.

6. Marongiu A, Hasan O, Ali A, Bakhsh S, George B, Irfan N, Minelli C, Canova C, Schofield S, De Matteis S, Cullinan P: Are welders more at risk of respiratory infections? Findings from a cross-sectional survey and analysis of medical records in shipyard workers: the WELSHIP project. Thorax 2016, 71:601-606.

7. Suri R, Periselneris J, Lanone S, Zeidler-Erdely PC, Melton G, Palmer KT, Andujar P, Antonini JM, Cohignac V, Erdely A, et al: Exposure to welding fumes and lower airway infection with Streptococcus pneumoniae. J Allergy Clin Immunol 2016, 137:527-534.e527.

8. Arsenic, metals, fibres, and dusts. IARC Monogr Eval Carcinog Risks Hum 2012, 100:11-465.

9. Melkild A, Langard S, Andersen A, Tonnessen JN: Incidence of cancer among welders and other workers in a Norwegian shipyard. Scand J Work Environ Health 1989, 15:387-394.

10. Danielsen TE, Langard S, Andersen A, Knudsen O: Incidence of cancer among welders of mild steel and other shipyard workers. Br J Ind Med 1993, 50:1097-1103.

11. Hansen KS, Lauritsen JM, Skytthe A: Cancer incidence among mild steel and stainless steel welders and other metal workers. Am J Ind Med 1996, 30:373-382. 
12. Siew SS, Kauppinen T, Kyyronen P, Heikkila P, Pukkala E: Exposure to iron and welding fumes and the risk of lung cancer. Scand J Work Environ Health 2008, 34:444-450.

13. Falcone LM, Erdely A, Meighan TG, Battelli LA, Salmen R, McKinney W, Stone S, Cumpston A, Cumpston J, Andrews RN, et al: Inhalation of gas metal arc-stainless steel welding fume promotes lung tumorigenesis in A/J mice. Arch Toxicol 2017, 91:2953-2962.

14. Zeidler-Erdely PC, Meighan TG, Erdely A, Battelli LA, Kashon ML, Keane M, Antonini JM: Lung tumor promotion by chromium-containing welding particulate matter in a mouse model. Part Fibre Toxicol 2013, 10:45.

15. Antonini JM, Afshari AA, Stone S, Chen B, Schwegler-Berry D, Fletcher WG, Goldsmith WT, Vandestouwe KH, McKinney W, Castranova V, Frazer DG: Design, construction, and characterization of a novel robotic welding fume generator and inhalation exposure system for laboratory animals. J Occup Environ Hyg 2006, 3:194-203; quiz D145.

16. Falcone LM, Erdely A, Meighan TG, Battelli LA, Salmen R, McKinney W, Stone S, Cumpston A, Cumpston J, Andrews RN, et al: Inhalation of gas metal arc-stainless steel welding fume promotes lung tumorigenesis in A/J mice. Arch Toxicol 2017.

17. Ma J, Mercer RR, Barger M, Schwegler-Berry D, Cohen JM, Demokritou P, Castranova V: Effects of amorphous silica coating on cerium oxide nanoparticles induced pulmonary responses. Toxicology and applied pharmacology 2015, 288:63-73.

18. McKinney W, Jackson M, Sager TM, Reynolds JS, Chen BT, Afshari A, Krajnak K, Waugh S, Johnson C, Mercer RR, et al: Pulmonary and cardiovascular responses of 
rats to inhalation of a commercial antimicrobial spray containing titanium dioxide nanoparticles. Inhal Toxicol 2012, 24:447-457.

19. Mercer RR, Scabilloni JF, Hubbs AF, Wang L, Battelli LA, McKinney W, Castranova V, Porter DW: Extrapulmonary transport of MWCNT following inhalation exposure. Part Fibre Toxicol 2013, 10:38.

20. Mercer RR, Scabilloni JF, Wang L, Battelli LA, Antonini JM, Roberts JR, Qian Y, Sisler JD, Castranova V, Porter DW, Hubbs AF: The Fate of Inhaled Nanoparticles: Detection and Measurement by Enhanced Dark-field Microscopy. Toxicol Pathol 2018, 46:28-46.

21. Erdely A, Hulderman T, Salmen-Muniz R, Liston A, Zeidler-Erdely PC, Chen BT, Stone S, Frazer DG, Antonini JM, Simeonova PP: Inhalation exposure of gas-metal arc stainless steel welding fume increased atherosclerotic lesions in apolipoprotein $\mathbf{E}$ knockout mice. Toxicol Lett 2011, 204:12-16.

22. Raabe OG, Al-Bayati, M.A., Teague, S.V., Rasolt, A., : Regional deposition of inhaled monodisperse coarse and fine aerosol particles in small laboratory animals. Ann Occup Hyg 1988, 32:53-63.

23. Stone KC, Mercer RR, Gehr P, Stockstill B, Crapo JD: Allometric relationships of cell numbers and size in the mammalian lung. Am J Respir Cell Mol Biol 1992, 6:235-243.

24. Groch KM, Khan MA, Brooks AL, Saffer JD: Lung cancer response following inhaled radon in the A/J and C57BL/6J mouse. Int J Radiat Biol 1997, 71:301-308.

25. Curtin GM, Higuchi MA, Ayres PH, Swauger JE, Mosberg AT: Lung tumorigenicity in A/J and rasH2 transgenic mice following mainstream tobacco smoke inhalation. Toxicol Sci 2004, 81:26-34. 
26. Borak J, Cohen H, Hethmon TA: Copper exposure and metal fume fever: lack of evidence for a causal relationship. Aihaj 2000, 61:832-836.

27. Markert A, Baumann R, Gerhards B, Gube M, Kossack V, Kraus T, Brand P: Single and Combined Exposure to Zinc- and Copper-Containing Welding Fumes Lead to Asymptomatic Systemic Inflammation. J Occup Environ Med 2016, 58:127-132.

28. Tisato F, Marzano C, Porchia M, Pellei M, Santini C: Copper in diseases and treatments, and copper-based anticancer strategies. Med Res Rev 2010, 30:708-749.

29. Chromium, nickel and welding. IARC Monogr Eval Carcinog Risks Hum 1990, 49:1648.

30. Costa M: Molecular mechanisms of nickel carcinogenesis. Annu Rev Pharmacol Toxicol 1991, 31:321-337.

31. Kasprzak KS, Sunderman FW, Jr., Salnikow K: Nickel carcinogenesis. Mutat Res 2003, 533:67-97.

32. Shen HM, Zhang QF: Risk assessment of nickel carcinogenicity and occupational lung cancer. Environ Health Perspect 1994, 102 Suppl 1:275-282.

33. Langard S: Nickel-related cancer in welders. Sci Total Environ 1994, 148:303-309.

34. Nickel compounds and metallic nickel. Rep Carcinog 2011, 12:280-283.

35. Cai Y, Zhuang Z: [DNA damage in human peripheral blood lymphocyte caused by nickel and cadmium]. Zhonghua Yu Fang Yi Xue Za Zhi 1999, 33:75-77.

36. Chiou YH, Wong RH, Chao MR, Chen CY, Liou SH, Lee H: Nickel accumulation in lung tissues is associated with increased risk of p53 mutation in lung cancer patients. Environ Mol Mutagen 2014, 55:624-632. 
37. Dumala N, Mangalampalli B, Chinde S, Kumari SI, Mahoob M, Rahman MF, Grover P: Genotoxicity study of nickel oxide nanoparticles in female Wistar rats after acute oral exposure. Mutagenesis 2017, 32:417-427.

38. M'Bemba-Meka P, Lemieux N, Chakrabarti SK: Nickel compound-induced DNA single-strand breaks in chromosomal and nuclear chromatin in human blood lymphocytes in vitro: role of oxidative stress and intracellular calcium. Mutat Res 2005, 586:124-137.

39. Tessier DM, Pascal LE: Activation of MAP kinases by hexavalent chromium, manganese and nickel in human lung epithelial cells. Toxicol Lett 2006, 167:114-121.

40. Zhao J, Shi X, Castranova V, Ding M: Occupational toxicology of nickel and nickel compounds. J Environ Pathol Toxicol Oncol 2009, 28:177-208.

41. Sorensen AR, Thulstrup AM, Hansen J, Ramlau-Hansen CH, Meersohn A, Skytthe A, Bonde JP: Risk of lung cancer according to mild steel and stainless steel welding. Scand J Work Environ Health 2007, 33:379-386.

42. Hedenstedt A, Jenssen D, Lidestein BM, Ramel C, Rannug U, Stern RM: Mutagenicity of fume particles from stainless steel welding. Scand J Work Environ Health 1977, 3:203-211.

43. Pool-Zobel BL, Lotzmann N, Knoll M, Kuchenmeister F, Lambertz R, Leucht U, Schroder HG, Schmezer P: Detection of genotoxic effects in human gastric and nasal mucosa cells isolated from biopsy samples. Environ Mol Mutagen 1994, 24:23-45.

44. Dally H, Hartwig A: Induction and repair inhibition of oxidative DNA damage by nickel(II) and cadmium(II) in mammalian cells. Carcinogenesis 1997, 18:1021-1026. 
45. Antonini JM, Badding MA, Meighan TG, Keane M, Leonard SS, Roberts JR: Evaluation of the Pulmonary Toxicity of a Fume Generated from a Nickel-, Copper-Based Electrode to be Used as a Substitute in Stainless Steel Welding. Environ Health Insights 2014, 8:11-20.

46. Badding MA, Fix NR, Antonini JM, Leonard SS: A comparison of cytotoxicity and oxidative stress from welding fumes generated with a new nickel-, copper-based consumable versus mild and stainless steel-based welding in RAW 264.7 mouse macrophages. PLoS One 2014, 9:e101310. 
Figure legends

Figure 1. Timelines of experimental protocols. Panel A - Experimental protocol for whole lung metal analysis. Mice were exposed by whole-body inhalation to filtered air $(\mathrm{n}=10)$ or $\mathrm{Cu}$ Ni fume $(n=10)$ for 4 hours. Inductively coupled argon plasma, atomic emission spectroscopy was used to analyze metal content of lungs. Panel B - Experimental protocol for two-stage (initiation-promotion) bioassay. Mice received MCA $(n=60)$ or corn oil $(n=60)$ injections and beginning 1 week later were exposed to $\mathrm{Cu}-\mathrm{Ni}$ fume or air inhalation 4 hours/day $\mathrm{x} 4$ day/week $\mathrm{x}$ 9 weeks before terminal sacrifice at 30 weeks

Figure 2. Particle size distribution of $\mathrm{Cu}-\mathrm{Ni}$ welding fume comparing mass concentration versus particle size as measured using the MOUDI and Nano-MOUDI impactor systems.

Figure 3. Panel A - Enhanced dark-field microscopy image of $\mathrm{Cu}$-Ni welding fume deposits (arrows) in the alveoli of a mouse 30 weeks after a 9 week inhalation exposure to $\mathrm{Cu}-\mathrm{Ni}$ fume. Panel B - Enhanced dark-field microscopy image showing no deposits in the alveoli of a mouse 30 weeks after a 9 week inhalation exposure of air.

\section{Figure 4. Average tumor number per mouse lung (tumor multiplicity) upon gross examination in $\mathbf{A} / \mathbf{J}$ mice following initiation-promotion study at 30 week sacrifice.} $\mathrm{MCA} / \mathrm{Cu}-\mathrm{Ni}$ fume significantly decreased lung tumor number compared to air controls $(7.11 \pm$ 0.93 and $15.57 \pm 0.75$, respectively). As expected, mice treated with CO had low tumor number. Horizontal bars represent mean tumor numbers per group. Circles $=\mathrm{CO} /$ Air, squares $=\mathrm{CO} / \mathrm{Cu}$ Ni fume, upward triangles $=\mathrm{MCA} / \mathrm{air}$, downward triangles $=\mathrm{MCA} / \mathrm{Cu}-\mathrm{Ni}$ fume. ${ }^{*} p<0.0001-$ compared to $\mathrm{CO} / \mathrm{air} ;{ }^{* *} p<0.0001$ - compared to MCA/air 
Figure 5. Gross images of A/J mouse lung exposed to MCA/air (panel A) or MCA/Cu-Ni welding fume (panel B). Images represent lung tumor morphology 24-h post-fixation. Fixation allows for more accurate enumeration of tumors. Tumors (arrows) were on average $\sim 1$ $\mathrm{mm}$ in diameter in MCA/air mice and $\sim 0.5 \mathrm{~mm}$ in diameter in $\mathrm{MCA} / \mathrm{Cu}-\mathrm{Ni}$ welding fume exposed mice. 


\section{Figures}

Figure 1.

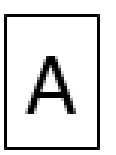

Cu-Ni fume $\left(43 \mathrm{mg} / \mathrm{m}^{3}\right) \longrightarrow$ Whole lung metal analysis by ICP-AES or air whole body inhalation (4 h)

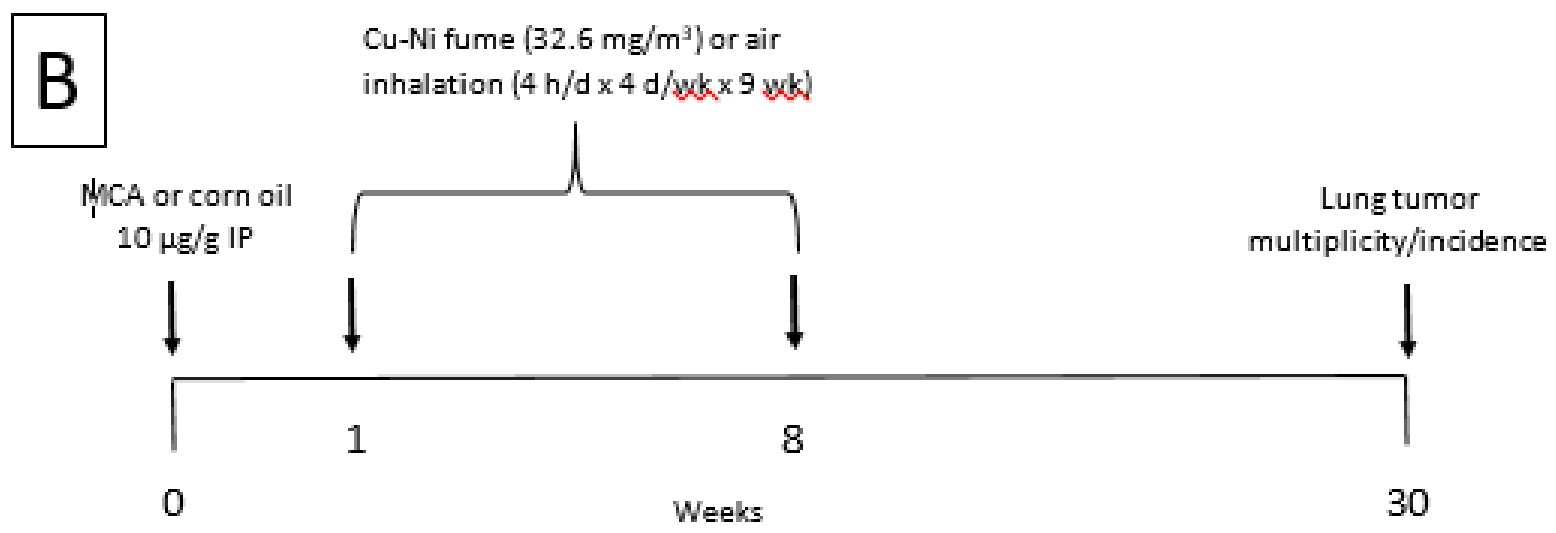


Figure 2.

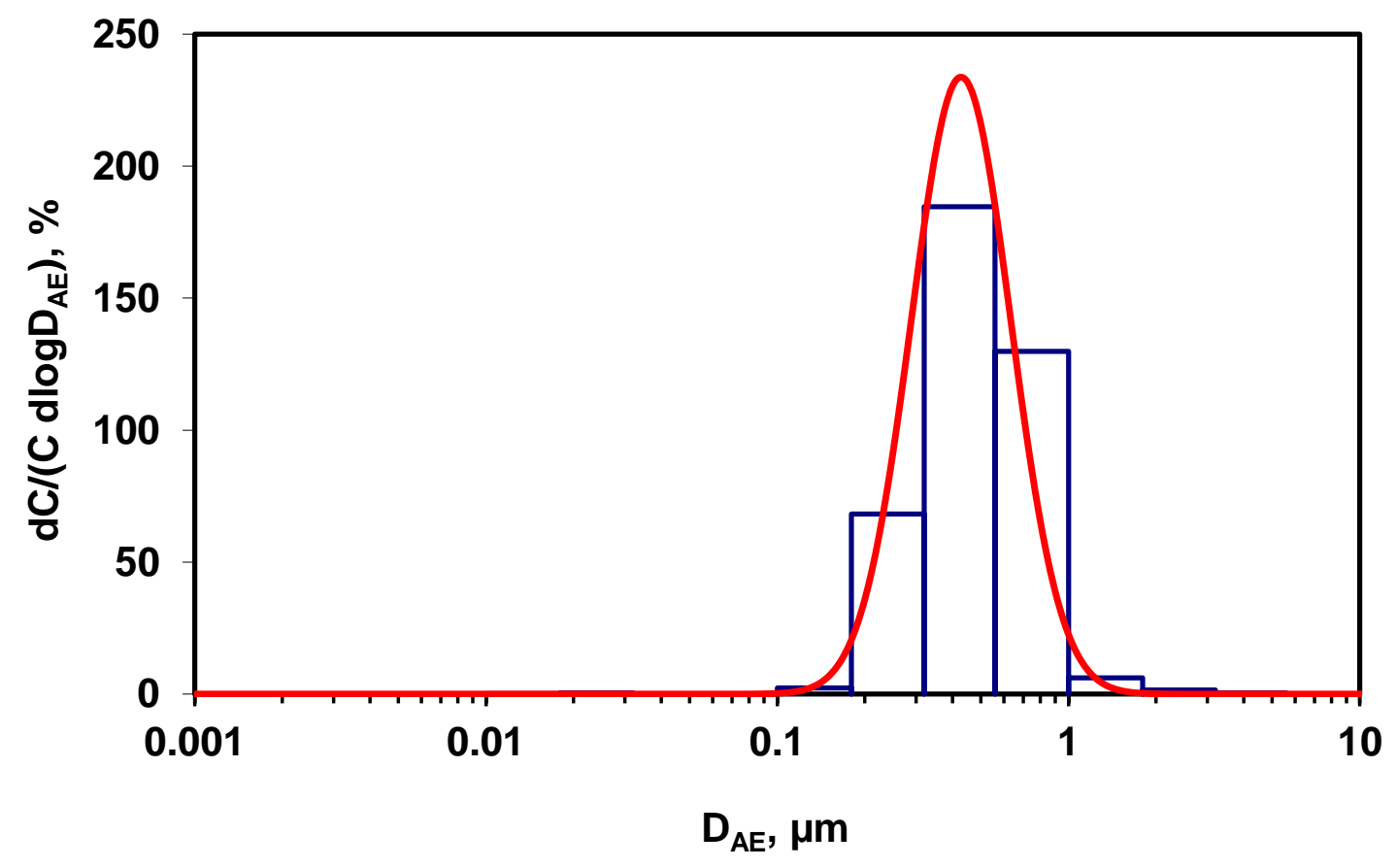


Figure 3.

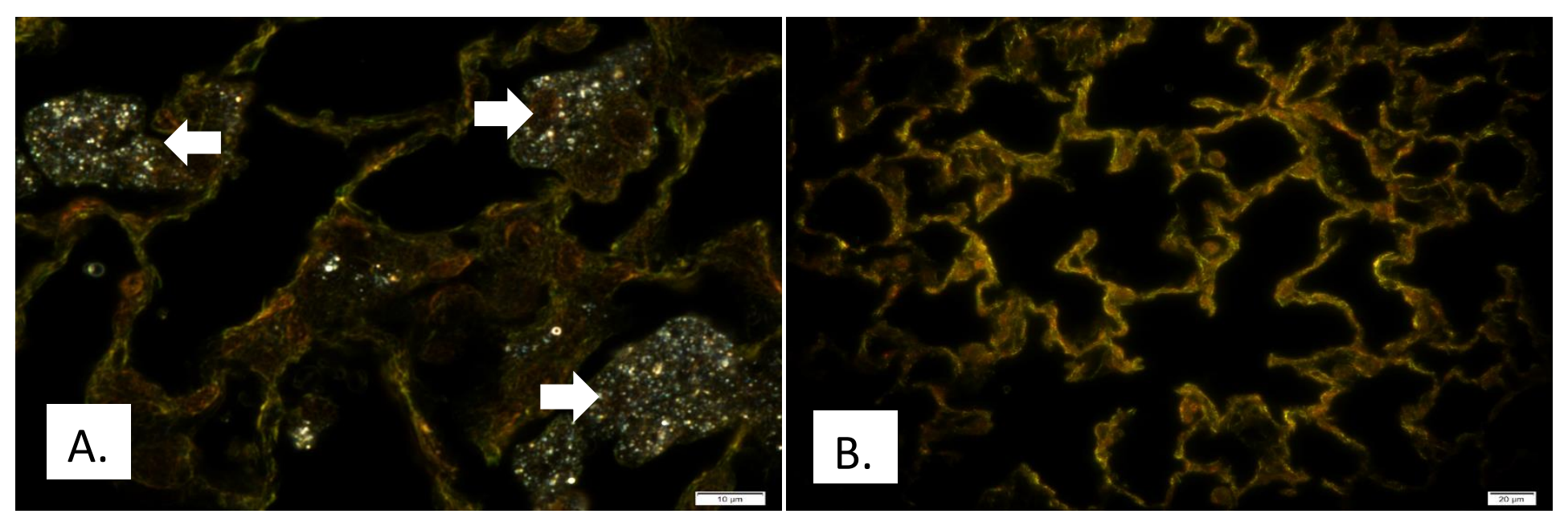


Figure 4.

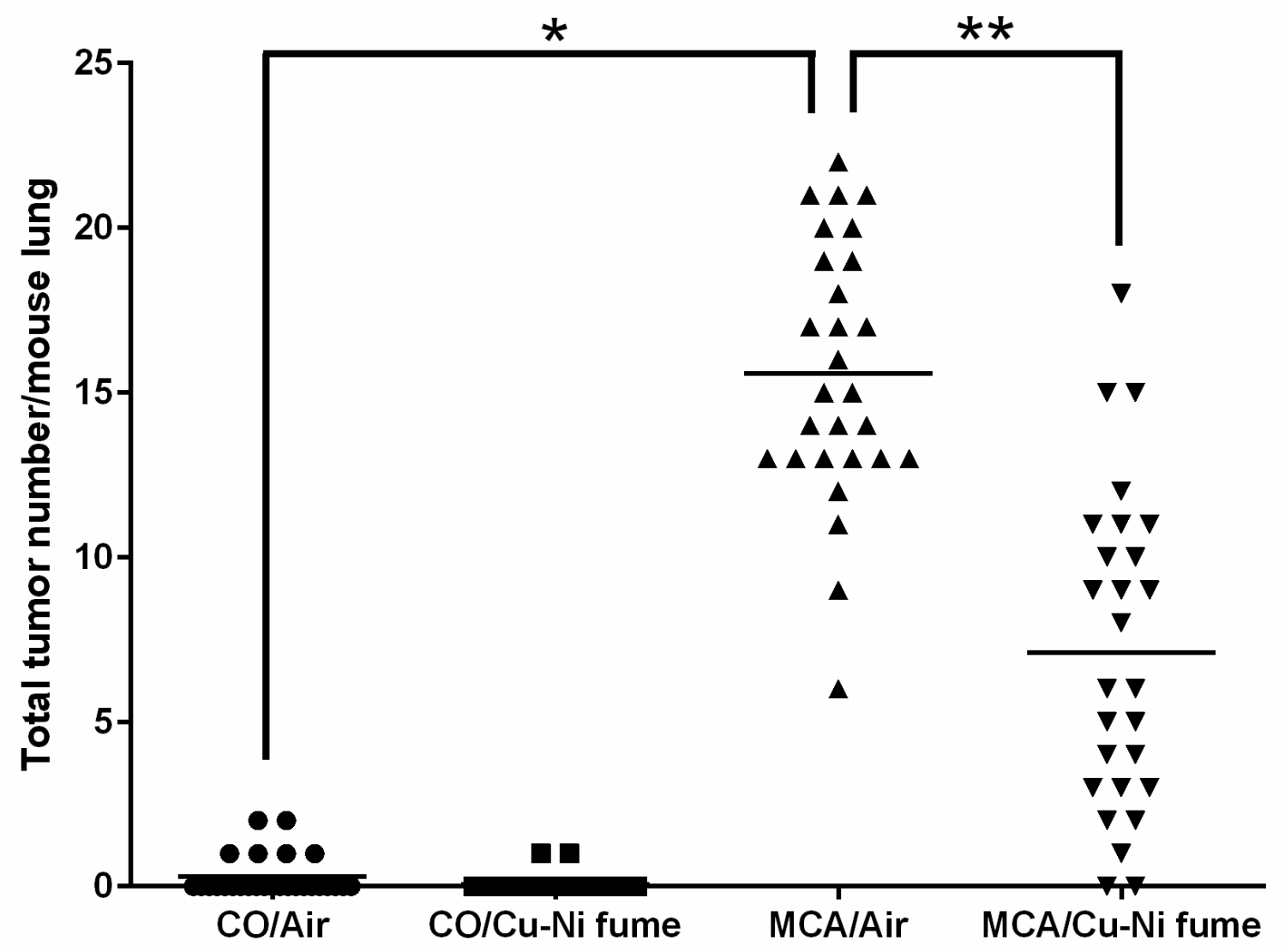


Figure 5.

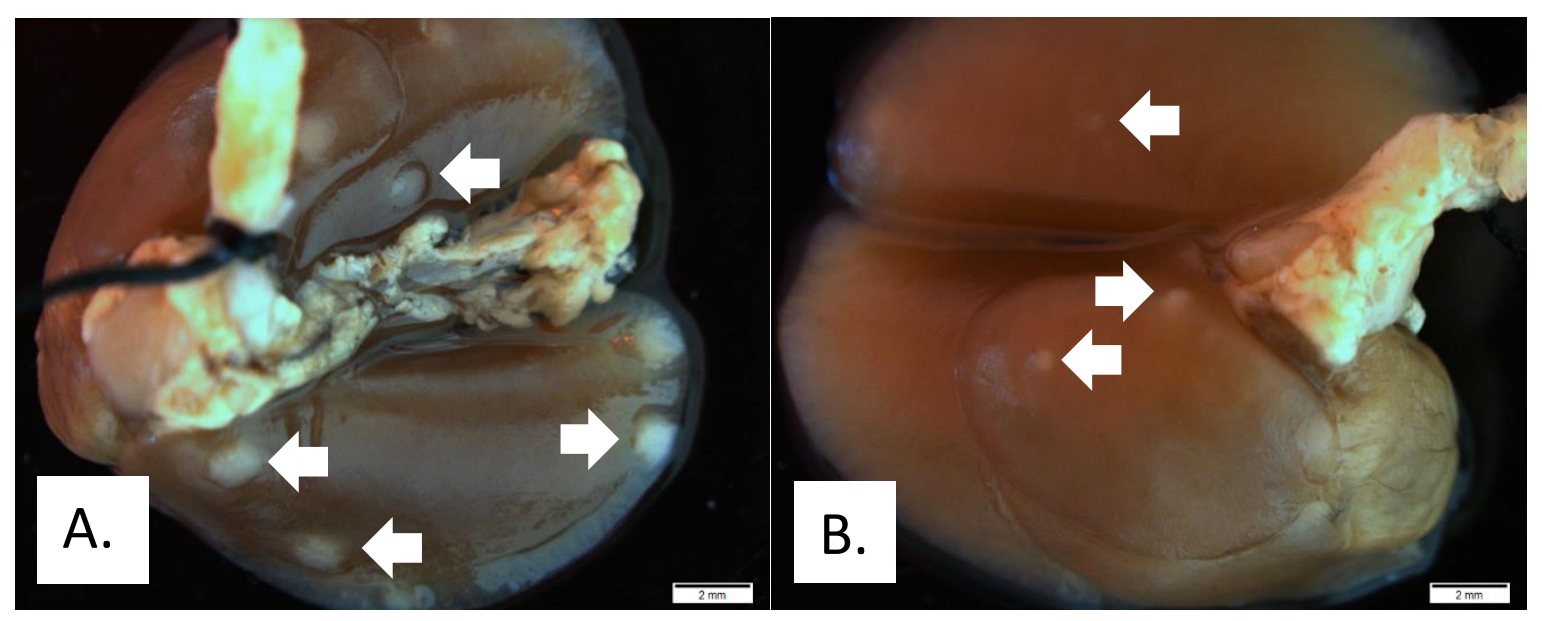




\section{Tables.}

Table 1. Metal composition of $\mathrm{Cu}-\mathrm{Ni}$ fume

\begin{tabular}{cc}
\hline Metals Analyzed & Weight \% of Metals \\
$\mathrm{Cu}$ & 76.35 \\
$\mathrm{Ni}$ & 11.60 \\
$\mathrm{Fe}$ & 5.10 \\
$\mathrm{Ti}$ & 2.86 \\
$\mathrm{Mn}$ & 2.27 \\
\hline
\end{tabular}

GMAW-MS fume was analyzed for aluminum (Al), barium (Ba), calcium $(\mathrm{Ca})$, chromium $(\mathrm{Cr})$, cobalt $(\mathrm{Co})$, copper $(\mathrm{Cu})$, iron $(\mathrm{Fe})$, potassium $(\mathrm{K})$, lithium $(\mathrm{Li})$, manganese $(\mathrm{Mn})$, magnesium $(\mathrm{Mg})$, nickel $(\mathrm{Ni})$, phosphorus $(\mathrm{P})$, lead $(\mathrm{Pb})$, strontium $(\mathrm{Sr})$, titanium $(\mathrm{Ti})$, vanadium $(\mathrm{V})$, zinc (Zn), and zirconium (Zr) by Inductively Coupled Plasma-Atomic Emission Spectroscopy.

Samples were prepared according to the NIOSH method 7300 for bulk samples. Trace amounts $(<1 \%)$ of $\mathrm{Al}, \mathrm{Ba}, \mathrm{Ca}, \mathrm{Co}, \mathrm{Cr}, \mathrm{K}, \mathrm{Li}, \mathrm{Mg}, \mathrm{P}, \mathrm{Pb}, \mathrm{Sr}, \mathrm{Ti}, \mathrm{V}, \mathrm{Zn}$, and $\mathrm{Zr}$ were found. Weight $\%$ is relative to all metals analyzed. 
Table 2. Lung metal deposition in $\mathrm{A} / \mathrm{J}$ mice after air or $\mathrm{Cu}-\mathrm{Ni}$ fume inhalation for 4 hours at a concentration of $43 \mathrm{mg} / \mathrm{m}^{3}$

\begin{tabular}{c|ccccc}
\hline Exposure & $\mathbf{C u}(\boldsymbol{\mu g} / \mathbf{l u n g})$ & $\mathbf{N i}(\boldsymbol{\mu g} / \mathbf{l u n g})$ & $\mathbf{F e}(\boldsymbol{\mu g} / \mathbf{l u n g})$ & $\mathbf{T i}(\boldsymbol{\mu g} / \mathbf{l u n g})$ & $\mathrm{Mn}(\boldsymbol{\mu g} / \mathbf{l u n g})$ \\
\hline Air & $0.30 \pm 0.01$ & $0.05 \pm 0.02$ & $9.95 \pm 0.35$ & $0.04 \pm 0.02$ & $0.03 \pm 0.00$ \\
\hline $\mathrm{Cu}-\mathrm{Ni}$ & $5.40 \pm 0.17$ & $1.23 \pm 0.07$ & $10.74 \pm 0.27$ & $0.16 \pm 0.03$ & $0.16 \pm 0.00$ \\
\hline
\end{tabular}

Freeze-dried whole lung tissue was analyzed for aluminum $(\mathrm{Al})$, barium $(\mathrm{Ba})$, calcium $(\mathrm{Ca})$, chromium $(\mathrm{Cr})$, cobalt $(\mathrm{Co})$, copper $(\mathrm{Cu})$, iron $(\mathrm{Fe})$, potassium $(\mathrm{K})$, lithium $(\mathrm{Li})$, manganese (Mn), magnesium (Mg), nickel (Ni), phosphorus $(\mathrm{P})$, lead $(\mathrm{Pb})$, strontium $(\mathrm{Sr})$, titanium $(\mathrm{Ti})$, vanadium (V), zinc (Zn), and zirconium (Zr) by Inductively Coupled Plasma-Atomic Emission Spectroscopy. Samples were prepared according to the draft NIOSH method 8200 for bulk tissue samples. Levels of $\mathrm{Al}, \mathrm{Ba}, \mathrm{Ca}, \mathrm{Co}, \mathrm{Cr}, \mathrm{Li}, \mathrm{Mg}, \mathrm{P}, \mathrm{Pb}, \mathrm{Sr}, \mathrm{V}, \mathrm{Zn}$ and $\mathrm{Zr}$ were not included because they were not detectable, $<0.1 \%$ in the fume analysis, or not significantly higher in exposed animals. Note: Values are mean \pm standard error of the mean $(\mathrm{n}=6$ air; $\mathrm{n}=10 \mathrm{Cu}-\mathrm{Ni})$; 
Table 3. Total and average (in parenthesis) tumor number in $\mathrm{A} / \mathrm{J}$ mice across each of the individual lung lobes following GMAW-MS or air exposure 30 weeks post-initiation with MCA or corn oil

\begin{tabular}{|c|c|c|c|c|c|c|}
\hline & $\mathrm{n}$ & Left & Apical & Cardiac & Diaphragmatic & Azygos \\
\hline $\mathrm{CO} / \mathrm{air}$ & 27 & $4(0.15 \pm 0.07)$ & 0 & $1(0.04 \pm 0.04)$ & $2(0.07 \pm 0.05)$ & $1(0.04 \pm 0.04)$ \\
\hline $\mathrm{CO} / \mathrm{Cu}-\mathrm{Ni}$ & 29 & 0 & 0 & 0 & $2(0.07 \pm 0.26)$ & 0 \\
\hline $\mathrm{MCA} / \mathrm{air}$ & 28 & $133(4.75 \pm 0.41)^{*}$ & $54(1.93 \pm 0.21)^{* *}$ & $68(2.43 \pm 0.31)$ & $127(4.54 \pm 0.38)^{*}$ & $54(1.93 \pm 0.24)^{\wedge}$ \\
\hline $\mathrm{MCA} / \mathrm{Cu}-\mathrm{Ni}$ & 27 & $52(1.93 \pm 0.29)$ & $24(0.89 \pm 0.21)$ & $51(1.89 \pm 0.32)$ & $38(1.41 \pm 0.28)$ & $27(1.00 \pm 0.22)$ \\
\hline
\end{tabular}

$\mathrm{CO}$ - corn oil, $\mathrm{Cu}-\mathrm{Ni}$ - copper-nickel welding fume, $\mathrm{MCA}$ - 3-methylchloanthrene

$* \mathrm{p}<0.0001, * * \mathrm{p}<0.002, \hat{\mathrm{p}}<0.006$ - compared to $\mathrm{MCA} / \mathrm{Cu}-\mathrm{Ni}$ 


\section{Chapter 7: Conclusions}

Significant advancements have been made in the field of welding fume toxicology research in the past few years. In 2017, welding fumes were officially classified as a Group 1 carcinogen after being considered possibly carcinogenic to humans (Group 2B) since 1990. Epidemiological and worker studies have been important for establishing the connection between welding and lung cancer. However, these studies have shown mixed results, which highlights the difficulties of epidemiological studies given the potential for confounders like smoking and asbestos, the possibility of mixed welding fume exposures, personal safety habits, genetics, and other risk factors. Nevertheless, epidemiological studies have demonstrated that welding fume exposure poses a serious health risk and highlights the need for controlled scientific studies like were presented in this dissertation.

Our in vivo studies have demonstrated that many types of welding fumes have toxic and tumorigenic potential. We have demonstrated that GMAW-MS, GMAW-SS, and $\mathrm{Fe}_{2} \mathrm{O}_{3}$, an iron oxide found in many types of welding fumes, promote lung tumor formation in the A/J mouse model. We also showed that $\mathrm{Fe}_{2} \mathrm{O}_{3}$ was the most pneumotoxic metal oxide compared to $\mathrm{NiO}$ or $\mathrm{Cr}_{2} \mathrm{O}_{3} / \mathrm{CaCrO}_{4}$ at doses relevant to their percentages in the fume. However, GMAW-SS was more pneumotoxic than any of the individual metal oxides, suggesting there may be a synergistic or additive toxicity of the metal oxides when they come together in the fume. In contrast, GMAW-MS did not cause significant inflammation or cytotoxicity despite the tumorigenic effect. Most surprisingly, we found that a $\mathrm{Cu}-\mathrm{Ni}$ fume produced by GMAW reduced tumor size and tumor number in vivo.

There are a number of strengths as well as some limitations to this research. Many of these studies involved whole body inhalation exposures. In vivo inhalation exposures are most 
similar to how workers are exposed, and the NIOSH inhalation facility is able to closely monitor these exposures to maintain a target welding fume concentration and monitor environmental conditions like temperature and gas production. These research projects also utilized a large sample size of nearly 1,000 A/J mice across all studies. The A/J mouse is a commonly used strain in lung cancer research. These mice develop lung tumors both spontaneously as well as rapidly in response to carcinogens following a hyperplasia to adenoma to adenocarcinoma progression [1,2]. Lung tumorigenesis in this model is under complex genetic control involving the pulmonary adenoma susceptibility 1 (PasI) locus and Kras.[3] In humans, Kras mutations are common in lung adenocarcinoma [4]. More so, in most cases, both human and A/J mouse lung tumors originate from atypical hyperplastic lesions in the periphery of the lung [4-7]. The research presented in this dissertation entirely utilized A/J mice and did not investigate tumorigenic potential in other strains. However, previous research in our lab comparing A/J mice to lung tumor resistant $\mathrm{C} 57 \mathrm{BL} / 6 \mathrm{~J}$ mice showed that the latter strain had a smaller pneumotoxic response to welding fumes while the $\mathrm{A} / \mathrm{J}$ mice demonstrated a possible tumorigenic effect of GMAW-SS fume exposure, making the A/J strain a better model for our studies. The potential spontaneous tumor development is a clear limitation to the $\mathrm{A} / \mathrm{J}$ mouse model; yet, reported background tumor incidence is still relatively low at about $65 \%$ in 15 month old $\mathrm{A} / \mathrm{J}$ mice. In our two-stage model, the tumor background incidence in control mice was also very low (often $\sim 20 \%$ or less) in 30 week old mice. Regardless, in our studies, we saw clear and profound effects on lung tumors in response to welding fumes.

An additional limitation to this research was the fact that only male mice were used in our studies. While welding has traditionally been considered a male-dominated career, more women are choosing to enter the field. In a recent study investigating the health of a cohort of welders in 
Canada, it was found that both sexes appeared to have similar health at first follow-up, although women reported higher rates of depression than men.[8] Future studies should continue to investigate potential health differences among welders of both sexes. These studies were also limited in that we did not use enough different doses to observe clear dose-response effects. Additionally, we did not mix exposures to different welding fumes or create combinations of metal oxides for dosing which would have enabled us to explore additive or synergistic effects. However, given the complications and lack of clarity from epidemiological studies, we sought to keep these studies simple and straightforward by beginning our studies with just one sex and limited exposure groups.

Currently, little is known concerning the mechanisms by which welding fumes act as lung carcinogens. In 2016, Smith et al. identified 10 key characteristics of human carcinogens, with the understanding that most human carcinogens exhibit at least one of these characteristics [9]. A recent report from Guyton et al. 2018 reviewed the literature on welding fumes and concluded that the two most likely key carcinogenic characteristics of welding fumes include their ability to be immunosuppressive and induce chronic inflammation [10]. This classification was based on evidence from multiple studies demonstrating increases in lung and systemic inflammation biomarkers in welders. However, in vivo studies such as presented in this dissertation indicate that not all welding fumes induce overt inflammation; we observed that GMAW-SS induced inflammation in A/J mice while GMAW-MS did not. Eight other key characteristics of human carcinogens are recognized which could represent mechanisms of welding fume tumorigenesis. These characteristics include electrophilic properties or the ability to be metabolically activated, genotoxicity, the ability to alter DNA repair or cause genomic instability, induction of epigenetic alterations, induction of oxidative stress, modulating receptor- 
mediated effects, causing immortalization, and altering cell proliferation, cell death, or nutrient supply. It is possible welding fumes may cause tumorigenesis through one of these additional mechanisms. Future studies in our lab are planned at investigating potential epigenetic effects of welding fumes such as the presence of DNA methylation or histone modification.

The goal of this research is to better understand what welding fumes and component metals are most dangerous so that welders can ultimately be protected from adverse respiratory health effects like lung cancer, given that ventilation and personal protective equipment such as respirators are not sufficient. No ventilation is $100 \%$ effective, and there is evidence that some respirators are note entirely able to protect welders $[11,12]$. More so, many welders do not wear personal protective equipment, with a recent study of a cohort of welders from Canada indicating that nearly $50 \%$ of welders wore no respiratory protection when welding [8]. From a public health standpoint, there is a need to inform welders of the risks of welding fume inhalation and offer them enhanced protection in the workplace. The research in this dissertation as well as ongoing studies will be significant in clarifying which welding fumes and their metal constituents are most hazardous to worker health. This understanding could more appropriately guide worksite regulations regarding safe levels of welding fumes or component metals and help lead to the creation of welding consumables that are devoid of the more hazardous metal oxide components. With a better understanding of the hazardous components of the fume, we can better protect or prevent exposure in welders and hopefully reduce lung cancer rates in this occupation. 


\section{Bibliography}

1. Witschi H: The complexities of an apparently simple lung tumor model: The $\mathbf{A} / \mathbf{J}$ mouse. Exp Toxicol Pathol 2005, 57 Suppl 1:171-181.

2. Shimkin MB, Stoner GD: Lung tumors in mice: application to carcinogenesis bioassay. Adv Cancer Res 1975, 21:1-58.

3. Gariboldi M, Manenti G, Canzian F, Falvella FS, Radice MT, Pierotti MA, Della Porta G, Binelli G, Dragani TA: A major susceptibility locus to murine lung carcinogenesis maps on chromosome 6. Nat Genet 1993, 3:132-136.

4. Westra WH, Baas IO, Hruban RH, Askin FB, Wilson K, Offerhaus GJ, Slebos RJ: K-ras oncogene activation in atypical alveolar hyperplasias of the human lung. Cancer Res 1996, 56:2224-2228.

5. Belinsky SA, Devereux TR, Foley JF, Maronpot RR, Anderson MW: Role of the alveolar type II cell in the development and progression of pulmonary tumors induced by 4-(methylnitrosamino)-1-(3pyridyl)-1-butanone in the A/J mouse. Cancer Res 1992, 52:3164-3173.

6. Westra WH: Early glandular neoplasia of the lung. Respir Res 2000, 1:163-169.

7. Foley JF, Anderson MW, Stoner GD, Gaul BW, Hardisty JF, Maronpot RR: Proliferative lesions of the mouse lung: progression studies in strain A mice. Exp Lung Res 1991, 17:157-168.

8. Cherry N, Arrandale V, Beach J, Galarneau JF, Mannette A, Rodgers L: Health and Work in Women and Men in the Welding and Electrical Trades: How Do They Differ? Ann Work Expo Health 2018.

9. Smith MT, Guyton KZ, Gibbons CF, Fritz JM, Portier CJ, Rusyn I, DeMarini DM, Caldwell JC, Kavlock RJ, Lambert PF, et al: Key Characteristics of Carcinogens as a Basis for Organizing Data on Mechanisms of Carcinogenesis. Environ Health Perspect 2016, 124:713-721.

10. Guyton KZ, Rusyn I, Chiu WA, Corpet DE, van den Berg M, Ross MK, Christiani DC, Beland FA, Smith MT: Application of the key characteristics of carcinogens in cancer hazard identification. Carcinogenesis 2018.

11. Antonini JM: Health Effects Associated with Welding. 2014:49-70.

12. Chen HL, Chung SH, Jhuo ML: Efficiency of different respiratory protective devices for removal of particulate and gaseous reactive oxygen species from welding fumes. Arch Environ Occup Health 2013, 68:101-106. 
